CARLOS ALBERTO MURAD

DESENVOLVIMENTO DE NOVOS PRODUTOS CONSIDERANDO ASPECTOS DE CONFIABILIDADE, RISCO E FERRAMENTAS DE QUALIDADE

São Paulo 


\title{
DESENVOLVIMENTO DE NOVOS PRODUTOS CONSIDERANDO ASPECTOS DE CONFIABILIDADE, RISCO E FERRAMENTAS DE QUALIDADE
}

Tese apresentada à Escola Politécnica da Universidade de São Paulo para a obtenção do título de Doutor em Engenharia Mecânica

\author{
Àrea de Concentração: \\ Engenharia Mecânica de \\ Projeto de Fabricação \\ Orientador: Professor Livre-Docente \\ Gilberto Francisco M. de Souza
}

São Paulo 
Este exemplar foi revisado e alterado em relação à versão original, sob responsabilidade única do autor e com a anuência de seu orientador.

São Paulo, de agosto de 2011.

Assinatura do autor

Assinatura do orientador

Murad, Carlos Alberto

Desenvolvimento de novos produtos considerando aspectos de confiabilidade, risco e ferramentas da qualidade / C.A. Murad. - ed.rev. -- São Paulo, 2011.

$170 \mathrm{p}$.

Tese (Doutorado) - Escola Politécnica da Universidade de São Paulo. Departamento de Engenharia Mecânica.

1. Desenvolvimento de produtos (Confiabilidade; Ferramen tas) 2. Produtos novos 3.Qualidade da produção (Ferramentas) I. Universidade de São Paulo. Escola Politécnica. Departamento de Engenharia Mecânica II. t. 
DEDICATÓRIA

A minha família Marley, Gabriel e Rafael:

Eu sou uma pessoa de sorte por ter escolhido esta família e por eles terem me escolhido. 


\section{AGRADECIMENTOS}

Gostaria de agradecer a minha família que muito me ajudou ao entender minha ausência nas horas de estudo, em especial aos meus filhos Gabriel com 7 e Rafael com 5 anos de idade respectivamente, que sempre me perguntavam por que o meu professor me passava tanta lição de casa. A minha mãe professora Sada Salomão Murad que muito me ensinou e continua ensinando.

Meus sinceros agradecimentos a todos os colegas da GMB que diretamente ou indiretamente me ajudaram fornecendo informações e compartilhando seus conhecimentos e finalmente ao professor Gilberto F. Martha que suportou este trabalho com suas idéias de melhoria a cada conversa que tivemos durante os anos de estudo. 


\section{RESUMO}

A intensa competição no mercado global e as constantes mudanças nas exigências dos clientes têm feito com que muitas empresas repensem seus processos de negócios não somente para sobreviver, mas também para se manterem competitivas no mercado atual. O processo de desenvolvimento de produtos é um fator importante para qualquer empresa se manter competitiva neste cenário. A falta de um bom processo de desenvolvimento de produtos é sem dúvida uma grande desvantagem para uma empresa. Somente um bom processo de desenvolvimento não garante a vantagem competitiva das empresas, é necessário também que seus produtos sejam confiáveis e para que isto aconteça torna-se essencial desenvolver produtos com qualidade, através do uso disciplinado e constante de ferramentas de qualidade. Para ser competitivo um produto precisa ser desenvolvido com o mínimo de tempo, recursos e custo, para atender às necessidades de mercado. Algumas metodologias foram desenvolvidas e estas focam no desenvolvimento de um produto sempre pensando nas necessidades da manufatura, montagem, qualidade, confiabilidade e ciclo de vida do produto, evitando mudanças tardias no produto. Muitos estudos acadêmicos e industriais têm sido propostos nesta área. Cada empresa deve encontrar e se adaptar ao processo ou modelo mais adequado para ela dentro das suas necessidades técnicas e culturais. Este estudo apresenta uma metodologia a ser usada para melhorar a qualidade do produto e deve ser usada quando da fase conceitual onde se escolhem os melhores sistemas e/ou componentes para formar um novo produto final.

Palavras-chave: Confiabilidade, ferramentas de qualidade, DFMA, análise de risco, manutenção centrada em confiabilidade, FMEA, FTA. 


\begin{abstract}
The intense competition in global market along with constant changes in customers demands have forced companies to re-think some of their business processes, not only to survive, but also to stay competitive on this market. The product development process is one of the key business processes for any company to stay competitive and global on this scenario. The lack of a good development process is with no doubt a big disadvantage for any company. Only a good development process does not guarantee a competitive advantage for anyone, it becomes necessary to have reliable products in the field and to make this happens it is vital to develop products with quality through the use of quality tools in a constant and disciplined way. To be competitive, a product needs to be designed in a minimum amount of time, with minimum resources and cost. To meet market needs some methodologies were developed thinking on manufacturing, assembly, quality, reliability and life cycle avoiding late product changes. Many studies academic and industrial have been proposed in this area. Each company has to find and adapt the most appropriate model that fits its technical and cultural needs. This research presents a methodology to be used to improve product quality during the early phases of development when systems and/or components are chosen for a new product.
\end{abstract}

Key words: Reliability, quality tools, DFMA, risk analysis, reliability centered maintenance, FMEA, FTA. 


\section{SUMÁRIO}

DEDICATÓRIA



RESUMO ….................................................................................... III



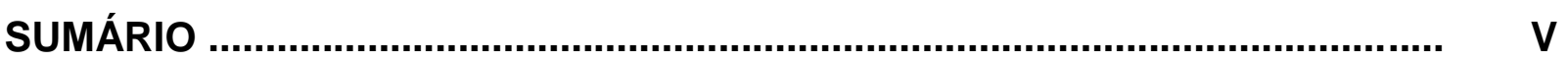

LISTA DE ABREVIATURAS E SIGLAS ……............................................. VIII

LISTA DE ILUSTRAÇÕES ..................................................................... IX

LISTA DE TABELAS



1.1 Considerações Iniciais ................................................................................

1.2 Objetivo do Trabalho ............................................................................... 6

1.3 Escopo do Trabalho .................................................................................. 7

2 FUNDAMENTOS TEÓRICOS ….......................................................... 9

2.1 Análise da Confiabilidade de Sistemas ...................................................... 12

2.2 Métodos de Crescimento de Confiabilidade .................................................. 22

2.3 Projeto para Manufatura e Montagem (DFMA) …………………............... 24

2.4 Análise de Risco e Confiabilidade .............................................................. 29

2.4.1 Metodologias de Avaliação de Risco ................................................. $\quad 30$

2.4.2 Ferramentas de Qualidade Utilizadas na Análise de Risco ...................... 32

2.4.3 Gerenciamento e Comunicação do Risco .............................................. 34

2.5 Manutenção Centrada em Confiabilidade ……......................................... 35

2.5.1 Abordagens Básicas de Manutenção …………………………............. 36

2.5.2 Identificação dos Itens Relevantes do Processo Produtivo ........................ $\quad 37$

2.5.3 Definição das Funções e Parâmetros de Desempenho Desejados .......... 38

2.5.4 Determinação das Falhas Funcionais ................................................ 39

2.5.5 Determinação do Modo de Falha, seus Efeitos e Consequências ............. 41

2.5.6 Seleção do Tipo de Manutenção ....................................................... 41

2.6 Comparação entre Projetos ........................................................... 43

2.6.1 Testes de Hipóteses: Comparação Projeto " $A$ " vs. Projeto " $B$ " ................. 45

3 PROPOSTA DO DESENVOLVIMENTO DO PRODUTO COM BASE EM CONFIABILIDADE E RISCO ................................................................... 48

3.1 Estado da Arte ................................................................................. 55 
3.2 Requisitos de Mercado: Análise das Necessidades dos Clientes

3.2.1 Necessidades dos Clientes: Processo nas Montadoras Americanas.......... 61

3.2.2 Necessidades dos Clientes: Processo na Toyota ................................... 63

3.3 Definição dos Sistemas com base em Confiabilidade e Risco ...................... 64

3.4 Identificação dos Perigos e Definição dos Cenários de Falha dos Sistemas.. 69

3.5 Coleta de Dados para Análise dos Sistemas ............................................ 71

3.6 Identificação do Modo de Falha, seus Efeitos e Consequências ................... 72

3.7 Melhoria Contínua para ganho de Confiabilidade ...................................... 75

3.8 Gerenciamento da Integridade dos Sistemas ............................................ 78

3.9 Contribuição do Método Proposto .......................................................... 79

4 ESTUDO DE CASO ........................................................................... 84

4.1 Análise de Sistemas nas Plataformas em Estudo ...................................... 85

4.2 Definição dos Sistemas para Análise ……………................................. 89

4.3 Coleta de Dados e Análise de Confiabilidade .............................................. 93

4.4 Análise de Confiabilidade: Bomba de Óleo ……........................................... 93

4.4.1 Comparativo de Projetos entre Plataformas de Veículos .......................... 99

4.5 Análise de Risco: Sistema de Freio ...................................................... 103

4.5.1 Sistema de Freio: Modos de Falha e Hipóteses de Análise ....................... 105

4.5.2 Sistema de Freio: Solução da Árvore de Falhas ...................................... 110

4.6 Manutenção Centrada em Confiabilidade: Vidro do Para Brisa ..................... 117

4.6.1 Célula de Aplicação de Cola no Para Brisa ............................................ 119

4.6.2 Metodologia de Análise e Escolha da Política de Manutenção .................. 122

4.6.3 Análise de Modos e Efeitos de Falhas .................................................... 125

4.6.4 Proposta da Política de Manutenção ...................................................... 129

4.7 Projeto para Manufatura e Montagem: Chicote do Motor ............................. 131

4.7.1 Aplicação dos Critérios de DFMA ........................................................... 134

4.8 Análise dos Resultados ................................................................ 138

4.8.1 Conclusões .......................................................................... 138

4.8.2 Análise da Confiabilidade da Bomba de Óleo ......................................... 139

4.8.3 Análise do Comparativo entre Projetos .................................................. 141

4.8.4 Análise do Risco do Sistema de Freio ............................................... 141

4.8.5 Análise da Manutenção Centrada em Confiabilidade ............................... 142

4.8.6 Análise do Projeto para Manufatura e Montagem ................................... 143 
5 CONCLUSÃO E RECOMENDAÇÕES

146

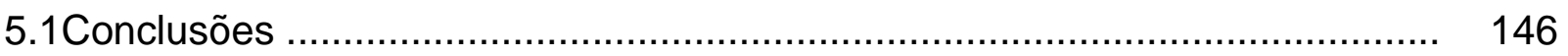

5.2 Recomendações para Trabalhos Futuros ............................................... 148



ANEXO 1: Distribuição F, com 95\% de confiança .......................................... 159

ANEXO 2: Teste de Hipótese - Projeto ALFA vs. GAMA .................................. 160

ANEXO 3: Teste de Hipótese - Projeto ALFA vs. DELTA …............................. 161

ANEXO 4: Teste de Hipótese - Projeto BETA vs. GAMA ……......................... 162

ANEXO 5: Teste de Hipótese - Projeto BETA vs. DELTA …….......................... 163

ANEXO 6: Teste de Hipótese - Projeto DELTA vs. GAMA ……....................... 164

ANEXO 7: Probabilidade de Ocorrência ………............................................. 165

ANEXO 8: Probabilidade de Detecção ....................................................... 165

ANEXO 9: Severidade das Consequências .................................................... 166 


\section{LISTA DE ABREVIATURAS E SIGLAS}

$\begin{array}{ll}\text { CKD } & \text { Completely Knock Down } \\ \text { SUP } & \text { Single Unit Package } \\ \text { ROI } & \text { Return on Investments } \\ \text { FMEA } & \text { Failure Mode and Effects Analysis } \\ \text { FMECA } & \text { Failure Mode and Effects Criticality Analysis } \\ \text { FTA } & \text { Failure Tree Analysis } \\ \text { CAD } & \text { Computer Aid Design } \\ \text { DFMA } & \text { Design for Manufacturing and Assembly } \\ \text { PHA } & \text { Preliminary Hazard Analysis } \\ \text { ETA } & \text { Event Tree Analysis } \\ \text { FTA } & \text { Fault Tree Analysis } \\ \text { HAZOP } & \text { Hazard Operability Study } \\ \text { MCC } & \text { Manutenção Centrada na Confiabilidade } \\ \text { RCM } & \text { Reliability Centered Maintenance } \\ \text { QFD } & \text { Quality Function Deployment } \\ \text { IPTV } & \text { Incidents per Thousand Vehicles } \\ f(t) & \text { Função Densidade de Probabilidade de falha de Weibull } \\ \text { R(t) } & \text { Função de Confiabilidade de Weibull } \\ \text { t } & \text { Tempo (neste estudo equivale a quilometragem da falha) } \\ \beta & \text { Constante de Forma na Distribuição de Weibull } \\ \eta & \text { Constante de Escala na Distribuição de Weibull } \\ \text { F(t) } & \text { Função Probabilidade Acumulada de falha de Weibull } \\ \text { DT } & \text { Dianteiro (a) } \\ \text { TR } & \text { Traseiro (a) } \\ \text { LD } & \text { Lado Direito } \\ \text { LE } & \text { Lado Esquerdo } \\ \text { AL } & \text { Ambos os Lados } \\ \text { F } & \text { F calculado da distribuição F } \\ \text { C } & \text { Constante de Dispersão } \\ \text { AC } & \text { Ar Condicionado } \\ \text { ECM } & \text { Eletronic Control Module } \\ \text { DFSS } & \text { Design for Six Sigma } \\ & \end{array}$




\section{LISTA DE ILUSTRAÇÕES}

Figura 1 - Plantas de Montagem Americanas: Horas por Veículos ……………. 3

Figura 2 - Confiabilidade e custos do ciclo de vida: Visão Tradicional ................. 14

Figura 3 - Confiabilidade e custos do ciclo de vida: Visão Moderna ………........ 15

Figura 4 - Função densidade de probabilidade de Weibull .................................... 16

Figura 5 - Período em estudo ................................................................... 17



Figura 7 - Dados Censurados ................................................................. 19

Figura 8 - Distribuição quilometragem para 12 meses de uso - Mercado



Figura 9 - Distribuição quilometragem para 12 meses de uso - Mercado

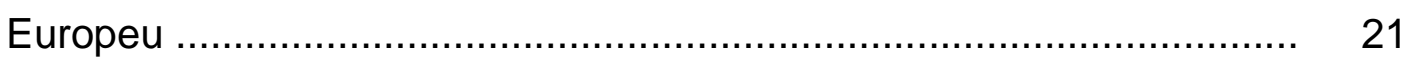

Figura 10 - Etapas de um programa de confiabilidade .................................... 23

Figura 11 - Tempo de desenvolvimento do produto com aplicação do DFMA ..... 25

Figura 12 - Custos durante o desenvolvimento vs custos do produto final .......... 26

Figura 13 - Passos na Engenharia Simultânea usando Critério de DFMA .......... 27

Figura 14 - Fluxograma de Análise para uso da Ferramenta DFMA .................. 28

Figura 15 - Percepção do Risco ………................................................. 29

Figura 16 - Métodos de Análise de Risco ................................................. $\quad 30$

Figura 17 - Processo de Análise Preliminar de Perigo ..................................... 32

Figura 18 - Processo da Análise dos Modos e Efeitos das Falhas ................... 33

Figura 19 - Um item passível de manutenção ……………………............... 39

Figura 20 - Definição de falha funcional .................................................... 40

Figura 21 - Exemplo de uma Curva de Probabilidade ...................................... 43

Figura 22 - Comparação entre dois Projetos - (Normal Plot) ………................. 44

Figura 23 - Comparação entre dois Projetos (Lognormal Plot) .......................... 44

Figura 24 - Comparação entre dois Projetos (Weibull Plot) ……....................... 45

Figura 25 - Processo Tradicional de Desenvolvimento ……………................ 50

Figura 26 - Cronograma de Desenvolvimento de um Veículo .............................. 51

Figura 27 - Proposta de Estudo ............................................................ 53

Figura 28 - Matriz QFD Parcial: Para choque de um veículo ............................. 61 
Figura 29 - Falhas Durante o Ciclo de Vida de um Veículo

Figura 30 - Proposta da primeira análise dos sistemas de veículos

Figura 31 - Curva da banheira 76

Figura 32 - Falha, Análise da Causa Raiz e Ação de Melhoria 77

Figura 33 - Desempenho do veículo ALFA durante período de garantia 86

Figura 34 - Desempenho do veículo BETA durante período de garantia 86

Figura 35 - Desempenho do veículo GAMA durante período de garantia 87

Figura 36 - Desempenho do veículo DELTA durante período de garantia 87

Figura 37 - Acúmulo de falhas dos veículos em estudo 88

Figura 38 - Curva de Confiabilidade: Bomba de Óleo 96

Figura 39 - Confiabilidade: 20 e 25 mil km 96

Figura 40 - Comparação Gráfica: Mercado Nacional vs Europeu 98

Figura 41 - Comparação Gráfica: Projeto ALFA vs. Projeto BETA 100

Figura 42 - Comparativo: Projeto ALFA vs. Projeto BETA 101

Figura 43 - Comparação Gráfica de $\mathrm{R}(\mathrm{t})$ entre Projetos 102

Figura 44 - Esquema do Sistema de Freio para a Análise de Risco 104

Figura 45 - Modos de Falha: Mola, Pedal e Pastilhas de Freio 105

Figura 46 - Modos de Falha: Disco, Sapata e Tambor de Freio 106

Figura 47 - Curva de Confiabilidade Disco e Tambor: Veículo DELTA 108

Figura 48 - Curva de Confiabilidade Sapata e Pastilha: Veículo DELTA . 108

Figura 49 - Árvore de Falhas: Sistema de Freio - 1 111

Figura 50 - Árvore de Falhas: Sistema de Freio - 2 112

Figura 51 - Árvore de falhas - Ramo: "Sem Fluido de Freio". 114

Figura 52 - Árvore de falhas - Solução dos Ramos Principais 115

Figura 53 - Incidência de Falhas: Vidro e Guarnição do Para Brisa 118

Figura 54 - Modos de Falha: Vidro e Guarnição do Para Brisa (Veículo Delta) ...

Figura 55 - Célula de Aplicação de Cola - Simplificada 118

Figura 56 - Metodologia da Análise e Escolha da Política de Manutenção 121

Figura 57 - Árvore Funcional da Célula de Cola do Para Brisa 122

Figura 58 - Proposta da Política de Manutenção 123

Figura 59 - Ventoinha de Arrefecimento 129

Figura 60 - Projeto Inicial: Ventoinha de Arrefecimento e Módulo 133

Figura 61 - Aplicação dos Critérios de DFMA 134 135 
Figura 62 - Novo Projeto: Ventoinha de Arrefecimento e ECM do Veículo 137

Figura 63 - Acúmulo de Quilometragem nos Dados Censurados 139

Figura 64 - DFMA: Comparação entre Projetos 


\section{LISTA DE TABELAS}

Tabela 1 - Comparativo do comportamento do usuário com 12 meses de uso ... 22

Tabela 2 - Comparativo entre as publicações pesquisadas ............................... 57

Tabela 3 - Comparativo entre publicações pesquisadas e o método proposto ... 81

Tabela 4 - Classificação dos Sistemas Quanto a Risco e Insatisfação ............... 92

Tabela 5 - Dados da Análise da Bomba de Óleo ............................................. 95

Tabela 6 - Confiabilidade da Bomba de Óleo: Mercado Nacional vs Europeu ... 97

Tabela 7 - Confiabilidade da Bomba de Óleo: Projeto ALFA e Projeto BETA .... 101

Tabela 8 - Comparativo entre os projetos - Bomba de Óleo .............................. 102

Tabela 9 - Falhas do Sistema de Freio no Período de Garantia ........................ 105

Tabela 10 - Confiabilidade e Probabilidade de Falha $(20.000$ km) .................... 109

Tabela 11 - Confiabilidade e Probabilidade de Falha $(25.000 \mathrm{~km})$.................... 109

Tabela 12 - Resultados Finais da Árvore de Falhas ...................................... 117

Tabela 13 - Parte A: Lista de Componentes Críticos da Célula de Cola ............ 127

Tabela 14 - Parte B: Lista de Componentes Críticos da Célula de Cola ............ 128

Tabela 15 - Proposta da Política de Manutenção ........................................... 130

Tabela 16 - Resultado do Projeto para Montagem do Estudo de Caso ............. 136

Tabela 17 - Resultado do Novo Projeto para Montagem ................................. 137

Tabela 18 - Análise Comparativa de Custo dos Projetos .................................. 138 


\section{INTRODUÇÃO}

\subsection{Considerações Iniciais}

Devido ao fenômeno da globalização, a competição tem aumentado consideravelmente em todos os setores da indústria, sendo mais perceptível nas indústrias automotivas e em seus fornecedores. A habilidade de trazer novos produtos ao mercado, com alta qualidade, inovadores e mais rápido, tornou-se a fórmula para o sucesso.

Atualmente, vários produtos automotivos (veículos, sistemas ou componentes) são desenvolvidos em um mercado e usados em outro. Assim, pode-se afirmar que as condições de operação são muitas vezes diferentes entre estes mercados e se estas diferentes condições de operação não forem consideradas durante 0 desenvolvimento e no processo de manufatura, pode-se dizer que, o produto não terá o desempenho esperado durante sua vida útil e poderá apresentar falhas em determinado mercado e diferentes falhas em outro mercado. A indústria automotiva enfrenta uma competitividade intensa nos mercados chamados maduros (Estados Unidos, Europa e Japão) e uma rápida expansão nos mercados chamados emergentes (China, Índia, Tailândia e Brasil). Por exemplo, a região da Ásia não é somente um mercado em rápido crescimento automotivo, mas também se tornou uma região de custos de manufatura competitivos, fazendo desta região a base de fornecimento para muitos mercados chamados maduros. Para aumentar as participações de mercado em suas regiões, as indústrias automotivas americanas, européias e japonesas exportam veículos já montados, processo chamado SUP (single unit package) e veículos desmontados para ser montado na região, processo chamado CKD (completely knock down) ou ainda desenvolvem e produzem os veículos nas plantas de manufatura destas regiões. Para aumentar a competividade nos mercados chamados maduros, as indústrias automotivas ainda compram sistemas e/ou componentes de fornecedores nos mercados asiáticos, para as suas produções no mercado americano, europeu e japonês. Neste cenário globalizado, os produtos, como por exemplo, veículos, sistemas ou componentes são muitas vezes desenvolvidos por engenheiros em um mercado para serem usados em outro mercado. As condições de operação são diferentes de um mercado para o outro e estas condições de operação devem ser consideradas durante o desenvolvimento e 
no processo de manufatura, caso contrário, este produto poderá não atender sua função completamente durante sua vida útil. Deste modo, torna-se vital para estas indústrias automotivas e seus fornecedores desenvolverem produtos robustos que atendam as condições de todos os mercados onde ele será usado.

Em 1990 o livro A Máquina que Mudou o Mundo chocou o setor automotivo, fornecendo provas irrefutáveis que as indústrias automotivas japonesas eram melhores do que as européias e americanas. Na realidade, eles não eram simplesmente um pouco melhor, eram muito melhores - de duas até dez vezes melhores nas medidas de desempenho, segundo Liker (2006). Para muitos o livro foi uma introdução da tremenda capacidade de desempenho do sistema de produção da Toyota. O livro introduziu o termo Manufatura Enxuta, ou seja, fazendo mais com menos, descrevendo um sistema de produção melhor, mais rápido, mais barato, com necessidade de menor espaço, menor inventário e evitando práticas de desperdício. Isto se tornou uma revolução no sistema de manufatura americano e em muitos outros países criando um fenômeno em consultorias pelo mundo, tornando "Manufatura Enxuta" no mais importante desenvolvimento sobre manufatura nas últimas duas décadas. A grande maioria das empresas durante o processo de transformação para a manufatura enxuta dedicou esforços focando exclusivamente no chão de fábrica, ou seja, na sua produção. Mas, isto não é o suficiente, é necessário ir mais além e dedicar mais atenção durante o desenvolvimento do produto durante a fase conceitual, onde se pode realmente evitar desperdícios na produção focando mais na engenharia do produto e no seu processo.

Atualmente a manufatura enxuta não é mais uma exclusividade competitiva da Toyota, muitos discípulos de Taiichi Ohno, o pai do Sistema de Produção da Toyota, ensinaram e introduziram em muitas regiões do mundo os princípios da manufatura enxuta. Na indústria automotiva, a manufatura enxuta tornou-se tão efetiva que cada empresa desenvolveu sua própria estratégia de manufatura enxuta e muitas foram bem sucedidas, embora muitas empresas ainda não tenham atingido a eficiência de produtividade da Toyota, conseguiram diminuir a distância entre eles. Na realidade, algumas empresas americanas até ultrapassaram a Toyota em algumas categorias de manufatura, conforme mostra a figura 1. 
A planta de montagem da GM em Oshawa foi à primeira com apenas 15,9 horas por veículo, em segundo está a NISSAN em Smyra, planta do Tennesse com 16,1 horas por veículo, seguida pela FORD em Atlanta com 16,6 horas por veículo, a planta da TOYOTA em Georgetown atingiu valores de 18,4 horas por veículo e a DCX ficou com 18,7 horas por veículo. É uma grande revolução se compararmos com as 40 horas reportadas pelo livro A Máquina que Mudou o Mundo para a planta da GM em Framingham em 1980.

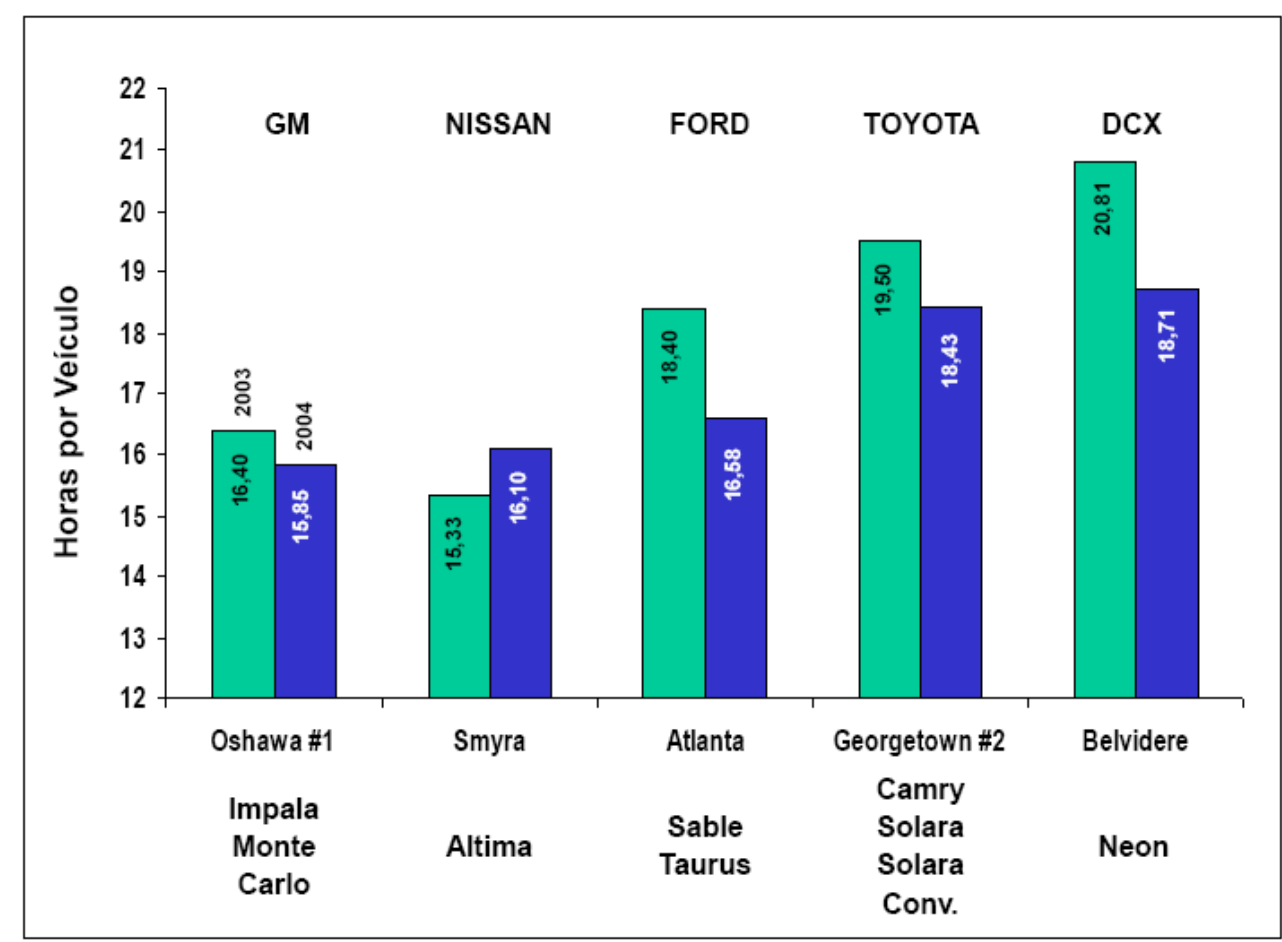

Figura 1. Plantas de Montagem Americanas: Horas por Veículos. (fonte: Liker, 2006)

O número de modelos de veículos oferecidos aos consumidores no mercado americano cresceu dramaticamente, enquanto o número de plataformas de veículos diminuiu. Isto também ocorreu no mercado brasileiro, porém, com um número bem menor. Para obter sucesso e continuarem competitivas, as indústrias automotivas estão oferecendo uma grande variedade de veículos e para isto estão usando o menor número possível de plataformas. Atualmente os consumidores selecionam os veículos pensando em estilo e opcionais disponíveis, mas custo e qualidade são fatores indispensáveis e considerados incorporados ao produto. Assim, as indústrias automotivas aceleram o desenvolvimento do produto e trazem ao mercado os produtos que os consumidores desejam e quando eles querem. Segundo Liker 
(2006), no mercado americano existe uma forte correlação entre a idade do modelo e sua participação de mercado, ou seja, quanto mais velho, menor sua participação de mercado. Mas este fato não se aplica totalmente ao mercado brasileiro, pois existem velhos modelos que resistem e proporcionam uma participação de mercado considerável através dos anos. Segundo Linebaugh (2008), as fábricas da Honda estão se tornando as mais flexíveis da América do Norte e essa destreza esta se tornando uma vantagem estratégica fundamental para a empresa. Com o crescente aumento dos combustíveis, esta destreza pode ajudar a ajustar a produção aos níveis de estoque mais rápido do que as concorrentes. O ano de 2008 foi muito difícil para as montadoras nos EUA, a crise imobiliária e o desaquecimento da economia do país reduziram a venda geral de veículos. O alto preço da gasolina, incentivou o consumidor americano a comprar carros menores em vez de caminhonetes e utilitários esportivos, tão populares no passado. Ainda, segundo Linebaugh (2008), nos primeiros oito meses de 2008, as vendas da Chrysler recuaram 24\%, as da GM caíram $18 \%$ e as da Ford 15\%. Até a poderosa Toyota viu suas vendas caírem em $7,8 \%$ nos EUA. Mas as vendas da Honda, segundo a montadora no Japão subiram $1,7 \%$ no mesmo período e sua participação de mercado nos EUA chegou ao nível recorde de $11,1 \%$ em agosto de 2008. Todo este desempenho é o resultado de um planejamento do produto que começou há dez anos, flexibilidade na linha de montagem é tão importante para o sucesso de uma empresa quanto à linha de produtos que ela oferece ao consumidor. Neste cenário, desenvolvimento do produto eficaz, com produtos de qualidade tornou-se uma grande vantagem competitiva para as indústrias.

No final dos anos 80 o tempo de desenvolvimento de um produto automotivo do momento onde se definia o seu estilo e conteúdo até a sua produção era tipicamente entre 36 a 40 meses. Atualmente este tempo de desenvolvimento tem uma média aproximada de 24 meses. A Toyota retrocedeu esta média de tempo de desenvolvimento para 15 meses e em alguns casos chegou até 10 meses, segundo Morgan (2002) e Liker (2006). Quando se avalia o desempenho do desenvolvimento do produto, é extremamente importante mencionar que os produtos desenvolvidos pelo sistema de desenvolvimento da Toyota são os mais bem produzidos em comparação com as outras montadoras, mostrando que a Toyota tem um dos melhores sistemas de manufatura conhecido como manufatura enxuta, sistema este bem explorado por acadêmicos no mundo inteiro, começando com Becoming Lean 
(Liker, 1997) e Lean Thinking (Womack and Jones, 1996) e isto deve ser considerado em qualquer proposta de melhoria. Mas com toda esta vasta literatura disponível e bem explorada não se pode desconsiderar que todo o foco deve ser voltado ao início de todo projeto, ou seja, o desenvolvimento do produto, onde é possível tornar mais eficiente o produto em desenvolvimento, aplicando-se conceitos de ferramentas de qualidades e confiabilidade como fatores para o sucesso de um produto no mercado.

As mudanças externas nos veículos como faróis, lanternas, pára choques, portas, para lamas, capô e tampa traseira mais conhecidas como mudanças de aparência, são as mais comuns nas indústrias automotivas, enquanto motores e transmissões são mais estáveis, sofrendo pequenas modificações ao longo dos anos. São estas modificações de aparência que trazem um novo estilo ao veículo e consequentemente passando ao consumidor o desejo de comprá-lo. Todavia, estas modificações ainda trazem grandes desafios às indústrias automotivas e elas podem ser consideradas como o caminho mais crítico em qualquer desenvolvimento do produto.

A grande maioria das indústrias americanas ainda precisa de pelo menos dois anos para fazer estas grandes modificações com um custo variando entre um terço até metade de um custo total para desenvolver um novo veículo, segundo Morgan (2002). Estas mudanças de aparência são as mais complexas, pois geram grandes interferências com outros sistemas do veículo, existem poucas partes que podem ser mudadas sem interferir com outros sistemas do veículo. Uma grande mudança em um veículo pode chegar até a 300 componentes, que devem ser projetados, ferramentados, testados, e finalmente lançados ao mercado. Se este desenvolvimento não considerar ferramentas básicas como DFMA (Design For Manufacturing and Assembly) - projeto para a manufatura e montagem, confiabilidade de sistemas, análises de risco, programas de manutenção etc. existe uma grande probabilidade de maiores ocorrências de falhas de campo, custos de garantia, desperdício de tempo e material quando da produção do modelo.

Estes detalhes podem se tornar um grande diferencial na linha de montagem do produto. Embora seja difícil correlacionar mudanças do estilo do produto com índices de qualidade ou garantia, deve-se sempre lembrar que estas mudanças impactam muito na qualidade de acabamento do produto, ou seja, na sua aparência. 
Estas mudanças de aparência passam aos consumidores a qualidade de acabamento de um produto, tornando-o ainda mais desejado e aceito no mercado.

\subsection{Objetivo do Trabalho}

O objetivo deste estudo é propor um modelo de desenvolvimento focando em qualidade e confiabilidade. O método proposto identificará e avaliará sistemas e/ou componentes através do comparativo entre as falhas de campo de quatro plataformas de veículos. O resultado deste comparativo mostrará quais são os itens mais críticos de falha por incidência e em alguns destes sistemas e/ou componentes as ferramentas de qualidade serão aplicadas para a melhoria do produto. Quando se adicionam ferramentas de qualidade, análise de risco, revisões de projeto com base em testes, comparativo entre projetos nas atividades de desenvolvimento e nas análises de falhas destes produtos, minimizam-se os riscos e as falhas até a um nível aceitável. O estudo proposto mostrará como cada uma destas ferramentas de qualidade pode melhorar a confiabilidade do produto, através de seu uso nos sistemas e/ou componentes durante o desenvolvimento.

A estatística confirma que uma população de componentes e/ou equipamentos em serviço sempre apresentará algum tipo de falha. Esta falha pode ser a quebra definitiva de um item de um equipamento e logicamente a sua parada ou ainda, mesmo sem uma quebra evidente o equipamento não mais atende às especificações estabelecidas para ele e por isto precisa sofrer uma intervenção para que volte a operar dentro de suas especificações.

A verdade é que, para qualquer desenvolvimento do produto deve-se sempre usar o bom senso de engenharia, embora seja óbvia esta afirmação, infelizmente não se vê aplicada em muitas situações. Não existe uma fórmula secreta para o sucesso de lançamento de um produto ao mercado, um bom desenvolvimento vem de trabalho duro, excelentes engenheiros, cultura de time de trabalho, o uso de ferramentas de qualidade simples, mas de grande eficiência e a constante melhoria contínua que sempre traz benefícios em cada novo projeto. 


\subsection{Escopo do Trabalho}

O presente estudo está propondo um modelo de melhoria de qualidade de um produto, este modelo mostrará como as ferramentas aqui usadas estão ligadas ao ganho de confiabilidade do produto e por consequência a melhoria do desempenho do mesmo no campo, reduzindo falhas de campo e custos de garantia. Este modelo estará comparando publicações e suas respectivas contribuições e o que esta proposta traz de diferente dos textos existentes, para melhorar a confiabilidade de um produto.

Quanto mais reduzido for o tempo de desenvolvimento, mais os engenheiros precisam focar em qualidade e confiabilidade, para atender a todas as especificações do produto de forma a eliminar futuras reclamações de campo. Qualquer atividade neste sentido deve-se iniciar na fase conceitual do desenvolvimento do produto, para que todos os problemas de qualidade sejam propriamente analisados e solucionados. O nível de qualidade de qualquer produto é medido pela satisfação dos clientes. Em um veículo estes critérios podem ser objetivos e medidos como, por exemplo, consumo de combustível, nível de ruído, conforto de um banco através de reclamações feitas por pesquisas de campo ou pelo sistema de garantia, ou critérios subjetivos como dirigibilidade ou aparência. Assim, qualidade é determinada por dois fatores determinantes: qualidade conceitual do projeto e a habilidade de produzir este projeto conceitual. Devido à atual competitividade entre as montadoras nos mercados, a margem de erro foi reduzida drasticamente e eliminar os problemas de qualidade e confiabilidade nestas fases não é mais uma opção e sim uma necessidade, caso contrário, pode-se colocar em risco todo desenvolvimento.

As novas tecnologias devem ser sempre adaptadas às pessoas e processos da empresa. É mais importante usar esforços e um tempo necessário para que as novas tecnologias venham a melhorar ainda mais os processos já implementados, padronizados e os times de trabalho organizados. Mas, como será mostrado nos capítulos seguintes, nada disto trará resultados positivos se não for entregue ao cliente exatamente aquilo que ele espera. Pois, seja qual for 0 tipo de desenvolvimento do produto usado por uma empresa, o primeiro passo é a identificação das necessidades daquilo que se propõe a desenvolver, para que atenda ou supere as expectativas dos clientes. 
Torna-se necessário estabelecer o que realmente agrega valor ao produto para o cliente e separar tudo aquilo que seja desperdício, isto pode parece óbvio, mas é algo bem comum de se ver em vários produtos devido à dificuldade de se entender exatamente as características que adicionam valor sob a perspectiva dos clientes daquele produto. Sejam quais forem os itens que agregam valor ao produto, um deles é comum entre os clientes, ninguém quer vivenciar uma falha em seu produto por um bom tempo de uso, e é neste item que este trabalho será focado, ou seja, na redução de falhas através do uso de ferramentas de qualidade. 


\section{FUNDAMENTOS TEÓRICOS}

Atualmente, é uma prática comum as empresas investirem grande quantidade de tempo tentando identificar quais são os atributos de um produto que serão importantes aos seus consumidores. As indústrias automotivas americanas gastam recursos juntando e estudando dados demográficos, revisando os resultados dos grupos alvo para cada modelo, fazendo comparações com os competidores e revendo dados de qualidade de algum modelo já em uso no campo. Uma vez que todos estes dados são entendidos, eles formam o documento de intenção da estratégia do produto, definindo o cliente alvo, os modelos com que se quer competir, modelo de custo praticável, objetivos de desempenho do novo veículo, entre outras informações. Todas estas informações analíticas são revisadas nas chamadas "revisões de negócios" para avaliar os dados que ditarão a direção e se o projeto do novo produto é viável ou não.

Nesta fase, o foco principal dos times de desenvolvimento é meramente fornecer números, especificamente requisitos financeiros, e preparar apresentações para as revisões de projeto com seus superiores. Isto causa pouco ou às vezes nenhuma conexão com o consumidor, o consumidor alvo não é o centro do processo, os números financeiros são. O fato é que, após a fase conceitual, o consumidor é raramente mencionado e todos focam claramente do início ao final do projeto no retorno dos investimentos ( $\mathrm{ROI}$ - Return on Investment) e raramente nas características que agregam valores aos consumidores e ainda são totalmente alheios aos desperdícios de engenharia causados por esta atitude.

Segundo Liker (2006), as montadoras americanas se esforçam para comunicarem aos seus times de trabalho o que sabem sobre o programa de desenvolvimento de forma analítica. Isto causa incertezas sobre o objetivo do programa de desenvolvimento, sobre o objetivo de cada área funcional e sobre a meta destes times de trabalho. Muitos participantes destes times de trabalho têm um vago entendimento do objetivo da sua própria atividade assim como das metas gerais do programa de desenvolvimento.

Esta falta de comunicação ainda se deteriora para os grupos inferiores de trabalho, ou seja, grupos fora do time de desenvolvimento, onde cada um tem seus próprios objetivos para o projeto. Isto causa uma grande falta de comprometimento 
destes times inferiores, não dando assim a oportunidade para que estes times colaborem de forma significativa, fornecendo informações importantes para 0 desenvolvimento do produto, evitando desperdícios e sugerindo reduções de custo inteligentes. Isto inibe a habilidade das empresas americanas em passar ao consumidor aquilo que realmente importa, criando também atrasos no programa de desenvolvimento, aumento de custos e normalmente gera um produto de qualidade inferior para o consumidor final.

Assim como as empresas americanas, as japonesas também avaliam dados de campo, realizam pesquisas de mercado e fazem comparações com os competidores. Mas as similaridades terminam aqui. Segundo Liker (2006), a Toyota seleciona os líderes de cada programa de desenvolvimento baseando-se na experiência que cada um deles tem com cada produto, estabelecendo assim uma conexão emocional com o consumidor alvo. Como explicou Kousuke Shiramizo, alto executivo da Toyota e o guru de qualidade para o programa de desenvolvimento Lexus "Engenheiros que nunca colocaram o pé em Beverly Hills, não tem nenhuma experiência para projetar um Lexus". Na Toyota é necessário para os engenheiros de desenvolvimento, além deste tipo de experiência, ter um ótimo entendimento dos valores para os consumidores de cada um dos seus produtos e como as características destes valores são integradas ao desempenho do produto durante o desenvolvimento.

Para se obter este tipo de experiência, um grupo de engenheiros da Toyota do projeto Sienna, realizou uma viagem de avaliação de mais de 50.000 milhas com um modelo anterior, através dos Estados Unidos, Canadá e México. Estes engenheiros acumularam uma grande experiência sobre o produto e as reais necessidades dos seus clientes durante esta viagem, como por exemplo, aumento do espaço interno para carregar pranchas padrão de compensado, diminuição do raio de giro, aumento do número de suportes para copos e melhor estabilidade do veículo, entre outras melhorias. Este tipo de processo, embora simples, mostra uma das maneiras de comprometimento em desenvolver um novo produto considerando características que realmente agregam valores ao consumidor final.

Uma vez determinadas quais são estas características cabe ao lider do projeto montar o documento de estratégia do novo produto. Isto passa por vários meses de reuniões de trabalho com todas as áreas envolvidas para que cada característica 
seja transformada em objetivos mensuráveis. Uma vez aprovado o documento de estratégia, este passa a ser o guia, como uma lei, para o desenvolvimento do novo produto.

Quando se iniciam as atividades de desenvolvimento de um novo produto, deve-se estar preparado para identificar e resolver os problemas de forma rápida e robusta. A capacidade de resolver problemas melhorará a competência do desenvolvimento do produto. Os problemas durante um desenvolvimento devem ser vistos como oportunidades de aprendizado, crescimento e melhoria do desempenho, criando assim um pensamento positivo para as soluções de problemas. Este tipo de comportamento ajudará aos times de desenvolvimento a confrontar e resolver os problemas nas fases iniciais, obtendo assim, soluções melhores e mais rápidas. Embora pareça óbvio, esta atitude fomenta o pensamento crítico e introduz a soluções melhores, esta é a vantagem competitiva permanente que é difícil de copiar, segundo Liker (2006).

Um processo de desenvolvimento enxuto deve analisar os problemas como oportunidades não somente como melhoria do produto, mas também como melhoria da capacidade do processo de desenvolvimento. Em geral, as montadoras americanas não têm o mesmo comportamento quanto aos problemas, os vêem de forma negativa e inesperada, e quando eles aparecem, surgem também muitos apontando ou procurando um culpado. Este tipo de atitude existe porque os problemas são vistos como indicadores de baixo desempenho. Assim, muitos engenheiros aprendem rapidamente a esconder os problemas o quanto for possível. E quando estes problemas são trazidos ao conhecimento do time de desenvolvimento, são mais difíceis de solucionar podendo causar atrasos ao desenvolvimento do produto.

A fase onde se iniciam as montagens dos protótipos é um período de grande aprendizado, é o momento onde os componentes ou sistemas projetados tornam-se peças físicas para serem montadas. É neste período que se consegue obter um desenvolvimento enxuto, resolvendo os problemas que aparecem de forma rápida e permanente. Estes problemas devem ser transformados em oportunidades de melhoria contínua, isto significa investir o tempo necessário para a solução dos problemas e os mecanismos de como evitá-los no futuro. Além disto, é necessário compartilhar esta experiência e/ou solução com outros engenheiros antes que estas 
sejam esquecidas, outra afirmação óbvia, mas de difícil coordenação e execução.

Segundo Morgan (2002), a Toyota consegue executar estas atividades através da padronização de muitas atividades do processo de desenvolvimento. Para que um processo de solução de problemas seja eficiente deve-se:

- Identificar a causa-raiz do problema;

- Avaliar os impactos de todas as possíveis soluções;

- Produzir soluções que resolvam o problema de imediato e previnam a sua reocorência;

- Comunicar os resultados com outros times de desenvolvimento a atualizar o banco de dados de lições aprendidas.

\subsection{Análise da Confiabilidade de Sistemas}

A palavra confiabilidade é amplamente utilizada nos dias de hoje. O ponto de vista mais simplista de confiabilidade seria quando um produto é avaliado através de determinadas especificações ou conjunto de atributos e se aprovado seria então entregue ao cliente. $O$ cliente tendo aceitado o produto sabe que ele poderá falhar no futuro, e esta simples definição está associada ao custo de garantia da empresa.

A qualidade de um produto é um atributo instantâneo para o início de vida do produto e sua confiabilidade é um retrato móvel de sua utilização. As falhas ocorridas em tempo zero são aquelas que passaram pelos métodos de garantia da qualidade da empresa e as falhas que ocorreram durante o tempo de uso são as falhas de confiabilidade. Portanto os objetivos da engenharia de confiabilidade, em ordem de prioridade são:

$\rightarrow$ Aplicar os conhecimentos de engenharia e técnicas especiais para prevenir ou reduzir a frequência de falhas,

$\rightarrow$ Identificar e corrigir a causa das falhas que ocorreram, apesar dos esforços para prevení-las,

$\rightarrow$ Aplicar métodos para estimar a confiabilidade de novos projetos, baseando-se na análise dos dados de campo de um projeto já existente. 
A razão para se priorizar deve-se ao fato de facilitar a observação de resultados intermediários que melhoram a confiabilidade do produto em produção, atingindo o objetivo imediato de redução de custo, como objetivo futuro, ter-se-á o projeto e a produção de componentes e sistemas de maior confiabilidade. Os requisitos necessários, portanto, são: a habilidade de entender e antecipar as possíveis causas de falhas, e o conhecimento de como prevení-las. Também é necessário conhecer os métodos que podem ser usados para analisar os projetos e os dados de campo. Estes requisitos nada mais são do que experiência e bons conhecimentos de engenharia e a engenharia de confiabilidade é a melhor prática a ser usada durante desenvolvimentos dos projetos.

Os veículos atualmente são mais complexos, através da adição de mais componentes e de novas tecnologias com a intenção de competir melhor com seus concorrentes. Deste modo estes veículos que precisam apresentar uma confiabilidade aceitável pelo cliente devem ser monitorados constantemente, pois este aumento de complexidade pode causar um decréscimo de confiabilidade. Se uma empresa automotiva aumenta a confiabilidade de seus veículos, ela consequentemente aumentará os custos de projeto ou de produção. O custo total de um veículo não é calculado baseando-se simplesmente no custo de quando o veículo deixa a fábrica, mas sim com todo o custo até o final de sua garantia. $\mathrm{Na}$ aprovação de um novo projeto, todos os gastos esperados e retorno do investimento são considerados, inclusive os gastos estimados de garantia durante o período da mesma.

A figura 2 é uma representação teórica clássica da relação custo benefício dos esforços gastos em atividades de análise de confiabilidade. Todavia, apesar de seu apelo e frequente uso em livros e cursos de qualidade e confiabilidade, esta figura ainda não reflete totalmente a realidade. Sabe-se que não será atingida a confiabilidade perfeita, ou seja, 100\%, logo sempre se têm algum tipo de falha, mas deve-se perguntar: Quais seriam os custos para prevenir ou corrigir estas falhas, comparados com os custos de não prevení-las, ou seja, não fazer nada? 




Figura 2 - Confiabilidade e custos do ciclo de vida: Visão Tradicional.

(fonte: O'Connor, 2002)

Quando cada modo de falha potencial é analisado desta maneira, é claro que o custo total continua a diminuir assim como a confiabilidade é melhorada. Todos os esforços gastos em programas de confiabilidade nada mais são do que investimentos, com grande retorno em curto período de tempo. A grande dificuldade enfrentada atualmente é que não é tão simples quantificar os efeitos dos programas de confiabilidade como quantos testes devem ser feitos para se atingir a confiabilidade planejada. A experiência tem mostrado que a maneira mais realista de se ilustrar este conceito está representada na figura 3. Nesta figura pode-se observar que com 0 aumento da confiabilidade, menor será o número falhas e consequentemente os custos destas falhas e os custos de desenvolvimento diminuirão, pois serão menores as intervenções para correções de falhas e investimentos em novas soluções. Tudo isto resulta em uma redução do custo total de todo projeto.

Desenvolver produtos confiáveis requer uma integração total entre projeto, treinamento, teste e produção assim como com programas de desenvolvimento de confiabilidade. Logo, torna-se difícil separar e identificar os custos de cada atividade, especialmente aquelas voltadas para a confiabilidade. É importante a participação dos especialistas em confiabilidade nos times funcionais durante todas as fases de um projeto. 




Figura 3 - Confiabilidade e custos do ciclo de vida: Visão Moderna.

(fonte: O’Connor, 2002)

Existem várias distribuições de probabilidade utilizadas na caracterização da função densidade de probabilidade dos tempos de falha e da função de taxa de falha. Neste estudo se assumirá a distribuição de Weibull como a distribuição de probabilidade recomendada para estudo da confiabilidade dos sistemas e/ou componentes eletros-mecânico. A distribuição de Weibull é um modelo estatístico muito usado para estudos de fadiga e resistência em componentes e/ou sistemas de engenharia e muitos exemplos podem ser encontrados nas indústrias de eletrônicos, automotiva, em materiais e na aeronáutica. Na engenharia de confiabilidade a distribuição de Weibull é amplamente utilizada e sua popularidade é o resultado de sua flexibilidade. A função densidade de probabilidade de falha $f(t)$ de Weibull é mostrada na Equação (1).

$$
f(t)=\frac{\beta}{\eta}\left(\frac{\mathrm{t}-\mathrm{t}_{0}}{\eta}\right)^{\beta-1} \cdot \exp \left[-\left(\frac{\mathrm{t}-\mathrm{t}_{0}}{\eta}\right)^{\beta}\right]
$$

onde:

$t_{0}$ : constante de localização - define a posição em que a função densidade de probabilidade tem origem;

$\eta$ : $\quad$ constante de escala - define o espalhamento da distribuição ao longo do eixo das abscissas (eixo $\mathrm{x}$ ); 
$\beta$ : constante de forma.

Sendo $\beta$ e $\eta$ sempre valores positivos.

Assim, pode-se dizer que a distribuição de Weibull é definida por três parâmetros: $t_{0}, \beta$ e $\eta$. Isto a torna bastante flexível, sob o ponto de vista de permitir a representação de uma grande variedade de mecanismos de falha. Variando a constante de forma $\beta$ a função densidade de probabilidade de Weibull assume uma grande variedade de formas conforme ilustra a figura 4.



Figura 4 - Função densidade de probabilidade de Weibull.

(fonte: Dodson e Nolan 1995)

A distribuição de Weibull pode ser usada em uma grande variedade de situações e depende apenas do parâmetro de forma $\beta$ como exemplo de referência:

a) Para valores de $\beta=1 \rightarrow$ a distribuição de Weibull é idêntica a distribuição Exponencial, representando mecanismos de falha aleatória;

b) Para valores de $\beta<1 \rightarrow$ a função densidade de probabilidade é decrescente para um aumento da magnitude de $t$, representando as falhas de mortalidade infantil, ou seja, falhas associadas a erros de montagem ou problemas de qualidade dos materiais;

c) $\underline{\text { Para valores de } \beta>1} \rightarrow$ a curva da função densidade de probabilidade apresenta 
picos bem definidos, representando falhas associadas à mecanismos danos aumentados como fadiga, desgaste e corrosão;

d) Para valores de $\beta=2,5 \rightarrow$ a distribuição de Weibull aproxima-se da distribuição lognormal;

e) Para valores de $\beta=3,44 \rightarrow$ a distribuição de Weibull aproxima-se da distribuição normal.

Neste estudo o tempo "t" é caracterizado como a quilometragem reportada pela concessionária quando do reparo feito do componente e/ou sistema reclamado pelo cliente. Assim, se tem os dados necessários para a análise dos sistemas escolhidos, as quilometragens das falhas dos sistemas em estudo e a estimativa das quilometragens dos veículos que não apresentaram falhas durante o mesmo período, conforme ilustra a figura 5. Mas, ainda é necessário algumas considerações para o uso do banco de dados, a ser mostrado posteriormente.



Figura 5 - Período em estudo.

Torna-se necessário agora assumir hipóteses do tempo " $\mathrm{t}$ " onde se determinará a confiabilidade dos sistemas em estudo, conforme ilustra a figura 6 . 




Figura 6 - Confiabilidade $\mathrm{R}\left(\mathrm{t}_{\mathrm{i}}\right)$ no tempo $\mathrm{t}_{\mathrm{i}}$.

Os dados de um sistema de garantia automotivos têm uma característica básica, ele é não é claro o suficiente para os estudos de confiabilidade, assim é necessário considerar os seguintes pontos:

- Veículos que apresentaram mais do que uma falha no mesmo sistema serão considerados somente como uma única falha, separando assim falhas de reparo das falhas de qualidade do sistema e/ou da montagem do veículo.

- As quilometragens reportadas pelos técnicos de serviço serão consideradas como a quilometragem da falha do sistema.

- Veículos com poucos meses de uso com quilometragem muito alta e veículos com muitos meses de uso com quilometragem muito baixa, não serão considerados, assumindo-se que estes foram erros de entrada no banco de dados de garantia.

Existe sempre preocupação quando ao uso de dados de garantia automotiva, pois a informação proveniente dos bancos de dados não são consistentes. Isto se deve ao fato que a informação de campo representa somente aqueles veículos que apresentaram falhas em seus componentes e/ou sistemas durante o período em 
análise. Pouco ou quase nada se sabe dos veículos que não apresentaram tais falhas durante este mesmo período (incluindo qual sua quilometragem ao término da garantia).

A qualidade da informação é de grande importância para a exatidão da predição da confiabilidade do componente ou sistema em análise. Assim, do ponto de vista da estatística, amostras de falhas de campo extraídas dos bancos de dados de garantia são consideradas como dados censurados. Segundo Dodson e Nolan (1995) dados censurados incluem informações sobre componentes que falharam e componentes que sobreviveram a um teste específico ou, no caso automotivo, passaram pelo período de garantia sem apresentar o modo de falha em estudo, ou seja, têm-se informações de falhas de somente uma parte da amostra.

Segundo Coit (1998) os dados de campo geralmente são classificados como censurados, existindo dois tipos: Tipo I e Tipo II. Os dados censurados do Tipo I são aqueles em que o teste termina após um período de tempo pré-determinado, sabese o número de itens que falharam e seus respectivos tempos de falha e também se sabe o número de itens que sobreviveram, porém os dados de falhas destes itens que sobreviveram são desconhecidos. Os componentes que permanecem funcionando após este período são chamados de censurados ou suspensos. Os dados censurados do Tipo II são aqueles em que se determina um número de falhas desejado e encerra-se o teste quando se observa este número de falhas. $A$ figura 7 ilustra os dois tipos de dados censurados.





Figura 7 - Dados Censurados.

(fonte: Krishnamoorthi, 1992) 
Conforme Campean (2000), uma maneira de superar as dificuldades de análise estatística deste tipo de dados, consiste na investigação e obtenção de informações de veículos que não falharam, por exemplo, a quilometragem acumulada por veículos que não apresentaram falhas do sistema em análise durante o período de garantia ou o período em estudo.

A proposta neste estudo consiste em analisar sistemas e/ou componentes durante o período de garantia. Por este motivo um estudo adicional foi feito com veículos de outro ano modelo com o objetivo de se obter o comportamento dos usuários durante o período de garantia. Assim, estes valores serão assumidos como os dados censurados para o estudo. Deste modo, uma análise do banco de dados foi realizada com veículos que estavam completando 12 meses de uso e que por qualquer motivo retornaram a uma concessionária para algum reparo. Ao fazê-lo a concessionária registrou a falha e a quilometragem destes veículos e assim se tem o comportamento dos usuários quanto à quilometragem de seus veículos com 12 meses de uso. A amostra destes veículos obedeceu às seguintes regras:

- Usar somente a última reclamação reportada por veículo (estas reclamações contêm o máximo de quilometragem acumulada pelos clientes no período em análise).

- Usar as reclamações que ocorreram com veículos produzidos e vendidos no que completaram 12 meses de uso.

- Usar somente as reclamações de maior incidência no período em estudo, com isto aumenta-se a amostra e a confiança da análise.

A figura 8 foi o resultado da pesquisa ao banco de dados de uma determinada plataforma de veículo de passageiros onde são mostradas as faixas de quilometragens que estes veículos acumularam durante o período em estudo. Para tornar possível a análise de confiabilidade os pontos médios da tabela serão usados como dados censurados para cada faixa de quilometragem, ou seja, se estará assumindo estes valores de quilometragem como dados censurados Tipo I.

Com os dados de falhas de campo mais a distribuição de acúmulo de quilometragem como dados censurados mostrados na figura 8 pode-se: 




Figura 8 - Distribuição quilometragem para 12 meses de uso.

- Mercado Nacional -

a) Determinar a confiabilidade de um sistema e/ou componente em qualquer instante de tempo.

b) Monitorar o desempenho de um sistema e/ou componente compará-lo com os objetivos traçados para o produto e finalmente priorizar ações corretivas para que todo o sistema esteja dentro do objetivo planejado.

c) Detectar componentes onde o nível de confiabilidade tem apresentado mudança significativa ao longo do tempo.

Outro estudo foi feito para o mercado europeu, conforme ilustra a figura 9.

\begin{tabular}{|c|c|c|c|c|c|c|}
\hline \multicolumn{7}{|c|}{ Mercado Europeu } \\
\hline $\begin{array}{c}\text { Quilometragem } \\
\text { Acumulada }\left(\times 10^{2} \mathrm{Km}\right)\end{array}$ & $\begin{array}{c}\% \\
\text { Veículos }\end{array}$ & & & & & \\
\hline $0-50$ & 1,5 & & & & & \\
\hline $50-100$ & 20,2 & & & & 20,2 & \\
\hline $100-150$ & 27,1 & & & & & 27,1 \\
\hline $150-200$ & 25,3 & & & & & 25,3 \\
\hline $200-250$ & 12,2 & & & 12,2 & & \\
\hline $250-300$ & 5,6 & & 5,6 & & & \\
\hline $300-400$ & 5,4 & & 5,4 & & & \\
\hline $400-500$ & 2,0 & & & & & \\
\hline $500-600$ & 0,1 & 0,1 & & & & \\
\hline $600-700$ & 0,3 & 0,3 & & & & \\
\hline $700-800$ & 0,3 & 0,3 & & & & \\
\hline
\end{tabular}

Figura 9 - Distribuição quilometragem para 12 meses de uso.

- Mercado Europeu - (fonte: Campean, 2000) 
Comparando as informações das figuras 8 e 9 tem-se a tabela 1, onde é possível se obter a melhor quilometragem para se determinar a confiabilidade dos sistemas em estudo. Como se quer obter os melhores desempenhos dos componentes e/ou sistemas e abranger a maior incidência de quilometragem serão usados as quilometragens de 20 e 25 mil quilômetros como o instante de tempo onde serão feitos os estudos de confiabilidade. Com isto se tem aproximadamente $97 \%$ da população de veículos para o mercado nacional e $86 \%$ no mercado europeu.

Tabela 1 - Comparativo do comportamento do usuário com 12 meses de uso.

\begin{tabular}{|c|c|c|}
\hline $\begin{array}{c}\text { Faixa de } \mathrm{Km} \\
\left(\mathrm{x} 10^{2}\right)\end{array}$ & $\begin{array}{c}\text { Mercado Brasileiro } \\
\text { (veiculos em estudo) }\end{array}$ & $\begin{array}{c}\text { Mercado Europeu } \\
\text { (Campean 2000) }\end{array}$ \\
\hline $0-50$ & $29,6 \%$ & $1,5 \%$ \\
\hline $50-100$ & $31,7 \%$ & $20,2 \%$ \\
\hline $100-150$ & $18,5 \%$ & $27,2 \%$ \\
\hline $150-200$ & $17,3 \%$ & $25,3 \%$ \\
\hline $200-250$ & $1,0 \%$ & $12,2 \%$ \\
\hline $250-300$ & $0,7 \%$ & $5,6 \%$ \\
\hline $300-350$ & $0,7 \%$ & $5,4 \%$ \\
\hline $350-400$ & $0,5 \%$ & $2,7 \%$ \\
\hline
\end{tabular}

Até este ponto do estudo tem-se:

$\rightarrow$ Uso da distribuição de Weibull para as análises de confiabilidade,

$\rightarrow$ Dados censurados para os veículos em estudo,

$\rightarrow \mathrm{O}$ instante de tempo "t" onde se quer determinar qual a confiabilidade dos componentes.

\subsection{Métodos de Crescimento de Confiabilidade}

Durante os estágios iniciais do desenvolvimento de um novo produto, estudos de confiabilidade são feitos como parte do projeto. Muitos destes estudos são derivados de solicitações e de reclamações formuladas pelo próprio cliente e são adicionados ao projeto pelo time de desenvolvimento. A confiabilidade é uma parte importante para se ter uma visão preliminar do projeto, onde se pode estabelecer o nível de confiança desejado para que o produto tenha a confiabilidade esperada no 
campo. Deficiências nesta fase do projeto afetarão o produto e certamente custará mais para corrigi-las nas fases mais adiantadas do desenvolvimento ou mesmo após o início de produção.

Portanto, torna-se necessário para todo time de desenvolvimento ter disciplina durante o projeto, pois isto minimiza a possibilidade de ocorrência de erros e permite que as deficiências de projeto sejam detectadas nas fases iniciais e corrigidas o quanto antes.

Conforme Neubeck (2004), em geral estes estudos podem ser divididos em duas categorias: análise de componente e análise de sistema. Análise de componente pode ser: análise de solicitação externa e predição da taxa de falha. Quando se aplica estes dois tipos de análise, obviamente inicia-se uma análise de sistema, dos quais os componentes são parte. Isto inclui análise de modo e efeitos de falha potencial (failure mode and effects analysis - FMEA) e análise da árvore de falhas (failure tree analysis - FTA). A figura 10 mostra a proposta de programa de desenvolvimento de confiabilidade.



Figura 10 - Etapas de um programa de desenvolvimento de confiabilidade.

(Adaptado de Neubeck, 2004)

As etapas mostradas na figura 10 farão parte da proposta deste estudo e serão discutidas propriamente nos capítulos seguintes. A análise da confiabilidade depende de uma série de dados que devem ser tratados estatisticamente. Estes dados serão extraídos dos dados de campo dos veículos em produção corrente. 
Quando do uso de dados de garantia automotiva é necessário saber a causa raiz das falhas ocorridas. Somente com uma análise das peças falhadas pode-se obter a causa raiz dos problemas reportados e assim propor mudanças de projeto adequadas para se ter resultados satisfatórios e confiáveis no campo, caso contrário as correções acabam sempre em tentativa e erro e neste caso a efetividade das correções serão quase nulas.

\subsection{Projeto para Manufatura e Montagem (DFMA)}

As empresas estão sempre em constantes desafios para produzir produtos melhores e mais rápidos. Atualmente as empresas não dispõem de tempo para reprojetar um produto e menos ainda longos desenvolvimentos de novos produtos. Os engenheiros do produto não podem simplesmente passar o conceito de engenharia para o engenheiro de manufatura encontrar as maneiras e/ou processos de se produzir o produto. $\mathrm{O}$ engenheiro do produto e o engenheiro da manufatura devem trabalhar juntos para se certificarem que serão usados os melhores conceitos de projeto e as melhores soluções de manufatura, resultando em produtos de custos mais competitivos, segundo Boothroyd (1994).

Para ser competitivo, um produto precisa ser desenvolvido com o menor tempo possível e com o mínimo de recursos e custos da empresa. Para atender as necessidades de mercado, muitas filosofias tais como, projeto para a manufatura, projeto para a montagem, projeto para a qualidade, projeto para um ciclo de vida do produto são desenvolvidas.

O primeiro objetivo desta ferramenta é estabelecer quais são as necessidades da manufatura, montagem, qualidade e ciclo de vida do produto durante o processo de desenvolvimento do produto. Diferentes empresas desenvolvem diferentes conceitos de projeto para atender as mesmas necessidades. A solução para uma determinada aplicação depende de como um problema é definido para o engenheiro do produto assim como de seus conhecimentos e da sua criatividade como projetista. Como existem muitas soluções para um problema de engenharia, fica difícil saber qual é a melhor solução para cada situação. Projeto para a manufatura e montagem é uma ferramenta que guia o engenheiro do produto a melhores opções de projeto. 
É uma ferramenta para uso na criação do conceito, sua aprovação e melhoria contínua do produto. Isto significa integrar conhecimentos de processos e de projeto para se obter o máximo de benefícios e capacidade de um método de manufatura. Para se ter 0 melhor projeto, o engenheiro de manufatura precisa ter bons conhecimentos dos benefícios e limitações das várias técnicas de manufatura.

As mudanças de projeto podem ser muitas, o que resultará em atrasos para a entrega do produto final. Portanto, é importante considerar manufatura e montagem durante as fases iniciais do desenvolvimento de um produto. Isto é ilustrado na figura 11, conforme Boothroyd (1994), onde se mostra que o tempo investido no projeto inicial, nas fases conceituais de desenvolvimento, é recompensado em ganho de tempo na fase de protótipos, reduzindo custos e introduzindo o produto no mercado mais rápido.

O uso da ferramenta do DFMA reduz custo do produto final, reduz os componentes a serem montados e consequentemente o tempo de montagem, e também acelera o ciclo de desenvolvimento do produto.



Figura 11 - Tempo de desenvolvimento do produto com aplicação do DFMA. (fonte: Boothroyd - 1994). 
Outra razão para considerar manufatura e montagem nas fases iniciais do desenvolvimento de um produto é que $70 \%$ do custo final são determinados durante o projeto, conforme ilustra a figura 12.



Figura 12 - Custos durante o desenvolvimento vs. custos do produto final. (fonte: Boothroyd - 1994).

A figura 13 mostra os passos na aplicação de um DFMA durante um projeto. A análise do projeto para montagem (DFA) considera a simplificação do produto e é neste ponto que se melhora a confiabilidade do mesmo, pois se diminuem os componentes e os erros de montagem. O primeiro passo é obter as estimativas iniciais de custo para o projeto original e para as novas propostas, onde então as decisões são tomadas. 




Figura 13 - Passos na Engenharia Simultânea usando Critério de DFMA. (fonte: Boothroyd - 1994).

O fluxograma da figura 14 mostra um método de análise para o uso da ferramenta DFMA. Quanto às vantagens na aplicação do DFMA, pode-se afirmar que esta ferramenta fornece um processo de análise onde se considera o ponto de vista de montagem e manufatura.

Este processo resulta em produtos mais simples e confiáveis, mais fáceis de produzir e montar e quando isto é introduzido em uma linha de montagem diminuemse as possibilidades de erros de montagem do produto e consequentemente $o$ número de falhas prematuras, melhorando a qualidade do produto na fase inicial da curva da banheira. Este é o ganho de confiabilidade que será explorado com o uso desta ferramenta neste estudo. 




Figura 14 - Fluxograma de Análise para uso da Ferramenta DFMA. 


\subsection{Análises de Risco e Confiabilidade}

O trabalho dos engenheiros do produto é projetar e manter um produto de tal modo que sua falha seja adiada ao máximo possível. Nesta tarefa encontram-se problemas com muitas variáveis como materiais, processos e aplicações. Estas variáveis e suas possibilidades têm grande influência ao se determinar a confiabilidade da maioria dos sistemas ou produtos. Entender estas variações, e suas possibilidades de causa e efeito, torna-se necessário para o desenvolvimento de produtos confiáveis e para a solução dos problemas que poderão aparecer. O mercado atual exerce uma grande pressão e desafios nestes desenvolvimentos como competição, cronogramas diminuídos, custo da falha, evolução dos novos materiais, sistemas mais complexos e necessidade de reduzir custos. Todos estes fatores aumentam o risco de desenvolvimento de um produto. O risco está associado a todos os projetos e negócios, independente do seu tamanho, natureza, tempo e local de execução. O risco está presente em várias formas e níveis em nossas vidas e estes riscos podem resultar em perdas significativas de orçamento do projeto, atrasos, falhas, impactos ambientais e até mesmo perda de vidas. A figura 15 mostra as pressões em um desenvolvimento que fornece uma idéia da percepção do risco. A engenharia de confiabilidade se desenvolveu para ajudar a controlar estes riscos e entender os princípios da confiabilidade e os riscos envolvidos é um ingrediente essencial na engenharia moderna.



Figura 15 - Percepção do Risco.

(fonte: O'Connor - 1990). 
Os métodos de análise de risco são ferramentas ou processos usados para avaliar e gerenciar o risco de um componente ou sistema. Estes métodos podem ser classificados em gerenciamento de risco onde se tem a análise e avaliação do risco, controle do risco usando prevenção de falhas e mitigação das consequências e a comunicação do risco, conforme mostra a figura 16.



Figura 16 - Métodos de Análise de Risco.

(fonte: Ayyub, B.M. - 2001)

\subsubsection{Metodologias de Avaliação de Risco}

Estudos de análise de risco requerem métodos analíticos para a análise das probabilidades de falha e das consequências da ocorrência das mesmas nos sistemas, subsistemas e seus componentes. Análises quantitativas e qualitativas são usadas na avaliação das probabilidades de falha e suas consequências. Uma análise sistemática de risco permite ao analista avaliar sistemas complexos quanto à segurança e risco sob diferentes condições de operação. A habilidade de avaliar quantitativamente estes sistemas ajuda na redução de custos em reprojetos, reparos, mudanças de componentes, subsistemas e sistemas. Os resultados de uma análise de risco podem ser utilizados em métodos de tomada de decisão baseados em custo. Análise de risco é um processo técnico e científico, onde um risco de uma dada situação para um sistema é modelado e quantificado. Análise de risco requer e 
proporciona dados qualitativos e quantitativos para a tomada de decisão no gerenciamento do risco.

Em um processo de análise de risco utilizam-se pessoas com experiência em projetos similares, banco de dados, modelos anteriores de análise de risco e experiências de outras empresas, além de ferramentas para avaliação e predição de falhas. As etapas da metodologia proposta para análise de risco consistem dos seguintes passos:

1. Definição dos objetivos da análise e do limite sistema;

2. Identificação dos perigos e definição dos cenários de falha;

3. Coleta de dados referentes às falhas observadas ao longo da vida operacional;

4. Análise qualitativa de risco;

5. Análise quantitativa de risco;

6. Gerenciamento da integridade dos sistemas e a prevenção das falhas.

A primeira etapa em uma avaliação de risco é a escolha do sistema a ser analisado. Em seguida deve-se decompor o sistema em subsistemas ou componentes para identificar quais deles será a fonte de risco maior. Esta primeira etapa fica dividida em:

$\rightarrow$ Identificar o perigo.

$\rightarrow$ Identificar as partes do sistema que podem gerar o perigo.

Uma boa análise de perigo de um sistema depende de bons conhecimentos de engenharia, dos impactos ambientais, dos processos de fabricação e dos equipamentos em estudo. Sempre se faz necessário colocar parâmetros ou fronteiras na análise técnica do sistema e do meio ambiente. Segundo Henley e Kumamoto (1992), não é razoável, por exemplo, fazer um estudo de análise de risco de um evento como um avião batendo em uma coluna de destilação, mas um evento de baixa probabilidade de perigo pode ser considerado como por exemplo, um evento em uma usina nuclear. Neste caso pode-se se preparar contra este perigo e teoricamente um acidente em uma usina nuclear pode matar mais pessoas do que uma coluna de destilação. Assim, pode-se dizer que nesta primeira etapa os objetivos são: definir o sistema, as fronteiras e os potenciais perigos. 
Frequentemente nesta análise inicial usa-se uma ferramenta chamada de Análise Preliminar de Perigos (Preliminary Hazard Analysis - PHA). Isto envolve mais do que uma simples identificação do sistema ou elementos que conduzem ao perigo. A análise é feita de modo qualitativo, tornando-se necessário considerar a sequência de eventos que transformam o perigo em acidente, assim como, as medidas corretivas e as consequências do acidente. A figura 17 mostra o processo da análise preliminar de perigos conforme Ayyub, 2001.



Figura 17 - Processo de Análise Preliminar de Perigo.

(fonte: Ayyub, B.M. 2001)

\subsubsection{Ferramentas de Qualidade Utilizadas na Análise de Risco}

A segunda etapa do trabalho inicia-se após a escolha do sistema a ser estudado. As duas técnicas mais comuns nesta etapa são a árvore de eventos e de falhas. Modelar um evento é uma maneira eficiente de identificar os cenários de um acidente e quantificar o risco. A combinação de uma análise de árvore de eventos (event tree analysis - ETA) e uma análise de árvore de falhas (fault tree analysis FTA) conduz a uma excelente análise de segurança de um sistema. Um cenário completo é formado, mostrando o sucesso e a falha dos principais eventos. A probabilidade de ocorrência do evento principal na árvore de eventos pode ser determinada usando a árvore de falhas. A árvore de eventos é usada se a operação 
do componente ou sistema depende do sucesso de um grupo de eventos, identificando várias combinações do sucesso ou falha do evento cobrindo todos os cenários possíveis. O resultado final é uma sequência de eventos que identifica o cenário completo de cada um dos eventos, cada caminho mostrando um cenário de falha com variações de probabilidade e risco.

Análise dos Modos e Efeitos das Falhas (FMEA) é outra maneira popular de se analisar o risco, como mostrado na figura 18, esta ferramenta de análise assume que determinado modo de falha ocorrerá em um sistema através de um mecanismo de falha assim, o efeito desta falha em outro sistema e/ou componente é analisado.

A classificação do risco pode ser desenvolvida para cada modo de falha, através do efeito que este causa no sistema e/ou equipamento.



Figura 18 - Processo da Análise dos Modos e Efeitos das Falhas.

(fonte: Ayyub, M.B. 2005)

Quando as ferramentas de qualidade mostradas acima são utilizadas em um processo de desenvolvimento tornam claros os pontos de melhoria do produto como seus modos de falha e suas medidas corretivas. Quando as melhorias são introduzidas ao produto, este apresentará melhoria de desempenho que resultará em um produto mais confiável e consequentemente melhorando a confiabilidade do sistema estudado. Quando as falhas ocorrerem em um veículo, e as falhas ocorrerão, sua detecção ficará mais fácil possibilitando correções rápidas sem a possibilidade de retorno a uma concessionária, devido a uma má avaliação. Quando mais esta atitude for disseminada, mais se estará melhorando o banco de dados para futuras análises e reduzindo custos devido aos reparos incorretos. Atualmente, um banco de dados 
automotivo contém muitos casos de retorno de veículos às concessionárias com a mesma de falha em um sistema, evidenciando análises incorretas nas reclamações reportadas.

\subsubsection{Gerenciamento e Comunicação do Risco}

Gerenciar risco é adicionar controles ao sistema após sua avaliação. Usam-se informações de outras análises e/ou processos que fazem com que as decisões tomadas sejam mais maduras quanto à segurança do sistema. Para o gerenciamento do risco é necessário alocar recursos adequados para suportar as decisões do time, é preciso definir a aceitação do risco, comparar a evolução das opiniões e decisões tomadas constantemente. Seus objetivos são reduzir o risco até um nível aceitável e/ou priorizar os recursos com base em análises comparativas. A redução de certo risco é atingida quando existem medidas de prevenção para um cenário desfavorável, através da redução da frequência e das consequências que determinada falha possa causar.

Quanto à aceitação do risco, pode-se dizer que este é um tema muito complexo e normalmente controverso. A determinação dos níveis de aceitação de risco torna-se importante quando da avaliação de risco que um sistema, pois estas informações dirão se o sistema é seguro ou não. Conforme Frosdick (1997), a aceitação do risco depende da percepção de uma sociedade, e as decisões de análise de risco baseiam-se não somente de uma avaliação de engenharia, mas também em valores econômicos, políticos, ambientais e legais, entre outros.

Outro fator que afeta a aceitação do risco é a magnitude das consequências que certo evento de falha pode causar caso venha a ocorrer. A decisão normalmente trata de três elementos: alternativas, consequências e preferências. As alternativas são as escolhas possíveis a serem consideradas, ou seja, após uma análise de risco, sabese o que precisa ser feito para eliminar ou minimizar o perigo. As consequências são o resultado potencial da decisão tomada.

A comunicação do risco pode ser o processo de troca de informações entre os diferentes grupos de trabalho em uma empresa. O processo de comunicação trata das informações técnicas e estas podem ser muito polêmicas, portanto, precisa ser cuidadosamente elaborado para que não cause nenhum mal entendido ou mesmo o pânico. O processo de comunicação do risco precisa sempre considerar aspectos 
como: processo, mensagem e os consumidores. O conteúdo das mensagens deve considerar a orientação para audiência, prover comparações de risco e as incertezas envolvidas, caso exista. Melhorar a capacidade de entendimento do público quanto ao risco é um fator importante no processo de comunicação de risco.

\subsection{Manutenção Centrada em Confiabilidade}

No mundo competitivo, as organizações devem buscar a excelência dos bens e serviços de sua competência de produção. Para isso, buscam inovações e liderança no desenvolvimento de seu processo produtivo. A função manutenção é desafiada para apresentar resultados positivos de desempenho visando a garantir ganhos em produtividade e qualidade, sempre otimizando os custos de manutenção.

$\mathrm{Na}$ atualidade, devido às pressões por tecnologias avançadas para se obter processos de manufatura cada vez mais eficazes em termos de custos, a importância de se dispor de políticas adequadas, técnicas de gestão e práticas de manutenção torna-se crítica. Conforme Righini (1999), em muitas empresas dos mais diversos tipos, a falta de disponibilidade do equipamento produtivo, em grande parte devido à negligência ou má gestão da manutenção, provoca redução na receita e declínio na lucratividade. Outro fator importante de custo é o impacto ambiental, decorrente de danos causados por acidentes com os componentes, equipamentos de segurança, sistemas de controle de processos etc. Deste modo, comprova-se que com métodos adequados e de gestão da manutenção as perdas econômicas podem ser reduzidas e a disponibilidade e segurança aprimoradas. Resultados mais satisfatórios podem ser obtidos com a implantação de critérios de confiabilidade na definição e aprimoramento do planejamento de manutenção. Na verdade as tarefas de manutenção têm sido normalmente estabelecidas tomando por base a orientação de fornecedores, ou fabricantes de equipamentos ou a experiência ao longo do tempo de execução de atividades de manutenção. Uma consequência disso pode ser a freqüência exagerada e inútil de intervenções de manutenção.

A introdução de critérios de confiabilidade na definição e aprimoramento da manutenção permite uma correta definição das estratégias de manutenção que

devem ser adotadas para cada componente. Ainda, como a execução da 
manutenção gera acréscimo de custos, sem eliminar aqueles devido a falhas que podem sempre ocorrer independentemente da frequência de manutenção, esses métodos atualizados permitem ajustar o melhor compromisso entre custos devidos á execução de manutenção preventiva e aqueles devido a falhas pertinentes às restrições estabelecidas de confiabilidade e disponibilidade dos sistemas em análise.

Nas últimas décadas, entre as práticas utilizadas pelas organizações, para garantir competitividade e sobrevivência no mercado, surge a Manutenção Centrada na Confiabilidade (MCC) tradução de "Reliability Centered Maintenance" ou simplesmente RCM. Segundo Kardec e Nascif (2001), a filosofia RCM é usada para caracterizar os requisitos de manutenção de qualquer item físico no seu contexto operacional. Com essa finalidade, a RCM analisa as funções e padrões de desempenho:

- De que forma ocorre a falha?

- O que causa cada falha?

- O que acontece quando ocorre a falha?

- O que deve ser feito para sua prevenção?

Em função dessa atuação, aprimora-se a disponibilidade de um equipamento produtivo, tornando-o mais estável e diminuindo variabilidade de processo. Com isto se tem produtos com menores variações e melhores desempenhos.

\subsubsection{Abordagens Básicas de Manutenção}

Atualmente as atividades de manutenção resultam de uma combinação de três abordagens básicas para cuidar dos equipamentos ou sistemas produtivos:

- Manutenção Corretiva: significa deixar os equipamentos continuarem operando até que se falhem. A intervenção é realizada somente após a falha ter ocorrido. Certamente, televisores, chuveiros elétricos, lâmpadas e aparelhos de telefone somente serão submetidos a ações da manutenção depois de manifestarem falhas. Algumas peças de reposição deverão estar em estoque para enfrentar situações desse tipo. É bem verdade que as falhas nessas condições não podem ser catastróficas nem tão freqüentes para 
justificar inspeções regulares do estado de cada dispositivo.

- Manutenção preventiva: a partir de limpeza, lubrificação, substituição e verificação das instalações, em intervalos pré-estabelecidos, procuram-se eliminar ou reduzir a probabilidade de falhas. "Os motores de um avião de passageiros são verificados, limpos e calibrados de acordo com uma programação regular depois de determinado número de horas de vôo. Tirar o avião de suas obrigações regulares para manutenção preventiva é claramente uma opção dispendiosa para qualquer empresa aérea. As consequências de falha em serviço, entretanto, são consideravelmente mais sérias. O princípio também é aplicado a instalações com conseqüências menos catastróficas das falhas. A limpeza e lubrificação de máquinas, e até mesmo a pintura periódica de um edifício, podem ser consideradas manutenção preventiva", segundo Slack (2002).

- Manutenção preditiva: tem por objetivo realizar manutenção somente quando as instalações precisarem dela. Equipamentos de processo contínuo, como a mesa transportadora da laminação de tiras a quente de uma siderúrgica, operam por longos períodos, de modo a atingir a alta utilização necessária para a produção eficiente em custos. Parar a máquina para trocar um mancal, ou rolamento, de um dos cilindros da mesa, quando não é absolutamente necessário fazê-lo, retiraria a mesa de operação por longos períodos e reduziria sua utilização. Nesse caso, ações preditivas de manutenção devem incluir o monitoramento do estado (monitoração contínua das vibrações). A análise dos resultados deste monitoramento forma a base para tomada de decisão quanto a parar a mesa e substituir os mancais ou rolamentos.

\subsubsection{Identificação dos Itens Relevantes do Processo Produtivo}

É fundamental decidir quais equipamentos são mais prováveis de se beneficiarem da abordagem da $R C M$ e, se assim for, exatamente como eles irão se beneficiar. Os recursos requeridos para aplicação da abordagem aos ativos 
selecionados deverão ser identificados e, nos casos onde os prováveis benefícios justificam o investimento, decidir em que detalhe, quem realizará e quem será o auditor de cada análise, e quando e onde ocorrerão. A implantação requer que seja previsto treinamento adequado da equipe envolvida. De modo geral, os itens relevantes para a manutenção são identificados usando técnicas como FMEA (Failure Mode and Effect Analysis), FMECA (Criticality Analysis), e FTA (Fault Tree Analysis). Isso corresponde a um criterioso processo de seleção da área do processo produtivo adequado para a aplicação da $R C M$, identificando os equipamentos da empresa que serão tratados segundo a abordagem da $R C M$. Nesta etapa devem ser organizadas de modo criterioso todas as informações sobre os equipamentos para que se possa fazer um meticuloso planejamento para a implantação da RCM. Em resumo, o equipamento deverá ser escolhido, as fronteiras devem ser definidas, assegurando que o contexto operacional do equipamento esteja claramente entendido.

\subsubsection{Definição das Funções e Parâmetros de Desempenho Desejados}

RCM é definida conforme Moubray (1992) como um "processo usado para determinar as exigências da manutenção para qualquer equipamento no seu contexto atual. Esse contexto se insere inteiramente no processo de formulação estratégica da manutenção, começando com a definição de funções". Antes que a abordagem $R C M$ determine o que deve ser feito para assegurar que o equipamento continue a fazer o que os seus usuários querem que ele faça, deve-se providenciar:

a) Determinar o que o usuário quer que ele faça isto é, identificar o desempenho desejado.

b) Assegurar que ele seja capaz de fazer o que os seus usuários querem fazer capabilidade intrínseca, ou seja, ter a capacidade tecnológica para o processo produtivo. Cada equipamento ou componente possui funções que podem ser classificadas em:

1) Funções Primárias: são as funções que justificaram a aquisição do equipamento. Esta categoria de função pode abranger o conhecimento de velocidades, quantidades, capacidades de transporte ou armazenagem, assim como da qualidade do produto e serviços prestados ao cliente. 
2) Funções Secundárias: são funções do item reconhecidas e desejadas além das suas funções principais, já que os usuários também têm expectativas nas áreas de segurança, controle, conforto e economia. Na prática, muitos equipamentos são adequadamente projetados e construídos com esta finalidade. Assim, é possível desenvolver programas de manutenção que assegurem que tais equipamentos continuem a fazer o que seus usuários esperam. Tais ativos são passíveis de manutenção, como mostra a figura 19. A definição de uma função deve consistir de um verbo e o padrão de desempenho desejado. Conforme Moubray (1992), se os usuários de um equipamento não podem especificar precisamente qual o desempenho que eles querem para o equipamento, não podem exigir que a manutenção seja responsável por sustentar este desempenho.



Figura 19 - Um item passível de manutenção.

(fonte: Moubray, 1992)

\subsubsection{Determinação das Falhas Funcionais}

Uma falha é definida como a perda da função. Uma falha funcional é definida como a incapacidade de qualquer equipamento de cumprir uma função, para um padrão de desempenho que é aceitável pelo usuário. Os padrões de desempenho devem ser definidos em conjunto pelos departamentos de engenharia, produção e 
manutenção. Na figura 20 está representada a definição da falha funcional.

O desempenho desejado de um equipamento é maior que a sua capabilidade, isto é, maior que a capacidade produtiva do ativo. Todas as falhas funcionais que afetam cada função devem ser registradas. As falhas funcionais podem ser classificadas em falhas parciais e totais, falhas limites inferiores e superiores e falhas de contexto operacional.



Figura 20 - Definição de falha funcional.

(fonte: Moubray, 1992)

- Falhas parciais e totais: A definição de falha funcional total significa perda total da função. Nesta situação, o equipamento pode ainda funcionar, mas fora dos limites aceitáveis. A falha parcial é causada de forma diferente da falha total, isto é, o ativo está falhando, mas ainda funciona dentro dos limites aceitáveis de desempenho requerido pelo usuário.

- Falhas Limites inferiores e superiores: São falhas funcionais que estão relacionadas a uma faixa de desempenho, isto é, o desempenho é associado a alguma função, que pode variar entre um limite inferior e um limite superior. Um equipamento estará na condição de falha se trabalhar abaixo do limite inferior e/ou acima do limite superior. Nestes casos, as duas situações de falha devem ser investigadas separadamente, pois podem ter os modos de falha e conseqüências diferentes. 


\subsubsection{Determinação do Modo de Falha, seus Efeitos e Consequências}

Uma vez que cada falha funcional foi identificada, o próximo passo é tentar identificar todos os eventos prováveis (modo de falha) que causam cada falha funcional, os efeitos e as consequências de cada falha funcional. Para determinar os modos, efeitos e conseqüências da falha, utiliza-se uma técnica conhecida como Análise de Modos de Falha e Seus Efeitos, do inglês FMEA (Failure Mode and Effect Analysis).

Para a aplicação da técnica $F M E A$, numa investigação de uma falha funcional de um item, a metodologia utiliza um formulário com várias perguntas que poderão conduzir o gestor do processo a optar por um determinado tipo de ação para eliminar a causa da falha, amenizar o efeito da falha e/ou, até, amenizar as consequências da falha. A técnica FMEA é uma ferramenta de qualidade que nos permite de modo sistemático antecipar modos de falhas conhecidos ou potenciais e recomendar ações corretivas para eliminar os efeitos das falhas.

\subsubsection{Seleção do Tipo de Manutenção}

Após a conclusão da Análise de Modo de Falha e Efeitos - FMEA, selecionar o tipo de manutenção preventiva tecnicamente adequada para assegurar que a falha não acontecerá e se acontecer, que os seus efeitos sejam adequadamente tratados. Podem-se definir como manutenção preventiva as tarefas efetuadas a intervalos predeterminados, conforme critérios prescritos e planejados, destinados a reduzir a probabilidade de falha ou a degradação do desempenho de um item. As tarefas de manutenção preventiva podem então ser classificadas como segue:

- Baseada no tempo (Manutenção Preventiva): Destinada à prevenção ou postergação da falha. Pode incluir: substituição, restauração ou inspeção. Este tipo de manutenção tem a característica de que suas ações e sua periodicidade são predeterminadas e ocorrerão sem informações adicionais na data preestabelecida. Estas ações são viáveis quando:

- Há um ponto identificável do aumento da taxa condicional de falha; 
- A maioria dos itens sobrevive àquela data;

- Restaura a resistência do item ao valor inicial;

- Baseada na condição (Manutenção Preditiva): Destinada á detecção do início da falha ou do sintoma da falha. Este tipo de manutenção tem a característica de se poder medir um parâmetro de desempenho diretamente e obter-se uma correlação com a iniciação da falha. Este tipo de manutenção é viável quando:

- É possível se identificar claramente o processo de deterioração;

- O tempo para a falha é razoavelmente determinável;

- O intervalo das medições é menor que o intervalo para falha;

- O tempo para a falha após a medição é suficiente para prevenir ou evitar as consequências da falha funcional.

\section{- Baseada em testes para descobrir a falha (Manutenção Detectiva):}

Determinada a revelar falhas ocultas, antes de uma necessidade operacional. Este tipo de manutenção tem a missão de descobrir falhas ocultas. As falhas ocultas são aquelas que não se tornam evidentes ao operador ou equipe em condições normais de operação. Alguns exemplos de testes para descobrir a falha são teste em alarmes de níveis, teste em motogeradores reservas, testes em motobombas reservas e testes em válvulas de segurança.

- Manutenção corretiva: Chama-se de manutenção corretiva aquela tarefa efetuada após a ocorrência de uma falha e destinada a recolocar um item num estado em que possa executar sua função requerida. A manutenção corretiva é efetiva quando:

- Nenhuma manutenção preventiva for efetiva;

- O custo da falha é menor que a manutenção preventiva para evitar a falha;

- A falha é de baixa importância. 


\subsection{Comparação entre Projetos}

Durante o desenvolvimento de um novo produto se faz necessária a comparação entre dois ou mais projetos, para se determinar qual destes projetos atende melhor aos requisitos do novo desenvolvimento. Quando um produto entra em produção, a necessidade de comparação continua principalmente quando se quer melhorar ainda mais o desempenho do processo e do produto corrente. As análises dos dados de campo podem mostrar as diferenças quanto ao uso do produto, projeto novo vs. projeto velho, diferentes áreas geográficas e diferentes lotes de produção. Segundo Wasserman (2002), a maneira mais simples de se fazer estas comparações é através do método gráfico de comparações distribuições de probabilidades das falhas associadas aos dados da amostra e teste de hipótese nos parâmetros de interesse. Este método consiste dos seguintes passos:

1. Com base nos dados de falha e dados censurados de cada projeto em estudo, faz-se a curva de probabilidade de falha do sistema e/ou componente para cada um dos projetos, conforme mostra um exemplo fictício na figura 21.



Figura 21 - Exemplo de uma Curva de Probabilidade

2. Quando se tem uma separação completa dos dados dos dois projetos em análise, pode-se dizer que existe forte evidência de diferença entre os projetos, conforme 
ilustra o exemplo na figura 22.



Figura 22 - Comparação entre dois Projetos (Normal Plot) (fonte: Wasserman, 2002)

3. Quando se tem uma interseção dos intervalos de confiança, considerando tempo de vida perto de $\mathrm{B}_{10}$ (tempo de vida onde $10 \%$ da amostra falhará), conforme ilustra o exemplo na figura 23 , ainda pode-se dizer que existem diferenças entre os projetos.

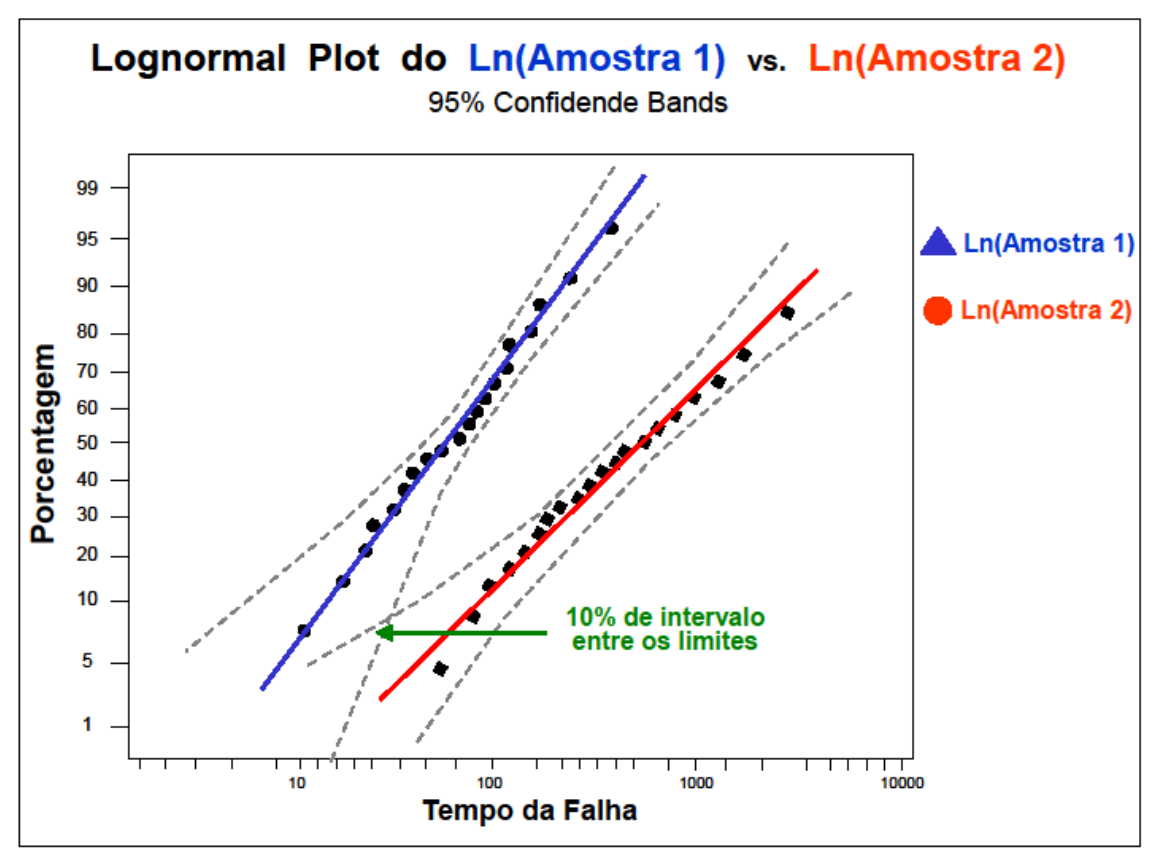

Figura 23 - Comparação entre dois Projetos (Lognormal Plot) (fonte: Wasserman, 2002) 
4. Nos casos onde existem interseções entre os dados de cada projeto (das retas ou intervalos de confiança), não se pode usar o método gráfico, conforme ilustra a figura 24, nestes casos se faz necessário testes de hipóteses para se tirar alguma conclusão.

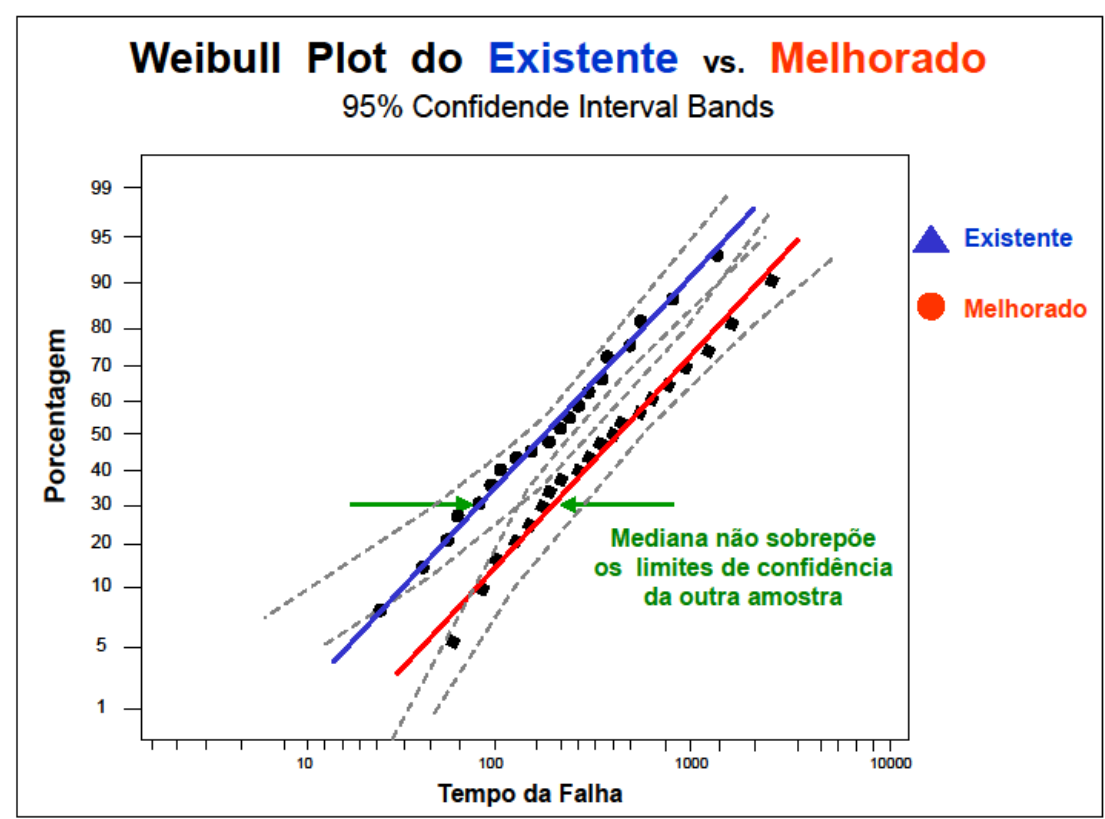

Figura 24 - Comparação entre dois Projetos (Weibull Plot) (fonte: Wasserman, 2002)

\subsubsection{Testes de Hipóteses: Comparação Projeto " $A$ " vs. Projeto " $B$ "}

Segundo Kapur e Lamberson (1977), quando se testam dois projetos, dois parâmetros exponenciais são escolhidos como função densidade de probabilidade (p.d.f) da população. As amostras são designadas como $S_{1}$ e $S_{2}$, onde $S_{1}=\left(x_{11}, x_{12}\right.$, $\left.\ldots x_{1 r 1}\right)$ e $S_{2}=\left(x_{21}, x_{22}, \ldots x_{2 r 2}\right), n_{1}$ e $n_{2}$ são o tamanho de cada amostra e $r_{1}, r_{2}$ são respectivamente os pontos truncados $\left(r_{1} \leq n_{1}, r_{2} \leq n_{2}\right)$, ou seja, a quantidade de falhas observadas em cada um dos projetos. Neste estudo os valores de $\left(x_{11}, x_{12}, \ldots\right.$, $\left.x_{1 r 1}\right)$ e $\left(x_{21}, x_{22}, \ldots, x_{2 r 2}\right)$ são os valores das quilometragens que ocorreram as falhas durante o período em estudo dos projetos.

Considerando as seguintes hipóteses: $H_{0}: \theta_{1}=\theta_{2}$ e $\quad H_{1}: \theta_{1} \neq \theta_{2}$

A hipótese $\mathrm{H}_{0}$ (chamada de hipótese nula) é uma afirmação que diz que o 
parâmetro $(\theta)$ populacional é tal como especificado, ou seja, é a afirmação correta. A hipótese $H_{1}$ (chamada de hipótese alternativa) é uma afirmação que oferece uma alternativa à alegação, ou seja, o parâmetro é maior, menor ou diferente que o valor alegado.

Para isto aplica-se o teste de Snedecor (homogeneidade entre duas variâncias a certa probabilidade). Este é um teste de hipóteses desenvolvido por George Waddel Snedecor e baseia-se na distribuição F (desenvolvida por Ronald Aylmer Fischer).

Segundo Kapur e Lamberson (1977), o procedimento para o teste consiste nos seguintes passos:

a) Calcular C (constante de dispersão), conforme equação 4:

$$
\mathrm{C}=\frac{\sum_{\mathrm{j}=1}^{\mathrm{r}_{2}}\left(x_{2 j}-x_{21}\right)+\left(n_{2}-r_{2}\right)\left(x_{2 r 2}-x_{21}\right)}{\sum_{\mathrm{j}=1}^{\mathrm{r}_{1}}\left(x_{1 j}-x_{11}\right)+\left(n_{1}-r_{1}\right)\left(x_{1 r 1}-x_{11}\right)}
$$



$$
F_{c}=\frac{\left(r_{1}-1\right)}{\left(r_{2}-1\right)} C
$$

c) Comparar o $F_{\text {calculado }}$ com $\circ F_{\text {tabelado }}$ e rejeitar a hipótese $\mathrm{H}_{0}$ se ocorrer qualquer uma das situações abaixo, conforme equações 6 e 7 : 


$$
\begin{aligned}
& F_{c}>\mathrm{F}_{\frac{\alpha}{2}}, 2 \mathrm{r}_{2}-2,2 \mathrm{r}_{1}-2 \\
& F_{c}<\frac{1}{\mathrm{~F}_{\frac{\alpha}{2}}, 2 \mathrm{r}_{1}-2,2 \mathrm{r}_{2}-2}
\end{aligned}
$$

Os valores de $F_{\text {tabelado }}$ podem ser obtidos através do Anexo 1 - Distribuição $F$, com 95\% de confiança. (Morettin e Bussab - 2004).

Neste estudo, rejeitar a hipótese $\mathrm{H}_{\mathrm{o}}$ (hipótese nula) e aceitar a hipótese $\mathrm{H}_{1}$ (hipótese alternativa) significa dizer, com 95\% de confiança, que o desempenho do projeto "A" é diferente do projeto "B". 


\section{PROPOSTA DE DESENVOLVIMENTO DO PRODUTO COM BASE EM CONFIABILIDADE E RISCO}

O desenvolvimento de um produto é a atividade mais crítica para o desempenho econômico de uma empresa. Ao se escolher qualquer dia de trabalho dos engenheiros automotivos ao redor do mundo, pode-se dizer que, estes estão elaborando estudos conceituais, construindo modelos de argila, testando veículos protótipos, resolvendo problemas de corrida piloto nas plantas de montagem e/ou iniciando a produção de um novo modelo. Todos têm acessos aos mais modernos sistemas computacionais, na grande maioria das vezes trabalham com os mesmos fornecedores e possuem a mesma formação acadêmica. Todavia, apesar de todas estas similaridades o resultado de seus trabalhos é bem diferente, não somente em conceitos e estilo, mas também em resultados práticos no desenvolvimento, como por exemplo, o tempo de desenvolvimento para cada novo produto e a qualidade de sua execução.

Desenvolver um novo veículo começa com a geração do conceito de posicionamento deste veículo no mercado. Nesta fase os estudos devem mostrar as futuras necessidades do mercado, as possibilidades tecnológicas e a viabilidade econômica. Esta fase é de grande importância para o desempenho que o produto apresentará durante seu ciclo de vida e gerenciar esta fase é uma atividade complexa, pois, a geração do conceito não é somente um esforço criativo, mas também um momento de decisões que consideram as restrições e oportunidades de introdução do novo produto.

Atualmente as empresas sabendo em qual segmento querem participar, comparam toda concorrência neste segmento num esforço para entender todos os pontos positivos e negativos de cada produto no mercado. Isto feito, somado aos estudos de marketing avançado, pode-se formar um conteúdo para o desenvolvimento de um veículo, ou seja, quais atributos importantes para o consumidor estarão neste novo veículo, quais necessidades e desejos este novo produto atenderá.

Segundo Clark e Fujimoto (1991), outro fator a ser considerado nesta fase são 
os planos estratégicos que a empresa realiza para toda sua linha de produtos, baseando-se em disponibilidade de recursos, tendências de mercado, tecnologia disponível para novos processos de produção e para componentes e finalmente a faixa de preço onde este novo produto estará. Apesar de todas as mudanças tecnológicas ocorrerem com certa rapidez, as empresas podem ser bem sucedidas se focarem em desenvolvimento do produto, não somente na função do produto final, em cronogramas e custo, mas também no ciclo de vida do produto, customização, riscos técnicos, simplicidade, produtividade, qualidade, inovação e serviços. As fases tradicionais durante o desenvolvimento de um novo produto são classificadas abaixo, conforme Priest e Sánchez (2001) e exemplificado nas figuras 25 e 26:

- Definição dos requisitos do projeto: A primeira fase do processo de desenvolvimento de um novo produto é identificar as necessidades de seus usuários, definir os objetivos de negócio e projeto para este produto. Nesta fase são identificadas, definidas e documentadas as necessidades para 0 seu desenvolvimento, é a primeira fase do ciclo de desenvolvimento. O objetivo é identificar e consolidar as necessidades para que o projeto seja viável e realístico, atendendo aos requisitos do produto. Durante esta fase de definição dos requisitos de projeto muitas idéias são elaboradas, mas no final desta fase apenas algumas atenderão aos requisitos de projeto. Requisitos do produto e suas especificações é o resultado final desta fase.

- Projeto conceitual: O processo do projeto conceitual é a identificação de várias alternativas que podem atender aos requisitos do projeto já definidos anteriormente, para que a melhor alternativa seja então escolhida, atendendo a todos os requisitos. Além disto, análises financeiras, modelos matemáticos, simulações e estimativas de custo são usadas para que a melhor alternativa seja escolhida. Esta fase ditará o melhor caminho a seguir, onde idéias tornam-se tarefas. É durante esta fase que os requisitos para produtividade, qualidade e confiabilidade são escolhidos e documentados. 


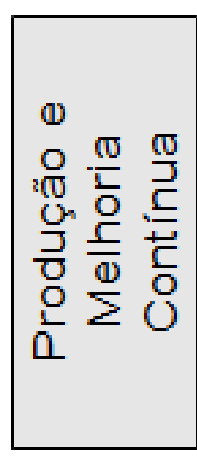

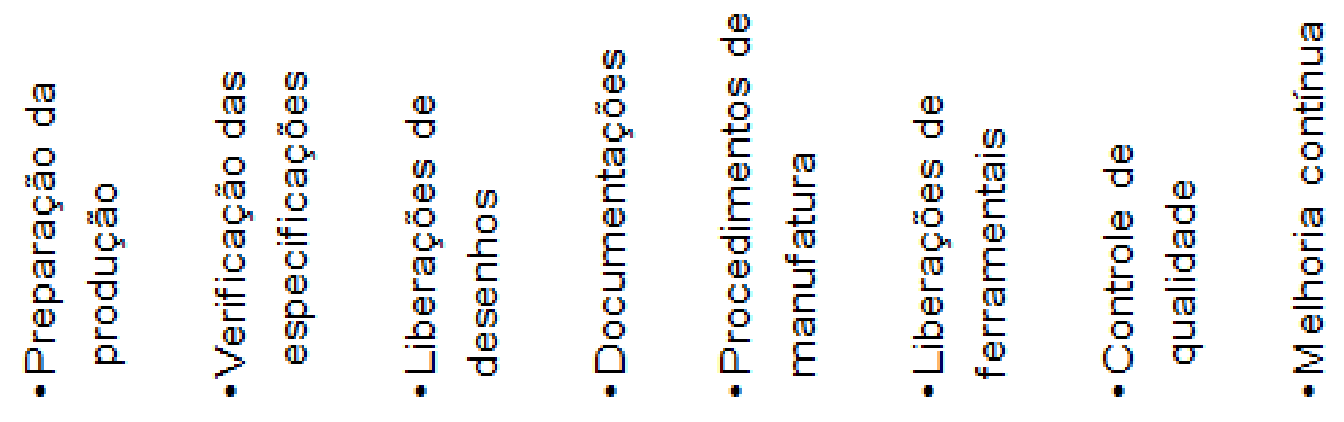

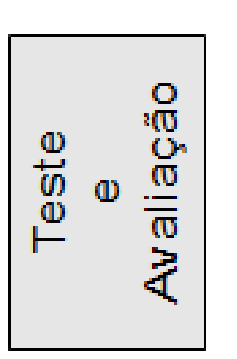

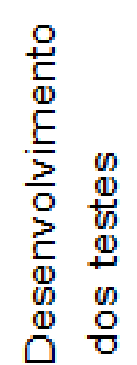

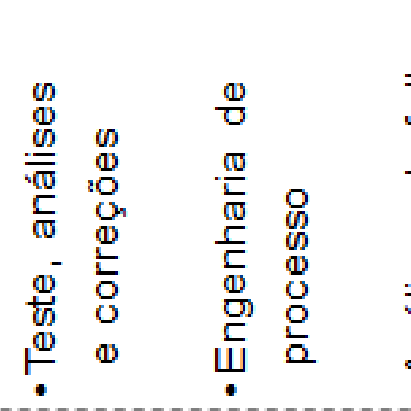

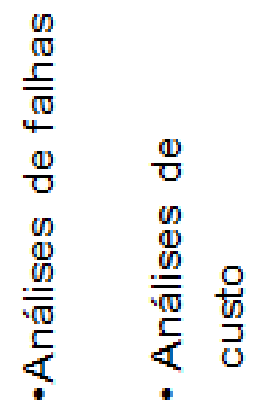

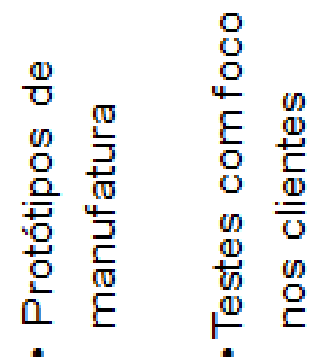

Ë 只





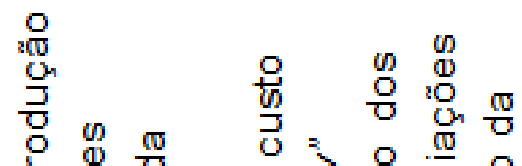

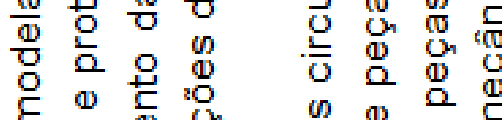

$E$ D

$\frac{\mathbb{D}}{\mathrm{O}}$

응

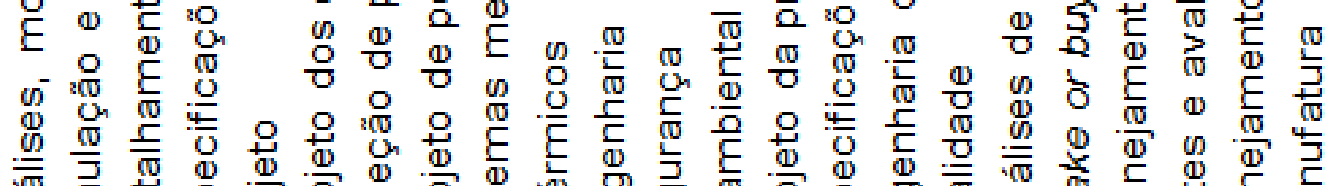

可 䎡




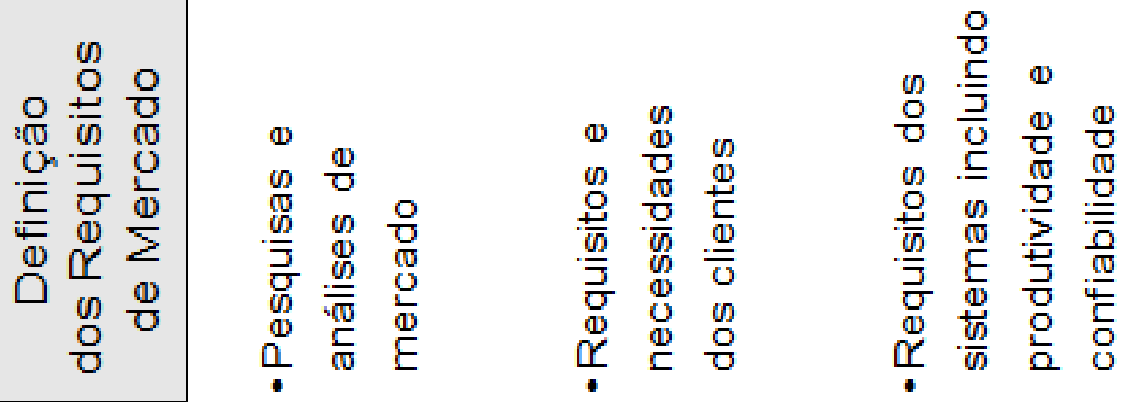

Figura 25 - Processo Tradicional de Desenvolvimento.

(fonte: Priest e Sánchez, 2001) 
- Detalhamento do projeto: O processo de detalhamento é fazer com que os requisitos de projeto sejam definidos e atendidos nas fases iniciais. Análises críticas são feitas pelo time de desenvolvimento com o objetivo de melhorar o projeto. Estas análises de projeto são feitas com o objetivo de atender as especificações técnicas como análise de stress, modos de falha, confiabilidade, segurança e custo. Nesta fase são construídos os modelos em laboratórios e depois protótipos para testes e verificação de resultados analíticos. Esta fase requer a interação de todo time de trabalho, comunicação e coordenação tornam-se vitais durante a avaliação e análise de todos os itens que possam colocar em risco o projeto.

- Teste e avaliação: é um conjunto de avaliações integradas com o objetivo de melhorar o projeto e qualificá-lo. Quando qualquer sistema é projetado, normalmente não se atinge a todos os requisitos de projeto nas fases iniciais e melhorias são necessárias durante estes testes para que este esteja pronto para produção. Assim, pode-se dizer que esta fase é uma poderosa ferramenta para identificar, corrigir problemas e reduzir riscos técnicos. Um projeto é considerado maduro quando foi testado, avaliado e atende a todos os requisitos especificados. O objetivo nesta fase é identificar áreas de melhoria no projeto, aumentando a produtividade, sua confiabilidade e reduzindo riscos técnicos.

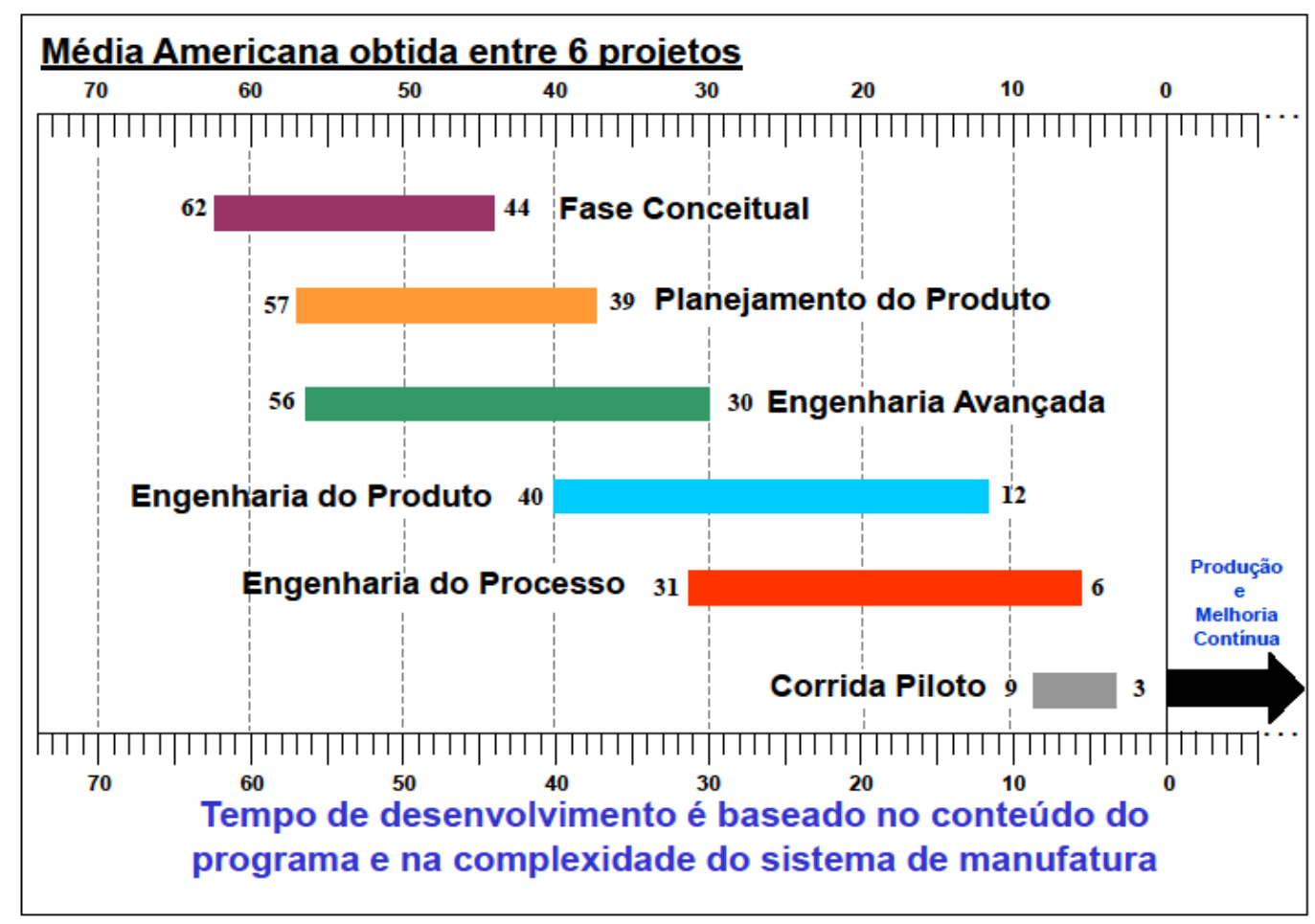

Figura 26 - Cronograma de Desenvolvimento de um Veículo.

(fonte: Clark e Fujimoto 1991) 
A fase inicial de desenvolvimento de um novo veículo caracteriza-se pela seleção de seguimento ao qual o veículo competirá, motorização, regiões a que se destina o produto, volume de vendas, entre outras. Existe uma etapa onde são escolhidos os sistemas e/ou componentes a serem usados neste novo produto, alguns são exatamente iguais a um sistema já utilizado em outro veículo, outros são modificados e outros são completamente novos.

O presente estudo mostrará um modelo de análise com foco em confiabilidade, análise de risco e com o uso de ferramentas de qualidade, quando da seleção destes sistemas. Este modelo mostra, diferentemente dos estudos já publicados, como a aplicação de cada ferramenta está ligada ao ganho de confiabilidade do produto. Como a partir de um banco de dados, filtrar os dados para uso em estudos de confiabilidade, como se estimar os dados censurados e selecionar os componentes para estudo. O modelo mostrará a comparação entre a proposta do estudo e dos trabalhos citados, visualizando assim qual o diferencial em relação ao que se aplica atualmente. A figura 27 ilustra as principais atividades do método proposto neste trabalho. Estas atividades são explicadas ao longo do capítulo. 
Desenvolvimento de novos produtos considerando aspectos de confiabilidade e risco



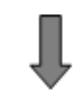

2

Definição dos

Sistemase

Componentes

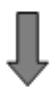

3

Identificação dos perigose definição dos cenários de falha

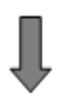

4

Coleta de dados
referentes as
falhas observadas
ao longo do
período de
garantia

Como obter os dados para análise?

Como selecionar os tipos de sistemas para atender $\mathrm{R}(\mathrm{t})$ e risco para um produto.

Relacionar os sistemas com base em:

- Requisitos de projeto para $\mathrm{R}(\mathrm{t})$ e risco, - Seleção dos sistemas para estudo:

1. Quanto a segurança,

2. Perda de capacidade,

3. Quanto a incidência de falha.

Como cada componente contribui para a falha do sistema e quais são os riscos quando cada falha ocorre.

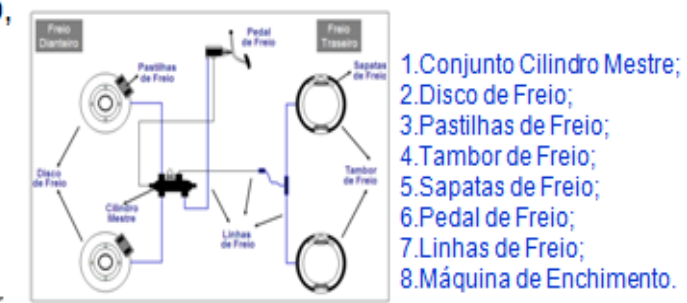

1. Perda do fluido de freio;

2. Pastilhas e/ou sapatas de freio gastas excessivamente;

3. Cilindro mestre com vazamentos;

4. Disco e/ou tambor empenados ou gastos excessivamente.
5

Identificação dos modos de falha

6

Tempo das falhas e método de análise dos dados censurados
Obtenção do tempo das falhas para cada componente do sistema em estudo. Método de análise com base em dados censurados.
Identificar os modos de falha de cada sistema através de um gráfico de Pareto.
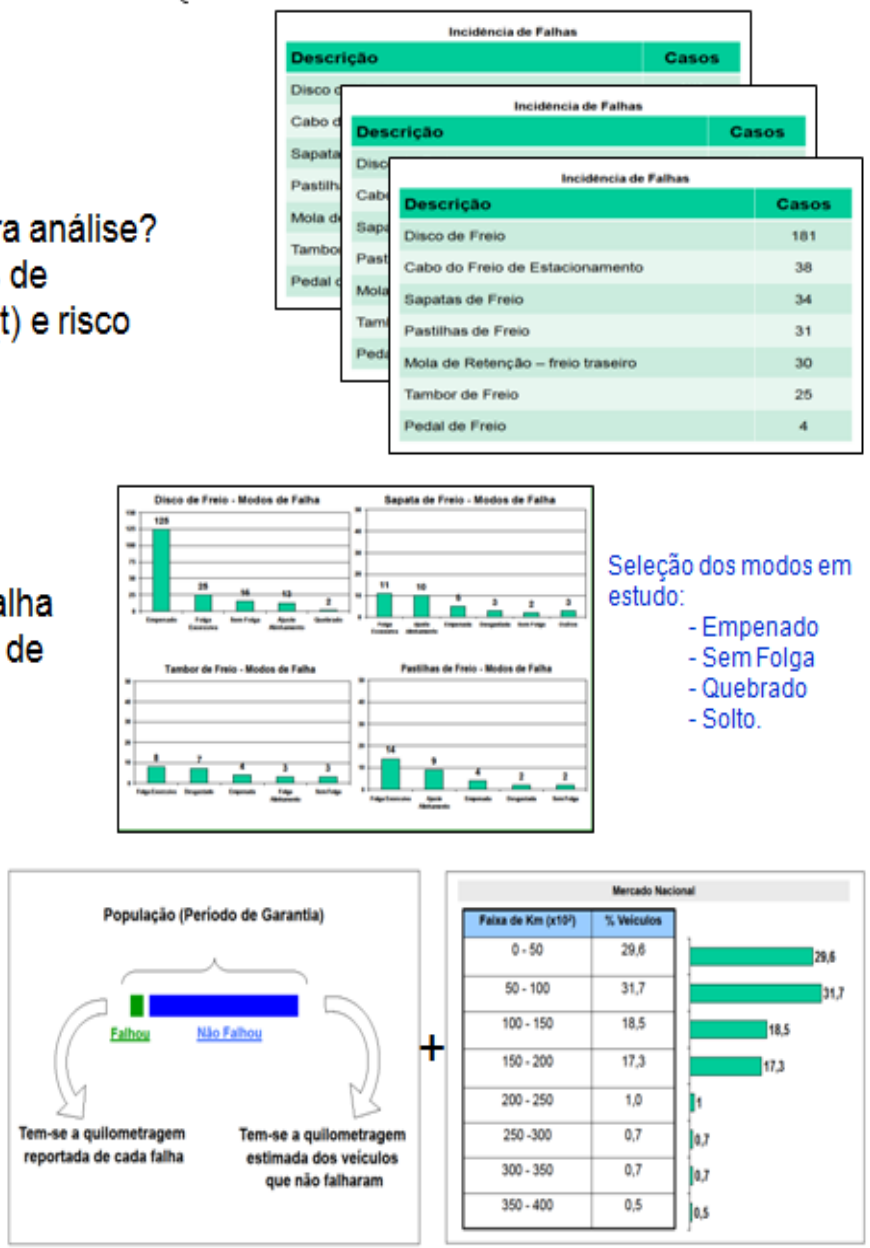

Figura 27 - Proposta de Estudo (continuação) 


\section{Desenvolvimento de novos produtos considerando aspectos de confiabilidade e risco (continuação)}



Obtenção $R(t)$ e da probabilidade de falha do componente em estudo.

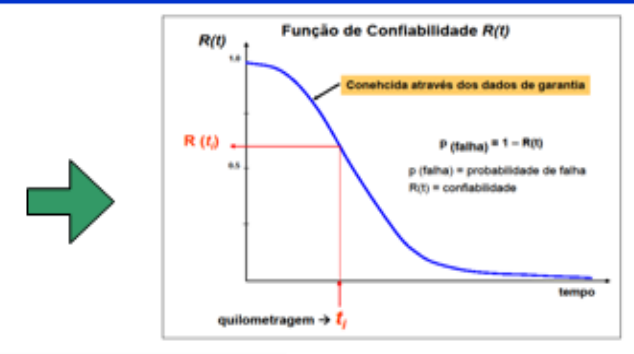

8

Escolha do
melhor sistema.
Comparação
entre projetos

Comparação entre projetos: Comparação gráfica, teste de hipóteses e $R(t)$ nos instantes de tempo do estudo.

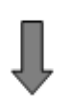

9

Árvore de falhas
DFMA/ MCC
dos sistemas

Elaboração da árvore de falhas para 0 sistema escolhido com base em $\mathrm{R}(\mathrm{t})$ e risco.

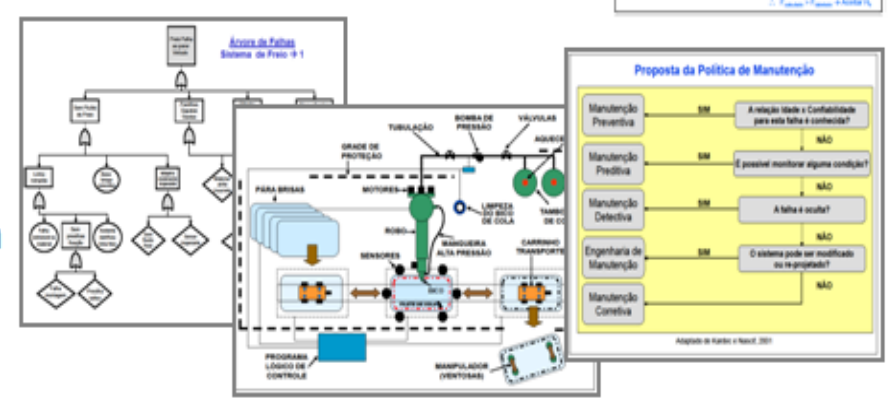

10

Avaliação probabilística da árvore de falha

Resolução da árvore de falhas, através das probabilidades de falhas obtidas.

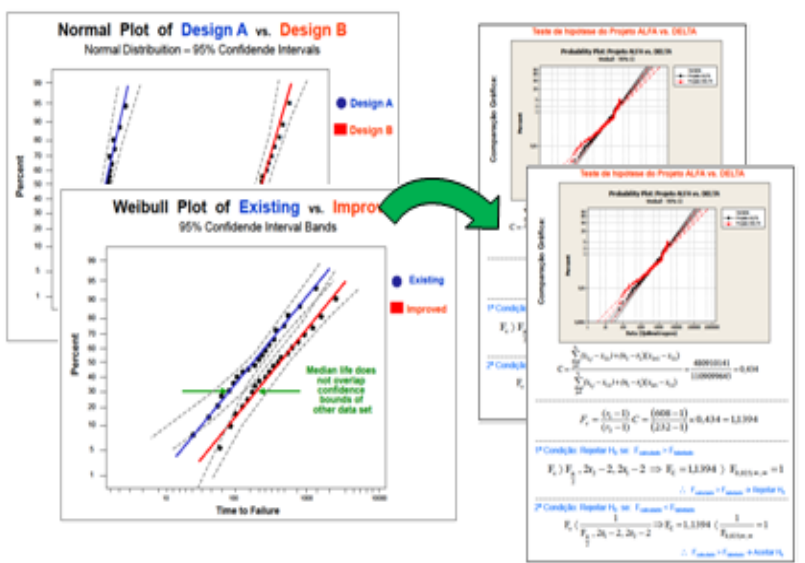



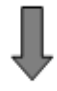

11

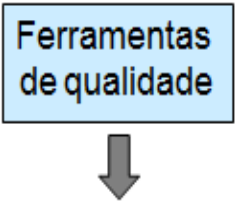

12

Gerenciamento da integridade dos sistemas

Uso de ferramentas de qualidade para melhorias em novos projetos e ganho de $R(t)$.

Propostas de Melhorias.

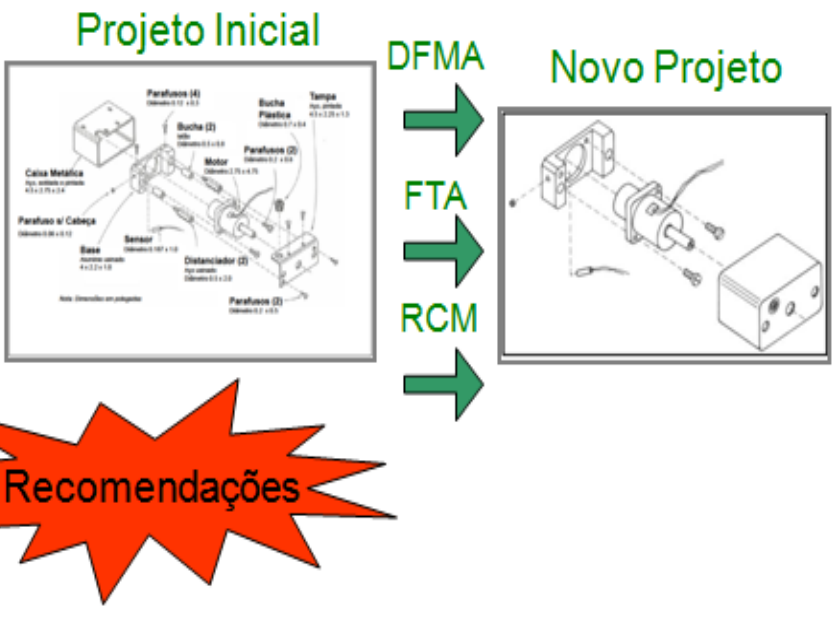

Figura 27 - Proposta de Estudo (final) 


\subsection{Estado da Arte}

Os artigos de melhoria de qualidade e confiabilidade que foram pesquisados neste estudo mostram diferentes metodologias para se melhorar um produto, porém, apresentam lacunas quanto às informações necessárias para que um estudo de confiabilidade possa ser realizado. Estes métodos, por exemplo, não mostram como tratar as informações provenientes dos bancos de dados e como cada ferramenta de qualidade está ligada com a melhoria da confiabilidade.

Para que qualquer estudo de melhoria de confiabilidade possa ser feito em um produto, é preciso entender quais são os sistemas e/ou componentes que mais contribuem para as falhas e a partir deste ponto, investigar seus modos de falha e propor melhorias. Para que isto ocorra, é necessário que se tenha um bom banco de dados de falhas de campo, o que normalmente as montadoras de veículos possuem. A melhoria de um produto se consegue quando os engenheiros de confiabilidade coletam as informações de falhas durante o período de garantia, analisam estas informações e melhoram o desempenho do produto atual e para os próximos lançamentos, quando do uso dos mesmos sistemas e/ou componentes em novos desenvolvimentos.

Alguns autores como Jones e Hayes (1997) sugerem metodologias de melhoria de confiabilidade através da consulta ao banco de dados, mas não mostram como determinado componente foi escolhido para análise, ou seja, já iniciam os estudos de confiabilidade com um componente escolhido, sua incidência de falha e seus modos de falha. Autores como Kim e Nakhai (2008) mostram métodos de melhoria contínua com base em custo e seu impacto na qualidade final do produto. Isto pode ser aplicado quando se quer reduzir os custos de garantia do produto, mas estas melhorias podem não ser percebidas pelo cliente final.

Setijone e Dahlgaard (2007) sugerem modelos de melhoria em itens de qualidade percebida e em itens de desempenho final do produto, mas não partem de nenhum banco de dados para consulta e/ou análise de confiabilidade. A melhoria da confiabilidade é de grande importância para as montadoras e para o cliente final, melhorar a confiabilidade em um novo produto gera aumento do custo de um 
componente e às vezes até investimentos em novos ferramentais, mas normalmente o ato de não fazer nada a pagar os custos de garantia pode ser muito maior, Murthy e Virtanen (2009) sugerem um método para balancear os custos de investimento de melhorias com os futuros custos de garantia. Isto pode funcionar quando somente os números financeiros importam, não se importando com a aceitação final do produto, o que certamente causaria uma imagem ruim para o produto no campo.

Outro autor Jiang e Murthy (2009) analisa os efeitos das variações de manufatura (erros de montagem e componentes não conforme) na confiabilidade de um produto e sugere um modelo onde compara os resultados de acompanhamentos dos componentes quando do seu recebimento e montagem com os resultados de garantia. Booker (2003) também menciona que o verdadeiro inimigo da qualidade é a variação de determinadas características de um produto associada às variações de montagem que juntas afetam diretamente a confiabilidade final do produto, aumento assim seus custos de garantia.

A tabela 2 faz um comparativo entre as publicações pesquisadas, mostrando qual a contribuição de cada modelo pesquisado durante a elaboração deste estudo, porém, estes métodos estão isolados entre si, fazem suas contribuições em uma ou duas áreas específicas, deixando uma lacuna a ser explorada. Esta é a proposta deste estudo, agrupar as ferramentas de qualidade e confiabilidade para e se obter em uma única proposta uma metodologia para melhoria da qualidade e confiabilidade de um produto. 
Tabela 2 - Comparativo entre as publicações pesquisadas.

\begin{tabular}{|c|c|c|c|c|c|c|c|c|c|c|c|c|c|c|c|c|c|c|c|c|c|c|c|}
\hline ARTIGOS / AUTORES & 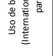 & 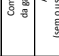 & & & 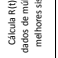 & &  & 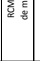 & 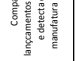 & & 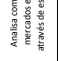 & 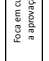 & 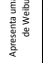 & & 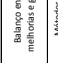 & 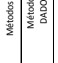 & & 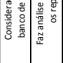 & 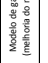 & 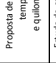 & & 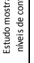 & 章量 \\
\hline $\begin{array}{l}\text { Design nuality: the crucial factor for product qualiti improvement in } \\
\text { international production networks. Alard, R. e e al. }\end{array}$ & & & & & & $\mathrm{x}$ & & & & $\mathrm{x}$ & & & & & & & & & & & & & \\
\hline $\begin{array}{l}\text { A decision support tool based on aFD and EMEA for the selection of } \\
\text { manufacturing technologies. Almannai, B. et at. }\end{array}$ & & & & $\mathrm{x}$ & & $\mathrm{x}$ & & & & & & & & & & & & & & & & & \\
\hline $\begin{array}{l}\text { A mixed-Weibull regression model for the analysis of automotive } \\
\text { warranty data. Attardi, Let at. }\end{array}$ & & & $\mathrm{x}$ & & & & & & & & & & $\mathrm{x}$ & & & & & & & & & & \\
\hline Reliability and validity of risk analysis. Aven, $T ;$; Heide, $B$. & & & & & & & & & & & & & & & & $\mathrm{x}$ & & & & & & & \\
\hline \begin{tabular}{|l|} 
An implementation of reliability analysis in the conceptual design phase of \\
drive trains. Avontuur, $G . C$. and K Kvan der Werff
\end{tabular} & & & $\mathrm{x}$ & & & & & & & & & & & & & & & & & & & & \\
\hline Risk analysis and management. Ayyub, M.B. & & & & & & & & & & & & & & & & $\mathrm{x}$ & & & & & & & \\
\hline $\begin{array}{l}\text { Risk analysis techniques and their application to software development. } \\
\text { Bennett, } J \text {. e et al. }\end{array}$ & & & $\mathrm{x}$ & & & & & & & & & & & & & $x$ & & & & & & & \\
\hline Industrial practice in designing for quality. Booker, J.D. & & & & $\mathrm{x}$ & & $\mathrm{x}$ & & & & $\mathrm{x}$ & & & & & & & & & & & & & \\
\hline Product design for manufacture and assembly. Boothroyd, G; Dewhurst, $\mathrm{P}$. & & & & & & & & & & $\mathrm{x}$ & & & & & & & & & & & & & \\
\hline $\begin{array}{l}\text { Improving reliability by addressing early failures: leveraging the use of } \\
\text { modern quality tools. Broome, } \mathrm{H} \text { :; Mccomb, M. }\end{array}$ & & & $\mathrm{x}$ & & & & & & & & & & & & & & & & & & & & \\
\hline $\begin{array}{l}\text { Reliability analysis of automotive field failure warranty data. Campean, } \\
\text { l.F, et at. }\end{array}$ & & & $\mathrm{x}$ & & & & & & & & & & & $\mathrm{x}$ & & & & & & & & & \\
\hline Failure analysis - assisted FMEA. Cassanelli, G et al. & & & & $\mathrm{x}$ & & & & & & & & & & & & & & & & & & & \\
\hline A framework for intelligent RCM analysis. Cheng, Z. et al. & & & & $\mathrm{x}$ & & & & $\mathrm{x}$ & & & & & & & & & & & & & & & \\
\hline $\begin{array}{l}\text { Warranty analysis: na approach to modeling imperfect repairs. Chukova, } \mathrm{S} \text {. } \\
\text { et al. }\end{array}$ & & & & & & & & & & & & & & & & & & $\mathrm{x}$ & & & & & \\
\hline $\begin{array}{l}\text { Component reliability assessment using quantitative and qualitative data. } \\
\text { Cizeli, R.. et al. }\end{array}$ & & & & & & & & & & & & & & & & $\mathrm{x}$ & & & & & & & \\
\hline \begin{tabular}{|l|} 
Analysis of grouped data field failure reporting system. Coit, D.W.; Daey, \\
K.A.
\end{tabular} & & & & & & & & & & & & & & $\mathrm{x}$ & & & & & & & & & \\
\hline $\begin{array}{l}\text { Application of RCM to a medium scale industry. Deshpande, V.S.; Modak, } \\
\text { (.P. }\end{array}$ & & & & & & & & $\mathrm{x}$ & & & & & & & & & & & & & & & \\
\hline $\begin{array}{l}\text { Towards more strategig product design for manufacture and assembly: } \\
\text { priorities for concurrent engineering. Edwards, K.L. }\end{array}$ & & & & & & & & & & $\mathrm{x}$ & & & & & & & & & & & & & \\
\hline $\begin{array}{l}\text { Modeling of uncertainties in RCM - a probabbilistic approach. Eisinger, S. et } \\
\text { al. }\end{array}$ & & & & & & & & $\mathrm{x}$ & & & & & & & & & & & & & & & \\
\hline The techniques of risk are insufficient in themselves. Frosdick, s. & & & & & & & & & & & & & & & & $\mathrm{x}$ & & & & & & & \\
\hline The effects of design quality on quality performance. Fynes, B; Burca S. & & & & & & & $\mathrm{x}$ & & & & & & & & & & & & & & & & \\
\hline $\begin{array}{l}\text { Design for manufacturing and assembly: case studies in its } \\
\text { limplementation. Gerhardt, DJ. et al. }\end{array}$ & & & & & & & & & & $\mathrm{x}$ & & & & & & & & & & & & & \\
\hline $\begin{array}{l}\text { Design for assembly (DFA)- the key to make parts-count reduction } \\
\text { profitable. Hart-Smith, LJ. }\end{array}$ & & & & & & & & & & $\mathrm{x}$ & & & & & & & & & & & & & \\
\hline $\begin{array}{l}\text { Conceptual process planning - na improvement approach using QfD, } \\
\text { FMEA and ABC methods. Hassan, A. et al. }\end{array}$ & & & & $\mathrm{x}$ & & $\mathrm{x}$ & & & & & & & & & & & & & & & & & \\
\hline A simulation model for warranty analysis. Hill V. L; ; et al. & & $\mathrm{x}$ & & & & & & & & & & & & & & & & & & & & & \\
\hline $\begin{array}{l}\text { Using qualitative data to learn customer needs: Understanding employer } \\
\text { desires when designing an MBA program. Hillmer, } S_{\text {S; Kocabasoglu, }} \text {. }\end{array}$ & & & & & & & $\mathrm{x}$ & & & & & & & & & & & & & & & & \\
\hline $\begin{array}{l}\text { Product development from quality and reliability perspectives. } \\
\text { Itabashi-Campbell, } R \text {. }\end{array}$ & & & & $\mathrm{x}$ & & & & & & & & & & & & & & & & & & & \\
\hline $\begin{array}{l}\text { Improving design for reliability with in-service data analysis. James, IJ. et } \\
\text { al. }\end{array}$ & & & & & & & & & & & & & & & & & & & & & & & $\mathrm{x}$ \\
\hline Impacts of quality variation on product reliability. Jiang, R.; Murthy, D.P.N. & & & & & & & & & $\mathrm{x}$ & & & & & & & & & & & & & & \\
\hline $\begin{array}{l}\text { Use of field faliure data base for improvement of product reliability. } \\
\text { Jones }, . A \text {. and Hayes }, A . \text {. }\end{array}$ & $\mathrm{x}$ & & & & & & & & & & & & & & & & & & & & & & \\
\hline Analysis of field data under two dimensional warranty. Jung, M. et al. & & & & & & & & & & & & & $\mathrm{x}$ & & & & & & & $\mathrm{x}$ & & & \\
\hline Reliability in engineering design. Kapur, K.C;; Lamberson, L.R. & & & & & & & & & & & & & & $\mathrm{x}$ & & & & & & & & & \\
\hline $\begin{array}{l}\text { The dynamics of quality costs in continuous improvement. Kim, S.; Nakhai, } \\
\text { B. }\end{array}$ & & & & & & & & & & & & $x$ & & & & & & & & & & & \\
\hline \begin{tabular}{|l} 
Reliability improvement through alternative designs - A case study. \\
Kumar, S. and Gopi Chattopadhyay
\end{tabular} & & & $\mathrm{x}$ & & & & & & & & & & & & & & & & & & & & \\
\hline $\begin{array}{l}\text { Use of fault tree analysis for evaluation of system-reliability improvement } \\
\text { in design phase. Krasich } \mathrm{M} \text {. }\end{array}$ & & & $x$ & $\mathrm{x}$ & & & & & & & & & & & & & & & & & & & \\
\hline  & & & & & & $\mathrm{x}$ & & & & & & & & & & & & & & & & & \\
\hline $\begin{array}{l}\text { Global failure modes and effects analysis: a planning tool for global } \\
\text { product development. Leung, p. et al. }\end{array}$ & & & & $\mathbf{x}$ & & $\mathrm{x}$ & & & & & & & & & & $\mathrm{x}$ & & & & & & & \\
\hline $\begin{array}{l}\text { An analysis of desigining for quality in the automotive industry. } \\
\text { Lewis, w. W.; Samuel, } A \text {.E. }\end{array}$ & & & $x$ & & & $\mathrm{x}$ & & & & & & & & & & & & & & & & & \\
\hline $\begin{array}{l}\text { Areview of the Weibull distribution and selected engineering applications. } \\
\text { Luko, S.N. }\end{array}$ & & & & & & & & & & & & & $\mathrm{x}$ & & & & & & & & & & \\
\hline $\begin{array}{l}\text { Component-based modeling of systems for automated fault tree } \\
\text { generation. Majdara, A. et al. }\end{array}$ & & & $x$ & & & & & & & & & & & & & & & & & & & & \\
\hline A mixture model for automotive warranty data. Majeske, K. D. & & & & & $\mathrm{x}$ & & & & & & & & & & & & & & & & & & \\
\hline $\begin{array}{l}\text { Why do quality and reliability feedback loops not always work in practice: } \\
\text { a case study. Molenaar, P.A. et al. }\end{array}$ & & & & & & & & & & & & & & & & & & & & & $x$ & & \\
\hline \begin{tabular}{|l|} 
Analisse de confiabilidade de componentese sistemas. Murad, C.A.; \\
Martha de Souza, G.F.
\end{tabular} & & & $\mathrm{x}$ & & $\mathrm{x}$ & & & & & & & & & & & $\mathrm{x}$ & & & & & & & \\
\hline I Investiment in new product reliability. Murthy, D.N.P. et al. & & & & & & & & & & & & & & & $\mathrm{x}$ & & & & & & & & \\
\hline Standards in reliability and safety engineering. $o^{\prime}$ Connor, $P$. & & & & & & & & & & & & & & & & $\mathrm{x}$ & & & & & & $\mathrm{x}$ & \\
\hline $\begin{array}{l}\text { Determination of an optimal set of design requirements using house of } \\
\text { quality Park, T; Kim, K. }\end{array}$ & & & & & & $\mathrm{x}$ & & & & & & & & & & & & & & & & & \\
\hline A RCM strategy for a discret part manufacturing facility. Pujadas, W. et al. & & & & & & & & $\mathrm{x}$ & & & & & & & & & & & & & & & \\
\hline $\begin{array}{l}\text { A new method for reliability centered maintenance improvement. Righini, } \\
\text { R. }\end{array}$ & & & & & & & & $\mathrm{x}$ & & & & & & & & & & & & & & & \\
\hline Comparing safety analysis techniques. Rouvroye, J.L; Bliek, E.G. & & & $x$ & $\mathrm{x}$ & & & & & & & & & & & & $\mathrm{x}$ & & & & & & & \\
\hline $\begin{array}{l}\text { Failure mode and effects analysis (FMEA) in the context of risk } \\
\text { managemenent in the newproduct development. Segismundo, A. et al. }\end{array}$ & & & & $\mathrm{x}$ & & & & $\mathrm{x}$ & & & & & & & & & & & & & & & \\
\hline $\begin{array}{l}\text { An integrated approach to design for manufacturing and assembly based } \\
\text { on reduction of product development time and cost. Selvaraj, P. et al. }\end{array}$ & & & & & & & & & & $x$ & & & & & & & & & & & & & \\
\hline $\begin{array}{l}\text { A framework for reliability and risk centered maintemance. Selvik, }, I T . \text { et } \\
\text { al. }\end{array}$ & & & & $\mathrm{x}$ & & & & $\mathrm{x}$ & & & & & & & & & & & & & & & \\
\hline The value of quality improvement. Setijono, D.; Dahlgaard,,.$J$. & & & & & & & & & & & & $\mathrm{x}$ & & & & & & & & & & & \\
\hline $\begin{array}{l}\text { Mechanical system reliability analysis using a combination of graph } \\
\text { theory and Boolea function. Tang, } .\end{array}$ & & & & & & & & & & & & & & & & & $x$ & & & & & & \\
\hline An overal model for maitenance optimization. Vatn, $\rfloor$ et al. & & & & & & & & $\mathrm{x}$ & & & & & & & & & & & & & & & \\
\hline $\begin{array}{l}\text { Application of fautt tree analysis for assessment of power system } \\
\text { reliability. Volkanouski, } A ; ; \text { c Cepin, } M \text {; ; Makko, B. }\end{array}$ & & $\mathrm{x}$ & $x$ & & & & & & & & & & & & & & & & & & & & \\
\hline Learning to improve reliability during system development. Walls, L. et al. & & & & & & & & & & & & & & & & & & & $\mathrm{x}$ & & & & \\
\hline $\begin{array}{l}\text { customer satisfaction driven quality ymprovement target planning for } \\
\text { product development in automotive industry. Yadav, o. P;; ;oel, P.S. }\end{array}$ & & & & & & $\mathrm{x}$ & & & & & & & & & & & & & & & & & \\
\hline $\begin{array}{l}\text { Reliabitity and robustness mindset in automotive product development for } \\
\text { global markets. Zhou,J. }\end{array}$ & & & & & & & & & & & $\mathrm{x}$ & & & & & & & & & & & & \\
\hline
\end{tabular}




\subsection{Requisitos de Mercado: Análise das Necessidades dos Clientes}

Definir as necessidades dos clientes é um processo bem complexo e pode resultar em informações que geram mais conflitos. É importante reconhecer que os clientes às vezes não sabem exatamente o que desejam ou nem sempre são capazes de informar completamente o que eles desejam.

Às vezes é possível lançar um produto de desempenho médio, mas que atenda as necessidades dos clientes e para também abrir novos mercados. Como por exemplo, em fevereiro de 1900 George Eastman introduziu no mercado a Brownie, uma câmara fotográfica para fazer companhia as já famosas e caras linhas da Kodak. Eastman acreditava que as câmaras existentes eram muito complicadas e caras para os iniciantes na fotografia e para os jovens. Uma câmara simples, com um bom custo benefício era necessária para estes grupos de pessoas.

Com um preço de revenda de US $\$ 1$, a primeira Brownie foi feita de um papelão resistente e coberta com um material de cor preta imitando o couro, com um rolo de filme de 15 centavos que produzia seis negativos. Os requisitos de desempenho desta nova câmera foram estabelecidos para serem "médios", ou seja, produzir fotos razoáveis, com uma luz média e com pouca distância. A princípio os fotógrafos da época e revendedores rotularam a câmera Brownie de US\$1 como um brinquedo. Em menos de um mês depois que as primeiras 5000 câmeras foram para o mercado, foram recebidos pedidos adicionais de mais de 31.000 câmeras.

Este produto de desempenho médio resultou em vendas de mais de 50 milhões de câmeras. Ainda nos dias de hoje é possível identificar oportunidades como esta e para isto existem muitos métodos para se obter o conhecimento necessário para entender as necessidades dos clientes. Segundo Priest e Sánchez (2001), os métodos aplicados mais comuns são:

- Entrevistas com os clientes: são técnicas de pesquisas com foco nos supostos compradores do produto em estudo, considerando faixa etária, renda anual, estado civil, uso para família, trabalho ou lazer. Destas pesquisas iniciais, chamadas de clínicas, é possível se obter uma primeira visão sobre o 
conteúdo desejado do novo produto;

- Pesquisas em banco de dados e internet: neste tipo de pesquisa podem-se obter informações de clientes que já compraram um determinado produto, quais são as suas preferências, sendo dados reais de venda. A partir das informações obtidas com os dois métodos citados já é possível iniciar reuniões com o time de desenvolvimento para compartilhar estes dados, podendo assim até gerar novas idéias para o produto. Neste ponto podem-se compartilhar também as experiências passadas em outros projetos, mostrando os erros e acertos;

- Análises da competição "benchmark": nestes estudos pode-se obter exatamente o que está em uso no mercado corrente nos produtos da concorrência, pode-se ainda obter idéias e/ou soluções de problemas em determinado produto em produção e identificar as novas tendências para o mercado. É possível entender melhor quais são as necessidades dos clientes, suas preferências, identificar os pontos fracos e fortes da concorrência, identificar os itens de sucesso em cada veículo da concorrência como, desempenho, preço, serviços, confiabilidade e qualidade. Os passos para condução de um estudo de benchmark podem ser:

1. Analisar todos os aspectos da competição;

2. Determinar onde a empresa se coloca em relação à competição quanto a itens oferecidos em seus produtos e processos, ambos nos produtos correntes e nas predições de novos produtos;

3. Estabelecer qual o melhor produto e as características oferecidas;

4. Estabelecer parâmetros do produto e da sua manufatura com base nas informações do estudo de benchmark;

5. Introduzir melhorias nas melhores idéias já oferecidas nos produtos correntes.

- Protótipos e realidade virtual: são métodos mostrando desenhos ou até partes protótipos do veículo em estudo como estilos diferentes de faróis, lanternas, bancos com vários estilos e tecidos diferentes, capturando as 
reações dos clientes quanto às diferentes propostas e identificando áreas de melhoria já na fase conceitual. Suas etapas podem ser:

1. Produzir protótipos que forneçam uma visão realista da proposta;

2. Desenvolver quantos protótipos quanto forem necessários, dentro do orçamento definido para esta atividade;

3. Produzir protótipos através do processo de desenvolvimento do Produto;

4. Mostrar estes protótipos para todo time em revisões de projeto e registrar todos pontos levantados e implementar as melhorias apontadas.

- Casa da Qualidade (QFD: Quality Functional Deployment): esta ferramenta é usada para identificar as necessidades, compará-las com a competição e transformá-las em requisitos técnicos do produto. Esta simples técnica tem como objetivo de identificar todos os pontos que podem afetar o produto em atender as expectativas dos clientes, ajuda os engenheiros de desenvolvimento a determinar o que os clientes realmente querem, traduz a linguagem vaga do cliente em requisitos de projeto que podem ser quantificados.

Segundo Booker (2002), a linguagem de um projetista pode ser bem diferente da linguagem dos clientes e o objetivo é transformar esta linguagem em características de engenharia. Segundo O'Connor (2002) QFD é uma maneira da voz do cliente ser ouvida na empresa, ou seja, como os desejos do consumidor são transformados em especificações técnicas e vai mais além da confiabilidade, pois, também são cobertos itens de preferência dos clientes como toque, aparência, estilo, textura, cores, brilho, etc. É uma ferramenta útil para direcionar e controlar as atividades de projeto e processo para a garantia da confiabilidade. A técnica de QFD traz grandes vantagens ao processo de desenvolvimento do produto tais como, redução do tempo de introdução do produto ao mercado, melhora a comunicação do time de desenvolvimento, pois todos os participantes terão um entendimento comum dos objetivos durante o desenvolvimento, reduz de 30 a $50 \%$ de mudanças em projetos, conforme O'Connor (2002). Um exemplo de aplicação da técnica QFD de um 
para choque é representado na figura 28, conforme Hyman (1998).

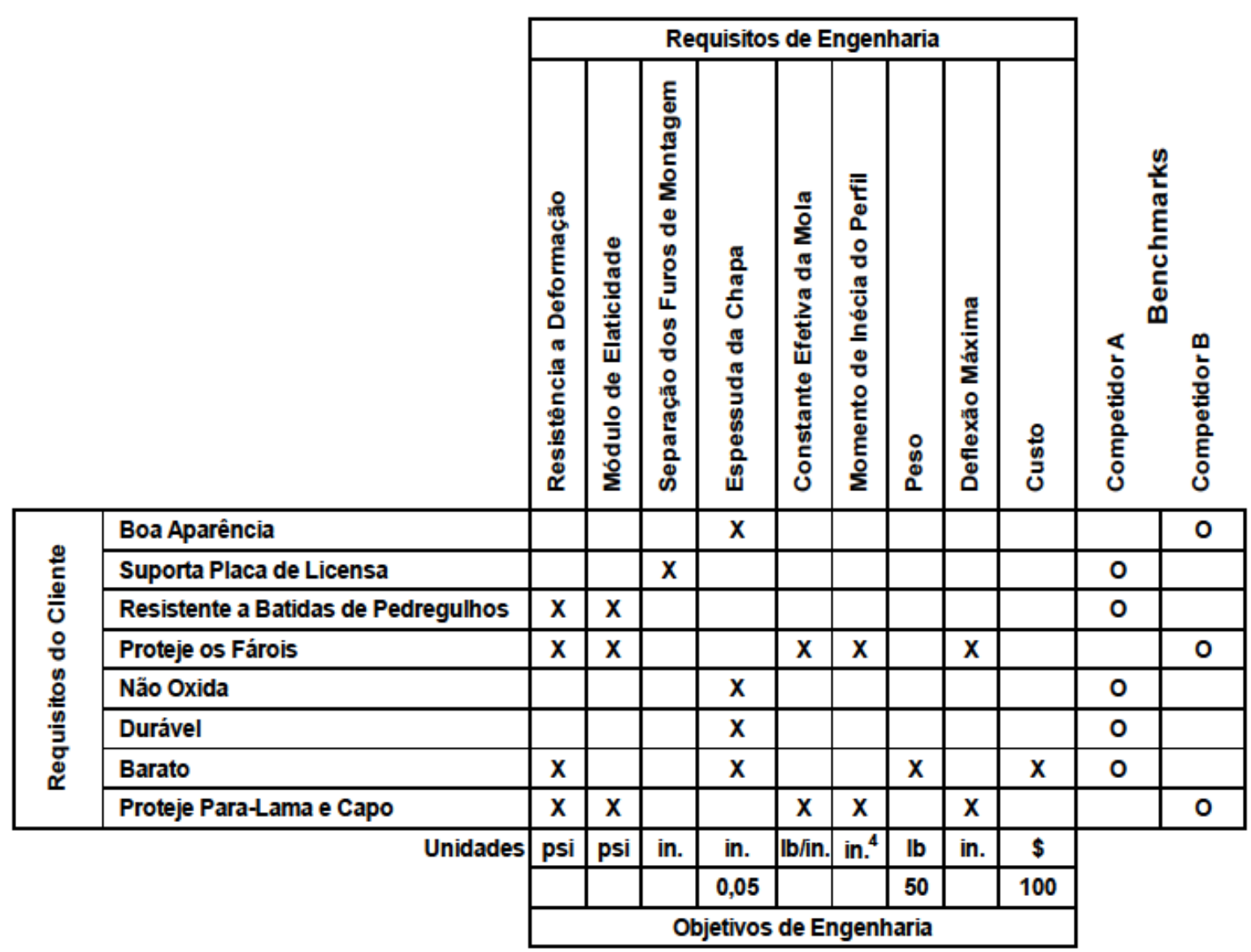

Figura 28 - Matriz QFD Parcial: Para-choque de um veículo.

(fonte: Hyman, 1998)

Yadav e Goel (2008) sugerem uma metodologia para identificar e priorizar as oportunidades de melhoria quando do uso da ferramenta QFD. Sua proposta mostra como uma determinada característica do veículo pode ser cascateada no nível de sistema, subsistema e finalmente no nível de componente, isto se torna útil quando se coloca objetivos a serem atingidos para o veículo e seus sistemas. Estas oportunidades de melhoria são então classificadas e priorizadas com base nas informações do mercado, comparações com os competidores (competitor bechmarkings), visão da organização e finalmente a estratégia de marketing.

\subsubsection{Necessidades dos Clientes: Processo nas Montadoras Americanas}

Todas as empresas gastam grande parte do tempo de desenvolvimento 
tentando identificar quais atributos são importantes aos seus clientes. As montadoras americanas gastam recursos significantes obtendo e estudando dados demográficos, revisando os dados de grupos de foco a cada produto, analisando os competidores e revisando os dados de campo de modelos em produção. Uma vez que todo este material é compilado, produz-se um documento detalhado descrevendo qual o grupo de clientes para o qual o produto será desenvolvido, o custo praticável a este modelo e os objetivos de desempenho para todo veículo. As empresas americanas usam ferramentas analíticas e constantes revisões de projeto para avaliar os dados e determinar a viabilidade e a direção do programa de desenvolvimento.

Este método analítico é muito objetivo, onde o foco principal do time de desenvolvimento é passar adiante os números do programa de desenvolvimento em estudo, especialmente os dados financeiros, com pouca atenção a qualquer outra coisa a não ser com as revisões do programa de desenvolvimento. Obviamente, isto faz pouco para estabelecer uma conexão com o cliente ou mesmo criar um senso de entusiasmo no time de desenvolvimento do novo produto. O centro deste processo são os números e não o cliente a que se propõe desenvolver este novo produto, o fato é que, nesta fase conceitual o cliente é raramente mencionado. Esta prática contribui para que através dos anos os produtos fiquem desatualizados e cada vez menos competitivos.

Pode-se afirmar que nesta fase inicial o foco é unicamente o retorno de investimentos, ficando para segundo plano as características que realmente agregam valores aos clientes, este tipo de condução de um projeto normalmente causa desperdícios futuros de engenharia. Existe um grande esforço em comunicar ao time de desenvolvimento de modo significativo e mensurável, todos os números do programa de desenvolvimento, deixando o time de desenvolvimento incerto quanto aos objetivos deste novo desenvolvimento, objetivos de cada área funcional e objetivos do time. Muitos membros destes times de desenvolvimento têm um vago conhecimento do seu papel dentro do programa de desenvolvimento e ainda pior dos objetivos do programa de desenvolvimento. Esta falta de entendimento do objetivo do programa de desenvolvimento torna-se ainda pior nos níveis mais baixos onde existem grupos de suporte ao desenvolvimento que possuem seus próprios objetivos 
para o programa de desenvolvimento com base nas experiências diárias de suas operações. Há uma falta de envolvimento destes grupos de suporte, pois os membros do time de desenvolvimento têm um vago entendimento do seu papel.

Os objetivos reais do programa de desenvolvimento não têm 0 comprometimento dos times de suporte e o pior ainda é que estes times de suporte não têm a oportunidade de colaborar com suas experiências no novo desenvolvimento. Esta falta de envolvimento dos times de suporte resulta no desalinhamento de informações na organização, causando confusões e conflitos nos times de desenvolvimento. Isto tudo inibe a habilidade em desenvolver produtos com valores aos clientes, podendo também causar atrasos nos programas de desenvolvimentos e com certeza aumentos de custos e geralmente lançando produtos de qualidade inferior ao mercado.

\subsubsection{Necessidades dos Clientes: Processo na Toyota}

Assim como as empresas americanas, a Toyota também avalia os dados de campo, faz suas pesquisas de mercado, faz comparações com os competidores para entender os clientes, mas as similaridades terminam aqui. O primeiro passo nos desenvolvimentos de novos produtos é selecionar as lideranças chave para o programa de desenvolvimento, a Toyota seleciona seus líderes para cada programa de desenvolvimento com base na experiência, através dos anos e experiência em estabelecer uma conexão com o cliente a que se destina o produto.

Os requisitos de um projeto são a fundação para todo processo de desenvolvimento de um produto, uma vez conhecido quais são estas características, o passo seguinte é comunicar a todos do time de desenvolvimento, alinhar e colocar em operação os objetivos de modo mensurável para que as atividades de cada membro do time de desenvolvimento possam ser executadas. Não se concentrar apenas no que pode ser executado em termos de projeto ou no que foi feito no passado. Concentrar-se na criatividade, nas características de valor para os clientes e no desenvolvimento de um produto para ser o melhor na sua categoria para vencer a competição sem riscos técnicos. Esta prática sim pode ser o grande fator de ganho no desenvolvimento, mostrando que todo time tem conhecimento dos objetivos do 
desenvolvimento e ista atitude contribui para produtos mais competitivos.

Seja qual for a o processo utilizado, o importante é oferecer exatamente aquilo que o cliente espera, podendo até superar as expectativas dos clientes. As especificações de projeto devem ser feitas para atender as necessidades dos clientes, e não o cliente se adaptar as especificações que a montadora tem. Ou seja, um produto deve ser bem feito, pensando em pequenos detalhes que somados fazem uma grande diferença para se ter um produto de qualidade. Esta é a grande lacuna existente em muitas montadoras que estão no mercado nacional e as que estão se fixando em nosso mercado.

\subsection{Definição dos Sistemas com base em Confiabilidade e Risco}

Confiabilidade de um sistema é um importante parâmetro durante o desenvolvimento de um produto e depende de ações tomadas durante 0 desenvolvimento e não no processo de manufatura ou nos testes de validações. Desenvolver os requisitos necessários para atender a confiabilidade de um produto e ao mesmo tempo fornecer um guia adequado e preciso aos engenheiros de projeto é uma tarefa difícil. Uma parte importante de todo este processo é a disponibilidade dos dados de confiabilidade de cada sistema em uso, seu modo operacional e sua manutenção. Também é uma atividade difícil para os engenheiros de projeto saber como os requisitos de confiabilidade podem ser afetados com as decisões diárias, ou seja, como cada decisão tomada pode estar afetando a confiabilidade de um sistema.

Estes requisitos de confiabilidade devem ser facilmente entendidos pelos engenheiros de projeto para que sejam a base de qualquer tomada de decisão durante todo processo desenvolvimento. Testes para medir e verificar a confiabilidade devem ser especificados até o nível dos componentes, quais os métodos de medição, definições das falhas, local e procedimentos dos testes. Após a identificação das falhas de um produto, é possível dividir estas falhas ao nível de sistemas e até componentes, assim é possível se obter modos quantitativos de se medir o progresso técnico, através das propostas de melhorias no projeto. A incerteza deve ser considerada em muitas das hipóteses usadas nas análises de projeto e nos parâmetros usados durante o desenvolvimento. Para compensar estas 
incertezas, coeficientes de segurança são usados em diversas fases do desenvolvimento, isto impõe ao projeto a atender a requisitos mais rigorosos do que o esperado, tornando o projeto mais robusto. Mas tudo isto deve ser muito criterioso, pois estas decisões podem aumentar o custo do projeto e o prazo de entrega de determinada atividade.

Atualmente em muitos casos de desenvolvimento, um produto é vendido e usado em outros países, os requisitos destes projetos devem também incluir as particularidades de cada um dos países considerados, como por exemplo, requisitos governamentais, as etiquetas que são fixadas no produto, lista de opcionais, cores internas e externas, manuais técnicos e planos de manutenção. Segundo Priest e Sánchez (2001), alguns requisitos de projeto para uso em diferentes regiões devem incluir entre outros:

- Apenas símbolos devem ser usados para passar alguma informação ao usuário;

- Instruções devem ser impressas em inglês, espanhol, Frances, Japonês e Chinês. Outras línguas deverão ser tratadas em fases mais adiantadas do desenvolvimento;

- Meio de transporte no caso dos veículos e embalagens no caso de outros produtos, devem ser suficientes e eficientes para atender os padrões internacionais.

Ao se iniciar um novo desenvolvimento, os engenheiros de projeto de cada sistema devem selecionar os melhores projetos em uso nos produtos correntes para que estes sejam usados no novo desenvolvimento. Normalmente em se podendo usar exatamente mesmo sistema já se tem uma grande vantagem em redução de custo e de tempo de desenvolvimento. Existem objetivos definidos no início de cada desenvolvimento para se usar o maior número possível de sistemas já conhecidos de outras plataformas de veículos. Porém nem sempre isto é possível, mesmo usando um sistema já validado torna-se necessário fazer pequenas modificações para que este se adapte ao novo projeto. A seleção dos melhores sistemas pode ser feita através da comparação dos dados de garantia dos produtos atuais. 
As informações de campo recebidas através de toda a rede de concessionárias são medidas através de incidentes pôr mil unidades vendidas (I/1000), sendo este sistema utilizado nas empresas americanas. Um incidente de garantia ocorre quando o veículo ou um sistema perde sua funcionalidade durante o período de garantia. Este sistema divide o veículo em doze categorias e/ou famílias de componentes, a saber:

$\rightarrow$ Pintura;

$\rightarrow$ Carroceria Externa, Carroceria Interna;

$\rightarrow$ Ar Condicionado, Ventilação e Aquecimento;

$\rightarrow$ Suspensão, Direção e Rodas;

$\rightarrow$ Eixo Traseiro, Freios, Motor, Transmissão;

$\rightarrow$ Sistema de Alimentação;

$\rightarrow$ Escapamento;

$\rightarrow$ Sistema Elétrico e Acessório.

Os dados de garantia são o acúmulo de todos os incidentes ocorridos durante a garantia dada pelo fabricante do veículo. Devido a sua grande versatilidade, estas informações são úteis para os engenheiros de confiabilidade na missão de análise e rastreabilidade das falhas de campo. Seu processamento é rápido e permitem informações atualizadas das falhas de campo, neste método os códigos de mão de obra estão agrupados conforme as categorias dos sistemas.

Quando ocorre qualquer falha de um componente, a concessionária efetua o reparo e entra com os dados do veículo no banco de dados. Esta informação de falha entra no sistema com a quilometragem, o código do defeito, data da reclamação entre outros. O processamento de todas estas informações separadas por cada tipo de veículo permite a geração de inúmeros relatórios sobre as falhas de campo. Deste modo é possível selecionar os melhores sistemas existentes, aqueles com melhor desempenho no campo, para serem usados em novos desenvolvimentos.

As falhas ocorridas com um veículo durante seu ciclo de vida estão representadas na figura 29 , conforme Singh (2009). O ponto número 1 indica o final 
das operações de manufatura de um veículo, deste ponto em diante o veículo estará em uso pelo cliente e submetido às condições do meio ambiente que terão um grande impacto durante seu ciclo de vida.



Figura 29 - Falhas Durante o Ciclo de Vida de um Veículo.

(fonte: Singh, 2009)

Os erros que acontecem no ponto número 2 estão associados à manufatura dos componentes e ao processo de montagem e podem ser detectados ainda na planta de montagem dos veículos, mas existe a possibilidade destas falhas passarem para a Fase-B. A venda do veículo no ponto número 3 inicia o período coberto pela garantia e isto varia para cada montadora. Normalmente, existe certo período entre a ocorrência da falha no ponto número 4 e sua detecção pelo cliente no ponto número 5. Este período é muito pequeno quando há uma falha severa que afeta o funcionamento do veículo e poderá ser um período maior quando a falha é branda que pode esperar até a próxima visita a uma concessionária. Assim, pode-se dizer que determinadas falhas ocorreram antes da quilometragem reportada pelo cliente, mas o exato momento onde estas falhas ocorreram não é conhecido.

Este estudo assumirá que estes períodos de tempo entre a ocorrência da falha e sua correção são desprezíveis. A duração das atividades nos pontos 
números 7, 8 e 9 quando o veículo retorna ao cliente, dependem muito da capacidade do processo de correção nas concessionárias. É importante citar que falhas repetidas em um mesmo veículo no ponto número 9, são devidas ao processo de correção inadequado nas concessionárias e não à falhas de qualidade de componentes e/ou processo de manufatura do veículo. Assim, estas falhas repetidas em um mesmo veículo não serão consideradas neste estudo. Estas considerações fazem parte dos filtros aplicados neste estudo no banco de dados, pois os bancos de dados das montadoras não são suficientes para estudos de confiabilidade sem estes filtros.

As falhas ocorridas do ponto número 11 poderiam fornecer informações importantes aos engenheiros de qualidade, porém estas informações ficam restritas apenas aos clientes dos veículos nesta fase, porque muitos clientes preferem outros locais de reparo, evitando o alto custo de reparo das concessionárias. As falhas que ocorrerão do ponto número 12 em diante são aquelas onde o custo do reparo é muitas vezes maior do que o custo do veículo, terminando assim o ciclo de vida do veículo. Neste ponto o presente estudo faz outra proposta para a estimativa dos dados censurados, ou seja, qual o comportamento estimado dos veículos que passaram pelo período de garantia sem apresentar falhas, diferentemente dos estudos pesquisados, onde não há citações de como estimar nenhum dado censurado.

Estudos feitos como, Jones et al (1997) e Kim et al (2008), mostram métodos de melhoria através de estudos de confiabilidade mas não citam como os os dados foram obtidos para cada proposta. Para a definição dos sistemas com base em confiabilidade e risco, uma metodologia para a identificação dos sistemas críticos e suas falhas seria a obtenção de um gráfico de Pareto das falhas ocorridas durante todo o período de garantia, para cada um dos sistemas das plataformas de veículos a serem estudadas. A figura 30 mostra apenas de forma ilustrativa como será feita esta primeira análise dos sistemas em uso nas plataformas de veículos. A partir deste material, pode-se obter mais informações sobre cada um dos sistemas das plataformas de veículos em estudo. Assim, é possível obter com base em incidência de falhas quais são os sistemas que mais contribuem para as falhas de campo e consequentemente aos custos de garantia, em seguida faz-se a seleção dos 
sistemas que colocam em risco a segurança dos passageiros. Com base neste material, já é possível traçar um plano de análise para o novo desenvolvimento. As análises de confiabilidade permitem que propostas de melhorias sejam feitas, porém, sempre terá um custo associado a cada uma destas propostas. Normalmente, se tem recursos limitados para o desenvolvimento. Assim, torna-se necessário balancear a melhoria a ser feita versus o seu custo, ou seja, uma estimativa da melhoria da confiabilidade do sistema, o custo associado e seu tempo de implementação.

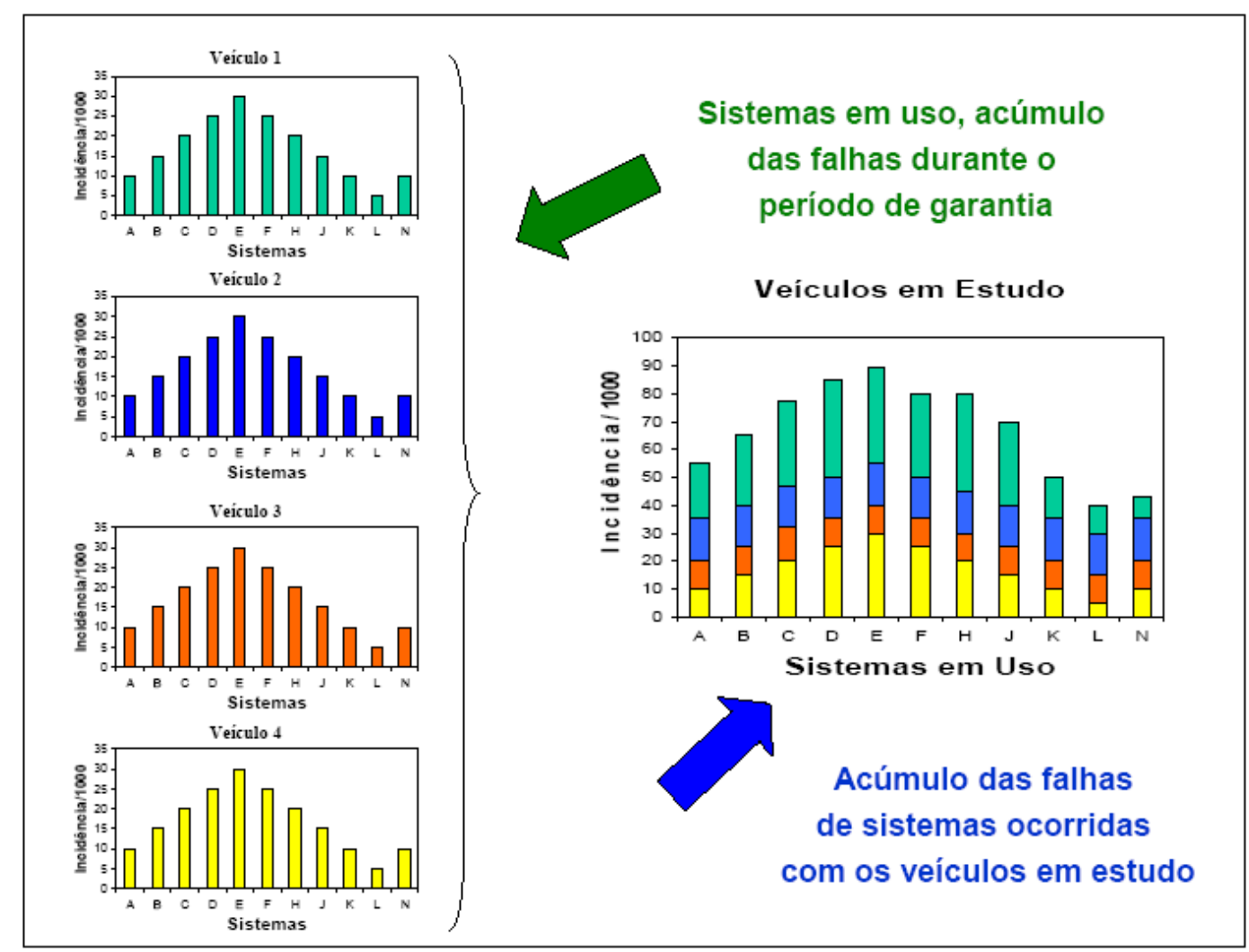

Figura 30 - Proposta da primeira análise dos sistemas de veículos.

Com esta análise das falhas ocorridas nas plataformas de veículos é possível se obter os itens para estudo com base em incidência e risco. Com o resultado deste estudo preliminar já é possível se determinar quais são os sistemas onde serão aplicadas as ferramentas de qualidade citadas neste estudo. Esta etapa é a definição dos sistemas e componentes citados no fluxograma da figura 27. Para cada sistema escolhido será mostrado como uma ferramenta de qualidade pode ser usada durante o desenvolvimento de um produto, quais devem ser as considerações feitas para cada uma delas e como cada uma pode melhorar um produto. 


\subsection{Identificação dos Perigos e Definição dos Cenários de Falha dos Sistemas}

Atualmente no mercado global um produto (sistema e/ou componente) é frequentemente desenvolvido por engenheiros em um mercado para ser usado em outro mercado, onde as condições de operação são diferentes de um mercado para outro. Se durante o desenvolvimento estas diferentes condições de operação não forem consideradas, o produto poderá apresentar maior número de falhas em determinada região do que em outras, não cumprindo sua função durante sua vida útil e consequentemente aumentada a insatisfação dos clientes e os custos de garantia para a montadora. Para evitar estas falhas, torna-se necessário durante o desenvolvimento antecipar o meio ambiente onde este produto será usado e seu efeito nos componentes individuais, nos sistemas e no produto final. Temperatura é o fator do meio ambiente que mais afeta os componentes eletrônicos, além disto, mudanças de temperatura têm um grande efeito sobre as propriedades dos materiais, podendo causar a fadiga de alguns deles, como trincas em soldas ou quebra em junções de chicotes. A adição da vibração nestas condições aumenta ainda mais os seus efeitos. Estes são fatores considerados durante o desenvolvimento, garantir que os componentes e/ou sistemas sejam produzidos com materiais que resistam a estas variações de temperatura. Outro problema é a alta umidade no meio ambiente, pois a absorção da umidade por alguns sistemas elétricos pode causar mudanças na condutividade e no fator de dissipação de alguns isoladores levando a algum tipo falha. Uma maneira de eliminar estes problemas de alta umidade é o uso de componentes e/ou sistemas selados, porém seu custo é alto. Assim, tornou-se necessário saber exatamente as condições de uso a que se destina o produto e evitar os potenciais modos de falha durante o desenvolvimento, tais como:

- Identificar os sistemas críticos considerando confiabilidade e risco;

- Identificar os potenciais modos de falha e suas condições de operação;

- Desenvolver projeto robusto e/ou propor melhorias para evitar que tais modos de falha ocorram;

- Verificar a efetividade destas melhorias nos testes de validação dos sistemas e/ou seu desempenho no campo. 
Assim, nesta etapa devem-se definir os sistemas a serem analisados, suas fronteiras e potenciais perigos. Os sistemas a serem analisados devem ser aqueles que não somente tragam algum perigo ao usuário quando da sua falha, mas também os que podem ser um grande fator de insatisfação, como por exemplo, aqueles sistemas que quando falham causam a parada do veículo, ou ruídos internos, mecanismos de levantamento de vidro, bancos, chicotes, painéis de portas, entre outros. Pode-se, por exemplo, definir os sistemas em duas categorias a seguir:

- Sistemas quanto a perigo: sistema de freio, sistema de alimentação de combustível, chicotes, ancoragem do cinto de segurança e bateria, caixa de direção mecânica.

- Sistemas quanto à insatisfação: sistema de fechamento das portas, painel de instrumentos, faróis e lanternas, coluna de direção e a chave multi função, buzina, sistema de exaustão, faróis de neblina, bancos e painéis de portas.

Nesta etapa serão identificados os perigos e a definição dos cenários de falhas, ou seja, a definição das fronteiras, quais serão os modos de falha considerados como maior risco para o sistema.

\subsection{Coleta de Dados para Análise dos Sistemas}

Os clientes respondem diferentemente aos modos de falha ocorridos durante o período de garantia. As falhas durante o período de garantia podem ser classificadas em duas categorias, falhas severas e falhas brandas. As falhas severas são aquelas onde o veículo fica inoperante até a sua correção e as falhas brandas são aquelas onde o veículo apresenta sistemas com sua função inoperante, mas o veículo ainda esta operante. Exemplos de falhas severas podem ser: sistema de alimentação de combustível, bateria, sistema de fechadura de portas do veículo (abertura de portas e a ignição do motor), e falhas brandas podem ser: luz de freio, mecanismos de levantamento do vidro, ruídos, painéis de porta. Deste modo, a data e/ou quilometragem da falha é diferente da data e/ou quilometragem da correção reportada e isto também é um fator que influência nos estudos de confiabilidade, outro ponto a ser considerado é que o processo de correção das falhas depende 
muito da capacidade de detecção da causa raiz e ocasionalmente existem modos de falha com diagnóstico errado. Assim, devem-se separar as falhas de manufatura e/ou sistemas das falhas da qualidade do serviço. Nestes casos recomenda-se usar sempre a primeira falha reportada em um sistema, ou seja, aqueles veículos que apresentaram mais do que uma falha reportada para o mesmo sistema não serão considerados.

Neste estudo serão considerados doze meses de uso dos veículos, ou seja, seus respectivos períodos de garantia. Por motivo de propriedade da informação os nomes dos veículos e seus respectivos anos modelos serão omitidos deste estudo. Diferentemente de estudos publicados de melhoria de melhoria de confiabilidade, como Broome (2004) e Majeske (2003) onde não há citações de como tratar os dados provenientes dos bancos de dados. Além disto, tem-se somente a informação dos dados durante o período de garantia, mas para um estudo de confiabilidade será necessário também o conhecimento dos veículos que não apresentaram falhas durante o mesmo período em análise (os chamados dados censurados), isto será devidamente exposto posteriormente. Resumindo, serão consideradas quatro plataformas de veículos do segmento chamado econômico, doze meses como período de garantia e dados censurados, conforme Murad e Martha de Souza (2006). Todas estas considerações fazem parte da proposta deste estudo, ou seja, até este ponto como tratar os dados provenientes dos bancos de dados de garantia e como estimar também os dados censurados. Nesta etapa serão obtidos os tempos que ocorreram as falhas, ou seja, as quilometragens onde cada veículo apresentou a falha para cada componente do sistema em estudo.

\subsection{Identificação do Modo de Falha, seus Efeitos e Consequências}

As falhas nos produtos e os problemas no processo de manufatura sempre ocorrerão, assim deve-se minimizar seu número, seu efeito e estar preparado para sua ocorrência. As falhas nos produtos afetam confiabilidade, segurança, manufatura e o mais importante, a satisfação dos clientes. Nesta etapa é importante saber quais são os modos de falha e suas possíveis variações, lembrando sempre o destino de uso do produto. Conforme Zhou (2005), estas variações podem ser:

1. Variações peça-peça: isto ocorre devido às variações do processo de manufatura no fornecedor do componente, devido às variações das 
propriedades dos materiais nos fornecedores de materiais e finalmente, variações no processo de montagem do veículo na montadora. Quando se desenvolve um sistema, é necessário entender os fatores de variações de peça-peça e sua extensão; a capabilidade do processo de manufatura na montadora, no fornecedor do sistema e/ou componente e no fornecedor da matéria prima e finalmente os potenciais modos de falha que estas variações peça-peça podem causar;

Como por exemplo, o farol de um veículo: as variações na colagem entre lente e corpo do farol quanto à resistência e sua uniformidade podem afetar a vedação do mesmo. As variações na montadora para os pontos de fixação do farol no veículo afetam as forças de atuação no corpo do farol. Quando estas forças são maiores do que a força de adesão, causam trincas na junção entre lente e carcaça do farol. Estas trincas tornam-se passagens para a infiltração de água e posteriormente causam a falha de condensação no farol, sua troca na garantia, aumento no índice de falha de campo, no custo de garantia e na satisfação do cliente. Este exemplo nos mostra a importância da variação peça-peça quando se compra um sistema e/ou componente em um mercado para ser usado em outro mercado.

2. Variações com o tempo de uso: estas são as variações que ocorrem com o desgaste do sistema e/ou componente devido ao uso, como variações dimensionais, desgaste ou fadiga e mudanças nas propriedades dos materiais. Quando se desenvolve um sistema, é necessário entender os fatores de variações pelo tempo de uso e sua extensão, mudança do mercado de utilização do produto e seus potenciais modos de falha. Por exemplo, a buzina de um veículo sob ação de carregamento térmico cíclico pode apresentar falha por fadiga. Assim, deve-se desenvolver uma buzina robusta considerando este tipo de modo de falha;

3. Variações devido ao uso do cliente: estas variações referem-se ao modo como o cliente usa o sistema, qual a frequência que o cliente usa o sistema e qual o carregamento que o cliente impõe ao sistema. Estas são considerações que devem ser feitas quando do desenvolvimento do 
produto, pois o uso do produto pode variar de mercado para mercado. Voltando ao exemplo da buzina, seu uso nos mercados asiáticos é bem mais frequente do que nos mercados americano e europeu, logo estas variações de uso excessivo para os mercados asiáticos devem ser consideradas pelos fornecedores de buzina, desenvolvendo uma buzina durável para evitar futuros modos de falha e consequentemente custos de garantia. Outro exemplo de uso pode ser os mercados onde o transito é muito intenso e os usuários são acostumados com as paradas bruscas, isto pode causar o uso excessivo das pastilhas de freio e em seguida 0 ruído de freio;

4. Variações do meio ambiente: estas variações são o meio ambiente onde o sistema é exposto como, sol, vento, temperatura, umidade, condições de tráfego, poeira, contaminações, água e finalmente as condições das estradas onde o produto é usado. Quando se desenvolve um sistema, é necessário entender os fatores de variações externos do meio ambiente, para que o projeto seja robusto o suficiente para atender a este requisito. Por exemplo, chuvas pesadas em determinadas épocas do ano causam enchentes em determinadas regiões, isto causa entrada excessiva de água nas buzinas. Uma buzina com entrada de água ou falha completamente ou fica com um som de baixa qualidade, assim vem a importância não somente do desenvolvimento de uma buzina robusta pelos fornecedores, mas também da sua localização dentro do compartimento do motor, evitando o quanto for possível o contato com a água;

5. Variações de interação sistema-sistema: estas variações entre os sistemas são os modos como os sistemas interagem entre eles, podendo ser o contato físico com outros sistemas ou componentes, transferência de energia térmica, troca de informação e troca de materiais.

Um exemplo clássico deste tipo de variação é o mecanismo de levantamento do vidro, isto inclui interações dos seguintes componentes: o trilho com o deslizador plástico, os braços para subir/descer o vidro, os braços com o deslizador, mecanismo de levantamento com a porta e com 
o motor elétrico. A interação entre estes sistemas e/ou componentes causam modos de falha como ruídos, esforço excessivo de levantamento e até a falha do motor elétrico.

O problema reportado pelo cliente e a peça reportada pelo técnico de serviço como sendo a causa raiz do problema são dois importantes fatores nas análises de falha de um sistema. Identificar a peça correta que causa a falha depende muito da capacidade dos técnicos de serviço.

\subsection{Melhoria Contínua para ganho de Confiabilidade}

Quando se identificam os sistemas mais críticos de um produto, deve-se aplicar as ferramentas de qualidade e de confiabilidade para melhoria contínua dos novos projetos e esta passa a ser uma das atividades mais críticas durante um desenvolvimento. Isto porque sempre se tem custos envolvidos e assim torna-se necessarário montar uma proposta completa de melhoria, ou seja, a proposta técnica da melhoria, os investimentos envolvidos, o acréscimo de custo de componentes e o tempo de introdução da proposta.

Muitas vezes estas propostas de melhorias são rejeitadas, pois não apresentam números satisfatórios e a decisão final acaba sendo feita com base nos custos de investimento e não na melhoria do produto, pois tais custos de melhoria não podem ser adicionados ao preço do produto. É uma prática comum definir o preço de um produto como sendo a soma total dos custos mais a margem de lucro, mas Setijono (2008) sugere que o custo total deve ser a soma dos custos que agregam valor ao produto e dos custos que não agregam valor ao produto. Isto quer dizer que, para aumentar a margem de lucro ou reduzir o preço do produto deve-se continuamente reduzir os custos que não agregam valor ao produto, ou seja, custos de atividades devido a falhas e/ou imperfeições de sistemas.

Como este estudo considera o período de garantia, têm-se muitos casos de falhas prematuras, uma quantidade menor de falhas aleatórias e raras falhas por desgaste, conforme a curva da banheira, representada na figura 31. Isto porque o período de garantia é muito pequeno se comparado com a vida útil do veículo, mas são dados suficientes para se propor muitas melhorias ao produto e reduzir os 
custos de atividades que não agregam valor ao produto. Embora não se possa eliminar completamente as falhas aleatórias e as falhas por desgaste, os engenheiros podem aplicar métodos para que estes valores fiquem dentro do aceitável para o produto. Podem-se programar melhores planos de manutenção, melhorias de projeto que aumentam o tempo de vida de sistemas ou ainda reduzir o número de peças nos sistemas.

Qualquer que seja a melhoria introduzida, pode-se obter ganhos significativos tanto em redução do custo de garantia como também no número de incidência da falha, conforme ilustra a figura 32. Uma evidência destas melhorias é a extensão de garantia oferecida pelas montadoras. Atualmente, conforme Broome (2004), muitas montadoras oferecem três, quatro ou até seis anos de garantia em alguns novos modelos.



Figura 31 - Curva da banheira.

(fonte: Broome, 2004)

Entre as muitas ferramentas para ganho de confiabilidade, este estudo faz uma proposta contendo análise de confiabilidade de sistemas, análise de risco, manutenção centrada em confiabilidade, projeto para a manufatura e projeto para montagem. Após o levantamento dos itens mais críticos apontados pelo estudo, estar-se-á propondo melhorias através do uso destas ferramentas que reduzam ou eliminam os problemas a níveis aceitáveis. 




Figura 32 - Falha, Análise da Causa Raiz e Ação de Melhoria.

(fonte: Barkai, 2004)

Estas ferramentas focam atenção em problemas potenciais que podem ocorrer devido a qualquer mudança de projeto, do meio ambiente ou do processo produtivo do sistema em análise. Boas práticas de qualidade podem até superar um projeto de pobre execução, mas eliminar com sucesso o problema de falhas é concentrar esforços no uso das ferramentas de melhoria de qualidade para eliminar todos os defeitos do produto e do processo.

Cada uma das ferramentas mostradas neste estudo tem seu papel na melhoria da confiabilidade do produto, por exemplo, quando da elaboração de um estudo comparativo entre as plataformas de veículos, aponta-se quais itens mais afetam a confiabilidade dos produtos. Esta comparação inicial também aponta quais itens estão presentes em mais de uma plataforma de veículo, mostrando que um mesmo componente pode afetar a confiabilidade de outros produtos. Com estes itens identificados pode-se iniciar as investigações quanto ao tempo de falha e seus diferentes modos de falha. Para cada modo de falha investigado são aplicadas as propostas de melhorias, que diminuirão as incidências de falhas, melhorando a confiabilidade do produto. Cada uma das ferramentas mostradas será mais explorada e discutida no capítulo seguinte, com o objetivo de ligar cada uma delas com o ganho de confiabilidade. 


\subsection{Gerenciamento da Integridade dos Sistemas}

Gerenciar a integridade dos sistemas é adicionar controles e/ou melhorias nos sistemas após sua avaliação. Usam-se as informações obtidas das análises de campo e/ou processos de produção que faz com que as decisões tomadas sejam mais maduras quanto à segurança e à confiabilidade do sistema. Para o gerenciamento do risco destes sistemas é necessário alocar recursos adequados para suportar as decisões do time, comparar a evolução das melhorias e decisões tomadas constantemente. Seu objetivo é reduzir o risco até um nível aceitável e/ou priorizar os recursos com base em análises comparativas. A redução de certo risco é atingida quando existem medidas de prevenção para um cenário desfavorável, através da redução da frequência e das consequências que determinada falha possa causar. A determinação dos níveis de aceitação de risco torna-se importante quando da avaliação de risco de um sistema, pois estas informações dirão se o sistema é robusto ou não. Se um sistema tem um nível de confiabilidade abaixo do aceitável, ações de melhoria do sistema devem ser tomadas para a redução destas falhas e consequentemente atingirem níveis de aceitáveis.

A análise de decisão fornece maneiras de tratar problemas complexos, os dados obtidos podem ser estruturados de modo que auxilie a responder determinado problema. A decisão normalmente trata de três elementos: alternativas, consequências e as preferências. As alternativas são as escolhas possíveis a serem consideradas, ou seja, após uma análise de risco, sabe-se o que precisa ser feito para eliminar ou minimizar a falha. As consequências são o resultado potencial da decisão tomada. Pode-se também gerenciar estas melhorias através de uma análise de custo-benefício, mostrando de forma gráfica as várias alternativas de eliminação ou redução da falha, seus níveis de risco e respectivos custos.

Segundo Broome (2004), o resultado da eliminação e/ou redução significativa das falhas prematuras gerou uma diminuição dos custos de garantia em até 12 milhões de dólares por ano nas indústrias automotivas no mercado americano. A devida atenção em qualidade, confiabilidade, segurança no projeto, desenvolvimento, produção e manutenção são atividades praticáveis e grande redução de custos futuros de garantia. Além disto, aumentar a confiabilidade de determinado produto, 
faz com que sua reputação no mercado melhore e isto influencia na participação de mercado. Todo este estudo trata da redução da probabilidade de falhas dentro de um cenário conhecido, como meio ambiente e tempo de uso determinado. Projetar, desenvolver e produzir produtos e sistemas modernos e confiáveis é, portanto uma atividade importante e economicamente rentável. Estes custos devem ser tratados como um investimento, pois os produtos terão suas falhas de campo reduzidas, consequentemente reduzindo os altos custos de garantia.

O sucesso de implementação de cada proposta de melhoria é, portanto montar relatórios para a tomada de decisão contendo sempre as possíveis alternativas com os respectivos ganhos obtidos com cada uma delas, tanto na diminuição dos custos de garantia, como também na satisfação dos clientes. Finalmente, projetar, desenvolver e produzir sistemas e produtos modernos com confiabilidade é muito importante, os princípios da engenharia de confiabilidade precisam ser seguidos, pois, uma boa engenharia de desenvolvimento conduz a bons produtos no mercado.

\subsection{Contribuição do Método Proposto}

O modelo aqui proposto traz uma metodologia de como se conduzir melhorias em produtos, considerando aspectos de confiabilidade e risco. O trabalho tem início na consulta ao banco de dados e coleta de dados de falhas de campo em quatro plataformas de veículos. Após esta seleção das falhas das plataformas de veículos, se faz a seleção de sistemas mais críticos por incidência e em seguida se obtém os tempos de falha da cada sistema selecionado e seus modos de falha, nesta parte são mostradas as considerações necessárias para o uso correto das informações provenientes de banco de dados e sua aplicação nos estudos de confiabilidade.

Para o estudo de confiabilidade ser completo é necessário conhecer o comportamento de toda população, ou seja, a que falhou e a que não falhou, para isto são feitas as hipóteses para uso dos dados censurados obtidos através da mesma população de veículos no caso do mercado nacional e extraída de um artigo no caso do mercado europeu. 
Diferentemente dos estudos pesquisados, que mostram modelos com propostas isoladas de ganho de confiabilidade e a aplicação das ferramentas de qualidade, o presente estudo mostra em um único modelo desde as hipóteses a serem consideradas na coleta de dados para o uso da informação de campo e como cada ferramenta de qualidade está ligada com a melhoria do produto e consequentemente com a melhoria da confiabilidade do mesmo. A tabela 3 foi outro estudo adicional onde se compara a contribuição de cada publicação pesquisada com o método proposto, mostrando a contribuição deste modelo em comparação com outros trabalhos publicados.

Assim esta proposta vem adicionar em um único modelo todas as fases para a melhoria de um produto. Iniciando-se na coleta de dados, seleção dos sistemas, aplicação das ferramentas de qualidade e as propostas de melhoria e o que se ganha com isto é uma visão de todo o ganho que se obtém em forma de melhoria do produto em um novo desenvolvimento.

Com esta forma diferente de se aplicar as ferramentas de qualidade pode-se saber exatamente qual o ganho que se obtém em termos de redução de falhas de um sistema e de seus respectivos custos de garantia. Isto faz com que as decisões a serem tomadas fiquem mais fáceis, pois cada ganho deste é contabilizado como melhoria de confiabilidade. 
Tabela 3 - Comparativo entre trabalhos publicados e método proposto.




Trabalhos como o publicado por Jones (1997) apresentam um modelo de uso de falhas de campo para melhoria de confiabilidade, mas os dados utilizados são adquiridos de empresas que testam componentes para a coleta destas falhas, além disto, não faz nenhuma citação quanto ao uso dos dados censurados do método proposto.

Kumar (2007) mostra outro modelo de estudo de confiabilidade, onde há a preocupação de se localizar os componentes mais críticos para então substituí-los, evitando assim paradas excessivas de manutenção do equipamento em estudo, mas não indica como os componentes foram selecionados.

Krasich (2000) usa um modelo para mostrar como as ferramentas de FTA e FMEA são úteis na condução de análise de falhas, mas não mostra nada quanto a uso de banco de dados e nem como solucionar a árvore de falhas.

Volkanovski (2009) usa a árvore de falhas para mostrar a importância deste tipo de análise na melhoria de um sistema de força, porque este apresentava muitas paradas por falhas de componentes, ou seja, aplicação de FTA em um sistema com problemas de falhas, sem nenhum modelo de seleção e solução da árvore de falhas.

Majeske (2003) traz um modelo de análise de confiabilidade em sistemas automotivos considerando duas variáveis como a quilometragem que ocorreu a falha e o tempo de exposição do veículo. Com isto procura evidenciar que determinadas falhas estão relacionadas ao processo de manufatura, processo de montagem e ao processo de reparo na concessionária.

Om (2008) faz uma proposta de desenvolvimento para atender a satisfação dos clientes e reduzir tempo de desenvolvimento com base em matrizes de decisões de atividades técnicas.

Hillmer (2008) mostra uma metodologia para entender as necessidades dos clientes e propor melhorias nos novos desenvolvimentos, mas foca mais em entrevistas a grupos de potenciais clientes e usam os dados coletados nestas entrevistas como seu banco de dados para futuras análises.

Deshpande (2001) apresenta um modelo de manutenção centrada em confiabilidade onde o foco é dado somente à manutenção preventiva para a prevenção de modos de falhas em uma indústria de média escala, mostra os conceitos da RCM, mas não indica nada como os sistemas foram escolhidos e nada cita quanto ao ganho de confiabilidade obtido. 
Jiang (2008) faz considerações sobre o impacto das variações dimensionas de manufatura sobre o produto final e como estas variações podem ser minimizadas.

Edwards (2002) faz o uso de DFMA focando na redução de custo, mas não relaciona com nenhum ganho em qualidade do produto.

Zhou (2005) faz uma excelente análise dos modos de falhas em outros mercados para a melhoria do produto, mas há um ganho de confiabilidade que não foi explorado no modelo.

Setijono (2008) e Kim (2008) fazem análises dos custos de garantia e através destes resultados fazem as propostas de melhoria. O foco nestes modelos é avaliar os custos de garantia com mão de obra para reparo e componentes trocados.

Booker (2002) faz uma revisão das técnicas de melhoria disponíveis e sua integração no desenvolvimento do produto e como elas devem ser usadas, porém não cita exemplos de ganho em confiabilidade.

Todos os modelos citados na tabela 3 têm sua aplicação em algum ponto do desenvolvimento, porém todos estes modelos são mostrados isoladamente, o modelo aqui proposto traz como diferencial a união de todos estes modelos, partindo do tratamento e considerações necessárias aos dados de campo, como um item foi selecionado e como as ferramentas de qualidade foram usadas para a melhoria do produto. Isto vem adicionar ao desenvolvimento de produtos um modo de se conduzir melhorias onde cada proposta traz dados para a tomada de decisão como incidência de falhas e custo de garantia, embora este último não tenha sido o foco da proposta, ficando uma oportunidade para futuros estudos. Com isto espera-se obter ganhos de confiabilidade nos produtos, pois existe um elo entre cada melhoria proposta e 0 ganho de confiabilidade. Um projeto para manufatura e montagem (DFMA) é normalmente aplicado quando há a necessidade de mudanças do processo de manufatura devido a alguma inviabilidade, este estudo onde o DFMA é aplicado em um componente já em produção, mostrando seu impacto na diminuição das falhas, através da melhoria do sistema, da diminuição de componentes e diminuição dos erros de montagem. A ferramenta manutenção centrada em confiabilidade (MCC) partiu de uma falha de campo e faz uma proposta de melhoria no processo de manufatura, tornando os equipamentos da célula de montagem mais estáveis e consequentemente uma menor dispersão nas falhas na condição de projeto e com esta diminuição da variabilidade do processo há um ganho de confiabilidade. 


\subsection{ESTUDO DE CASO}

O fluxograma proposto na figura 27 mostra o modelo de análise deste estudo. Os clientes muitas vezes não sabem exatamente o que querem em seus produtos, mas com certeza um ponto em comum é que ninguém gostaria de ter um produto que falhesse durante o período de garantia e mesmo após este período. É claro que um veículo com aproximadamente 15 mil componentes sempre apresentará algum tipo de falha, principalmente nos itens que apresentam falhas associadas a algum dano cumulativo, a proposta deste estudo será identificar quais são estes sistemas e/ou componentes que os clientes não querem que falhem. Entender como estes modos de falha ocorrem propor melhorias através do uso das ferramentas de qualidade e confiabilidade mostradas neste estudo, para assim tornar o sistema e/ou componente mais robusto para o veículo corrente ou para uso em futuros desenvolvimentos.

Nos últimos anos os engenheiros de melhoria contínua têm feito um trabalho muito importante para melhorar a confiabilidade através da eliminação das falhas ou para a redução da probabilidade de ocorrência das mesmas, nas três regiões da curva da banheira (falhas prematuras, falhas aleatórias e falhas por desgaste). Embora o desgaste não possa ser eliminado, os engenheiros trabalham com novos materiais, melhores métodos de manutenção e projetos mais robustos que aumentam a vida útil e reduz os impactos do desgaste em muitos produtos. O período de garantia de um produto é muito pequeno se comparado a sua vida útil, mas será neste período que os dados para análise serão coletados para a condução deste estudo. Altas taxas de falhas na primeira região da curva da banheira podem estar relacionadas a defeitos de montagem ou adicionadas ao produto durante ao período de entrega do mesmo ao cliente, devido a possíveis danos ocorridos durante 0 transporte do veículo.

Para isto uma análise comparativa será feita com quatro plataformas de veículos para a identificação dos sistemas e/ou componentes onde se poderão elaborar propostas de melhorias. Por motivos de confidencialidade os veículos e seus respectivos anos modelo serão omitidos neste estudo. A razão para a escolha destas plataformas de veículos é meramente aleatória, são veículos do segmento chamado econômico. 


\subsection{Análise de Sistemas nas Plataformas em Estudo}

Uma análise dos sistemas e/ou componentes pode ser feita quando se tem um bom banco de dados de garantia, como é o caso das montadoras. Mas obter a mesma análise com os dados da concorrência é impossível, pois não se tem acesso a tais informações. O máximo que se consegue são análises estáticas para comparações quanto à execução dos sistemas e/ou componentes, ou seja, como ele é manufaturado, qual é o seu modo de fixação, sua localização no veículo e seu acabamento, mas não seu desempenho no campo, embora muitas vezes tais sistemas e/ou componentes podem ser produzidos pelo mesmo fornecedor e fornecidos a várias montadoras. O primeiro passo será a obtenção dos dados de cada um dos veículos para o estudo, que serão denominados de veículos Alfa, Beta, Gama e Delta. Uma análise de confiabilidade através dos dados de garantia requer algumas considerações tais como:

1. Todo reparo de garantia corresponde a uma falha do sistema e/ou componente;

2. O tempo/quilometragem do reparo corresponde ao tempo/quilometragem da falha, o que é verdade para as falhas graves onde o sistema/componente não funciona mais, afetando o desempenho do veículo e o consumidor procura uma concessionária imediatamente. Este fato não é verdade para falhas brandas (que não afetará o desempenho do veículo) onde normalmente o consumidor deixa para a próxima visita a concessionária o seu reparo;

3. Falhas com quilometragem muito alta ou muito baixa (dependendo do tempo de uso) serão desconsideradas do estudo (falhas de quilometragens menores do que $50 \mathrm{~km}$ e maiores do que $40.000 \mathrm{~km}$ ), por se entender que seja um erro de lançamento no sistema;

4. As falhas ocorridas com um mesmo sistema e/ou componente mais de uma vez em um mesmo veículo serão descartadas, por serem entendidas como uma falha do reparo e não do sistema e/ou componente.

Após consulta ao banco de dados, tem-se a primeira imagem do desempenho dos veículos conforme ilustram os gráficos nas figuras 33, 34, 35 e 36. Estes gráficos 
mostram as falhas ocorridas com cada um dos veículos em estudo durante o período de garantia. Ou seja, veículos que deram entrada na concessionária para algum reparo durante o período em estudo. Nos gráficos o índice Incidência significa falhas ocorridas para cada mil veículos.



Figura 33 - Desempenho do veículo ALFA durante período de garantia.

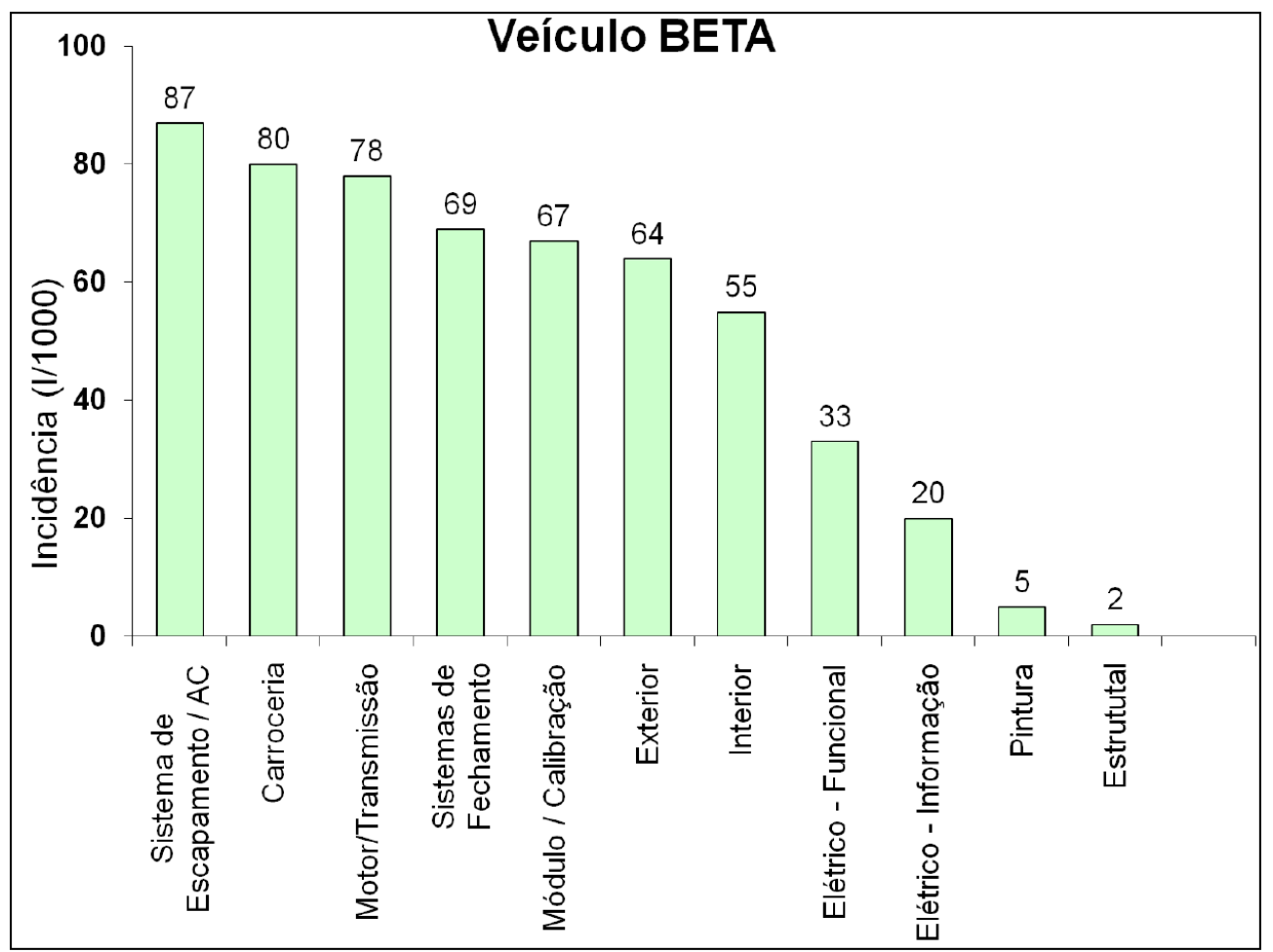

Figura 34 - Desempenho do veículo BETA durante período de garantia. 


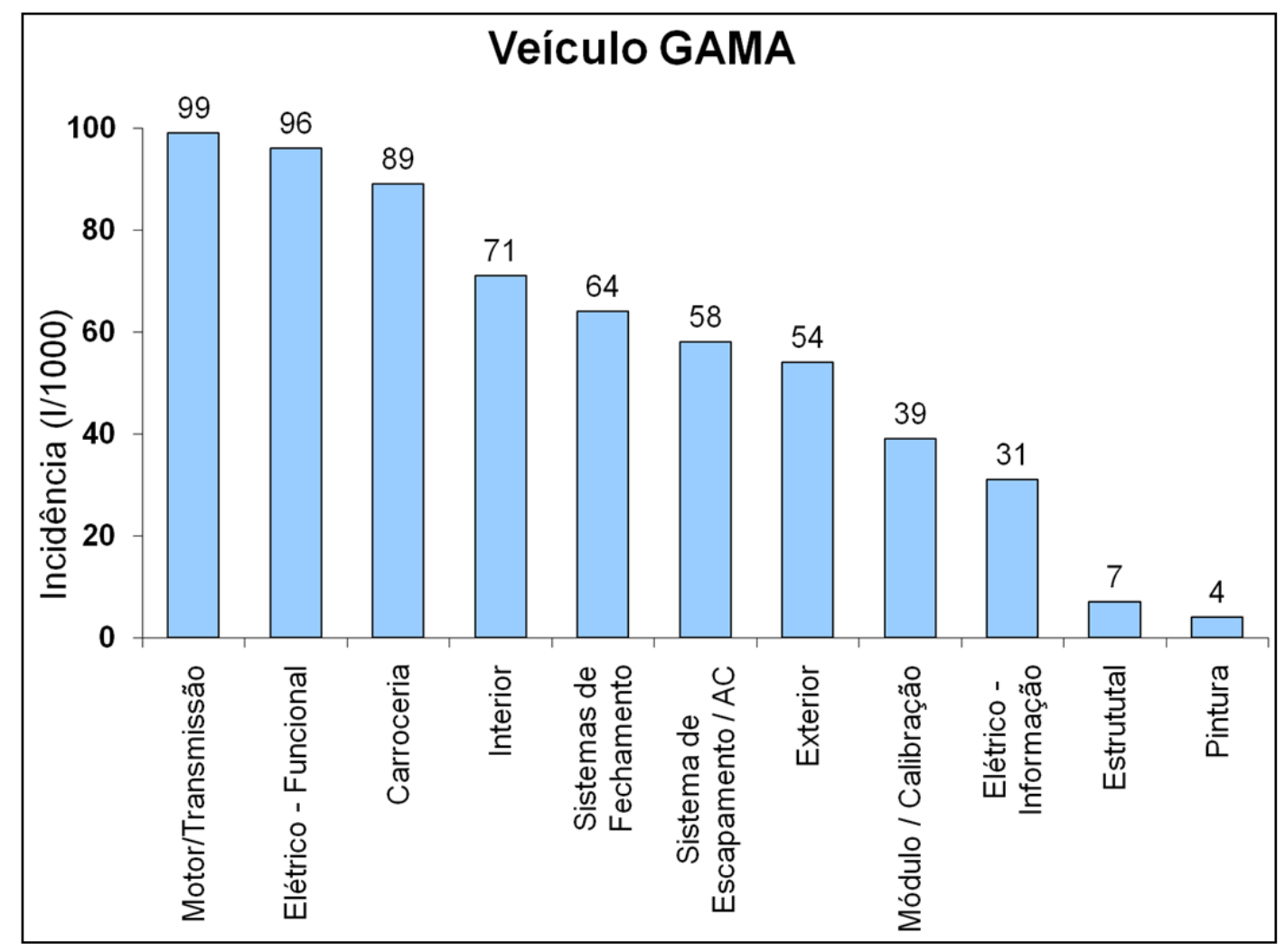

Figura 35 - Desempenho do veículo GAMA durante período de garantia.

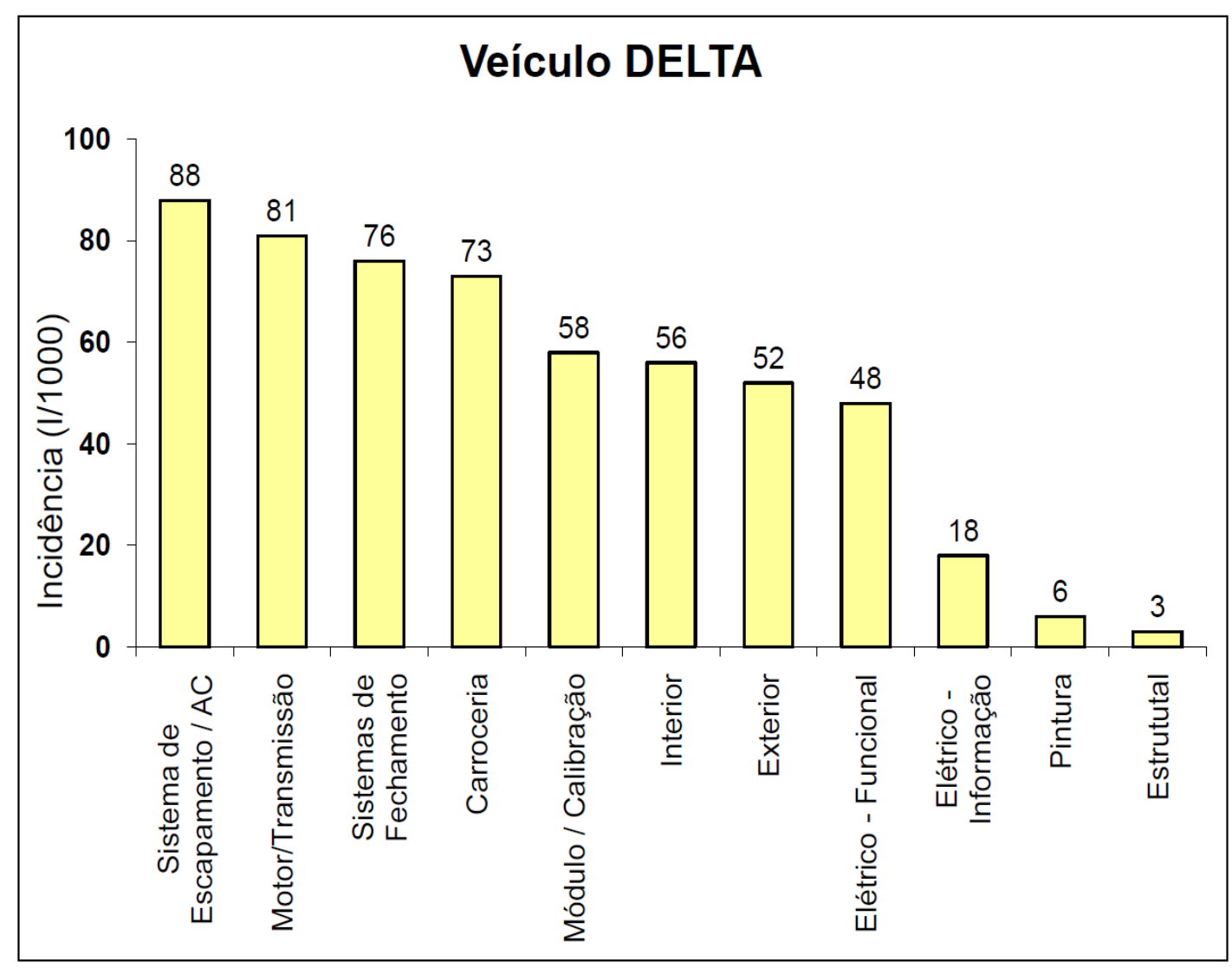

Figura 36 - Desempenho do veículo DELTA durante período de garantia. 
Após este levantamento de dados já é possível saber quais são os sistemas mais críticos destas plataformas de veículos e através deste material se obter os sistemas para este estudo. A figura 37 ilustra na forma de um gráfico de histograma o acúmulo de todas as falhas observadas nos quatro veículos em estudo. Através deste gráfico tem-se a seguinte lista de sistemas em ordem decrescente do número de falhas observadas, conforme segue:

1. Motor / Transmissão

2. Carroceria

3. Sistemas de Escapamento, Aquecimento e Ar Condicionado

4. Sistemas de Fechamento

5. Interior

6. Módulo Eletrônico / Fixações

7. Exterior

8. Elétrica - Funcional

9. Elétrica - Informação

10. Pintura

11. Estrutural

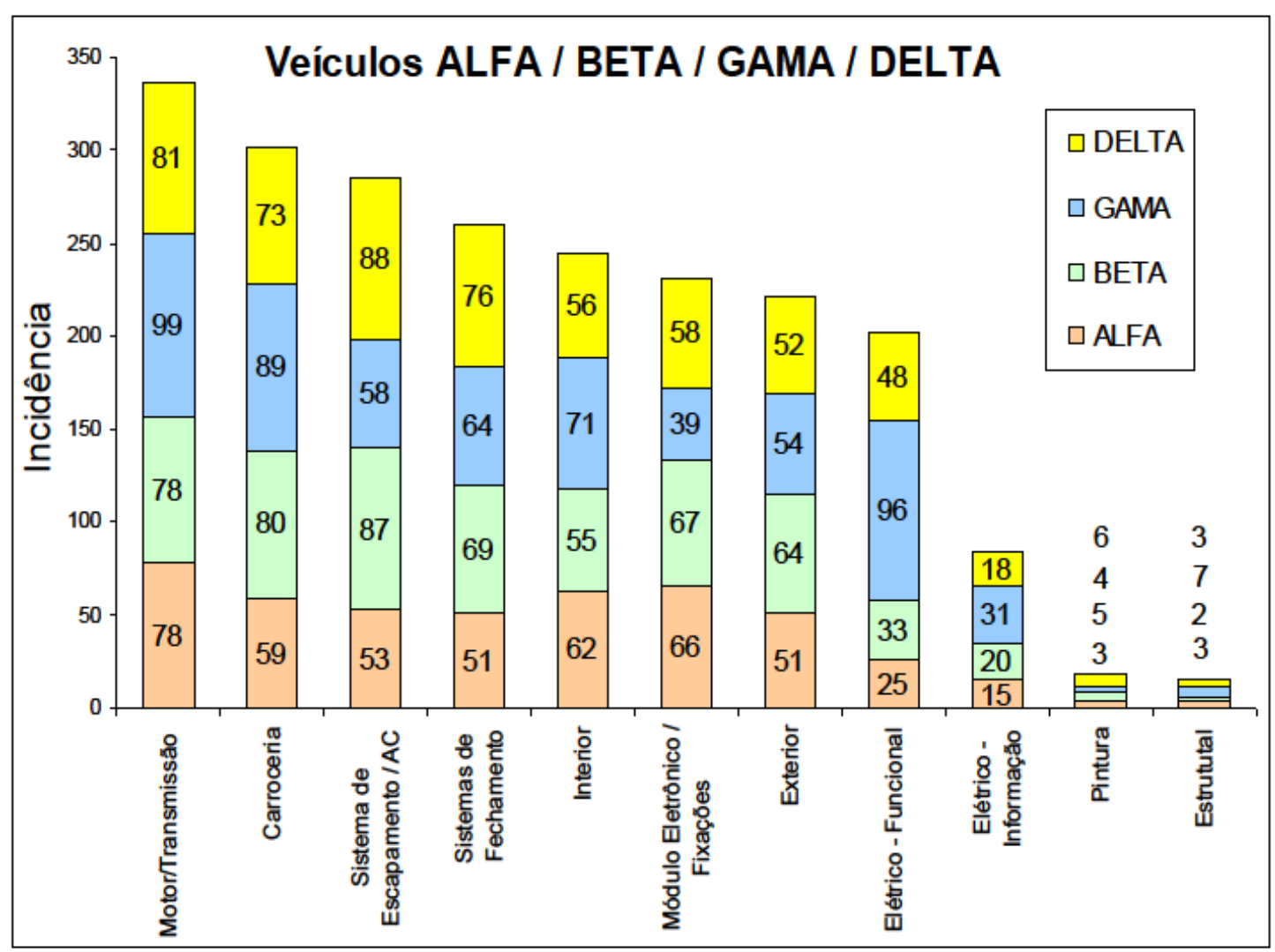

Figura 37 - Acúmulo de falhas dos veículos em estudo. 
Sabendo-se quais os sistemas mais críticos, o próximo passo é identificar quais são os componentes que mais contribuem para a ocorrência das falhas em cada um destes sistemas e onde se estará aplicando as ferramentas de qualidade e confiabilidade para a melhoria do produto, quanto à segurança e a perda de capacidade do componente ao longo da vida operacional do veículo.

\subsection{Definição dos Sistemas para Análise}

Com os sistemas mais críticos identificados torna-se fácil definir quais subsistemas e/ou componentes são os que mais colaboram para as falhas de campo e consequentemente aumentando o custo de garantia e a perda em confiabilidade. Seguindo as etapas do modelo proposto, o próximo passo é relacionar os sistemas quanto à segurança e a perda de confiabilidade.

Para a primeira barra do gráfico de Pareto da figura 37, têm-se o sistema MOTOR / TRANSMISSÃO e como subsistemas mais críticos os seguintes itens:

\section{Motor}

$\rightarrow$ Bomba de Óleo do Motor

$\rightarrow$ Bomba D’Água

\section{Transmissão}

$\rightarrow$ Junta/Vedador Seletor de Mudanças

$\rightarrow$ Carter de Óleo do Motor

$\rightarrow$ Plato e Disco de Embreagem

$\rightarrow$ Alavanca / Acionamento Embreagem

$\rightarrow$ Rolamento da embreagem

Na sequência, para cada uma das barras do gráfico de Pareto da figura 37, têm-se os seguintes sistemas e subsistemas e/ou componentes mais críticos:

\section{Carroceria}

$\rightarrow$ Suspensão Dianteira: Suporte do Tirante (Ambos os Lados)

Mola Helicoidal da Suspensão Dianteira - lado esquerdo (LE) / lado direito (LD)

Amortecedor da Suspensão LE/LD 
$\rightarrow$ Sistema de Direção: Caixa de Direção Hidráulica

Mangueiras do Sistema de Direção Hidráulica

Caixa de Direção Mecânica

$\rightarrow$ Suspensão Traseira: Mola Helicoidal da Suspensão Traseira - LE/LD

$\rightarrow$ Sistema de Freio: $\quad$ Disco de Freio Dianteiro - Ambos os Lados

Tambor de Freio Traseiro - Ambos os Lados

Rolamento do Cubo da Roda Traseiro - Ambos os Lados

\section{Sistema de Escapamento e Ar Condicionado}

$\rightarrow$ Sistema de Escapamento: $\quad$ Silenciador Traseiro do Escapamento

Tubo Dianteiro de Escapamento

$\rightarrow$ Sistema de Ar Condicionado: Mangueiras / Tubos de Gás do Ar Condicionado

$\rightarrow$ Compressor e Dutos de AC: Compressor do Ar Condicionado

$\rightarrow$ Dutos de Circulação de Ar Interno: Caixa de $\mathrm{Ar}$

Motor / Hélice do Ventilador Interno

Válvula de Alívio da Cabine

\section{Sistema de Fechamento}

$\rightarrow$ Portas Dianteiras: $\quad$ Regulador do Vidro da Porta

Guarnições das Portas Dianteiras

$\rightarrow$ Tampa Traseira: $\quad$ Fechadura da Tampa Traseira

Engate da Fechadura da Tampa Traseira

$\rightarrow$ Portas Traseiras: $\quad$ Cabo de Acionamento da Fechadura Tampa Traseira

Fechadura da Tampa Traseira

Guarnições das Portas Traseiras

\section{Interior}

$\rightarrow$ Painel de Instrumentos: $\quad$ Cobertura do Painel de Instrumentos

Tampa do Porta Luvas

Caixa do Porta Luvas

$\rightarrow$ Cintos de Segurança: $\quad$ Cinto de Segurança Banco/Retrator

$\rightarrow$ Bancos Dianteiros: $\quad$ Capa do Assento do Banco Dianteiro

Capa do Encosto do Banco Dianteiro

$\rightarrow$ Painel de Portas: $\quad$ Painel de Acabamento da Porta Dianteiro 
$\rightarrow$ Volante: $\quad$ Cobertura da Buzina no Volante

Suporte de Contato da Buzina

\section{Módulo Eletrônico / Fixações}

$\rightarrow$ Medidor e Bomba de Combustível: Medidor de Combustível

Bomba de Combustível

\section{Exterior}

$\rightarrow$ Fárol Conjunto: $\quad$ Farol Ambos os Lados

$\rightarrow$ Para Brisa: $\quad$ Guarnições do Para Brisa

Vidro do Para Brisa

$\rightarrow$ Lanternas: $\quad$ Lâmpada da Lanterna Traseira

Lanterna Traseira

$\rightarrow$ Para Choque: $\quad$ Para Choque Dianteiro

\section{Elétrico - Funcional}

$\rightarrow$ Chicotes: $\quad$ Chicote Elétrico do Painel de Instrumentos

Chicote Elétrico do Motor

$\rightarrow$ Buzina: Buzina

$\rightarrow$ Bateria: $\quad$ Bateria

\section{Elétrico - Informação}

$\rightarrow$ Sistema de Controle DT: $\quad$ Cabo de Controle deTemperatura

$\rightarrow$ Chave Multi Função: $\quad$ Interruptor da Chave Indicadora de Direção

Neste estudo observou-se também que os seguintes sistemas presentes em todas as plataformas de veículos analisadas, colaboram para as falhas de campo, aumentando a incidência de falhas e os custos de garantia:

Motor / Transmissão: carter de óleo, bomba de óleo.

Carroceria: suspensão Dianteira e Traseira, sistema de freio, caixa de direção hidráulica, mangueiras.

Sistema de Fechamento: mecanismo de levantamento vidro, fechaduras das portas, guarnições de portas.

Sistema de Escapamento e Ar Condicionado: tubos de escapamento, mangueiras de 
ar condicionado.

Interior: painel de instrumentos, porta luvas, bancos, painel de porta, cinto de segurança.

Módulo Eletrônico / Fixações: medidor e bomba de combustível.

Exterior: farol, para brisa, lanternas, para choque.

Elétrico - Funcional: chicotes, buzina, bateria.

Elétrico - Informação: chave multi função.

Dentre os sistemas identificados neste estudo até este ponto, estar-se-á classificando os sistemas presentes em todas as plataformas de veículos quanto à gravidade e a insatisfação, conforme ilustra a tabela 4, que também mostra os itens mais críticos de todas as plataformas de veículos analisadas.

Tabela 4 - Classificação dos Sistemas Quanto a Gravidade e Insatisfação

\begin{tabular}{|c|c|c|c|}
\hline Sistema & Componente & Grave & Insatisfação \\
\hline Motor & $\begin{array}{l}\text {-Bomba de Óleo do Motor } \\
\text {-Carter de Óleo do Motor }\end{array}$ & $x$ & $\begin{array}{l}x \\
x\end{array}$ \\
\hline $\begin{array}{l}\text { Suspensão } \\
\text { Dianteira }\end{array}$ & $\begin{array}{l}\text {-Suporte do Tirante } \\
\text {-Mola Helicoidal: Suspensão Dianteira } \\
\text {-Amortecedor: Suspensão Dianteira }\end{array}$ & & $\begin{array}{l}X \\
X \\
X\end{array}$ \\
\hline $\begin{array}{l}\text { Sistema de } \\
\text { Direção }\end{array}$ & $\begin{array}{l}\text {-Caixa de Direção Hidráulica } \\
\text {-Mangueiras: Sistema Direção Hidráulica } \\
\text {-Caixa de Direção Mecânica }\end{array}$ & $\mathrm{x}$ & $\begin{array}{l}X \\
X \\
X\end{array}$ \\
\hline $\begin{array}{l}\text { Suspensão } \\
\text { Traseira }\end{array}$ & -Mola Helicoidal da Suspensão Traseira & & $x$ \\
\hline Sistema de Freio & $\begin{array}{l}\text {-Disco de Freio Dianteiro } \\
\text {-Tambor de Freio Traseiro } \\
\text {-Rolamento do Cubo da Roda Traseiro }\end{array}$ & $\begin{array}{l}X \\
X \\
X\end{array}$ & $\begin{array}{l}X \\
X \\
X\end{array}$ \\
\hline $\begin{array}{l}\text { Medidor e Sistema } \\
\text { de Alimentação de } \\
\text { Combustível }\end{array}$ & $\begin{array}{l}\text {-Medidor de Combustível } \\
\text {-Bomba de Combustível }\end{array}$ & $\begin{array}{l}X \\
X\end{array}$ & \\
\hline Para Brisa & $\begin{array}{l}\text {-Guarnições do Para Brisa } \\
\text {-Vidro do Para Brisa }\end{array}$ & & $\begin{array}{l}x \\
x\end{array}$ \\
\hline Lanternas & $\begin{array}{l}\text {-Lâmpada da Lanterna Traseira } \\
\text {-Lanterna Traseira }\end{array}$ & & $\begin{array}{l}X \\
X\end{array}$ \\
\hline Para Choque & -Para Choque Dianteiro & & $x$ \\
\hline Chicotes & $\begin{array}{l}\text {-Chicote Elétrico - Painel de Instrumentos } \\
\text {-Chicote Elétrico - Motor }\end{array}$ & $\begin{array}{l}x \\
x\end{array}$ & $\begin{array}{l}x \\
x\end{array}$ \\
\hline Buzina & -Buzina & & $\mathrm{X}$ \\
\hline
\end{tabular}


A classificação da tabela 4 adotou o critério de Gravidade quando a falha do sistema e/ou componente paralisa ou causa grande perda de desempenho do veículo e quanto a Insatisfação quando a falha não para o veículo, mas causa alguma perda da função de algum componente que incomoda o cliente.

Como exemplo de Gravidade se tem: a falha de uma bomba de óleo causa a parada do motor e consequentemente a do veículo, caso a caixa de direção mecânica venha a travar, poderá também causar a parada do veículo, a falha do sistema de freio poderá causar algum tipo de acidente grave, a quebra de uma bomba de combustível também causa a parada do veículo, assim como um medidor de combustível que esteja funcionando incorretamente pode causar a parada de um veículo, pois se pode ter uma informação incorreta da quantidade de combustível no tanque. Quanto aos exemplos de Insatisfação, se tem todas as outras falhas que não causaram a parada do veículo.

\subsection{Coleta de Dados e Análise de Confiabilidade}

Os dados de garantia são incompletos para uma análise de confiabilidade, logo, precisam ser analisados conforme explicado no item 4.1, antes do seu uso para a obtenção da confiabilidade dos sistemas. Com os itens já definidos, pode-se agora aplicar os conceitos citados para alguns dos sistemas mostrados na tabela 4 . Considerando Gravidade e Insatisfação, estar-se-á analisando os seguintes sistemas e/ou componentes:

Gravidade: bomba de óleo, sistema de freio. Insatisfação: vidro do para brisa.

\subsection{Análise de Confiabilidade: Bomba de Óleo}

Este componente apresentou uma grande incidência de falha em todas as plataformas de veículos analisadas. Neste momento estar-se-á analisando apenas a bomba de óleo da plataforma de veículo denominada Alfa, mas a forma de análise pode ser reproduzida para os demais componentes ou veículos.

A bomba de óleo de um veículo é uma importante parte do sistema mecânico de lubrificação do motor e provavelmente um dos componentes mais robustos do veículo. Uma bomba de óleo frequentemente não precisa de reparos, mas quando 
falha, impacta no desempenho do veículo. Esta percepção quanto ao seu desempenho pode ajudar a determinar se a bomba de óleo está em processo de falha. Os sintomas mais comuns são:

a) Diminuição da pressão de óleo do veículo: a bomba de óleo regula a pressão de óleo do motor, seu papel é pressurizar e mover o óleo dentro do motor. Este óleo é responsável por manter as partes móveis do motor lubrificadas, diminuindo o atrito ao mínimo possível. Na falta desta lubrificação os componentes internos do motor irão se aquecer, aumentando a temperatura do motor, a pressão de óleo diminuirá e a luz de alerta de óleo do motor acenderá no painel de instrumentos.

b) Alta temperatura operacional do motor: quando uma bomba de óleo falha ao pressurizar o óleo através do motor, causa o aumento do atrito entre os componentes móveis do motor e isto faz com que a temperatura operacional do veículo aumente e assim a luz de alerta de temperatura do motor ascenderá no painel de instrumentos.

c) Tuchos hidráulicos com ruído: os tuchos hidráulicos são componentes do sistema de válvulas do motor. Estes componentes como qualquer outro precisam de lubrificação adequada e a redução do fluxo de óleo nestes componentes causa muito ruído no motor e com o tempo um desgaste excessivo diminuindo a vida destes componentes. O ruído alerta o usuário para um problema de desempenho do motor

d) Eixo comando de válvulas: o sistema de válvulas inclui componentes importantes, além dos tuchos hidráulicos, também se tem as varetas, as guias das válvulas e os vedadores. Todos estes componentes precisam de lubrificação adequada, sem isto, estes componentes deixarão de funcionar corretamente ou de forma silenciosa. Uma bomba de óleo com problemas pode causar muito ruído do eixo comando de válvulas, alertando o usuário para um problema de desempenho do motor.

Com as consequências de falha da bomba de óleo mais frequentes identificados, pode-se agora, através do banco de dados, obter as quilometragens reportadas de falhas de cada um destes componentes. Nesta análise preliminar das quilometragens de falha, devem ser aplicados os conceitos mostrados no item 3.1 antes do seu uso para a obtenção da confiabilidade do componente em estudo. Com 
estes dados de falha mais os dados censurados mostrados na figura 8, considerando apenas o mercado nacional neste momento, pode-se agora determinar a curva de confiabilidade da bomba de óleo.

A Tabela 5 mostra os dados para a análise da bomba de óleo, com suas respectivas populações, falhas observadas, dados excluídos da análise, conforme hipóteses propostas e a quilometragem média dos veículos que falharam.

Tabela 5 - Dados da Análise da Bomba de Óleo

\begin{tabular}{|l|c|c|c|c|c|c|c|}
\hline Veículo & População & $\begin{array}{c}\text { Total de } \\
\text { Falhas } \\
\text { Observadas }\end{array}$ & $\begin{array}{c}\text { Falhas } \\
\text { Excluidas } \\
\mathbf{5} \mathbf{5 0} \mathbf{~ k m}\end{array}$ & $\begin{array}{c}\text { Falhas } \\
\text { Excluidas } \\
\mathbf{7} \mathbf{4 0 . 0 0 0} \\
\mathbf{k m}\end{array}$ & $\begin{array}{c}\text { Falhas } \\
\text { Excluidas } \\
\text { por } \\
\text { Reincidência }\end{array}$ & $\begin{array}{c}\text { Total } \\
\text { de } \\
\text { Falhas } \\
\text { para } \\
\text { Estudo }\end{array}$ & $\begin{array}{c}\text { Média } \\
\text { de km da } \\
\text { População } \\
\text { de Falhas }\end{array}$ \\
\hline ALFA & 120.103 & 772 & 1 & 8 & 166 & 606 & 9.965 \\
\hline BETA & 47.904 & 304 & 2 & 3 & 51 & 248 & 8.507 \\
\hline GAMA & 51.055 & 175 & 1 & 2 & 12 & 150 & 9.755 \\
\hline DELTA & 52.154 & 282 & 2 & 0 & 48 & 232 & 10.595 \\
\hline
\end{tabular}

A confiabilidade de um sistema ou componente é determinada em um instante de tempo, onde se estará adotando as hipóteses já mencionadas de 20 mil e 25 mil quilômetros para o componente em estudo. Para a obtenção da confiabilidade utilizou-se o distribuição de Weibull e o software Reliability \& Maintenance Analyst.

A figura 38 mostra a curva de confiabilidade correspondente aos dados da bomba de óleo e a figura 39 mostra a confiabilidade calculada nos instantes de tempo de 20 e 25 mil quilômetros. 


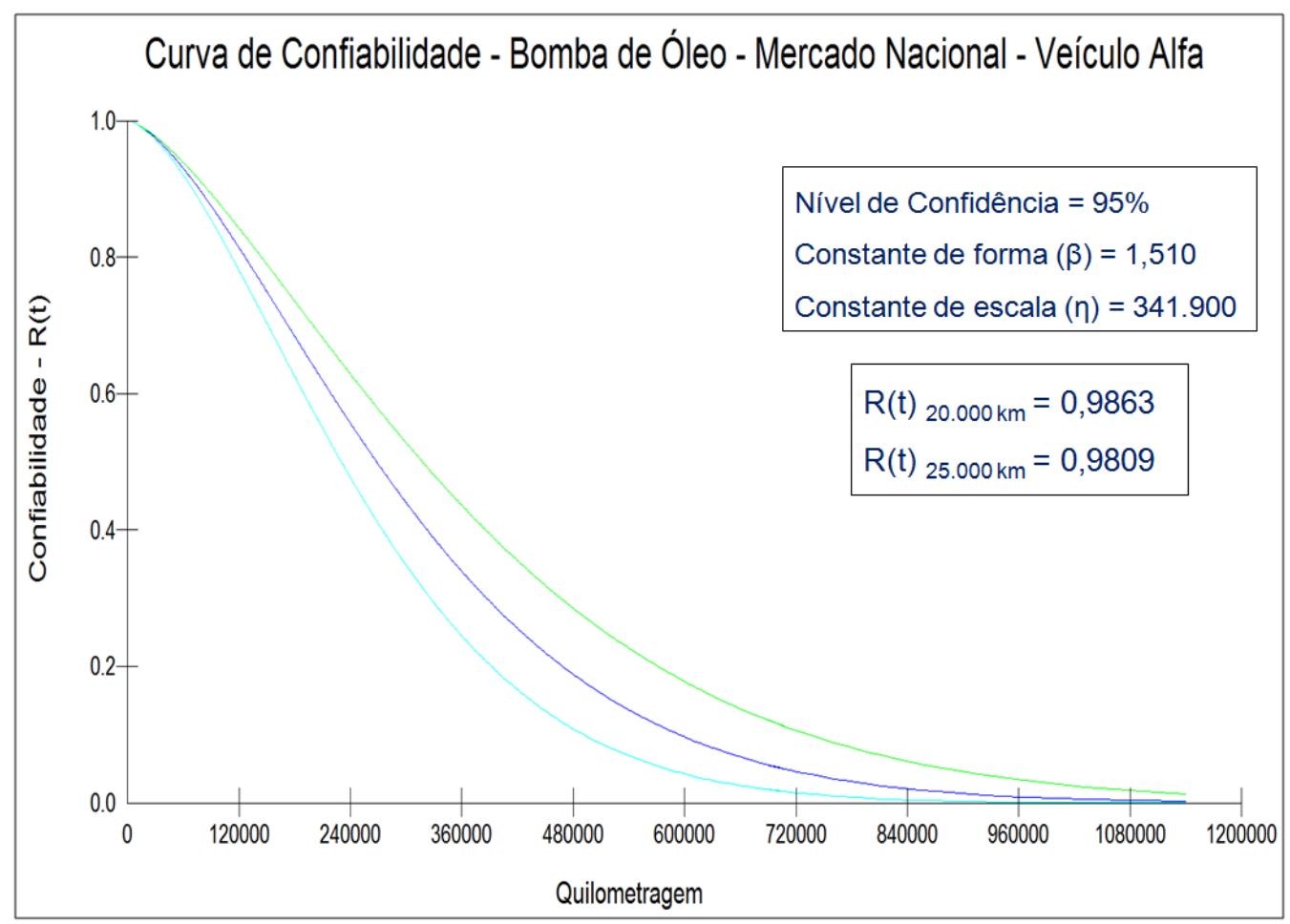

Figura 38 - Curva de Confiabilidade: Bomba de Óleo (fonte: software Reliability \& Maintenance Analyst)

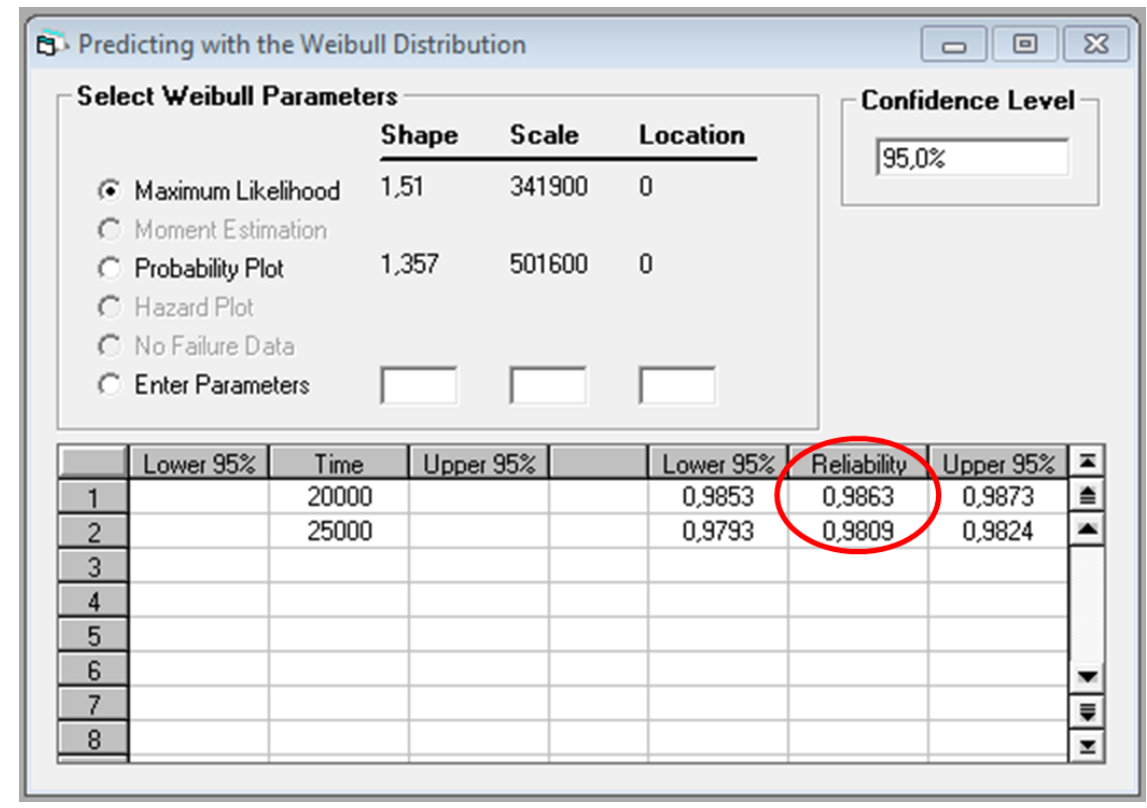

Figura 39 - Confiabilidade: 20 e 25 mil km (fonte: software Reliability \& Maintenance Analyst)

Aplicando- se a mesma metodologia, mas desta vez usando-se os dados censurados do mercado europeu, ou seja, assumindo o comportamento dos clientes europeus, para a mesma incidência de falhas. Conforme Campean (2000) se tem os 
seguintes resultados de confiabilidade comparada com o mercado nacional, conforme mostra a tabela 6.

Tabela 6 - Confiabilidade da Bomba de Óleo: Mercado Nacional vs Europeu

\begin{tabular}{|c|c|c|}
\hline Quilometragem & $\begin{array}{c}\text { Confiabilidade }-\mathrm{R}(\mathrm{t}) \\
\text { Mercado Nacional }\end{array}$ & $\begin{array}{c}\text { Confiabilidade }-\mathrm{R}(\mathrm{t}) \\
\text { Mercado Europeu }\end{array}$ \\
\hline $20.000 \mathrm{~km}$ & 0,9863 & 0,9940 \\
\hline $25.000 \mathrm{~km}$ & 0,9809 & 0,9925 \\
\hline
\end{tabular}

Como uma análise preliminar, pode-se dizer que a confiabilidade do componente em estudo, nos instantes de tempo citados, mostrou melhor resultado no mercado europeu, onde o usuário acumula uma quilometragem maior em seus veículos anualmente. Mas o fato é que aos $17.000 \mathrm{~km}$ se tem $97 \%$ da amostra para o mercado nacional e apenas $74 \%$ para o mercado europeu. Isto equivale dizer que o teste iniciou-se primeiro no mercado nacional e depois no mercado europeu.

Quando se fez a análise de confiabilidade nos pontos de 20.000 e 25.000 km a amostra do mercado nacional já tinha aproximadamente 98,8\% completado estas quilometragens e no mercado europeu apenas $86 \%$. Mas isto ainda não é o suficiente para uma comparação entre o desempenho destes projetos nestes mercados. Para tanto, faz-se necessário o uso do método gráfico de comparações de probabilidades dos dados da amostra e/ou teste de hipótese nos parâmetros de interesse. Fazendo-se a comparação entre projetos, conforme mostrado no item 2.6, o primeiro passo é a comparação gráfica, conforme ilustra a figura 40. 


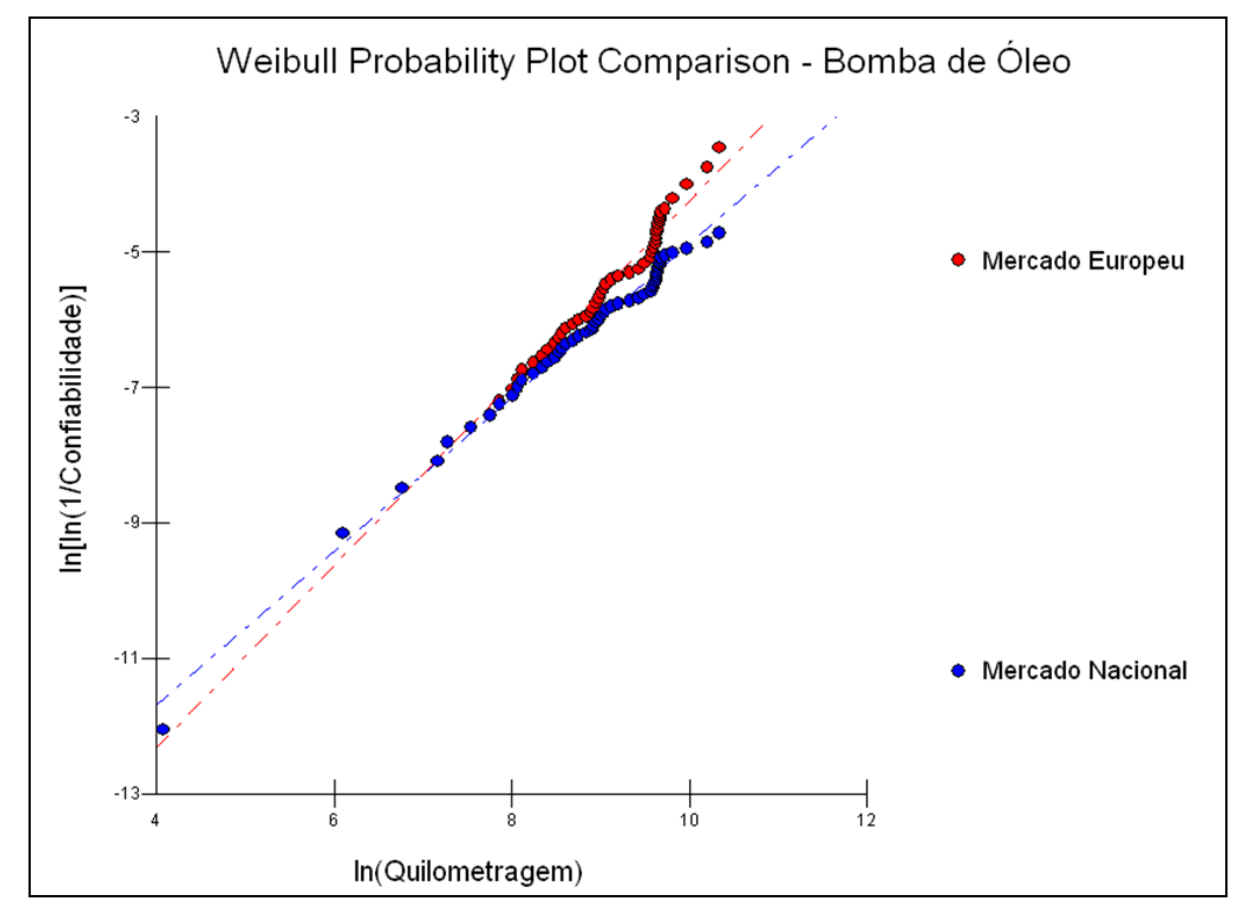

Figura 40 - Comparação Gráfica: Mercado Nacional vs. Europeu (fonte: software Reliability \& Maintenance Analyst)

Como há a interseção entre os dados, faz-se necessário o uso do teste de hipótese conforme mostrado no item 2.6.1

Considere as seguintes hipóteses: $\quad H_{0}: \theta_{1}=\theta_{2} \quad$ e $\quad H_{1}: \theta_{1} \neq \theta_{2}$

Aceitar a hipótese nula $\mathrm{H}_{0}$ é dizer que os projetos são iguais e rejeitá-la é dizer que os projetos são diferentes.

Cálculo de C (constante de dispersão), conforme item 3.10.1, equação (4)

$$
\mathrm{C}=\frac{\sum_{\mathrm{j}=1}^{\mathrm{r}_{2}}\left(x_{2 j}-x_{21}\right)+\left(n_{2}-r_{2}\right)\left(x_{2 r 2}-x_{21}\right)}{\sum_{\mathrm{j}=1}^{\mathrm{r}_{1}}\left(x_{1 j}-x_{11}\right)+\left(n_{1}-r_{1}\right)\left(x_{1 r 1}-x_{11}\right)}=\frac{2020563013}{1109099645}=1,8218
$$

Cálculo de $F_{c}\left(F_{\text {calculado }}\right)$, conforme item 3.10.1, equação (5)

$$
F_{c}=\frac{\left(r_{1}-1\right)}{\left(r_{2}-1\right)} C=1,8218
$$


Conforme equações 7 e 8 se tem:

$\rightarrow$ 1a condição: Rejeitar $\mathrm{H}_{0}$ se $\mathrm{F}_{\text {calculado }}>\mathrm{F}_{\text {tabelado }} \rightarrow \mathrm{F}_{\mathrm{c}}>\mathrm{F}_{\frac{\alpha}{2}}, 2 \mathrm{r}_{2}-2,2 \mathrm{r}_{1}-2$

$\mathrm{F}_{\mathrm{C}}=1,8218>\mathrm{F}_{0,025, \infty, \infty}=1 \rightarrow \mathrm{F}_{\text {calculado }}>\mathrm{F}_{\text {tabelado }} \rightarrow$ Rejeitar $\mathrm{H}_{0}$

ou

$\rightarrow 2^{\text {a }}$ condição: Rejeitar $\mathrm{H}_{0}$ se $\mathrm{F}_{\text {calculado }}<\mathrm{F}_{\text {tabelado }} \rightarrow \mathrm{F}_{\mathrm{c}}<\frac{1}{\mathrm{~F}_{\frac{\alpha}{2}}, 2 \mathrm{r}_{1}-2,2 \mathbf{r}_{2}-2}$

$F_{c}=1,8218<\frac{1}{F_{0,025, \infty, \infty}}=\frac{1}{1}=1 \quad$,neste caso $F_{c}$ não é menor.

Deve-se rejeitar $H_{0}$ quando ocorre qualquer uma das situações acima, portanto, rejeita-se $\mathrm{H}_{0}$, ou seja, pode-se concluir com $95 \%$ de confiança que o desempenho do componente em estudo é diferente nos dois mercados analisados.

\subsubsection{Comparativo de Projetos entre Plataformas de Veículos}

Considerando o mesmo componente (bomba de óleo), compara-se o comportamento dos quatro componentes entre as plataformas de veículos em análise considerando na análise apenas o mercado nacional. Faz-se a coleta dos dados de falha em cada uma das plataformas em análise e em seguida faz-se a comparação gráfica para cada combinação. Na figura 41 mostra-se a comparação gráfica entre do projeto ALFA vs. BETA, a título de exemplo. Os dados utilizados nestas análises estão na tabela 5 , onde para cada veículo se tem a população, as falhas obtidas e os dados censurados conforme mostram as figuras 8 e 9 . 


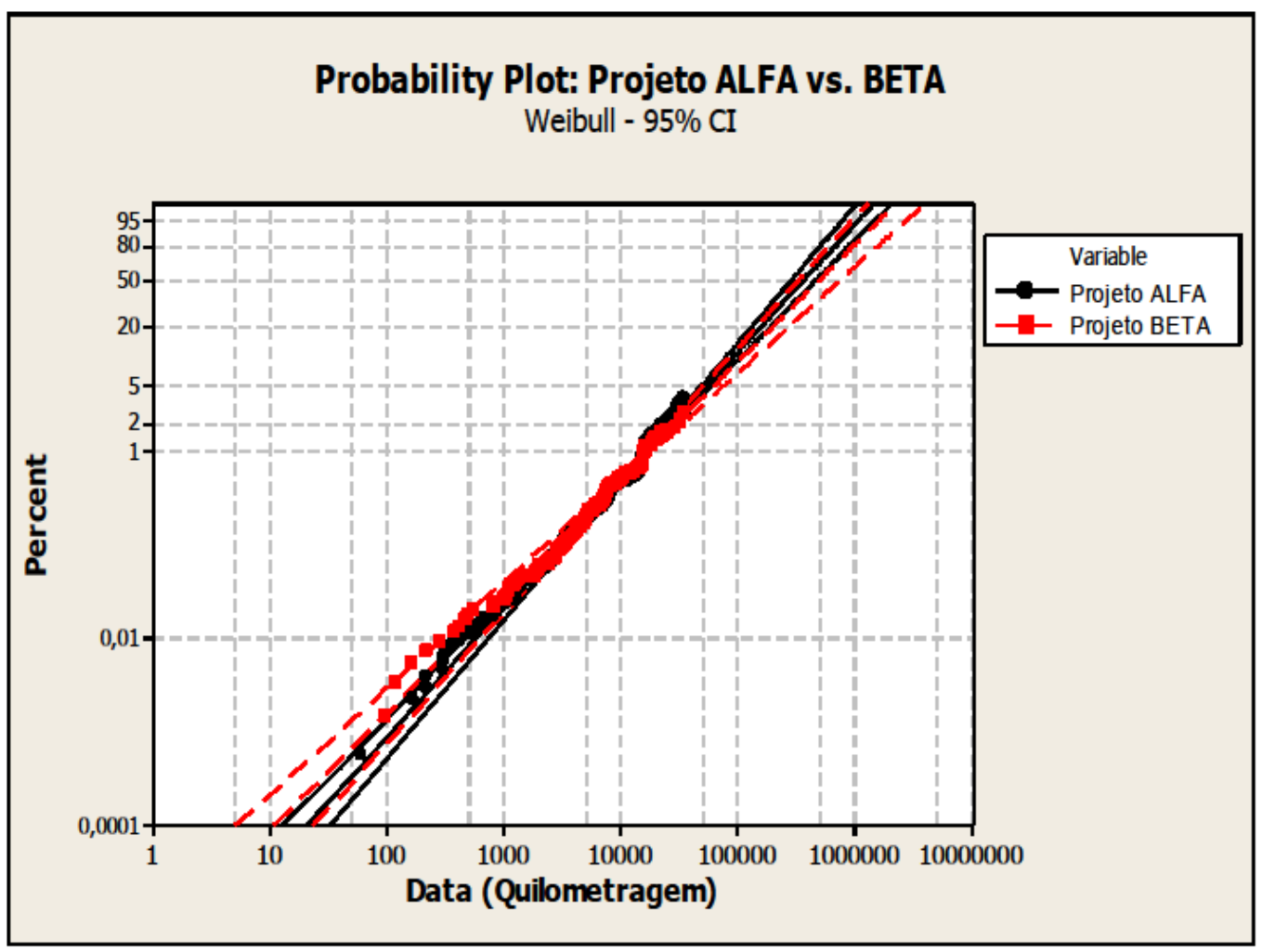

Figura 41 - Comparação Gráfica: Projeto BETA vs. Projeto ALFA

(fonte: software Minitab)

Como há a interseção entre as retas, faz-se necessário o uso do teste de hipótese conforme mostrado no item 2.6.1

Considere as seguintes hipóteses: $\quad H_{0}: \theta_{1}=\theta_{2} \quad$ e $\quad H_{1}: \theta_{1} \neq \theta_{2}$

Aceitar a hipótese nula $\mathrm{H}_{0}$ é dizer que os projetos são semelhantes e rejeitá-la é dizer que os projetos são diferentes.

A figura 42 mostra os cálculos realizados para se obter os valores de Fc, C e os respectivos comparativos das condições das hipóteses feitas. 


\begin{tabular}{|c|}
\hline $\begin{array}{c}\text { Teste de hipótese: Projeto ALFA vs. BETA } \\
\mathrm{C}=\frac{\sum_{\mathrm{j}=1}^{\mathrm{r}_{2}}\left(x_{2 j}-x_{21}\right)+\left(n_{2}-r_{2}\right)\left(x_{2 r 2}-x_{21}\right)}{\sum_{\mathrm{j}=1}^{\mathrm{r}_{1}}\left(x_{1 j}-x_{11}\right)+\left(n_{1}-r_{1}\right)\left(x_{1 r 1}-x_{11}\right)}=\frac{442583946}{1109099645}=0,399\end{array}$ \\
\hline$F_{c}=\frac{\left(r_{1}-1\right)}{\left(r_{2}-1\right)} C=\frac{(608-1)}{(248-1)} \times 0,399=0,9807$ \\
\hline $\begin{array}{l}\text { 19 Condição: Rejeitar } \mathrm{H}_{0} \text { se: } \mathrm{F}_{\text {calculado }}>\mathrm{F}_{\text {tabelado }} \\
\qquad \begin{array}{r}\mathrm{F}_{\mathrm{c}}>\mathrm{F}_{\frac{\alpha}{2}}, 2 \mathrm{r}_{2}-2,2 \mathrm{r}_{1}-2 \Rightarrow \\
\quad \mathrm{F}_{\mathrm{C}}=0,9807>\mathrm{F}_{0,025 ; \infty ; \infty}=1 \\
\therefore \mathrm{F}_{\text {calculado }}<\mathrm{F}_{\text {tabelado }} \rightarrow \text { Aceitar } \mathrm{H}_{0}\end{array}\end{array}$ \\
\hline $\begin{array}{l}\text { 2a Condição: Rejeitar } \mathrm{H}_{0} \text { se: } \mathrm{F}_{\text {calculado }}<\mathrm{F}_{\text {tabelado }} \\
\qquad \begin{aligned} \mathrm{F}_{\mathrm{c}}<\frac{1}{\mathrm{~F}_{\frac{\alpha}{2}}, 2 \mathrm{r}_{1}-2,2 \mathrm{r}_{2}-2} \Rightarrow & \mathrm{F}_{\mathrm{C}}=0,9807\left\langle\frac{1}{\mathrm{~F}_{0,025 ; \infty ; \infty}}=1\right. \\
\therefore \mathrm{F}_{\text {calculado }}<\mathrm{F}_{\text {tabelado }} \rightarrow \text { Rejeitar } \mathrm{H}_{0} & =1\end{aligned}\end{array}$ \\
\hline
\end{tabular}

Figura 42 - Comparativo: Projeto ALFA vs. Projeto BETA

Assim sendo, nestas duas condições testadas rejeita-se $\mathrm{H}_{0}$, ou seja, pode-se concluir com $95 \%$ de confiança que o desempenho da bomba de óleo nos veículos ALFA e BETA são diferentes.

Sendo o desempenho dos projetos diferentes pode-se compará-los nos instantes de tempo citados de 20 e 25 mil quilometros, conforme ilustra a tabela 7.

Tabela 7 - Confiabilidade da Bomba de Óleo: Projeto ALFA e Projeto BETA

\begin{tabular}{|c|c|c|}
\hline Quilometragem & Projeto ALFA & Projeto BETA \\
\hline $\mathbf{2 0 . 0 0 0} \mathbf{~ k m}$ & 0,9863 & 0,9871 \\
\hline $\mathbf{2 5 . 0 0 0} \mathbf{~ k m}$ & 0,9809 & 0,9827 \\
\hline
\end{tabular}

Ainda pode-se dizer que 0 projeto BETA possui um desempenho relativamente melhor nos instantes de tempo utilizados neste estudo. 
Usando a mesma metodologia, foram feitas as comparações gráficas e os cálculos de teste de hipótese para as quatro plataformas de veículos em estudo. Os Anexos 2, 3, 4, 5 e 6 mostram os gráficos comparativos entre os projetos e os testes de hipóteses feitos para cada um deles. A tabela 8 mostra os resultados das comparações entre os projetos.

Tabela 8 - Comparativo entre os projetos - Bomba de Óleo

\begin{tabular}{|c|c|c|c|c|c|}
\hline $\begin{array}{c}\text { Projeto } \\
\text { ALFA vs. BETA }\end{array}$ & $\begin{array}{c}\text { Projeto } \\
\text { ALFA vs. GAMA }\end{array}$ & $\begin{array}{c}\text { Projeto } \\
\text { ALFA vs. DELTA }\end{array}$ & $\begin{array}{c}\text { Projeto } \\
\text { BETA vs. GAMA }\end{array}$ & $\begin{array}{c}\text { Projeto } \\
\text { BETA vs. DELTA }\end{array}$ & $\begin{array}{c}\text { Projeto } \\
\text { DELTA vs. GAMA }\end{array}$ \\
\hline Rejeitar & Rejeitar & Rejeitar & Rejeitar & Rejeitar & Rejeitar \\
Projetos & Projetos & Projetos & Projetos & Projetos & Projetos \\
Diferentes & Diferentes & Diferentes & Diferentes & Diferentes & Diferentes \\
\hline
\end{tabular}

Conforme a tabela 8 , todos os projetos analisados são diferentes entre si, restou agora à comparação entre projetos quanto ao desempenho nos instantes de tempo citados anteriormente, conforme ilustra a figura 43.

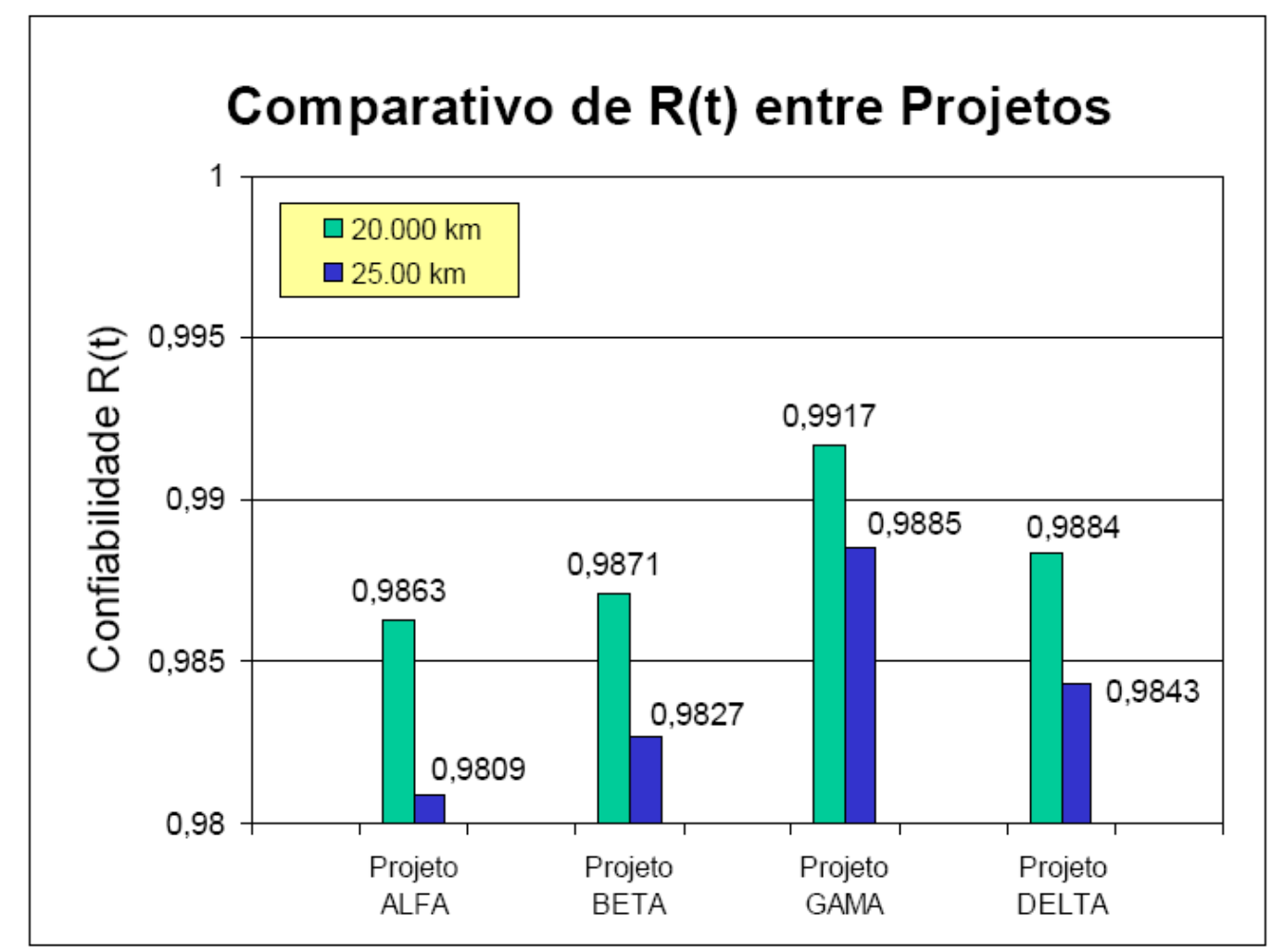

Figura 43 - Comparação Gráfica de R(t) entre Projetos 
Nesta forma gráfica é fácil observar que o projeto GAMA possui o melhor desempenho entre eles. Lembrando que no instante de tempo 25 mil quilômetros, $98,8 \%$ da amostra já completaram esta quilometragem.

Para a proposta deste estudo foram escolhidas quatro plataformas de veículos do mesmo segmento, considerados como veículos populares. Estes veículos possuem bombas de óleo semelhantes e até possuem alguns componentes internos iguais. Mas isto não justifica tal diferença de desempenho encontrado entre estes componentes. Quanto a suas fixações no motor, são robustas e não são a causa raiz de nenhum dos modos de falhas encontrados. Quando se analisou os componentes fisicamente, não foram encontradas diferenças de material entre os componentes falhados, porém foi observada a existência de dois fornecedores distintos e ambos importados, aqui denominados de fornecedores A e B apenas, sendo o fornecedor A o que apresentou melhor desempenho.

Quando se analisou o custo destes componentes, observou-se uma diferença de preço entre eles de $40 \%$. Sendo que o de maior custo é o que apresentou melhor desempenho (fornecedor A), que é usado no veículo GAMA, evidenciando a qualidade superior e o recomendado para uso em novos desenvolvimentos.

\subsection{Análise de Risco: Sistema de Freio}

Normalmente, durante o período de garantia, os tipos mais comuns de falhas que ocorrem nestes sistemas são o desgaste das pastilhas de freio, ajustes, disco ou tambores de freio com desgaste excessivo ou mesmo ajustes em geral quanto a ruído. Em geral é um sistema altamente confiável e raramente oferece risco ao condutor do veículo durante uma frenagem. A figura 44 ilustra de forma simplificada os principais componentes do sistema de freio automotivo.

O item 2.4 mostrou a Metodologia de Avaliação de Risco, neste momento estar-se-á aplicando esta metodologia para a análise do Sistema de Freio. O veículo a ser utilizado nesta análise será o Delta, devido à facilidade de visita até a linha de montagem, os dados extraídos do sistema de garantia são:

- População: 52.204 veículos

- Total de falhas observadas em garantia: 343 (para o sistema de freio)

- Média de quilometragem dos veículos falhados: $11.473 \mathrm{~km}$ 
O objetivo desta análise é identificar pontos que podem comprometer a segurança do veículo, ou seja, a perda da capacidade de frenagem.

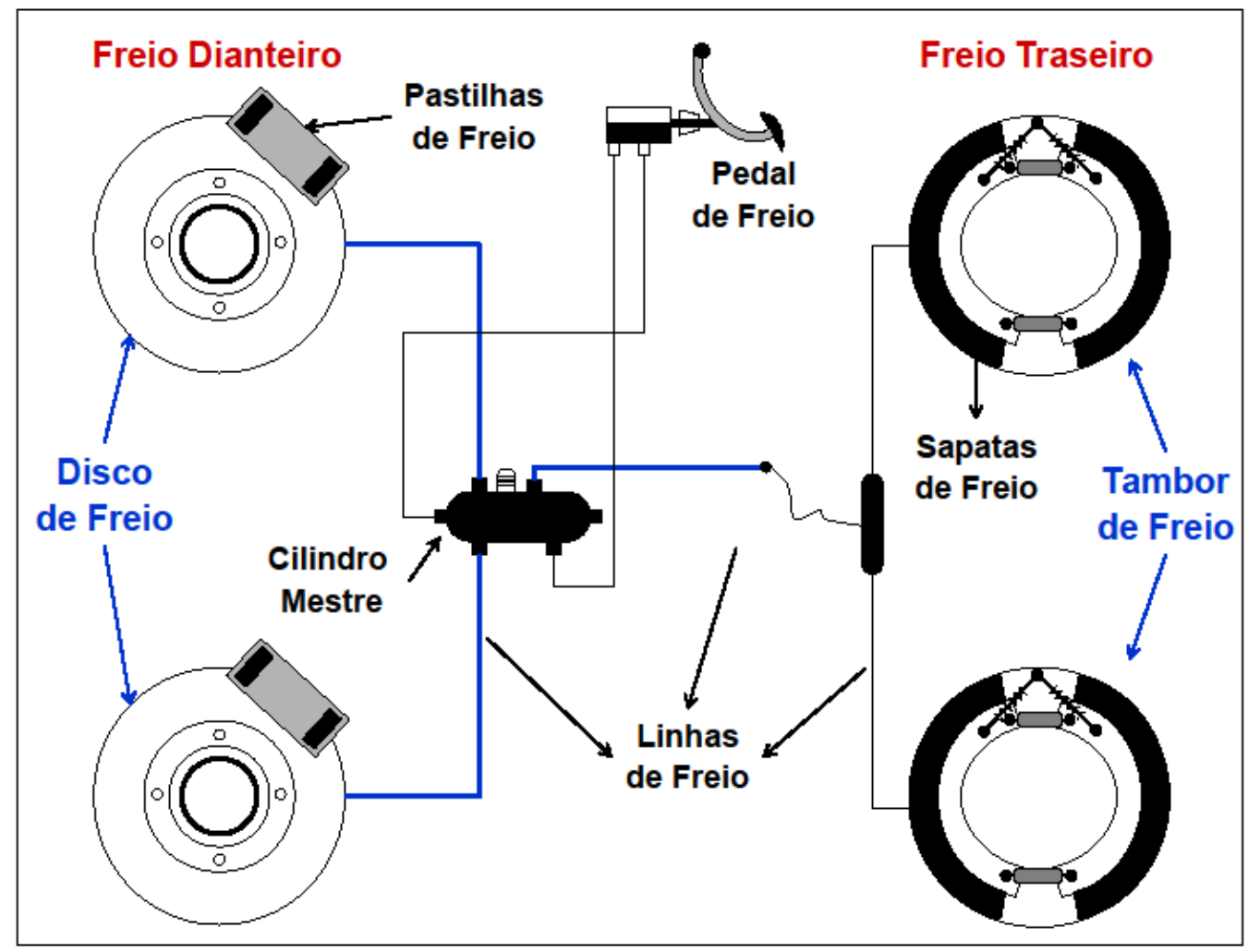

Figura 44 - Esquema do Sistema de Freio para a Análise de Risco.

Os componentes a serem considerados nesta análise, e mostrados na figura 44, são:
a) Conjunto Cilindro Mestre;
b) Disco de Freio;
c) Pastilhas de Freio;
d) Tambor de Freio;
e) Sapatas de Freio;
f) Pedal de Freio;
g) Linhas de Freio;
h) Máquina de Enchimento.

Através do banco de dados, observou-se que para o sistema de freio durante o período de garantia de 12 meses ocorreram falhas nos componentes, conforme mostra a tabela 9. 
Tabela 9 - Falhas do Sistema de Freio no Período de Garantia.

\begin{tabular}{|lc|}
\hline Item & Casos \\
\hline Disco de freio & 181 \\
\hline Cabo do freio de estacionamento & 38 \\
\hline Sapata de freio & 34 \\
\hline Pastilhas de freio & 31 \\
\hline Mola de retenção - freio traseiro & 30 \\
\hline Tambor de freio & 25 \\
\hline Pedal de freio & 4 \\
\hline
\end{tabular}

\subsubsection{Sistema de Freio: Modos de Falha e Hipóteses de Análise}

Para cada um dos componentes citados na tabela 9, fez-se uma nova análise ao banco de dados e foram observados vários modos de falha, conforme ilustram as figuras 45 e 46 . Ao se analisar o modo de falhas observou-se que apenas uma parte deles poderá causar a perda de freio durante uma frenagem de emergência.
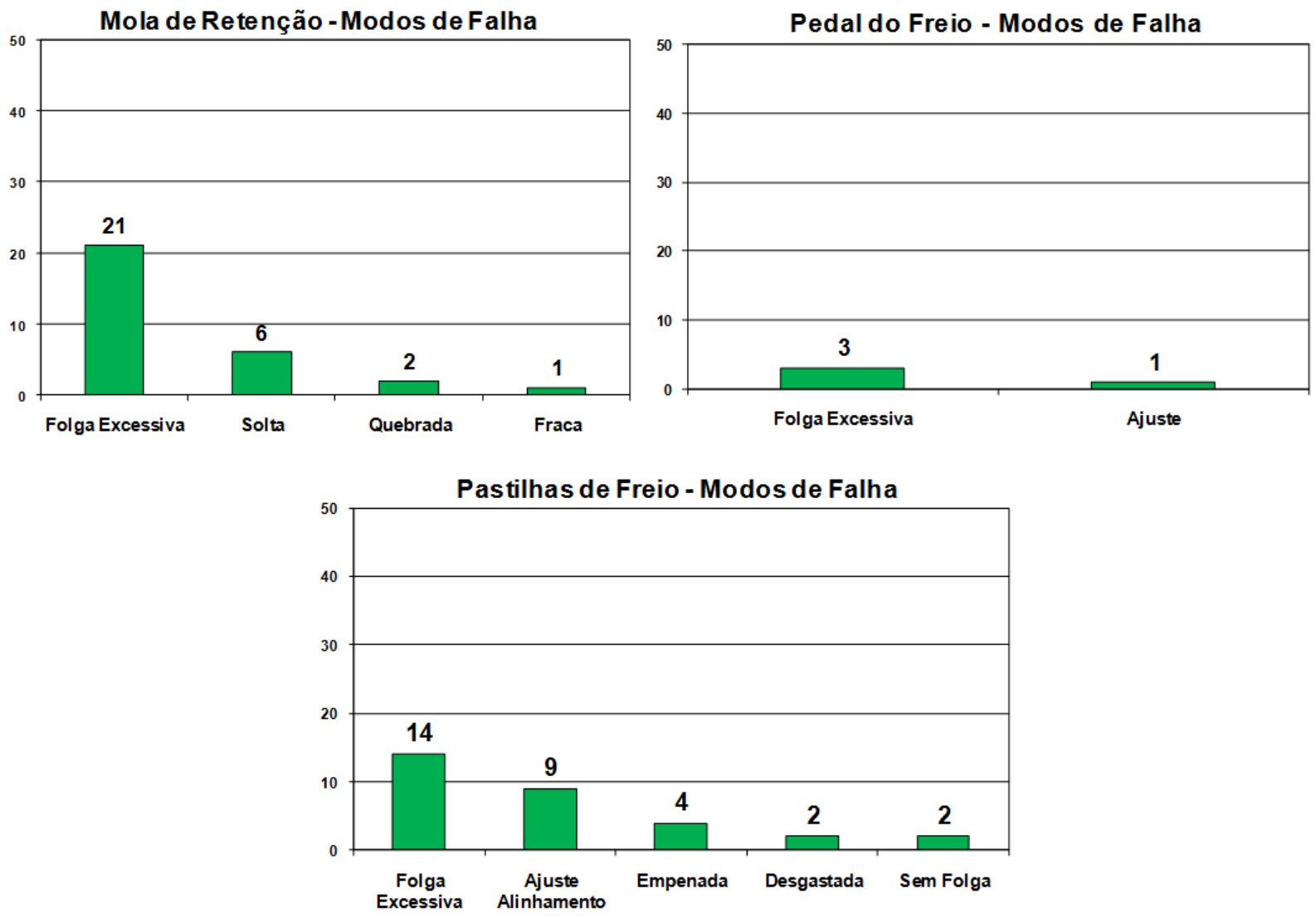

Figura 45 - Modos de Falha: Mola, Pedal e Pastilhas de Freio 

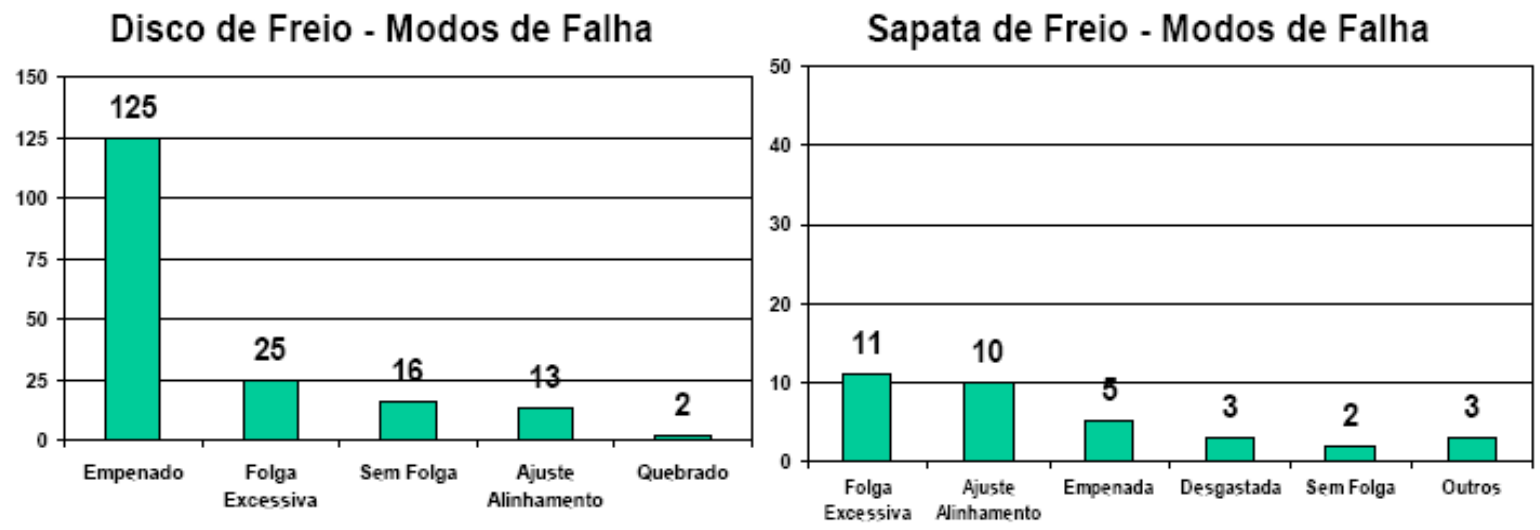

Tambor de Freio - Modos de Falha



Figura 46 - Modos de Falha: Disco, Sapata e Tambor de Freio.

Assim, para este estudo consideram-se somente os seguintes modos de falha com potencial de deterioração do sistema de freio:

$\rightarrow$ Empenado, Sem Folga, Quebrado e Solto.

Esta hipótese se faz necessária, pois não serão considerados os outros modos de falha que não comprometem a integridade do sistema, assim estes modos de falha não estarão no cálculo da confiabilidade de cada um destes componentes.

Os principais perigos que tem como consequência a perda de desempenho de frenagem em um sistema de freio podem ser listados como:

a) perda do fluido de freio;

b) pastilhas e/ou sapatas de freio gastas excessivamente;

c) cilindro mestre com vazamentos;

d) disco e/ou tambor empenados ou gastos excessivamente. 
Estas serão as principais falhas consideradas na árvore de falhas. A partir destes cenários de falha podem-se propor melhorias no produto e na manutenção de equipamentos do processo de montagem.

Através do banco de dados pode-se determinar a confiabilidade dos componentes falhados em campo durante a garantia do veículo e assim calcular sua probabilidade de falha através da seguinte relação:

$$
\mathrm{P} \text { (falha até o instante " } \mathrm{t} \text { ") }=1-\mathrm{R}(\mathrm{t})
$$

Onde:

$\mathrm{p}_{\text {(falha até } \mathrm{o} \text { instante }} \mathrm{t}$ ") $=$ probabilidade de falha;

$R(t)=$ confiabilidade (determinada através dos dados de garantia).

Para se determinar a probabilidade de falha dos componentes listados da tabela 9, foram obtidas as quilometragens de falha de cada um deles e como dados censurados foram utilizados os valores mostrados na figura 8 , considerando agora somente o mercado nacional.

Com estas informações dos dados de falha de cada componente mais os dados censurados pode-se agora determinar a confiabilidade de cada um dos componentes em estudo.

A confiabilidade de um sistema é determinada em um instante de tempo, onde se estará adotando as hipóteses já mencionadas de 20 mil e 25 mil quilometros para cada um dos componentes em estudo. Para a obtenção da confiabilidade, utilizou-se o software Reliability \& Maintenance Analyst e a distribuição de Weibull.

As curvas de confiabilidade mostradas nas figuras 47 e 48 ilustram o modo como foram determinadas as confiabilidades de dois componentes o disco/tambor $\mathrm{e}$ a sapata/pastilha de freio. Estas curvas foram determinadas a partir dos dados de falha de cada um dos componentes mais os dados censurados. Com isto, obtiveramse as confiabilidades nos instantes de tempo citados acima. 


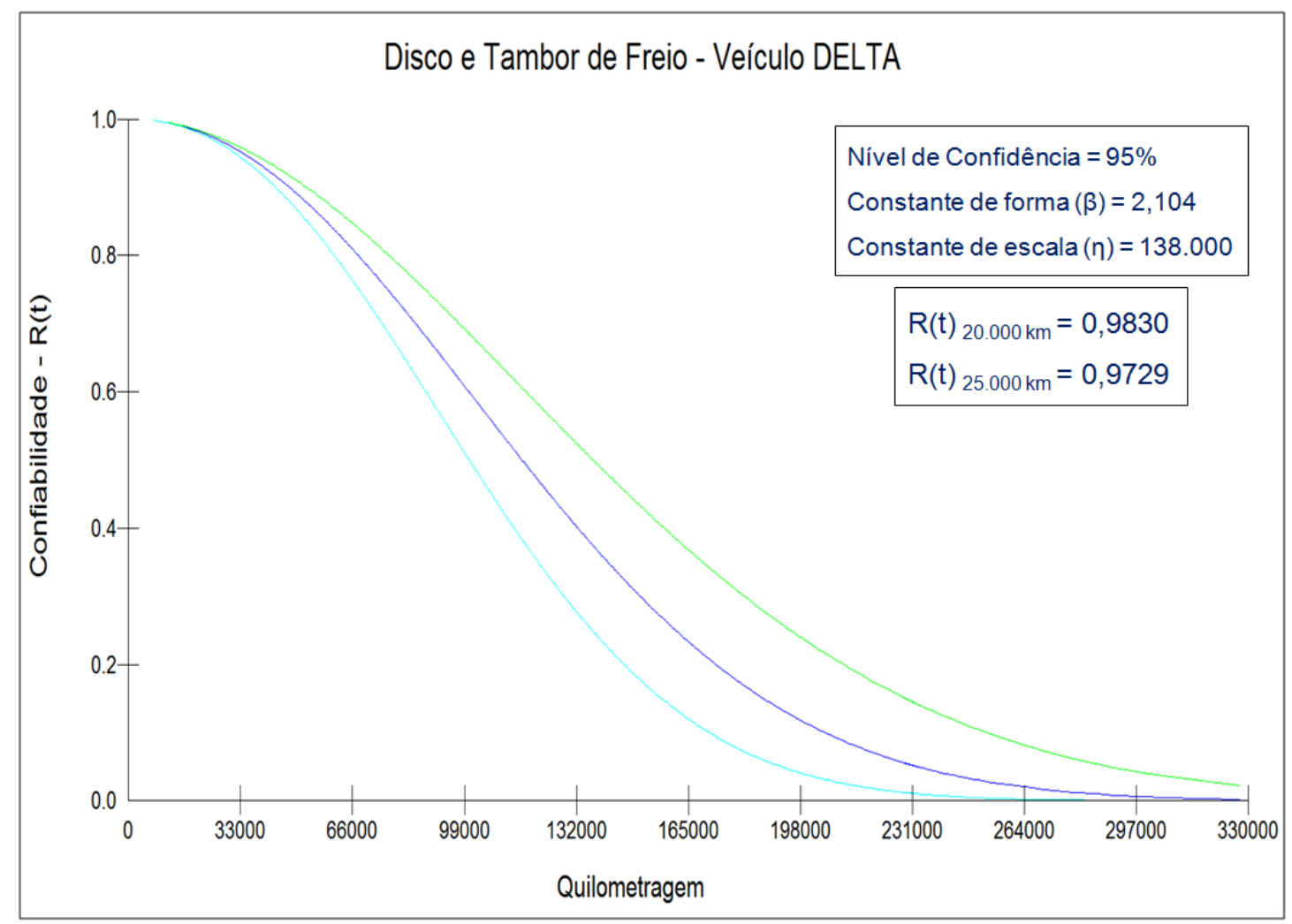

Figura 47 - Curva de Confiabilidade Disco e Tambor: Veículo DELTA (fonte: software Reliability \& Maintenance Analyst)

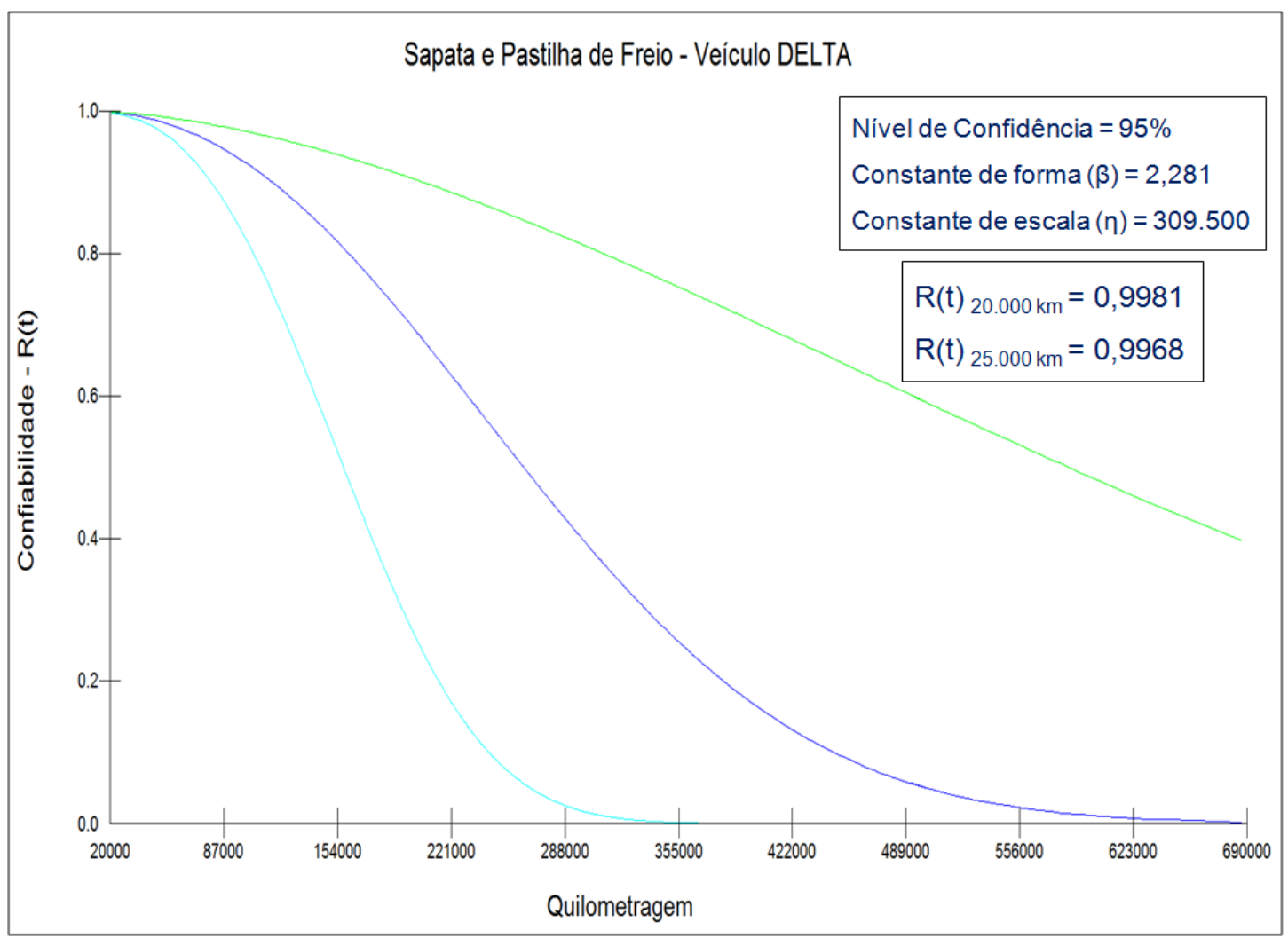

Figura 48 - Curva de Confiabilidade Sapata e Pastilha: Veículo DELTA (fonte: software Reliability \& Maintenance Analyst) 
As tabelas 10 e 11 mostram os resultados finais das confiabilidades dos componentes falhados e assumindo a quilometragem média anual de 20.000 e $25.000 \mathrm{~km}$ durante o período de garantia.

Tabela 10 - Confiabilidade e Probabilidade de Falha $(20.000$ km).

\begin{tabular}{|lcc|}
\hline Item & Confiabilidade $-\mathbf{R}(\mathbf{t})$ & $\begin{array}{c}\text { Probabilidade } \\
\mathbf{p}_{\text {(falha) }}\end{array}$ \\
\hline Conjunto Cilindro Mestre & 1 & 0 \\
\hline Disco e Tambor de Freio & 0.9830 & 0,0170 \\
\hline Sapata e Pastilha de Freio & 0,9981 & 0,0019 \\
\hline Pedal de Freio & 1 & 0 \\
\hline Mola do Tambor de Freio & 0,9992 & 0,0008 \\
\hline Linha de Freio & 1 & 0 \\
\hline Máquina de Enchimento & 0,9995 & $1 / 2000$ \\
\hline
\end{tabular}

Tabela 11 - Confiabilidade e Probabilidade de Falha $(25.000$ km).

\begin{tabular}{|lcc|}
\hline Item & Confiabilidade $-\mathbf{R}(\mathbf{t})$ & $\begin{array}{c}\text { Probabilidade } \\
\mathbf{p}_{\text {(falha) }}\end{array}$ \\
\hline Conjunto Cilindro Mestre & 1 & 0 \\
\hline Disco e Tambor de Freio & 0,9729 & 0,0271 \\
\hline Sapata e Pastilha de Freio & 0,9968 & 0,0032 \\
\hline Pedal de Freio & 1 & 0 \\
\hline Mola do Tambor de Freio & 0,9987 & 0,0013 \\
\hline Linha de Freio & 1 & 0 \\
\hline Máquina de Enchimento & 0,9995 & $1 / 2000$ \\
\hline
\end{tabular}

A máquina de enchimento é altamente confiável, mas apresentou um índice médio de falha de enchimento de uma falha a cada 2000 unidades montadas. Os itens com confiabilidade igual a 1, simplesmente não apresentaram falhas durante 0 período de garantia, assim, sua probabilidade de falha é de zero para o período de garantia de 12 meses. 
Embora, o conjunto cilindro mestre não tenha apresentado nenhuma falha de campo, foram detectadas falhas de vazamento na própria linha de montagem. Os valores de probabilidade de falha deste componente são calculados a partir destes dados e serão usados na solução da árvore de falhas.

\subsubsection{Sistema de Freio: Solução da Árvore de Falhas}

A próxima etapa da análise é a solução da árvore de falhas para o sistema de freio, tendo como evento principal: Freio falha ao parar veículo, conforme ilustram as figuras 49 e 50. Estas figuras representam o mesmo evento principal e foram divididas em duas partes para melhorar representação gráfica. Não se esta considerando nesta análise pistas molhadas ou cobertas de gelo ou ainda o efeito de pneus excessivamente gastos, que também exercem papel fundamental durante uma frenagem.

Os níveis mais baixos da árvore de análise de falhas terminam com o símbolo do diamante ou com o símbolo do círculo. O diamante mostra que a árvore de falhas pode continuar a partir deste evento, mas a sua continuidade não é considerada para a presente análise, ou mostrar a não existência de dados para continuar a análise a partir deste ponto. O círculo indica um evento básico durante a análise, que não pode ser decomposto a um nível mais baixo, estes são os eventos mais baixos na árvore de falhas que se pode obter. 


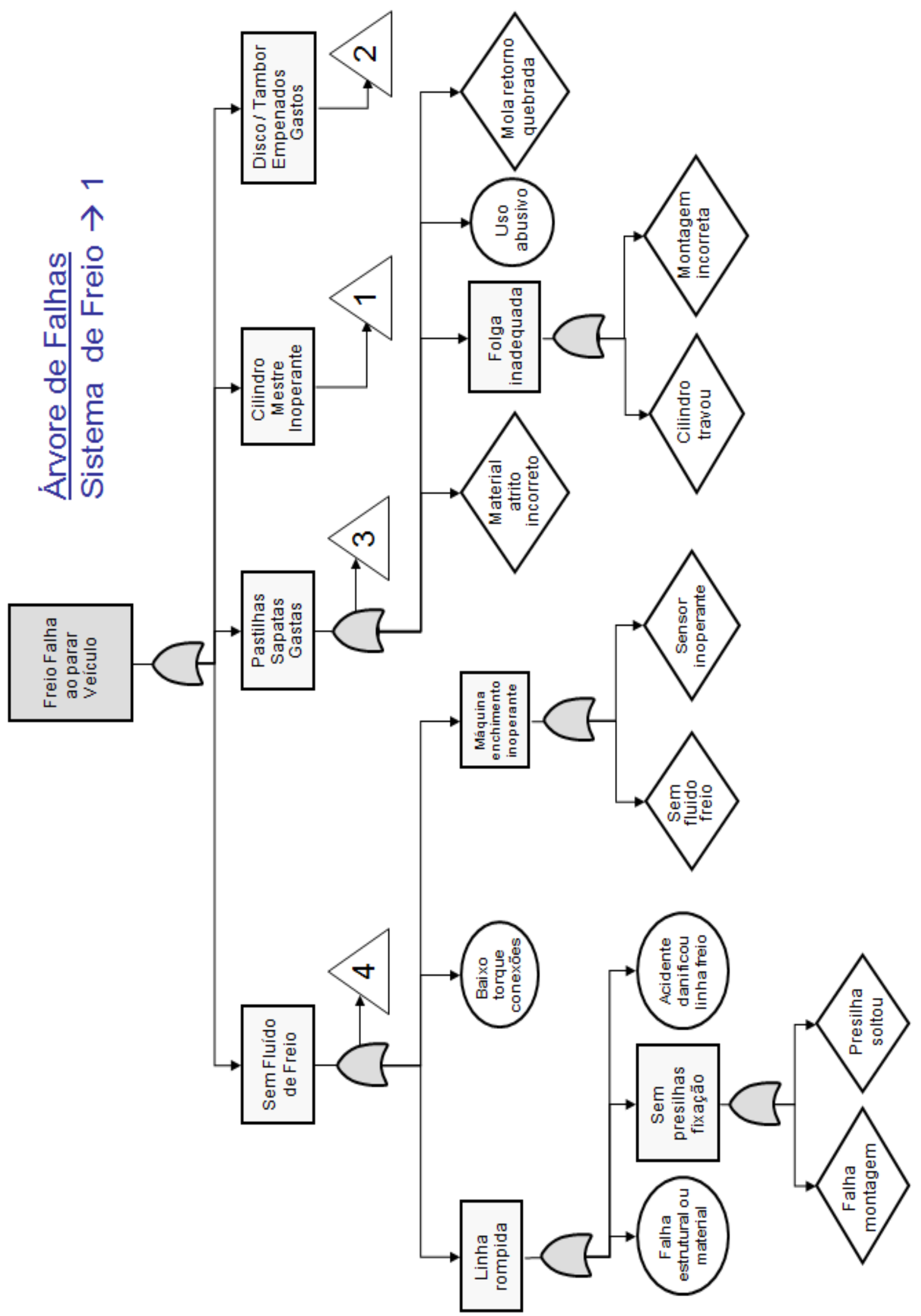

Figura 49 - Árvore de Falhas: Sistema de Freio - 1 (continuação) 


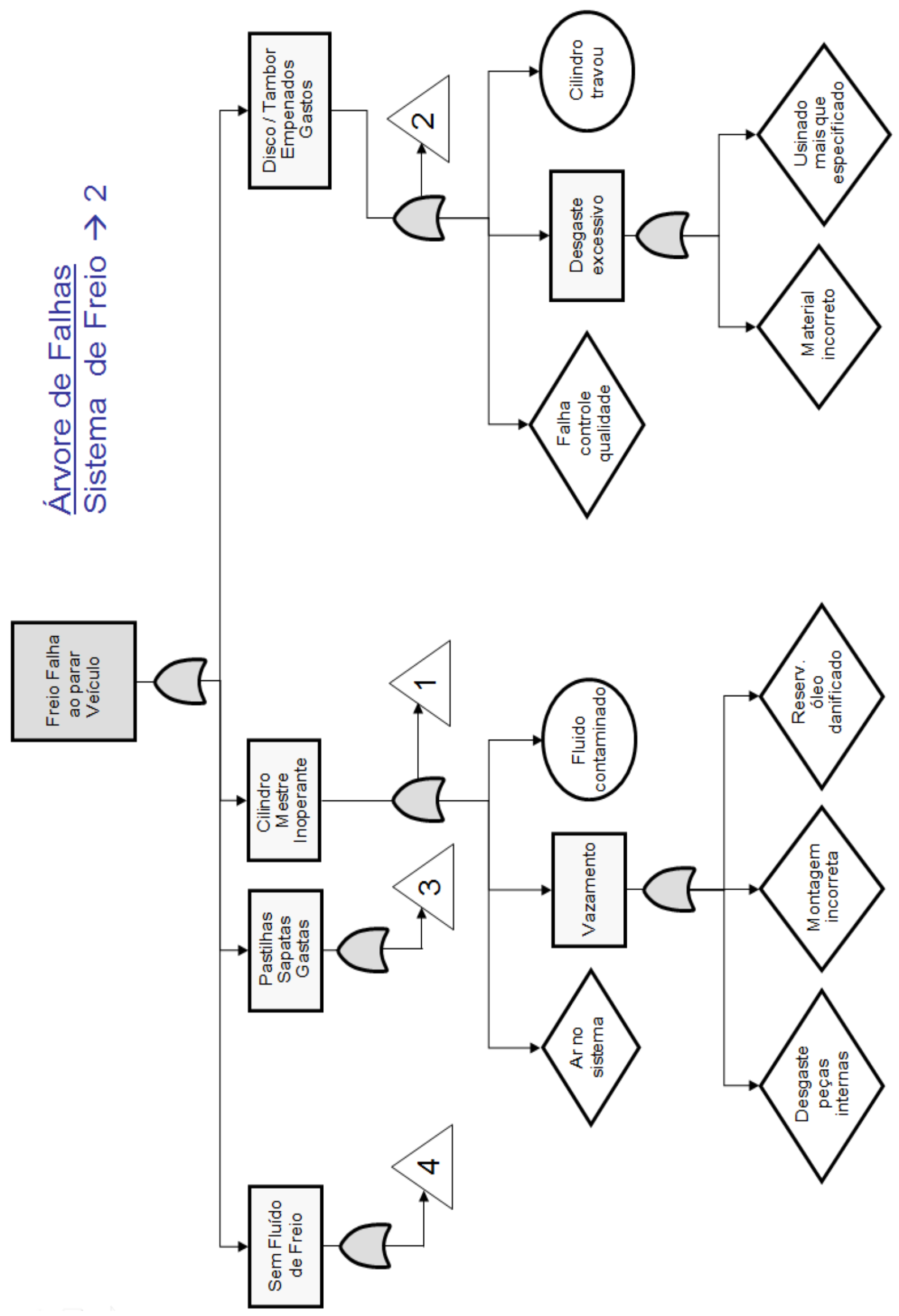

Figura 50 - Árvore de Falhas: Sistema de Freio - 2 (final) 
A solução da árvore de falhas pode ser feita pela Avaliação Probabilística da Árvore de Falhas ou pela Lógica Booleanana. A avaliação probabilística da árvore de falhas é feita quando se conhece a probabilidade de ocorrência de um evento básico. A probabilidade de ocorrência do evento principal pode ser calculada através dos portões lógicos “E” e "OU”. O resultado de tal análise é obtido da seguinte forma:

1) Portão "E": a probabilidade de ocorrência de um portão "E" de um evento $E_{0}$ é dado pela seguinte equação:

$$
P\left(E_{0}\right)=\prod_{i=0}^{n} P\left(E_{i}\right)
$$

Onde:

$P\left(E_{0}\right)=$ probabilidade de ocorrência de um portão $\mathbf{E}$ de um evento $E_{0}$.

$P\left(E_{i}\right)=$ probabilidade de ocorrência de um evento na árvore de falha, $i=1,2,3, \ldots, n$; considerados eventos independentes.

2) Portão "OU": a probabilidade de ocorrência de um portão "OU" de um evento $X_{0}$ é dado pela seguinte equação:

$$
P\left(X_{0}\right)=1-\prod_{i=0}^{k}\left\{1-P\left(X_{i}\right)\right\}
$$

Onde:

$P\left(X_{0}\right)=$ probabilidade de ocorrência de um portão OU de um evento $\mathrm{X}_{0}$.

$P\left(X_{i}\right)=$ probabilidade de ocorrência de um evento na árvore de falha, $i=1,2,3, \ldots, k$; considerados eventos independentes.

Como já se sabe a probabilidade de falha das Pastilhas/Sapatas e Disco/Tambor (calculadas através dos dados de campo) não é necessário solucionar esta parte da árvore de falhas. Assim, deve-se calcular separadamente somente o ramo "Sem Fluido de Freio", com os dados de falha obtidos na planta durante a montagem dos veículos e com os dados de registros de manutenção da máquina de enchimento. 
A figura 51 mostra o ramo da árvore de falhas "Sem Fluido de Freio" com as devidas nomenclaturas para o cálculo de probabilidade.

Os dados foram obtidos através de relatórios internos da qualidade da planta e de manutenção de equipamentos, onde se mostra a probabilidade de falhas observadas durante a produção do veículo, assim, torna-se possível calcular o evento principal da árvore de falhas conforme mencionado.

\section{Evento}

1. Falha de montagem

2. Presilha solta

3. Falha estrutural do material

4. Acidente danificou linha de freio

5. Sem fluido de freio

6. Sensor inoperante

7. Torque baixo nas conexões

\section{Probabilidade Evento}

\section{de Ocorrência}

$\rightarrow \quad 0,006 \quad \rightarrow E_{1}$

$\rightarrow \quad 0,006 \quad \rightarrow E_{2}$

$\rightarrow \quad 0 \quad \rightarrow \mathrm{E}_{3}$

$\rightarrow \quad 0,0002 \quad \rightarrow E_{5}$

$\rightarrow \quad 0 \quad \rightarrow \mathrm{E}_{6}$

$\rightarrow \quad 0,0005 \quad \rightarrow E_{7}$

$\rightarrow \quad 0,001 \quad \rightarrow E_{9}$

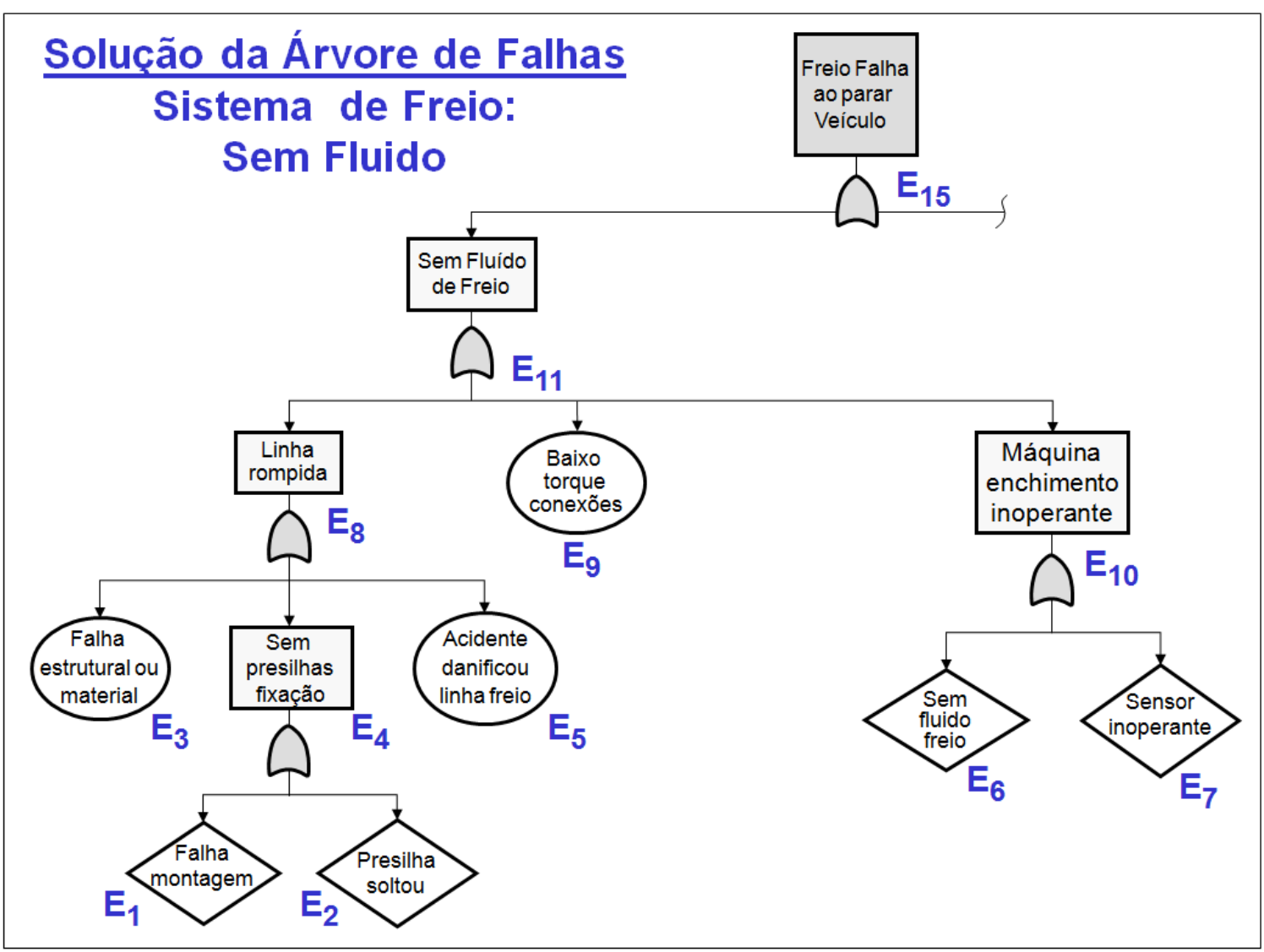

Figura 51 - Árvore de falhas - Ramo: "Sem Fluido de Freio". 
A probabilidade de ocorrência do evento $E_{11}$ é:

$P\left(E_{4}\right)=1-\left[1-P\left(E_{1}\right)\right] \cdot\left[1-P\left(E_{2}\right)\right]=1-[1-0,006] \cdot[1-0,0,006]=0,0120$

$P\left(E_{8}\right)=1-\left[1-P\left(E_{3}\right)\right] \cdot\left[1-P\left(E_{4}\right)\right] \cdot\left[1-P\left(E_{5}\right)\right]=1-[1-0] \cdot[1-0,012] \cdot[1-0,0002]=0,0122$

$P\left(E_{10}\right)=1-[1-P(E 6)] \cdot[1-P(E 7)]=1-[1-0] \cdot[1-0,0005]=0,0005$

$P\left(E_{11}\right)=1-\left[1-P\left(E_{8}\right)\right] \cdot\left[1-P\left(E_{9}\right)\right] \cdot\left[1-P\left(E_{10}\right)\right]=1-[1-0,0122] \cdot[1-0,001] \cdot[1-0,0005]=0,0137$

Com estes resultados pode-se agora determinar a probabilidade de ocorrência do evento principal. A figura 52 mostra a árvore de falhas com os eventos que podem conduzir ao evento principal. Para a solução deste ramo da árvore de falhas, devem-se considerar as seguintes probabilidades de ocorrência de falha para a primeira hipótese de $20.000 \mathrm{~km}$ :

$\rightarrow$ Quilometragem média anual de $20.000 \mathrm{~km}$ :

Evento

1. Sem Fluido de Freio

2. Pastilhas / Sapatas

3. Cilindro Mestre

4. Disco / Tambor
Probabilidade de Ocorrência

$\rightarrow \quad 0,0137$

$\rightarrow \quad 0,0019$

$\rightarrow \quad 0$

$\rightarrow \quad 0,017$

\section{Evento}

$\rightarrow \mathrm{E}_{11}$

$\rightarrow \mathrm{E}_{12}$

$\rightarrow \mathrm{E}_{13}$

$\rightarrow \mathrm{E}_{14}$

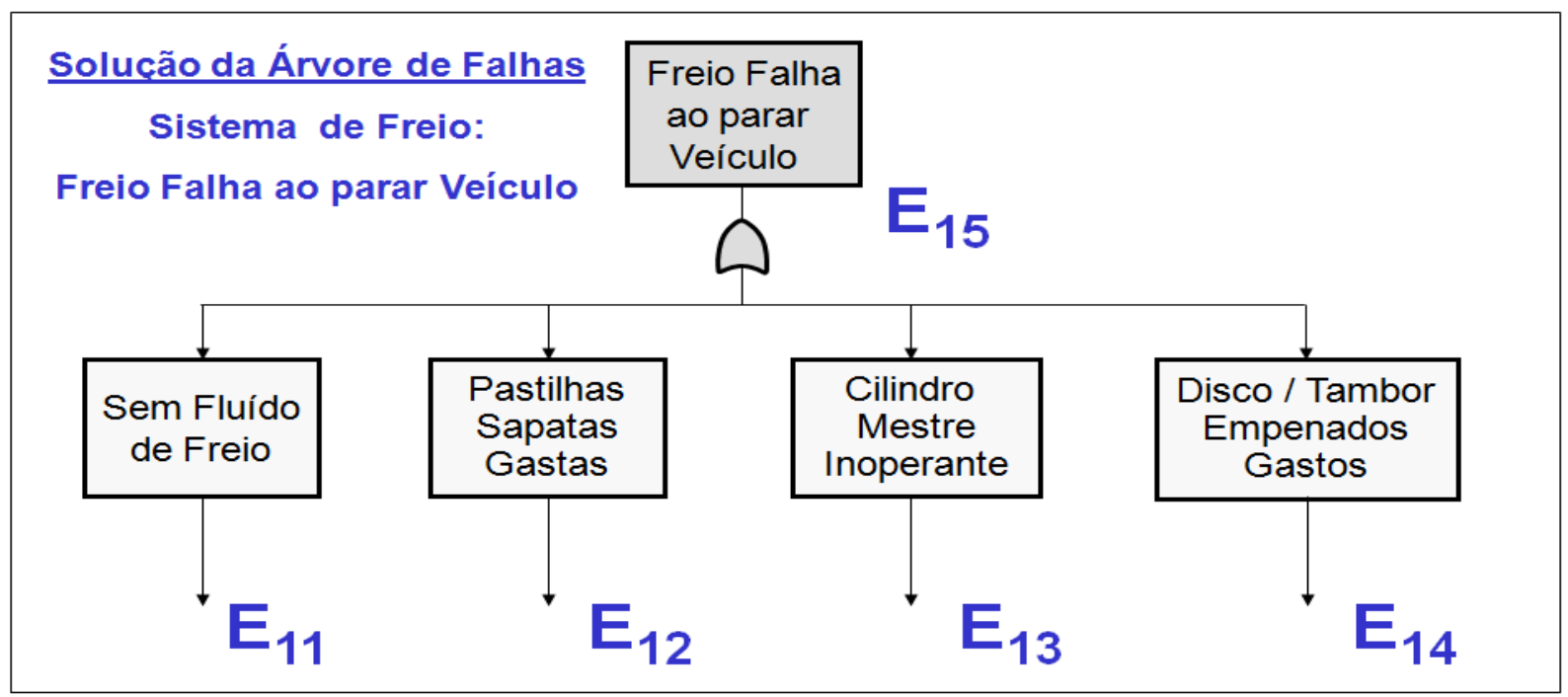

Figura 52 - Árvore de falhas - Solução dos Ramos Principais. 
Lembrado que as probabilidades de falha referentes às Pastilhas, Sapatas e Disco de Freio, Tambor de Freio foram obtidas através dos dados de campo. Assim, a solução final da árvore de falha, para 20.000 km será:

$P\left(E_{15}\right)=1-\left[1-P\left(E_{11}\right)\right] \cdot\left[1-P\left(E_{12}\right)\right] \cdot\left[1-P\left(E_{13}\right)\right] \cdot\left[1-P\left(E_{14}\right)\right]$

$P\left(E_{15}\right)=1-[1-0,0137] \cdot[1-0,0019] \cdot[1-0] \cdot[1-0,017]=0,0323$

A probabilidade de ocorrência do evento principal "Freio falha ao parar veículo" é $P\left(E_{15}\right)=0,032 \rightarrow$ assumindo uma quilometragem média anual de 20.000 $\mathrm{Km}$. Para as mesmas condições anteriores e assumindo uma quilometragem média anual de $25.000 \mathrm{~km}$ tem-se:

$\rightarrow$ Quilometragem média anual de $25.000 \mathrm{~km}:$

\section{Evento}

1. Sem Fluido de Freio

2. Pastilhas / Sapatas

3. Cilindro Mestre

4. Disco / Tambor
Probabilidade de Ocorrência

$\rightarrow \quad 0,0137$

$\rightarrow \quad 0,0032$

$\rightarrow \quad 0$

$\rightarrow \quad 0,0271$

\section{Evento}

$\rightarrow \mathrm{E}_{11}$

$\rightarrow \mathrm{E}_{12}$

$\rightarrow \mathrm{E}_{13}$

$\rightarrow \mathrm{E}_{14}$

Assim, a solução final da árvore de falha, para 25.000 km será:

$P(E 15)=1-[1-P(E 11)] \cdot[1-P(E 12)] \cdot[1-P(E 13)] \cdot[1-P(E 14)]$

$P(E 15)=1-[1-0,0137] \cdot[1-0,0032] \cdot[1-0] \cdot[1-0,0271]=0,0435$

A tabela 12 mostra os resultados da solução final da árvore de falhas para as hipóteses assumidas, ou seja:

a) Sem fluido de freio

b) Pastilhas e Sapatas excessivamente gastas

c) Cilindro Mestre inoperante 
d) Disco / Tambor empenados ou excessivamente gastos

e) Quilometragens anuais médias de 20.000 e $25.000 \mathrm{~km}$

Tabela 12 - Resultados Finais da Árvore de Falhas.

\begin{tabular}{|cc|}
\hline $\begin{array}{c}\text { Quilometragem } \\
\text { Acumulada } \\
\text { (Anual) }\end{array}$ & $\mathrm{p}$ (falha) \\
\hline $20.000 \mathrm{~km}$ & 0,0323 \\
\hline $25.000 \mathrm{~km}$ & 0,0435 \\
\hline
\end{tabular}

Embora a probabilidade de ocorrência do evento principal possa ser considerada alta ( 3 a $4 \%$ ), deve-se evidenciar que foram assumidos como hipóteses alguns modos de falha que somente em extremo uso causariam a ocorrência do evento principal. Neste estudo foram mencionados alguns pontos quanto à aceitação do risco, assunto de grande controvérsia, isto pode ser minimizado pelo fato que há muitos anos não houve nenhum caso de falha do sistema de freio que tenha causado algum tipo de acidente grave, ou seja, nenhuma das suas falhas apontadas pelo sistema de garantia colocou em risco a integridade dos passageiros.

\subsection{Manutenção Centrada em Confiabilidade: Vidro do Para Brisa}

Neste estudo apontou-se também o vidro do para brisa como um dos itens críticos dentro da tabela 4 e classificado como um item de insatisfação. Neste momento volta-se ao banco de dados para entender a participação deste componente nas plataformas de veículos em estudo. A figura 53 mostra as falhas observadas no vidro do para brisa e na guarnição do para brisa no mesmo período. 


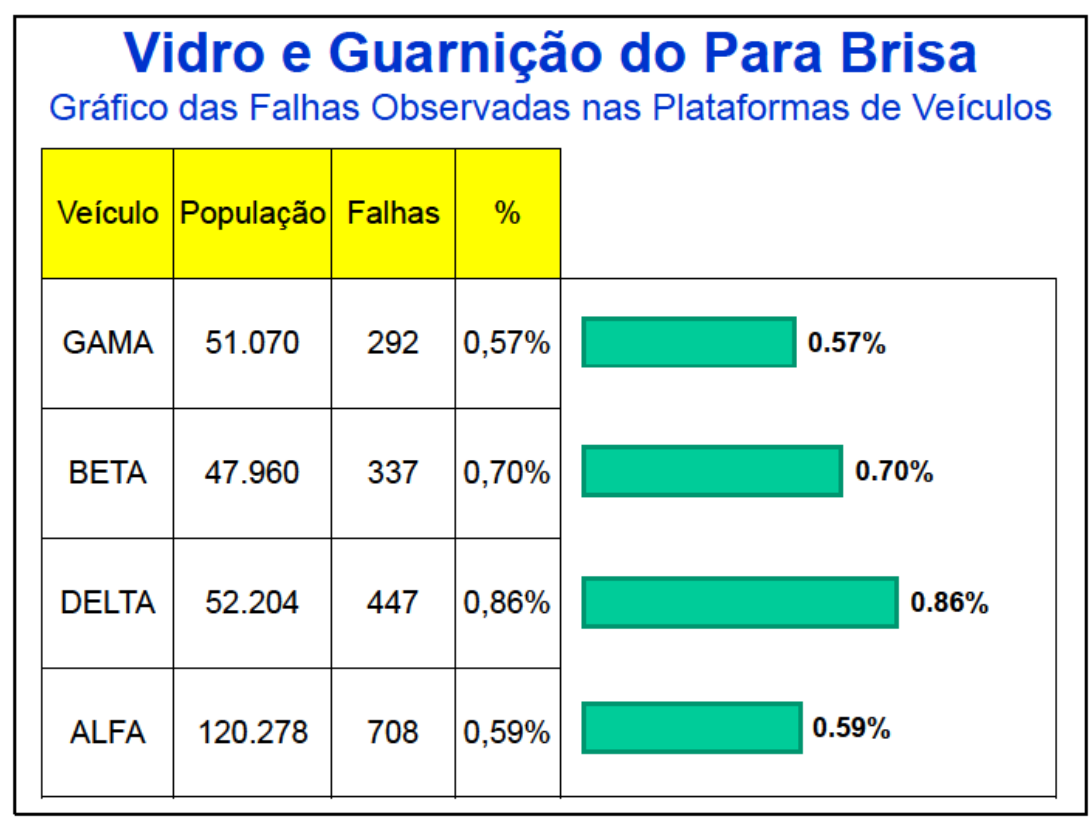

Figura 53 - Incidência de Falhas: Vidro e Guarnição do Para Brisa

Embora a plataforma de veículo Alfa tenha apresentado a maior incidência de falhas no vidro e guarnição do para brisa, este estudo irá considerar apenas a plataforma de veículo Delta devido à facilidade de visita até a linha de montagem deste veículo. O próximo passo é entender quais são os modos de falha que ocorreram na plataforma de veículo Delta, para então se iniciar a proposta deste estudo. A figura 54 mostra os modos de falha na plataforma de veículo Delta para o vidro e guarnição do para brisa.

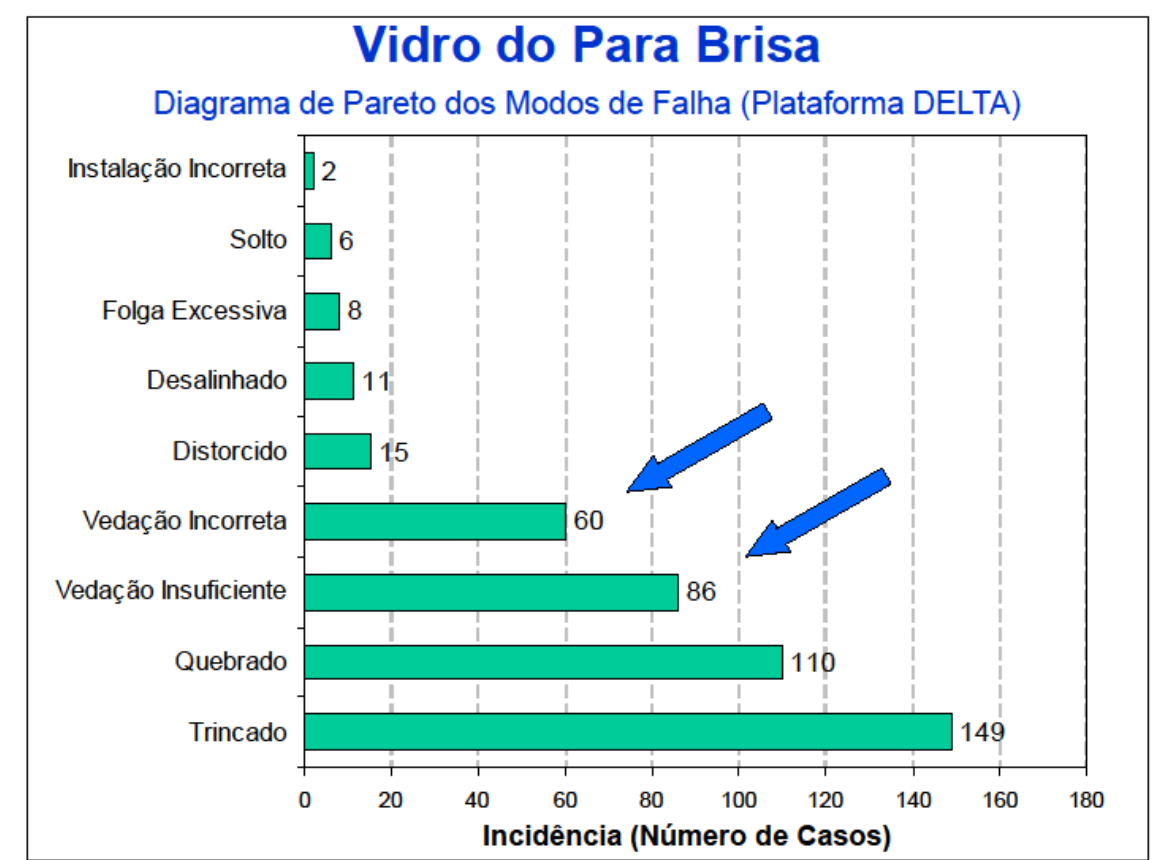

Figura 54 - Modos de Falha: Vidro e Guarnição do Para Brisa (Veículo Delta) 
Com estes dados de vedação incorreta e insuficiente é possível identificar problemas de aplicação de cola na célula do para brisa e assim iniciar um estudo detalhado nesta célula para identificar os componentes/sistemas mais críticos.

\subsubsection{Célula de Aplicação de Cola no Para Brisa}

A célula de aplicação de cola é uma parte do processo produtivo onde são montados todos os para brisas dos veículos produzidos nesta planta. Existem componentes que em sua falta, consegue-se continuar a montagem dos veículos, deixando a montagem deste componente para o final - método não muito comum. Porém, a parada da célula de aplicação de cola significa: parar a linha de montagem totalmente - isto porque o para brisa é um componente que não se consegue montar fora da linha de montagem.

Seja qual for o equipamento, quando ocorre uma parada da linha de montagem o custo estimado é de US\$500,00 por minuto. Mas isto ainda não significa que o processo de montagem seja robusto o suficiente para produzir veículos isentos de falhas no componente em estudo. Com esta proposta estar-se-á analisando a célula de aplicação de cola de tal modo que será possível identificar pontos críticos para priorizar sua manutenção.

A figura 55 representa de uma forma simplificada a célula de aplicação de cola na linha de montagem do veículo Delta. Esta célula é alimentada manualmente e todos os para brisas estão de forma sequenciada, ou seja, se tem os para brisas para todos os tipos de veículos programados para montar no dia de produção desta planta.

O operador da linha de montagem alimenta a célula colocando o para brisa em cima do carrinho de transporte, e este é conduzido até um suporte abaixo do robô de aplicação de cola e retorna a posição inicial.

Neste momento o para brisa é fixo e pela suas dimensões os sensores 
identificam qual o tipo de para brisa e conforme sua programação define o perímetro de cola a ser aplicado - cada veículo tem um para brisa com dimensões diferentes.

Assim que a fixação é concluída, o robô aplica o uretano (cola) a uma velocidade e vazão constante em todo perímetro do para brisa conforme sua programação (temperatura entre 30 a $34^{\circ} \mathrm{C}$ ) e ao final, libera a fixação do para brisa.

Neste momento o robô gira $90^{\circ}$ e conduz o bico de aplicação de cola até um subsistema onde o excesso de cola do bico é retirado com um jato de ar comprimido, voltando à posição original e assim, estará pronto para a próxima aplicação de cola. Outro carrinho de transporte retira o para brisa desta posição e o conduz até um novo ponto onde é retirado por dois operadores através de um manipulador (ventosa). Neste ponto o para brisa é então colocado na carroceria do veículo. 


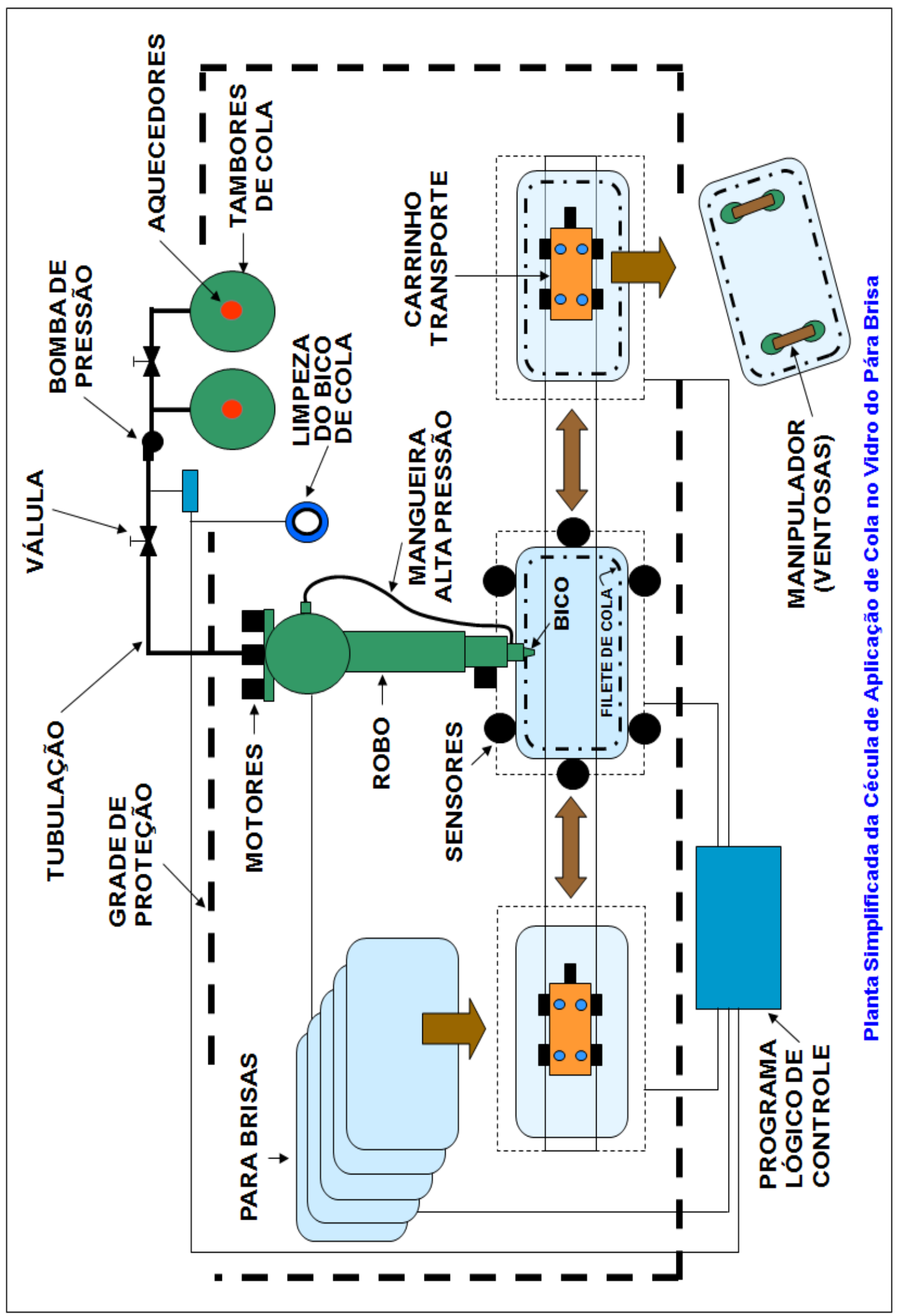

Figura 55 - Célula de Aplicação de Cola - Simplificada 


\subsubsection{Metodologia de Análise e Escolha da Política de Manutenção}

Este modelo baseia-se nos conceitos da Manutenção Centrada em Confiabilidade e seu objetivo é identificar os componentes críticos da célula de aplicação de cola no para brisa do veículo Delta, bem como propor políticas de manutenção para os mesmos, a fim de reduzir a incidência de falhas na instalação dos para brisas. A figura 56 mostra de forma esquemática a metodologia adotada neste trabalho, indicando a sequência das atividades, onde estar-se-a propondo a utilização da Análise de Modo e Efeito de Falhas (FMEA) para estudar as consequências da falha dos componentes desta célula.



Figura 56 - Metodologia da Análise e Escolha da Política de Manutenção. (fonte: Carazas, 2006)

Com a metodologia definida, a próxima etapa deste estudo será a elaboração da árvore funcional da célula de cola do para brisa, conforme mostra a figura 57.

Este diagrama indica os diversos componentes e/ou sistemas que compõe a célula de aplicação de cola. Sua elaboração foi baseada em informações internas e visita ao ponto de montagem do para brisa. Para sua construção deve-se observar que o sistema é composto por vários subsistemas e componentes que formam a célula, os quais apresentam uma interligação entre suas funções. Tal interligação permite que o sistema execute a função para a qual foi projetado. 


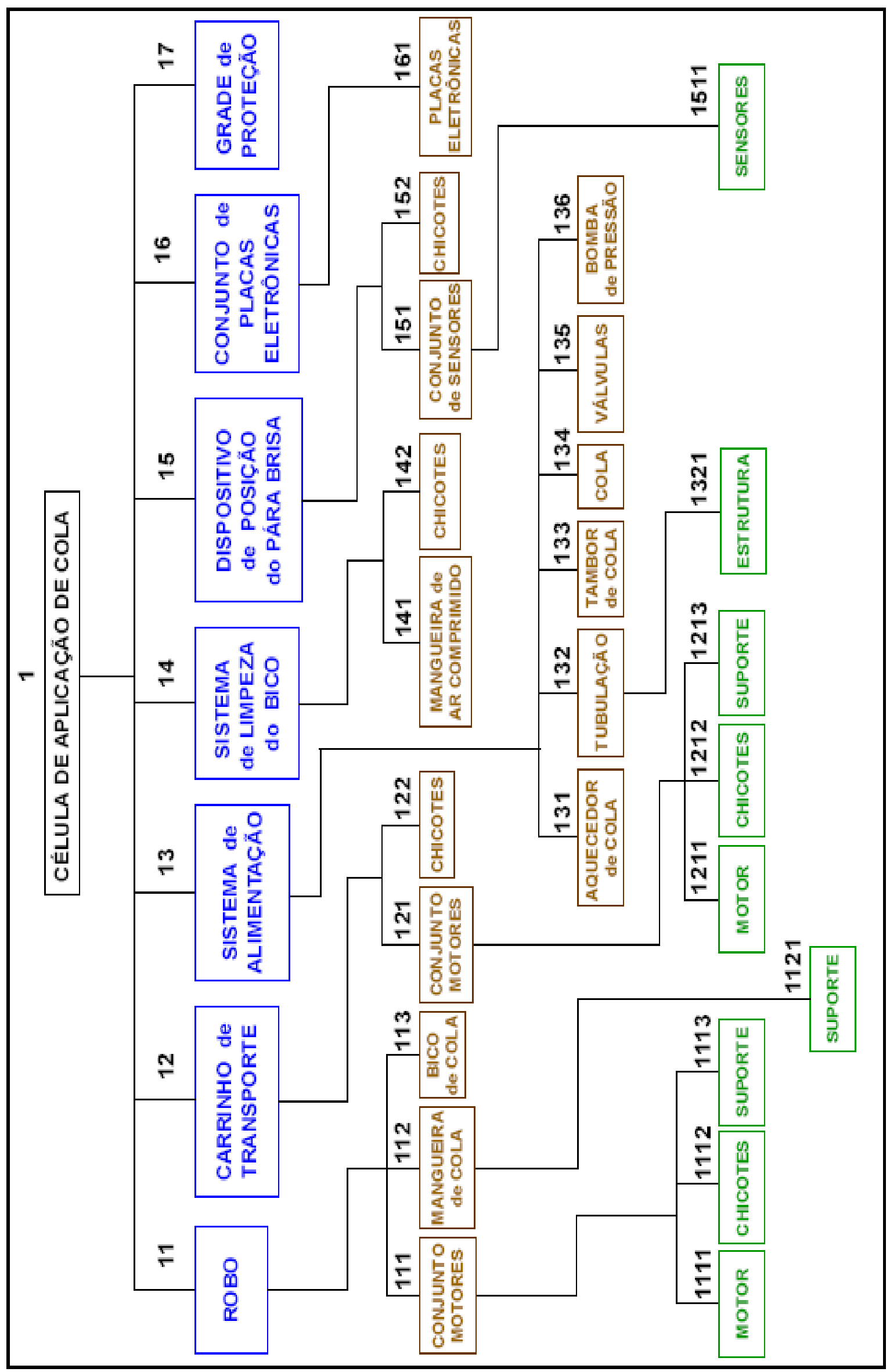

Figura 57 - Árvore Funcional da Célula de Cola do Para Brisa. 
A descrição funcional consiste na listagem de todos os componentes, acompanhados das suas respectivas funções principais. A lista abaixo representa a Descrição Funcional da Célula de Cola:

\section{0- CÉLULA INDUSTRIAL DE APLICAÇÃO DE COLA NO PARA BRISA}

1.1 - ROBO - Função primária: Aplicar cola no contorno de para brisas.

1.1.1 - Conjunto Motores $\rightarrow$ Função primária: Fornecer potência para acionar o edi

1.1.1.1 - Motor $\rightarrow$ Função primária: fornecer energia elétrica ao sistema

1.1.1.2 - Chicotes $\rightarrow$ Função primária: conduzir energia elétrica

1.1.1.3 - Suporte $\rightarrow$ Função primária: apoiar motor

1.1.2 - Mangueira de cola $\rightarrow$ Função primária: Conduzir a cola

1.1.2.1 - Suporte $\rightarrow$ Função primária: suportar mangueira de cola

1.1.3 - Bico de Cola $\rightarrow$ Função primária: Aplicar cola nos para brisas

1.2 - CARRINHO DE TRANSPORTE - Função primária: transportar para brisas

1.2.1 - Conjunto de Motores $\rightarrow$ Função primária: fornecer potência

1.2.1.1 - Motor $\rightarrow$ Função primária: fornecer energia elétrica ao sistema

1.2.1.2 - Chicotes $\rightarrow$ Função primária: conduzir energia elétrica

1.2.1.3 - Suporte $\rightarrow$ Função primária: apoiar motor

1.2.2 - Chicotes $\rightarrow$ Função primária: conduzir energia elétrica

1.3 - SISTEMA DE ALIMENTAC̣ÃO - Função primária: armazenar a cola

1.3.1 - Aquecedor de cola $\rightarrow$ Função primária: aquecer a cola

1.3.2 - Tubulação $\rightarrow$ Função primária: conduzir cola

1.3.2.1 - Estrutura $\rightarrow$ Função primária: suportar tubulação

1.3.3 - Tambor de cola $\rightarrow$ Função primária: armazenar cola

1.3.4 - Cola $\rightarrow$ Função primária: unir guarnição ao para brisa

1.3.5 - Vávula $\rightarrow$ Função primária: parar fluxo

1.3.6 - Bomba de pressão $\rightarrow$ Função primária: transferir cola

1.4 - SISTEMA DE LIMPEZA DO BICO - Função primária: limpar excesso de cola do bico entre aplicações

1.4.1 - Mangueira ar comprimido $\rightarrow$ Função primária: conduzir ar 
1.4.2 - Chicotes $\rightarrow$ Função primária: conduzir energia elétrica

1.5 - DISPOSITIVO DE POSICCÃO DO PARA BRISA - Função primária: posicionar para brisas

1.5.1 - Conjunto de sensores $\rightarrow$ Função primária: identificar para brisa

1.5.1.1 - Sensores $\rightarrow$ Função primária: identificar para brisa

1.5.2 - Chicotes $\rightarrow$ Função primária: conduzir energia elétrica

1.6 - CONJUNTO DE PLACAS ELETRÔNICAS - Função primária: gerenciar o robô

1.6.1 - Placas eletrônicas $\rightarrow$ Função primária: gerenciar subsistemas

\section{7 - GRADE DE PROTEÇÃO - Função primária: proteger contra acidentes}

\subsubsection{Análise de Modos e Efeitos de Falhas}

Durante a execução da análise de modos e efeitos de falha, deve-se iniciar com a definição dos modos de falha dos componentes da célula de cola, conforme mostrado na tabela 13. Alguns dos modos de falha desta célula de cola basearam-se em informações dos times de manutenção e alguns foram adicionados quando da elaboração do FMEA.

É importante lembrar que se está considerando componentes que operam de acordo com as especificações de projeto e que este é um processo produtivo. Para cada um dos modos de falha foram relacionados às possíveis causas, que podem ocorrer durante o funcionamento da célula de cola.

Com o levantamento dos modos de falha, podem-se avaliar as suas consequências (ou efeitos) em cada um dos subsistemas dos quais os componentes fazem parte. As consequências estão sempre relacionadas com uma parada da célula de aplicação de cola do para brisa, que diretamente impacta a linha de montagem de todos os veículos montados nesta planta e a um custo de aproximadamente US\$500,00 por minuto. 
Quando se tem componentes associados aos modos de falha e suas respectivas consequências para o funcionamento da célula de cola, podem-se priorizar os componentes conforme sua criticidade. A análise da criticidade foi adaptada de Lafraia (2001), e quando se trabalha com sistemas onde é conhecida a probabilidade de ocorrência e sua detecção, usam-se os Anexos 7 e 8 respectivamente.

É possível através da planilha usada definir a frequência da falha e da possibilidade de detecção de forma qualitativa, mas devido a falta de um banco de dados para tais componentes, neste estudo, para a análise de criticidade foi considerado, de modo relevante, o critério associado à Severidade, mostrado no Anexo 9, levando-se em conta impactos na continuidade da operação e na preservação de condições de segurança.

Como não se dispõe de imediato, de informações que permitam avaliar a probabilidade de ocorrência das falhas, e seus modos, não foi utilizado esse índice para avaliação da criticidade. A análise do tipo FMEA foi executada conforme mostrado nas tabelas 13 e 14 respectivamente. 
Tabela 13 - Parte A: Lista de Componentes Críticos da Célula de Cola




Tabela 14 - Parte B: Lista de Componentes Críticos da Célula de Cola

\begin{tabular}{|c|c|c|c|c|c|c|c|c|c|c|c|c|c|c|c|}
\hline & 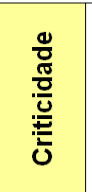 & 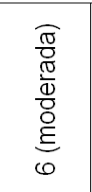 & 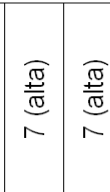 & 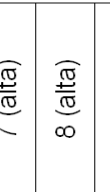 & $\begin{array}{l}\frac{\widehat{\frac{}{9}}}{\mathrm{~N}} \\
\stackrel{N}{N}\end{array}$ & $\frac{\frac{\widehat{\underline{w}}}{\underline{\underline{w}}}}{\infty}$ & 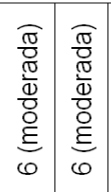 & 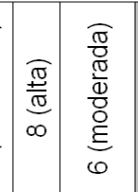 & 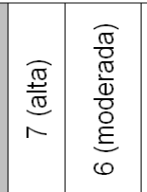 & 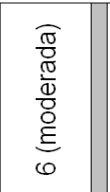 & $\frac{\frac{\widehat{\frac{}{0}}}{\mathrm{w}}}{\infty}$ & $\begin{array}{l}\frac{\widehat{\frac{\mathrm{I}}{\mathrm{w}}}}{\infty} \\
\frac{\mathrm{c}}{\mathrm{D}}\end{array}$ & $\frac{\frac{\widehat{\underline{O}}}{\mathrm{w}}}{\infty}$ & $\frac{\frac{\widehat{\underline{O}}}{\mathrm{~N}}}{N}$ & 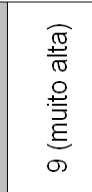 \\
\hline 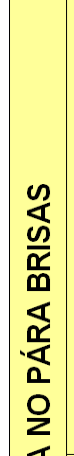 & 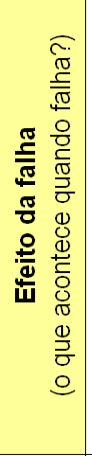 & 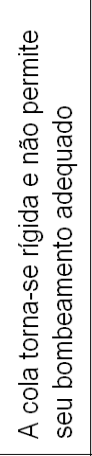 & 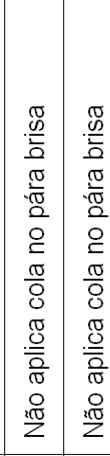 & 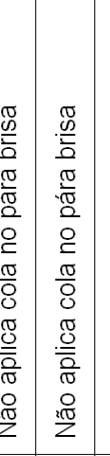 & 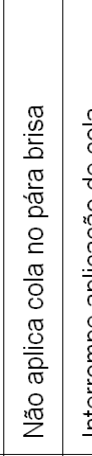 & 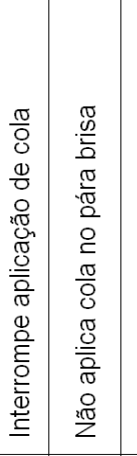 & 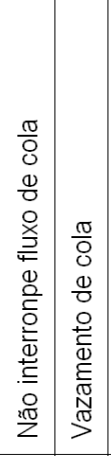 & 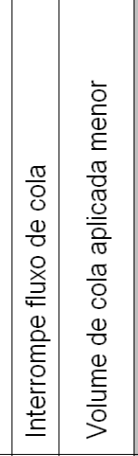 & 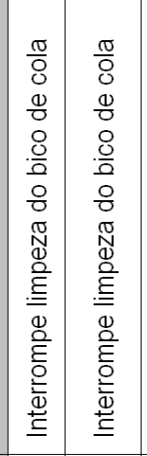 & 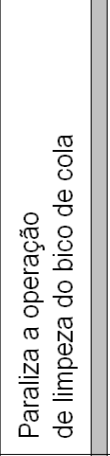 & 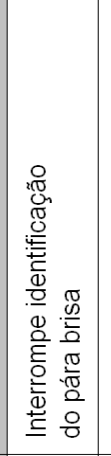 & 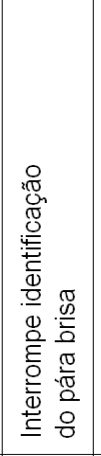 & 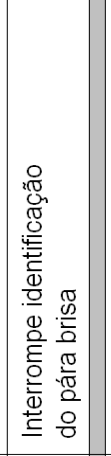 & 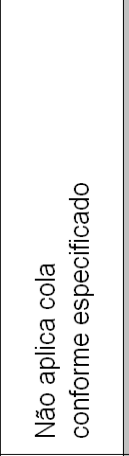 & 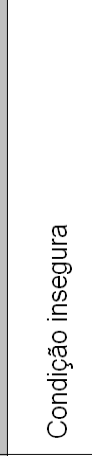 \\
\hline $\begin{array}{l}0 \\
\mathrm{u} \\
\mathrm{O}\end{array}$ &  &  &  & 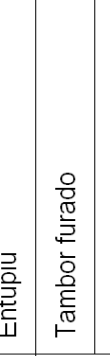 & 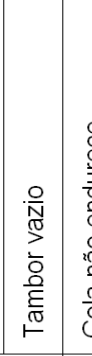 & 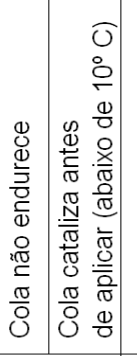 & 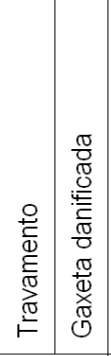 & 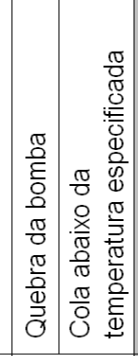 & 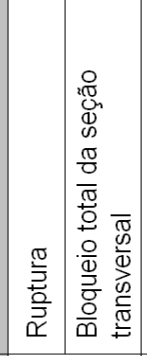 & 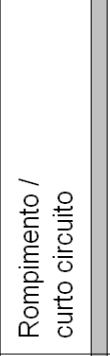 & 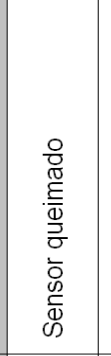 & 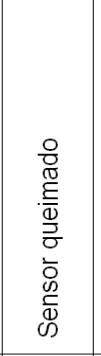 & 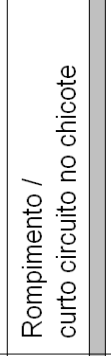 & 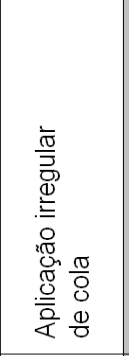 &  \\
\hline 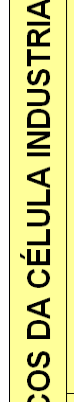 & 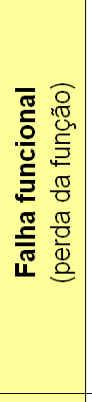 & $\begin{array}{l}\frac{\pi}{0} \\
0 \\
0 \\
0 \\
\frac{\omega}{0} \\
\frac{\sigma}{0} \\
\text { o. } \\
\frac{\text { on }}{2} \\
\end{array}$ & 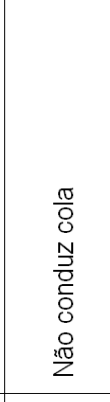 & 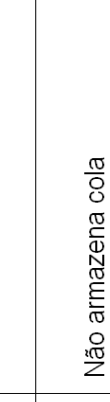 & 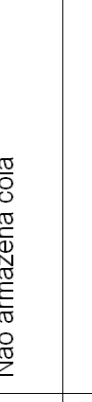 & 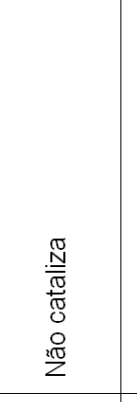 & 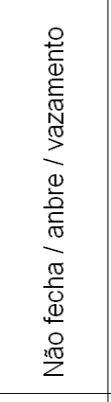 & 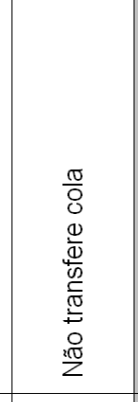 & 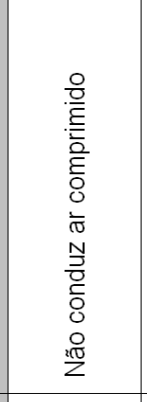 & 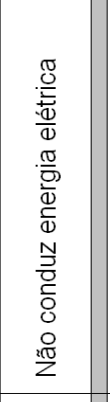 & 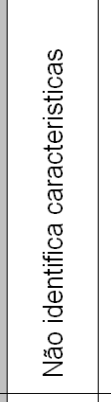 & 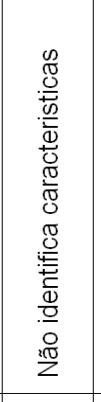 & 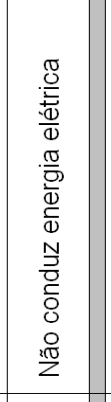 & 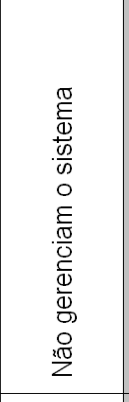 & 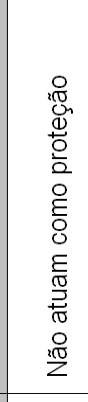 \\
\hline 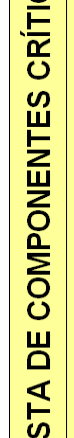 & 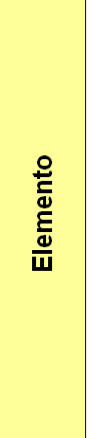 & 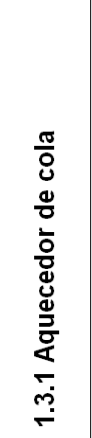 & 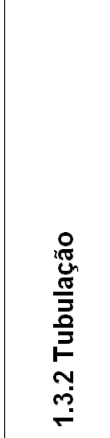 & 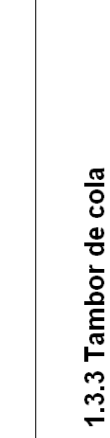 & 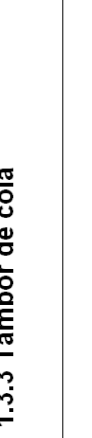 & $\begin{array}{l}\stackrel{\sigma}{0} \\
0 \\
\dot{m} \\
\stackrel{0}{\sim}\end{array}$ & 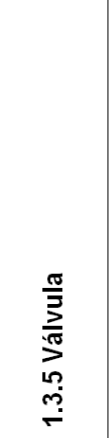 & 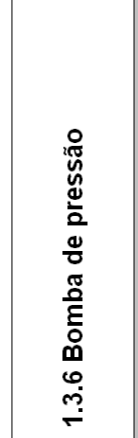 & 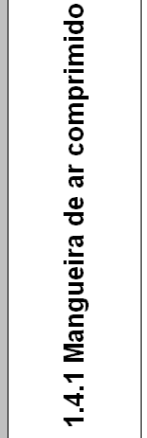 & 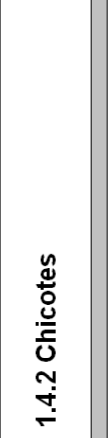 & 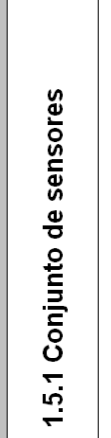 &  & 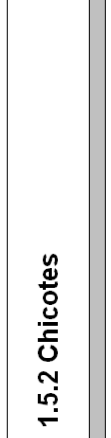 & 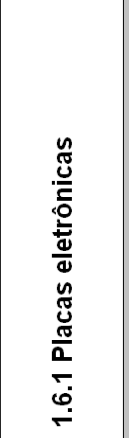 & 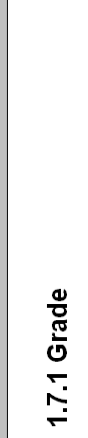 \\
\hline & 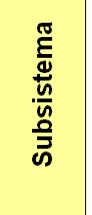 & 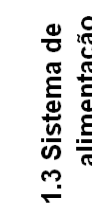 & & & & & & & 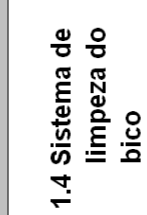 & & 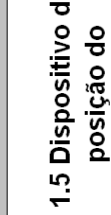 & & & 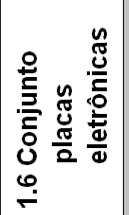 & 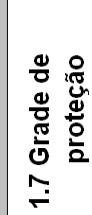 \\
\hline & 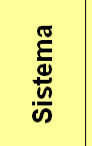 & 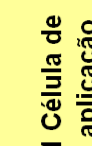 & & & & & & & & & & & & & \\
\hline
\end{tabular}




\subsubsection{Proposta da Política de Manutenção}

Com os resultados obtidos através da análise da função de cada componente, seus modos de falha e suas respectivas consequências, conforme mostram as tabelas 12 e 13, é possível identificar cada componente pela sua criticidade e para cada um destes componentes foi apresentado uma política de manutenção seguindo a ordem de sua criticidade.

A proposta da política de manutenção foi feita considerando-se a figura 58 , adaptada de Kardec e Nascif, 2001.

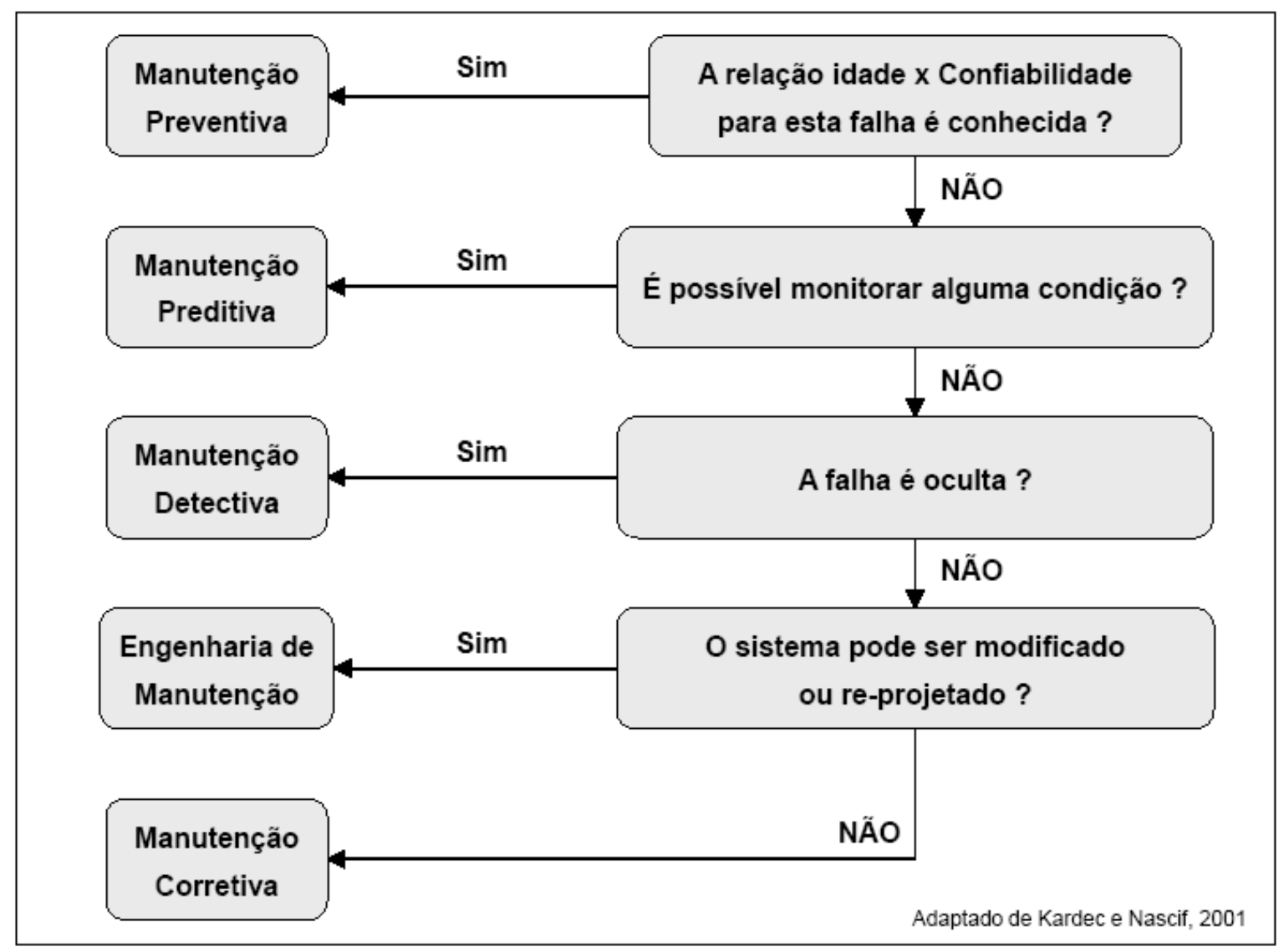

Figura 58 - Proposta da Política de Manutenção.

Usando como referência a figura 58 , foi possível propor para cada um dos componentes críticos uma política de manutenção conforme mostra a tabela 15. 
Tabela 15 - Proposta da Política de Manutenção

\begin{tabular}{|c|c|c|c|}
\hline \multicolumn{2}{|c|}{ Elemento } & \multirow{2}{*}{$\begin{array}{c}\text { Criticidade } \\
8 \text { (alta) }\end{array}$} & \multirow{2}{*}{$\begin{array}{c}\begin{array}{c}\text { Política de } \\
\text { Manutenção }\end{array} \\
\text { Corretiva }\end{array}$} \\
\hline 1.1 .1 & Conjunto de motores & & \\
\hline 1.1.1.1 & Motor & 8 (alta) & Corretiva \\
\hline \multirow{2}{*}{ 1.1.1.2 } & \multirow{2}{*}{ Chicote } & 8 (alta) & Corretiva \\
\hline & & 8 (alta) & Corretiva \\
\hline 1.1.1.3 & Suporte do Motor & 6 (moderada) & Corretiva \\
\hline \multirow{2}{*}{1.1 .2} & \multirow{2}{*}{ Mangueira de cola } & 8 (alta) & Preventiva \\
\hline & & 8 (alta) & Preventiva \\
\hline 1.2.2.1 & Suporte Mangueira & 5 (moderada) & Corretiva \\
\hline 1.1 .3 & Bico de cola & 8 (alta) & Preventiva \\
\hline 1.2 .1 & Conjunto de motores & 8 (alta) & Corretiva \\
\hline 1.2.1.1 & Motor & 8 (alta) & Corretiva \\
\hline \multirow{2}{*}{ 1.2.1.2 } & \multirow{2}{*}{ Chicote } & 8 (alta) & Corretiva \\
\hline & & 8 (alta) & Corretiva \\
\hline 1.2.1.3 & Suporte do Motor & 6 (moderada) & Corretiva \\
\hline 1.3 .1 & Aquecedor de cola & 6 (moderada) & Preventiva \\
\hline \multirow{2}{*}{1.3 .2} & \multirow{2}{*}{ Tubulação } & 7 (alta) & Corretiva \\
\hline & & 7 (alta) & Corretiva \\
\hline \multirow{2}{*}{1.3 .3} & \multirow{2}{*}{ Tambor de cola } & 8 (alta) & Preventiva \\
\hline & & 7 (alta) & Preventiva \\
\hline \multirow{2}{*}{1.3 .4} & \multirow{2}{*}{ Cola } & 7 (alta) & Preventiva \\
\hline & & 8 (alta) & Preventiva \\
\hline \multirow{2}{*}{1.3 .5} & \multirow{2}{*}{ Válvula } & 6 (moderada) & Preventiva \\
\hline & & 6 (moderada) & Preventiva \\
\hline \multirow{2}{*}{1.3 .6} & \multirow{2}{*}{ Bomba de pressão } & 8 (alta) & Preventiva \\
\hline & & 6 (moderada) & Preventiva \\
\hline \multirow{2}{*}{1.4 .1} & \multirow{2}{*}{ Mangueira de ar comprimido } & 7 (alta) & Preventiva \\
\hline & & 6 (moderada) & Preventiva \\
\hline 1.4 .2 & Chicotes & 6 (moderada) & Corretiva \\
\hline 1.5 .1 & Conjunto de sensores & 8 (alta) & Corretiva \\
\hline 1.5.1.1 & Sensores & 8 (alta) & Corretiva \\
\hline 1.5 .2 & Chicotes & 8 (alta) & Corretiva \\
\hline 1.6 .1 & Placas eletrônicas & 7 (alta) & Corretiva \\
\hline 1.7 .1 & Grade & 9 (muito alta) & Preventiva \\
\hline
\end{tabular}

Com o uso dos conceitos da manutenção centrada em confiabilidade, foi possível estabelecer as práticas de manutenção nos componentes cujos modos de falha geram consequências que afetam diretamente o desempenho do sistema de 
aplicação de cola. Para cada um dos modos de falha dos componentes, empregouse o método de seleção de práticas de manutenção.

Alguns componentes classificados como criticidade alta adotaram a política de manutenção corretiva, isto se deve ao fato que estes componentes são de fácil substituição e normalmente disponíveis em estoque.

A MCC, como estratégia de manutenção, torna clara a preservação das funções do equipamento e não do equipamento em si. Em resumo, o estudo permitiu confirmar benefícios de sua aplicação, já que atualmente a única política de manutenção empregada neste ponto é a corretiva.

\subsection{Projeto para Manufatura e Montagem: Chicote do Motor}

Todos os anos são desenvolvidos novos programas de lançamento de veículos. E este conteúdo de modificações do veículo pode variar desde uma simples moldura lateral e novas cores de exterior até uma grande modificação envolvendo partes estampadas, farois, lanternas, bancos e até mesmo partes de um motor, para atender alguma legislação ou alguma melhoria do desempenho do mesmo.

Embora a ferramenta de DFMA seja muito usada em novos desenvolvimentos, neste estudo de caso será aplicado no chicote do motor que é um produto já em produção e identificado na tabela 4 como um item de risco e insatisfação. Será nestes componentes (chicote, presilhas, suporte) que se estará aplicando o conceito da ferramenta DFMA. Neste caso o componente escolhido foi o sistema auxiliar de ventilação do motor.

Os chicotes utilizados nos veículos automotivos têm certa particularidade quanto aos seus dados de campo, raramente são trocados, ou seja, raramente se tem peças para análise. Quando se esta investigando falhas em chicotes, há a necessidade de constantes visitas às concessionárias para acompanhamento dos reparos efetuados nos veículos que apresentaram problemas de chicotes para se determinar a causa raiz do problema. As falhas mais comuns nestes casos são mau contato dos conectores, cortes nos fios e curtos circuitos e isto pode ser causado por uma das seguintes razões: 
a) O chicote é montado sem o conector estar fixado corretamente (e isto tem algumas causas como velocidade da linha de montagem o que gera sobrecarga de trabalho neste ponto de montagem, ou simplesmente uma distração do operador em observar o som causado quando se fixa o conector do chicote até o final de curso).

b) Os conectores não têm vedação contra infiltração de água, o que poderá eventualmente causar oxidações nos pinos do conector e a perda da condução de energia, causando algum tipo de falha (isto tem uma razão mais simples ainda, o custo destes conectores vedados é até duas vezes o custo de um conector comum).

c) Uso de conectores com uma trava externa a mais do que os conectores comuns, que elimina o problema de falha de montagem (mas normalmente é deixado de lado devido ao seu custo também elevado).

d) Existem problemas quanto à rota dos chicotes dentro do compartimento do motor ou no assoalho do veículo, abaixo do carpete. Estudos de rotas e sua fixação são muito importantes e evitam uma série de problemas futuros. Dentro do compartimento do motor também há o problema de interferência com possíveis arestas cortantes de chapas e passagem por áreas de aquecimento excessivo, o que causaria sérios danos aos fios dos chicotes. Nestes casos há a necessidade de desvio de rotas ou proteção térmica contra o aquecimento excessivo.

As explicações acima parecem óbvias e simplistas, mas normalmente são deixadas de lado durante o desenvolvimento e as decisões tomadas na escolhas dos componentes, rotas dos chicotes, sua fixação e suas proteções necessárias são feitas sem o conhecimento prévio de todo ambiente onde os chicotes serão montados.

A razão desta explicação sobre as falhas nos chicotes deve-se ao fato de que no estudo deste componente foram deixados de lado alguns dos passos do fluxograma proposto neste estudo (figura 27) e passou-se da coleta de dados do 
período de garantia direto para a aplicação da técnica de DFMA. A razão para tal decisão é que o registro das falhas de chicotes nos bancos de dados pouco oferecem para estudos de confiabilidade, mas foi útil para priorizar o componente para estudo.

Existem dois tipos de ventiladores usados em sistema de arrefecimento. Tradicionalmente, os veículos usam os ventiladores mecânicos, acionados por correias, ainda em uso em alguns tipos de caminhões pequenos. Os ventiladores elétricos começaram a ser usados nos anos 80 e são acionados somente quando necessário.

Esta evolução tornou-se necessária para o arrefecimento quando da montagem de motores transversais, para redução de peso e economia de combustível. Assim, pode-se dizer que, carros com tração dianteira possuem sistema auxiliar de arrefecimento, também conhecido por ventoinhas elétricas, conforme ilustra um exemplo típico na figura 59.

Estas ventoinhas são controladas por um módulo ou pela central eletrônica do motor e são acionadas quando a temperatura do líquido de arrefecimento sobe acima do ponto estabelecido e é desligada quando a temperatura cai abaixo deste ponto, podendo existir ventoinhas com velocidades diferentes, dependendo da necessidade do projeto.

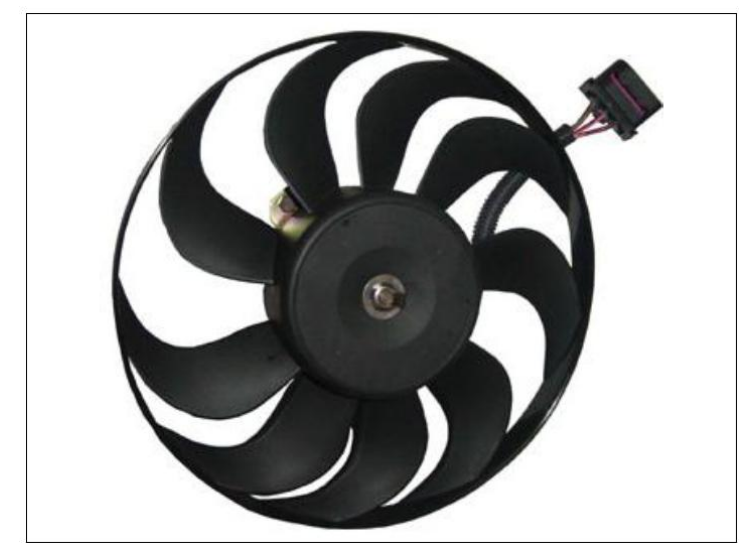

Figura 59 - Ventoinha de Arrefecimento.

Neste projeto em produção nas plataformas em estudo, tem-se a ventoinha do motor controlada por um módulo, com três velocidades de acionamento, conforme mostra a ilustração na figura 60. 


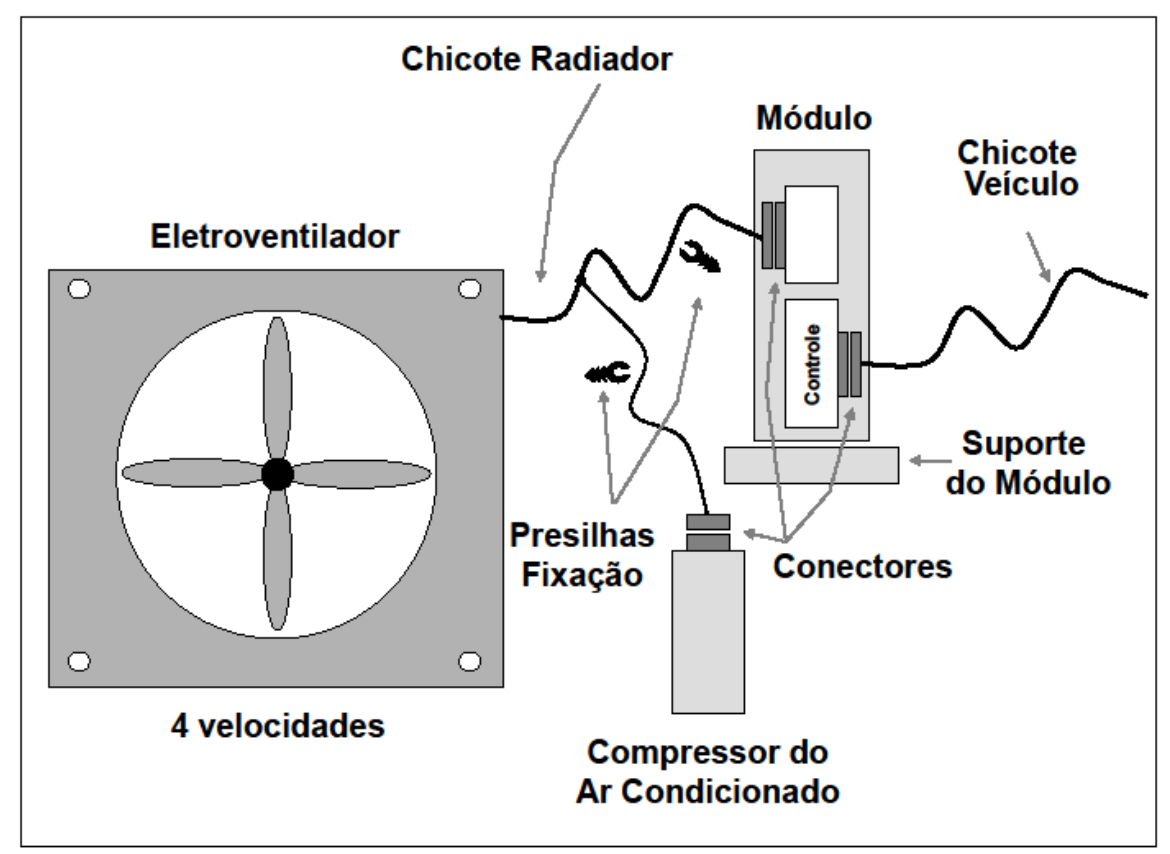

Figura 60 - Projeto Inicial: Ventoinha de Arrefecimento e Módulo.

Tem-se um chicote de $1050 \mathrm{~mm}$ com duas ramificações, uma até o módulo da ventoinha elétrica e a outra ramificação até o compressor do ar condicionado. Este chicote é encapado e têm dois conectores tradicionais (conectores simples de baixa pressão, que podem ser separados sem a ajuda de uma ferramenta), sua rota é fixada por duas presilhas plásticas. O módulo da ventoinha elétrica é programado para controlar as seguintes funções:

- temperatura do motor;

- pressão da linha de ar condicionado;

- chave liga / desliga do ar condicionado;

- kick down.

O objetivo da função kick down é desligar o ar condicionado quando há solicitação de maior potência do motor, como por exemplo, durante uma ultrapassagem. O módulo da ventoinha é um componente existente no mercado, mas neste caso é importado, este módulo é fixado por meio de dois parafusos.

\subsubsection{Aplicação dos Critérios de DFMA}

A aplicação dos critérios de DFMA ao projeto em produção constante da figura 60 , sua montagem ocorre da seguinte maneira: 
Componente (Quantidade)

1. Chicote do Radiador (1):

2. Módulo com Suporte (1):

\section{Comentário}

Teoricamente não é necessário

exatamente este chicote com $1050 \mathrm{~mm}$.

Este módulo pode ser substituido pelo módulo do veículo já existente, bastando apenas ser reprogramado.

3. Conector do Compressor AC (1): Continua sendo necessário.

4. Conectores do Módulo (2): Com a utilização do módulo do veículo, estes conectores perdem sua função.

5. Parafuso de Fixação do Módulo (2): Com a eliminação do módulo e suporte, estes perdem sua função.

6. Presilhas de Fixação do Chicote (2): Dependendo da nova proposta, podem ainda ser necessárias para uma rota de chicote.

A figura 61 ilustra a aplicação dos critérios do DFMA no projeto em estudo.

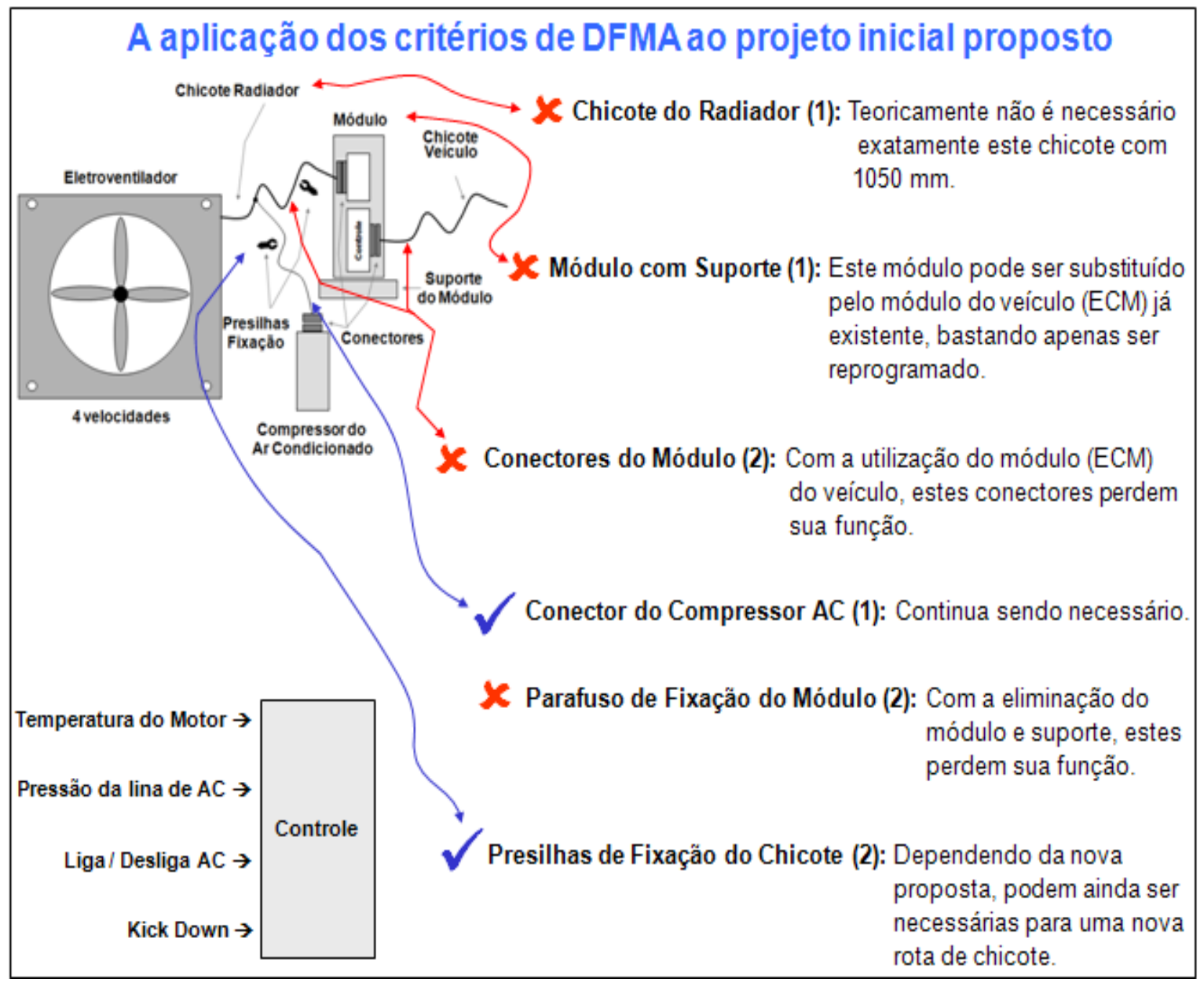

Figura 61 - Aplicação dos Critérios de DFMA 
Os tempos de montagem neste estudo consideram somente o tempo de montagem do sistema no veículo e não da fabricação do chicote no fornecedor.

A tabela 16 mostra os resultados da análise de montagem do sistema no veículo para o projeto original, onde se pode observar uma eficiência de projeto de 13,4\%. Isto foi obtido pela multiplicação da quantidade mínima teórica de componentes obtida (3), pelo tempo mínimo de montagem por item (3s), divididos pelo tempo total de montagem (67s), não se esquecendo de nenhum componente.

Tabela 16 - Resultado do Projeto para Montagem do Estudo de Caso.

\begin{tabular}{|c|c|c|c|c|}
\hline Componente & Quantidade & $\begin{array}{c}\text { Quantidade } \\
\text { Teórica }\end{array}$ & $\begin{array}{c}\text { Tempo de } \\
\text { Montagem (s) }\end{array}$ & $\begin{array}{c}\text { Custo de } \\
\text { Montagem (c) }\end{array}$ \\
\hline Chicote $(1050 \mathrm{~mm})$ & 1 & 0 & 10,0 & 6,7 \\
\hline Conectores do Módulo & 2 & 0 & 12,0 & 8,0 \\
\hline Conector do Compressor do AC & 1 & 1 & 6,0 & 4,0 \\
\hline Módulo com suporte & 1 & 0 & 16,0 & 10,7 \\
\hline Parafuso de fixação do Módulo & 2 & 0 & 15,0 & 10,0 \\
\hline \multirow[t]{2}{*}{ Presilhas Plásticas } & 2 & 2 & 8,0 & 5,3 \\
\hline & 9 & 3 & 67,0 & 45 \\
\hline Eficiência do Projeto $=(3 \times 3) / 67=$ & $13,4 \%$ & & & \\
\hline
\end{tabular}

A figura 62 mostra a nova proposta para o projeto, utilizando o próprio módulo eletrônico do veículo (ECM - eletronic control module) para gerenciar as informações de temperatura do motor, pressão da linha de ar condicionado, kick down e a chave ligar / desligar do ar condicionado. O módulo eletrônico (ECM) é um componente já existente no veículo e pode facilmente ser reprogramada para atender a esta nova solicitação, eliminando assim a necessidade do módulo da ventoinha, seria um componente a menos. 


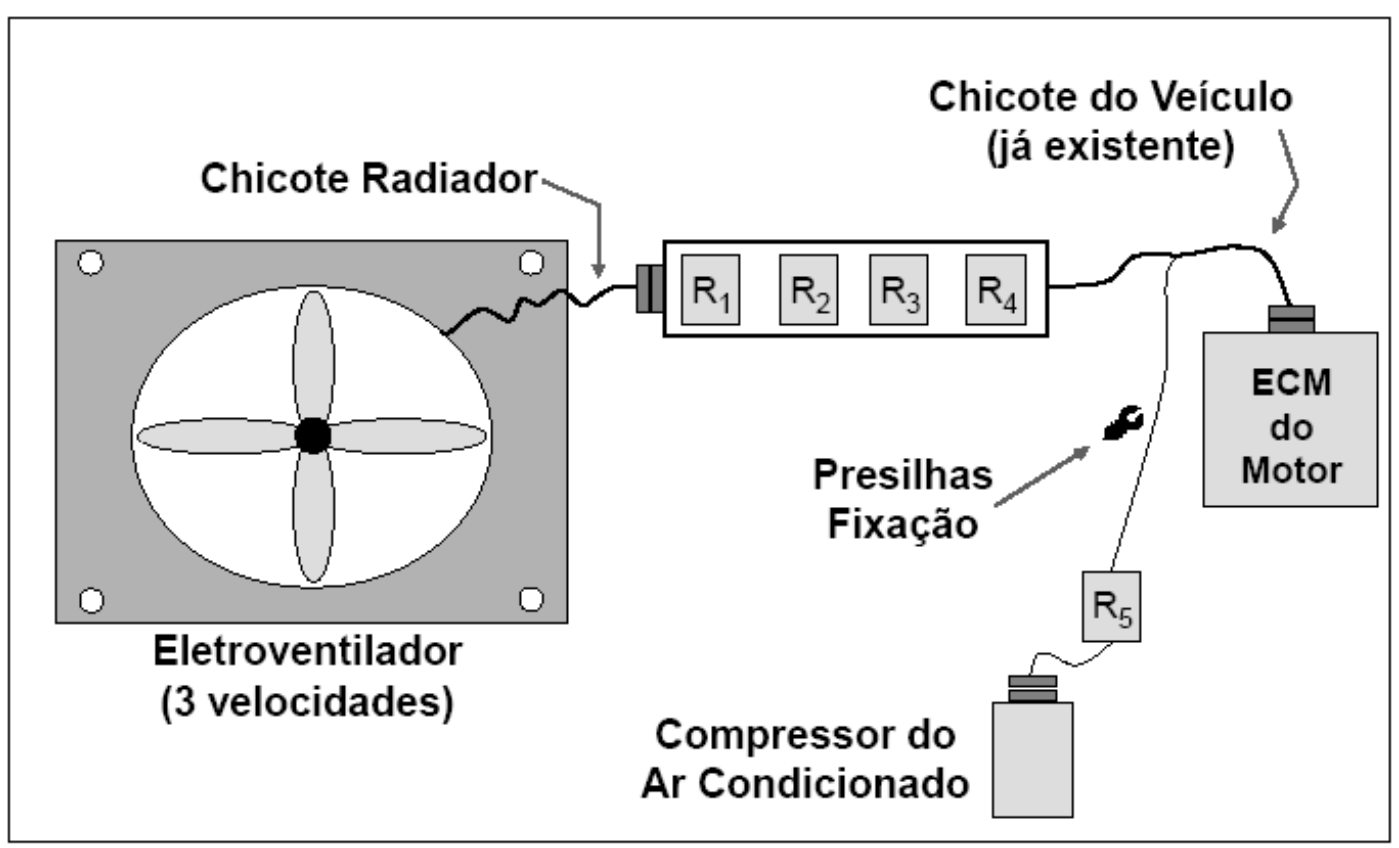

Figura 62 - Novo Projeto: Ventoinha de Arrefecimento e ECM do Veículo.

Esta nova proposta precisa de cinco reles, suporte dos reles que já podem estar montados no chicote e um conector. A tabela 17 mostra o resultado da análise de montagem do novo projeto, onde se pode observar uma eficiência de projeto de $62,5 \%$. Isto foi obtido pela multiplicação da quantidade mínima teórica de componentes obtida (10), pelo tempo mínimo de montagem por item (3s), divididos pelo do tempo total de montagem (48s), não se esquecendo de nenhum componente.

Tabela 17 - Resultado do Novo Projeto para Montagem.

\begin{tabular}{|c|c|c|c|c|}
\hline Componente & Quantidade & $\begin{array}{c}\text { Quantidade } \\
\text { Teórica }\end{array}$ & $\begin{array}{c}\text { Tempo de } \\
\text { Montagem (s) }\end{array}$ & $\begin{array}{c}\text { Custo de } \\
\text { Montagem (c) }\end{array}$ \\
\hline Relês & 5 & 5 & 16,0 & 10,7 \\
\hline Suporte dos relês & 1 & 1 & 8,0 & 5,3 \\
\hline Conector do Compressor do AC & 1 & 1 & 6,0 & 4,0 \\
\hline Conector do Radiador & 1 & 1 & 6,0 & 4,0 \\
\hline Parafuso de fixação Suporte dos Relês & 1 & 1 & 8,0 & 5,0 \\
\hline Presilha Plástica & 1 & 1 & 4,0 & 2,7 \\
\hline total $=$ & 10 & 10 & 48,0 & 32 \\
\hline
\end{tabular}

Eficiência do Projeto $=(10 \times 3) / 48=62,5 \%$

a para custo de mão de obra estimado de US $\$ 25 / h$.

$3 \mathrm{~s}=$ tempo de montagem mínimo de um item. 
A tabela 18 mostra a comparação entre o custo dos dois projetos, onde se pode observar uma economia de aproximadamente de $R \$ 18$ (ano base 2009) em custo dos itens para cada veículo.

É interessante notar que as sugestões do novo projeto foram feitas com a aplicação do conceito de projeto para montagem (DFM) usando o critério de número mínimo de componentes e a eliminação de componentes importados, que mostrou um grande diferencial na redução de custo.

Tabela 18 - Análise Comparativa de Custo dos Projetos

\begin{tabular}{|c|c|c|c|}
\hline \multicolumn{2}{|l|}{ (a) Projeto Proposto } & \multicolumn{2}{|l|}{ (b) Reprojeto } \\
\hline Item & Custo (R\$) & Item & Custo (R\$) \\
\hline Chicote $(1050 \mathrm{~mm})$ (1) & 6,00 & Relês (5) & 9,00 \\
\hline Conectores do Módulo (2) & 1,00 & Suporte dos relês (1) & 2,00 \\
\hline Conector do Compressor do AC (1) & 0,50 & Conector do Compressor do AC (1) & 0,50 \\
\hline Módulo com suporte (1) & 22,50 & Conector do Radiador (1) & 0,50 \\
\hline Parafuso de fixação do Módulo (2) & 0,10 & Parafuso de fixação Suporte dos Relês (2) & 0,10 \\
\hline \multirow[t]{2}{*}{ Presilhas Plásticas (2) } & 0,10 & Presilha Plástica (1) & 0,05 \\
\hline & 30,20 & total $=$ & 12,15 \\
\hline
\end{tabular}

Além da redução de custo do reprojeto, se tem um menor tempo de montagem do sistema na montadora. Esta redução de componentes diminui a incidência de falhas prematuras e consequêntemente aumenta a confiabilidade do sistema.

\subsection{Análise dos Resultados}

\subsubsection{Conclusões}

A consulta ao banco de dados para o levantamento da incidência de falhas nas plataformas de veículos mostrou um resultado interessante. Entre todos os dados apontados pode-se afirmar que os quinze componentes e/ou sistemas no topo das listas são os mesmos em todas as plataformas de veículos, variando apenas a sua ordem de incidência. Com os gráficos de Pareto mostrados neste estudo, 
podem-se priorizar os itens mais críticos para qualquer proposta de melhoria. $O$ fato é que, as informações levantadas nesta proposta poderão direcionar os esforços para um conjunto de quinze componentes e/ou sistemas, onde se alcançará uma melhoria significativa em todas as quatro plataformas de veículos mostradas neste estudo.

\subsubsection{Análise da Confiabilidade da Bomba de Óleo}

A escolha da bomba de óleo para análise de confiabilidade foi baseada na análise da tabela 3 , devido a grande incidência de falhas em todas as plataformas de veículos. O estudo de confiabilidade mostrou um modo de se determinar a confiabilidade nos instantes de tempo de 20 e 25 mil quilômetros, assumido as hipóteses de dados censurados para o mercado nacional e o mercado europeu. Isto mostrou que existem diferenças de comportamento entre os usuários destes dois mercados, conforme mencionado no início deste estudo. A figura 63 mostra o acúmulo de quilometragem (o quanto a população de veículos aumenta a quilometragem com o uso) dos dados censurados durante o período de garantia nos mercados nacional e europeu e os pontos onde foram calculadas as confiabilidades da bomba de óleo (pontos A e B).

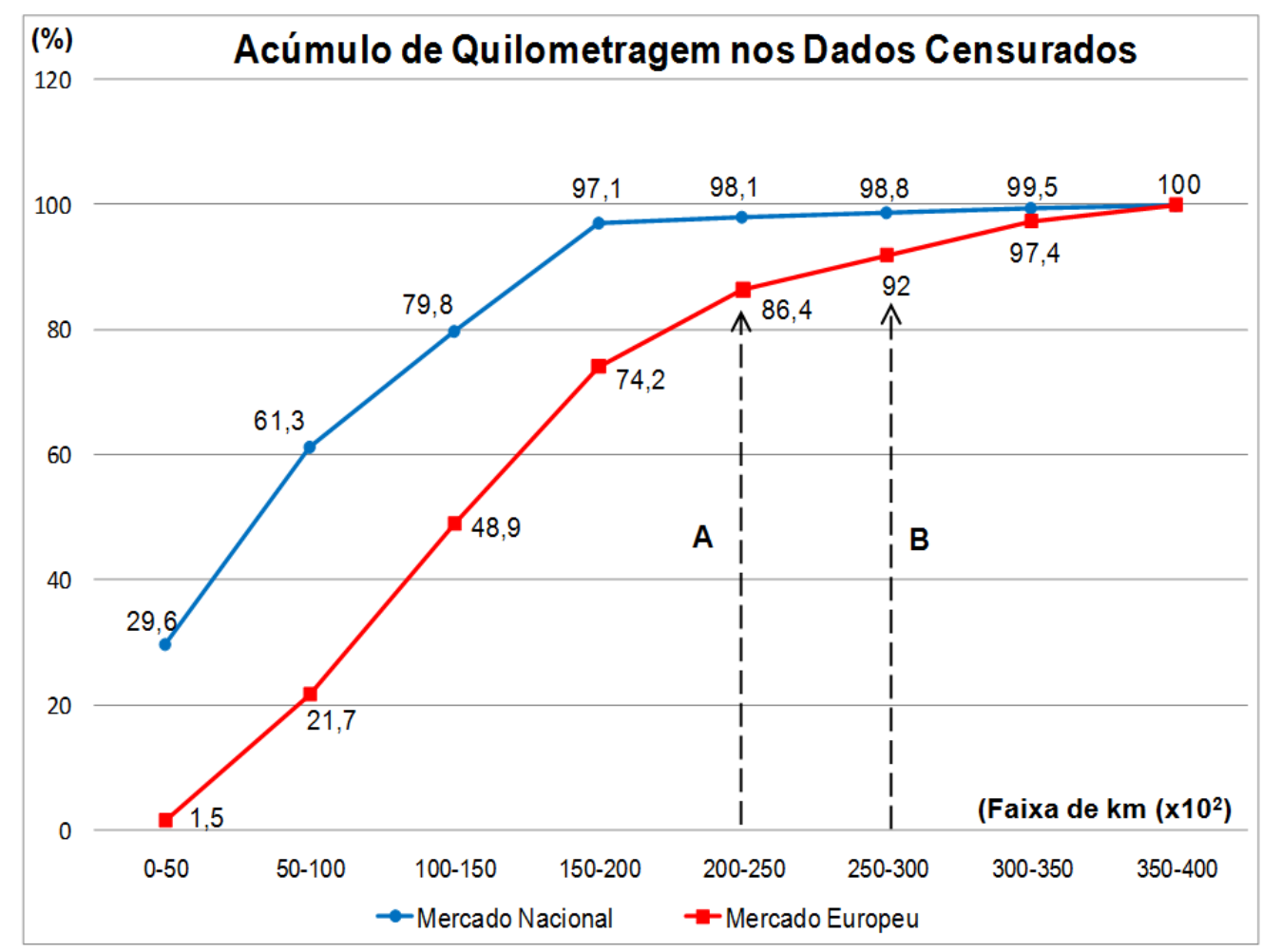

Figura 63 - Acúmulo de Quilometragem nos Dados Censurados 
Quando se compara os pontos "A" e "B" da figura 63, pode-se observar que os usuários no mercado nacional acumularam uma quilometragem maior em seus veículos nos instantes de tempo onde se determinou a confiabilidade da bomba de óleo. Isto equivale dizer que o "teste" iniciou-se primeiro no mercado nacional e depois no mercado europeu. Quando se fez a análise de confiabilidade nos pontos de 20.000 e 25.000 km a amostra do mercado nacional já tinha 98,8\% completado estas quilometragens e no mercado europeu apenas $86,4 \%$. Somente com esta primeira análise já se pode observar a importância de se conhecer o comportamento dos usuários do mercado a que se destina o produto, pois este conhecimento ajudará nas tomadas de decisão no desenvolvimento do produto. Mas a simples análise de valor numérico de confiabilidade não permite a obtenção de alguma conclusão quanto à diferença entre os projetos. Para tanto se fez necessário o teste de hipótese entre os projetos em estudo. Neste ponto pode-se concluir que o comportamento do usuário tem grande influência nestas comparações e que um estudo mais detalhado deste comportamento faz-se necessário para o melhor entendimento do uso dos veículos em outros países. Isto mostra também que um projeto de bom desempenho em determinada região não terá o mesmo comportamento em outras regiões. É este comportamento que se faz necessário conhecer com maiores detalhes quando do início de desenvolvimento de novos componentes e/ou sistemas.

Broome (2004) mostra uma proposta para a melhoria da confiabilidade trabalhando nas falhas prematuras, a qual coincide com a proposta deste estudo que também trabalha com as falhas do período de garantia, que podem ser classificadas como falhas prematuras quando se compara com a vida do veículo, porém autor não faz nenhuma citação sobre os dados censurados quando das propostas de melhoria

Attardi (2005) traz um modelo de análise de confiabilidade com dados de garantia da FIAT e estuda dois componentes do motor em dois tipos de veículos e faz uso de dados censurados. A proposta de Attardi, porém foca mais na combinação das populações dos dois veículos e suas implicações, mostrando sua utilidade quando da falta de dados para estudos de confiabilidade. 


\subsubsection{Análise do Comparativo entre Projetos}

Quando se comparou o comportamento do mesmo componente entre as plataformas de veículos em estudo, considerando apenas o mercado nacional, observou-se que existem diferenças entre os projetos, mas quando se fez o comparativo de confiabilidade em conformidade com as hipóteses assumidas, verificou-se que o projeto GAMA é o que apresentou melhor desempenho entre eles nos instantes de tempo estudados. Isto mostra que os componentes do projeto GAMA devem ser os escolhidos em novos desenvolvimentos por apresentarem melhor desempenho no mercado nacional. Na impossibilidade de seu uso, um entendimento melhor de todo sistema nas outras plataformas de veículo, como fixações, rota de mangueiras, matéria prima utilizada na construção, etc. de cada componente faz-se necessário para entender estas diferenças e corrigí-las para sua aplicação em novos desenvolvimentos ou ainda como uma melhoria contínua nas outras plataformas de veículo. Mas isto ainda não é o suficiente, faz-se necessário um estudo em todo processo produtivo do sistema como as falhas relacionadas ao processo de montagem e as falhas relacionadas ao projeto de cada componente. Isto se aplica nas revisões de projeto onde todo este detalhamento é mostrado para a tomada de decisão. Assim, fica mais fácil tomar a decisão sabendo-se o quanto ela afetará na qualidade final do produto e consequentemente no custo de garantia. Com a intenção de reduzir os custos de garantia todos os modos de falha identificados, ou pelo menos os mais críticos, precisam de planos de melhoria. Esta proposta foi feita considerando apenas a bomba de óleo do motor, mas o critério utilizado poderá ser aplicado a vários outros componentes mostrados na tabela 4.

\subsubsection{Análise do Risco do Sistema de Freio}

Com o uso dos conceitos de análise de risco foi possível estabelecer práticas de análise do projeto buscando melhoria do produto, indicando pontos vulneráveis do projeto e de seu processo de produção. A melhoria contínua do produto e do processo foi identificada, bastando para isto quantificar as melhorias propostas e o custo de cada uma delas para que se possa tomar a melhor decisão de custo e benefício. Sentiu-se falta de um banco de dados mais elaborado da máquina de 
enchimento do fluido de freio, isto poderia trazer melhores resultados ao estudo de caso e melhorar os dados para a tomada decisão.

Quanto aos outros componentes do sistema de freio, estes tiveram subsídios para a análise devido ao banco de dados do sistema de garantia que é bem completo. Embora a probabilidade de ocorrência do evento principal possa ser considerada alta, deve-se evidenciar que foram assumidos como hipótese alguns modos de falha que somente em extremo uso causariam a ocorrência do evento principal. Neste estudo foram mencionados alguns pontos quanto à aceitação do risco, assunto de grande controvérsia. Isto pode ser minimizado pelo fato que há muitos anos não houve nenhum caso de campanha no campo para qualquer correção do sistema de freio, ou seja, nenhuma das falhas apontadas pelo sistema de garantia colocou em risco a integridade dos passageiros.

Existem dados de campo suficientes para qualquer análise que se deseja conduzir em um veículo. Porém, durante a análise do sistema de freio verificou-se que a máquina de enchimento do fluido de freio não possui um banco de dados satisfatório para que uma boa análise seja propriamente conduzida. As recomendações para futuros estudos podem ser primeiro, a melhoria do banco de dados da máquina de enchimento - assim sempre será possível entender seu comportamento e tomar ações de manutenção evitando possíveis paradas da linha de montagem. Segundo, seria a condução de uma análise de risco mais elaborada somente na própria máquina de enchimento devido a sua complexidade e importância dentro do processo de enchimento do fluido de freio e finalmente, uma análise deste tipo em todos os pontos onde se monta os componentes do sistema de freio não somente na montadora, mas também nos fornecedores destes componentes.

\subsubsection{Análise da Manutenção Centrada em Confiabilidade}

Com o uso dos conceitos da manutenção centrada em confiabilidade foi possível estabelecer as práticas de manutenção nos componentes cujos modos de falha geram consequências que afetam diretamente o desempenho do sistema de aplicação de cola, ou seja, a qualidade de aplicação de cola no vidro do para brisa 
do produto. Para cada um dos modos de falha dos componentes empregou-se o método de seleção de práticas de manutenção conforme Kardec e Nascif (2001).

Embora esta análise tenha sido feita de forma simplificada, mostrou pontos críticos da célula de cola onde será preciso o levantamento de dados para implementar Manutenção Preventiva, pois afetam diretamente na qualidade do produto. Esta metodologia poderia ser mais completa ao se fazer uma análise mais detalhada, considerando-se todos os componentes passíveis de troca da célula de cola. Assim seria possível a identificação de outros elementos críticos e talvez não controlados atualmente. O método apresentado mostrou sua aplicabilidade, por este motivo é recomendável para outros dispositivos onde afetam diretamente satisfação do cliente e custos de garantia.

Este método também se aplicaria a outros sistemas, ou seja, um estudo em pontos de montagem de outros componentes apontados na tabela 4. Desta forma, também seria mostrado os planos de melhoria versus seus impactos na confiabilidade do produto final. Muitas vezes estes pequenos detalhes de propostas de melhoria versus seus impactos na confiabilidade são omitidos, pelo simples fato de não se saber quais são estes valores. Assim, a decisão final é deixada somente para a comparação de uma das variáveis de todo este processo: o custo.

\subsubsection{Análise do Projeto para Manufatura e Montagem}

Com o uso dos conceitos do projeto para manufatura e projeto para montagem foi possível estabelecer práticas de análise de projetos buscando melhoria do produto, redução de tempo de montagem, redução de componentes na montadora e finalmente redução de custo do produto. Através de um novo estudo do projeto, usando os critérios do DFMA, conseguiu-se uma melhoria de qualidade no produto final e uma redução de custo.

Este estudo de caso mostrou como as mudanças de projeto podem ser quantificadas para guiar o engenheiro do produto a projetos de menor custo e maior facilidade de montagem. Como uma ferramenta de qualidade o processo de DFMA nos mostra uma metodologia de como analisar as possíveis variações existentes em cada processo de fabricação. É de vital importância para os engenheiros de 
desenvolvimento o conhecimento dos processos de fabricação e das limitações de cada um deles. A figura 64 mostra o comparativo final entre os dois projetos, mostrando os ganhos em tempo e custo de montagem, eficiência e custo do projeto.

\begin{tabular}{|c|c|c|c|c|c|}
\hline \multicolumn{6}{|c|}{ DFMA: Comparação final entre Projetos } \\
\hline & $\begin{array}{c}\text { Qtde } \\
\text { Teórica de } \\
\text { Componentes }\end{array}$ & $\begin{array}{c}\text { Tempo de } \\
\text { Montagem } \\
\text { (s) }\end{array}$ & $\begin{array}{c}\text { Custo de } \\
\text { Montagem } \\
\text { (申) }\end{array}$ & $\begin{array}{c}\text { Eficiência } \\
\text { do Projeto } \\
\text { (\%) }\end{array}$ & 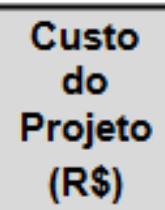 \\
\hline $\begin{array}{l}\text { Projeto } \\
\text { Inicial }\end{array}$ & 3 & 67 & 45 & 13,4 & 30,2 \\
\hline $\begin{array}{l}\text { Projeto } \\
\text { Proposto }\end{array}$ & 10 & 48 & 32 & 62,5 & 12,15 \\
\hline \multicolumn{6}{|c|}{ ganho de $\sim 30 \%$} \\
\hline
\end{tabular}

Figura 64 - DFMA: Comparação entre Projetos

Esta análise considerou somente os tempos de montagem dos componentes no veículo, ou seja, o tempo gasto na linha de montagem da montadora. Um mesmo estudo poderia ser conduzido no fornecedor e ainda se conseguir algumas melhorias do produto e talvez alguma redução de custo. Embora esta análise tenha sido feita de forma simplificada, buscando apenas mostrar a importância da ferramenta do DFMA, foi possível quantificar a melhoria. Isto também nos fornece um ganho de confiabilidade no produto, pois com a redução de componentes diminuem as chances de falhas prematuras, os erros de montagem e os custos de garantia. $\mathrm{O}$ método apresentado mostrou sua aplicabilidade, por este motivo é recomendado para outros projetos onde afetam diretamente os custos de garantia do produto.

Edwards (2002) faz o uso de DFMA focando na redução de custo dos produtos, mas não relaciona com nenhum ganho em confiabilidade do produto. Explica toda metodologia de DFMA aplicado em uma válvula, mas seu único foco é na redução de componentes e custo de manufatura.

Hart-Smith (1999) foca na aplicação da ferramenta DFMA como seu propósito original, ou seja, projetar para a manufatura e montagem e não simplesmente 
projetar para a redução de peças como tem sido aplicado em muitos casos. Seu objetivo é alcançado e coincidentemente acaba em alguns casos na redução de peças de um projeto. Porém, Hart-Smith também não faz nenhuma ligação entre melhoria de processo e montagem com ganho de confiabilidade nas análises feitas em seu artigo, não cita que embora não exista redução de componentes, há diminuição de erros de montagem e consequentemente diminuição de futuras falhas do produto.

Selvaraj (2008) faz um estudo mostrando que a aplicação da ferramenta de DFMA reduz o tempo de desenvolvimento e pode também reduzir o custo do produto, aplicando os conceitos de DFMA no desenvolvimento do produto conseguiu-se melhor integração entre as peças montadas e com isto se obteve diminuição do tempo de montagem. Embora exista uma forte relação entre esta proposta e o ganho de confiabilidade, isto não foi o foco do estudo e em nenhum momento este ganho foi mencionado. Isto mostra que estudos de DFMA focam mais na redução de componentes, tempo de desenvolvimento e custos. Não é explorado o ganho de confiabilidade que se obtém nestes estudos, mas apenas a redução de custo.

Gerhardt (1991) mostra em seu estudo como a ferramenta DFMA foi introduzida em uma empresa de compressores, como a foram treinados os engenheiros e sua grande aceitação nos times de desenvolvimento. Mostra a grande utilidade da ferramenta através de estudos de caso reais da empresa, porém não explora que além da redução de componentes para montagem o uso desta ferramenta traz redução de custo em desenvolvimento e ganho de confiabilidade ao produto. 


\section{CONCLUSÕES E RECOMENDAÇÕES}

\subsection{Conclusões}

A proposta deste trabalho mostra uma metodologia para a identificação de sistemas e/ou componentes críticos com base em incidência de falhas, baseando-se na consulta ao banco de dados. Embora o presente trabalho tenha considerado apenas os itens quanto a sua incidência de falhas, pode também ser aplicado considerando os itens de maior custo de garantia de produtos em produção. Para o uso do banco de dados foram feitas considerações importantes para que a confiabilidade estimada seja a mais próxima possível do seu real valor. Com isto foi possível se determinar quais foram os sistemas mais críticos das plataformas de veículos em estudo.

Após a identificação dos sistemas e/ou componentes, esta metodologia propõe o uso de técnicas de qualidade para a melhoria nos futuros desenvolvimentos, que nada mais é do que projetar para a qualidade, identificando características que representam potenciais falhas no produto em estudo e melhorando-as, não somente no produto corrente, mas tornando possível seu uso em futuros desenvolvimentos.

Embora esta seja uma simples afirmação, o presente estudo indicou a existência de sistemas e/ou componentes com o mesmo conceito de desenvolvimento que afetaram as quatro plataformas de veículos analisadas. Este resultado de análise mostrou espaço para melhoria de qualidade em muitos componentes dos produtos em estudo.

A vantagem desta proposta é que uma comparação feita entre todas as plataformas de veículos poderá identificar sistemas e/ou componentes semelhantes e críticos quanto a sua incidência de falhas, os quais afetam a confiabilidade final dos produtos. Pode-se assim, concentrar esforços para a solução de problemas comuns em todos os produtos analisados, também pode-se identificar quais sistemas e/ou componentes são os que mais afetam os custos de garantia nestas plataformas em estudo. Mesmo que se decida não fazer nada quanto à melhoria em determinado sistema e/ou componente mostra também quais tem melhor desempenho no campo para seu uso em futuros desenvolvimento, mesmo sem nenhuma melhoria. 
Pode-se dizer que este trabalho definiu seu objetivo geral e mostrou passo a passo a proposta de um modelo para selecionar e implementar melhorias em um produto com o uso de ferramentas tradicionais de qualidade e confiabilidade, mostrando qual a ligação entre cada uma delas com o ganho de confiabilidade na população de veículos em estudo. No decorrer dos estudos, observou-se que esta proposta traz um modelo inédito, pois na literatura não apresentava nenhum modelo que contemplasse todos os passos mostrados neste trabalho. Depois, com as propostas de melhoria da qualificação, os estudos avançaram e o modelo foi melhorado quando da comparação entre as contribuições deste modelo e dos modelos pesquisados, assim, tornou-se mais fácil observar a contribuição desta proposta de estudo. Considera-se ainda uma contribuição deste trabalho o levantamento, organização e seleção de sistemas e/ou componentes do setor automotivo, que certamente terão validade para aqueles interessados no projeto e desenvolvimento de produtos neste importante setor econômico.

Após a conclusão deste trabalho, alcançando-se o objetivo geral e os específicos da pesquisa, percebe-se que este trabalho também apresenta limitações. Uma das limitações observadas durante o desenvolvimento deste estudo é que a coleta de informações de campo e sua análise são trabalhosas, requerem análises de muitos dados para cada uma das plataformas de veículos estudadas para que se tenham informações suficientes para propor qualquer melhoria no produto. Outra limitação observada nesta proposta é que sua completa aplicação requer conhecimento e experiência em todas as ferramentas aqui apresentadas, o que normalmente não acontece com todos os engenheiros de desenvolvimento. Além disto, sugere-se que para cada plataforma de veículos se determine os dados censurados conforme mostrados neste estudo. Isto deixará o estudo de confiabilidade de cada um deles mais preciso, pois cada tipo de veículo tem um usuário com comportamento diferente e isto traz diferenças quanto à estimativa dos dados censurados. Por fim, observou-se outra limitação do método de pesquisa é que para determinados componentes apontados neste estudo a melhor maneira de se melhorar o produto é quando da sua substituição por outra tecnologia, como por exemplo, as lanternas, faróis e chicotes do motor. 


\subsection{Recomendações para Trabalhos Futuros}

Este estudo mostrou uma metodologia para a melhoria de um produto que pode ser aplicada durante o desenvolvimento de um novo produto ou para um produto já em produção e para tal algumas hipóteses foram assumidas. Quando se trabalha com dados de garantia é sempre útil entender cada mecanismo de falha, e tratá-los de forma independentes um do outro. Existem casos, porém, onde é possível agrupar alguns modos de falha, por exemplo, uma falha na composição química de uma tinta de pintura do veículo, pode se manifestar de diversas maneiras como trincas na pintura, descascando ou perdendo a sua cor original. Nestes casos os modos de falha não devem ser considerados independentes e sim como um único modo de falha, nestas situações, recomenda-se considerar todos estes modos de falha como sendo um único modo de falha. Cada proposta de melhoria deve estar ligada aos ganhos de qualidade e percepção do cliente para que justifique os custos de investimentos, caso contrário dificilmente a nova proposta será aprovada.

Normalmente os objetivos de melhoria são propostos no início de cada novo desenvolvimento e a grande dificuldade encontrada é saber o quanto cada decisão tomada durante o desenvolvimento afetará a confiabilidade final do produto. Porém, com a metodologia mostrada neste estudo é possível escolher os melhores sistemas em uso, melhorá-los com as ferramentas de qualidade propostas e reutilizá-los em novos desenvolvimentos ou mesmo nos produtos correntes. Uma melhoria nesta metodologia seria o entendimento do comportamento dos clientes nos mercados a que se destina o produto, neste caso os dados censurados de cada país, as condições de uso, suas estradas, etc. Isto ajudaria muito durante as investigações de causa raiz de problemas e nos cálculos de confiabilidade. Isto foi mostrado quando da comparação entre o comportamento dos clientes no mercado nacional e europeu. Também se pode adotar como hipótese que um usuário comum acumule 40.000 $\mathrm{km} / \mathrm{ano}$ em seu veículo e com este dado estimar a quantidade de dados censurados a cada $2.500 \mathrm{~km}$ para toda população. A confiabilidade é uma foto em determinado instante de tempo e a diferença mostrada entre as confiabilidades do componente em estudo se deve principalmente a diferença de comportamento dos usuários. 
Outro ponto de melhoria seria a introdução ao banco de dados com mais opções de consultas, como por exemplo, o comparativo usado neste estudo com a opção de escolha das plataformas de veículos, separando-os por sistema, componente e ano modelo. Isto ajudaria na visualização das prioridades de trabalho por custo e incidência não somente de uma plataforma de veículo, mas sim entre todas elas.

A ferramenta de DFMA mostrou seu valor quando do seu uso em um sistema de um produto que já esta em produção, mas também pode e deve ser aplicados em muitos outros componentes novos ou modificados que serão utilizados em futuros desenvolvimentos. Neste ponto fica a recomendação do uso constante dos conceitos de DFMA em qualquer desenvolvimento de um novo produto.

Quanto à manutenção centrada em confiabilidade, sabe-se que o método também se aplica a todo complexo fabril, mas um estudo mais detalhado poderia apontar áreas da linha de montagem que poderia afetar a confiabilidade do produto quando da sua parada ou falha. Desta forma, seria possível propor planos de melhoria versus seus respectivos impactos na confiabilidade do produto final.

Adicionalmente pode-se fazer uma comparação entre o método "Projeto para Seis Sigmas" (DFSS - Design for Six Sigma), cuja divulgação tem-se intensificado nestes últimos anos, e a metodologia proposta neste trabalho. O primeiro método deve ser usado no desenvolvimento de novos produtos visando obter desempenho muito satisfatório em características específicas, definidas como críticas para o consumidor. Tais características são definidas a partir de pesquisas de expectativa com relação à qualidade do produto. O método DFSS tem por objetivo aperfeiçoar o desempenho de um produto com relação às características críticas. Para tanto, tal método baseia-se fortemente no estudo dos desejos dos consumidores e na transformação destes em requisitos de projeto a serem atendidos pela Engenharia do Produto. As ferramentas de análise tipicamente utilizadas neste método são: Desdobramento da Função Qualidade, Análise de Modos e Efeitos de Falhas e simulação computacional.

O método proposto nesta tese tem por objetivo maximizar a confiabilidade de subsistemas específicos de um produto, neste caso o uso automotivo, os quais são selecionados baseando-se na análise de dados de falha de campo. Tal maximização reduz os custos associados à garantia do produto e pode indiretamente influenciar a qualidade do produto percebida pelo consumidor. Entretanto, o objetivo do método 
proposto, é desenvolver subsistemas críticos de um produto, sob o ponto de vista de segurança, custos de garantia e até mesmo requisitos dos clientes, com maior confiabilidade. O método baseia-se no uso de ferramentas de busca de causa raiz das falhas e ferramentas estatísticas de análise de confiabilidade.

Pode-se afirmar que os princípios do DFSS podem ser associados ao método proposto, ou seja, visando a maximização da confiabilidade como um requisito do cliente. Dessa forma adicionam-se mais parâmetros no momento de selecionar os subsistemas críticos quando da análise do banco de dados.

Finalmente, uma recomendação para futuros desenvolvimentos seria a própria melhoria do banco de dados, tornando possíveis consultas múltiplas de plataformas de veículos por famílias de sistemas. Isto mostraria de imediato quais os sistemas e/ou componentes que mais afetam as plataformas de veículos em incidência e em custo e por último fica a sugestão da mudança da divisão do trabalho por sistemas e não por plataformas de veículos. 


\section{REFERÊNCIAS BIBLIOGRÁFICAS}

Abernethy, R. B.: The Weibull Handbook. Fifth Edition by Dr. Robert B. Abernethy Author and Publisher (2004).

Almannai, B.; Greenough, R.; Kay, J.: A decision support tool based on QFD and FMEA for selection of manufacturing automation technologies. International Journal of Robotics and Computer-Integrated Manufacturing. 24 (2008) 501507.

Attardi, L.; Guida, M.; Pulcini, G.: A mixed-Weibull regression model for the analysis of automotive warranty data. Reliability Engineering and System Safety, 87 (2005) 265-273. Elsevier.

Aven, T.; Heide, B.: Reliability and validity of risk analysis. Reliability Engineering and System Safety, 94 (2009) 1862-1868. Elsevier.

Avontuur, G. C.; Werf, K.: An implementation of reliability analysis in the conceptual design phase of drive trains. Reliability Engineering and System Safety. 73 (2001) 155-165. Elsevier.

Ayyub, M. B.: The Engineering Handbook - Second Edition - chapter 207 Risk Analysis and Management. CRC Press LLC, 2005.

Barkai, J.: Quality Improvement and Warranty Cost Containment: Better Answers are in the Text. SAE Technical Papers Series 2004-01-2666.

Bennett, J. C.; et al.: Risk analysis techniques and their application to software development. Reliability Engineering and System Safety. 95 (1996) 467-475. Elsevier.

Booker, J.D.: Industrial Practice in Designing for Quality. The International Journal of Quality and Reliability Management; 2003; 20, 2/3; ABI/INFORM Complete pg.288. 
Boothroyd, G.; Dewhurst, P.; Knight, W.: Product Design for Manufacture and Assembly. Marcel Dekkers, Inc. New York 1994.

Broome, H.; McComb, M.: Improving Reliability by Addressing Early Failures: Leveraging the use of Modern Quality Tools. Annual Quality Congress Proccedings; 2004; 58 ABI/INFORM Complete; pg 237.

Campbell, R. I.: Product Development Process from Quality and Reliability Perspectives. SAE Technical Paper Series. 2006-01-1421.

Campean, I.F.; Kuhn, F.P., Khan, M.K.: Reliability Analysis of Automotive Field Failure Warranty Data. University of Bradford, Richmond Building, Bradford. (2000).

Carazas, F.J.G.: Análise de Disponibilidade de Turbinas a Gás Empregadas em Usinas Termoelétricas a Ciclo Combinado. Dissertação - Escola Politécnica da Universidade de São Paulo, 2006.

Cassanelli, G.; et al.: Failure Analysis-assisted FMEA. Microeletronics Reliability, 46 (2006) 1795-1799. Elsevier.

Cheng, Z.; et al.: A framework for intelligent reliability centered maintenance analysis. Reliability Engineering and System Safety, 93 (2008) 784-792. ScienceDirect.

Chukova, S.; et al.: Warranty analysis: An approach to modeling imperfect repairs. International Journal of Production Economics, 89 (2004) 57-68. Elsevier.

Cizelj, R. J.; Kljenak, M. I.: Component reliability assessment using quantitative and qualitative data. Reliability Engineering and System Safety, 71 (2001) 81-95. Elsevier.

Clark, K.B., Fujimoto, T.: Product Development Performance. Harvard Business School Press, Boston, Massachusetts, (1991). 
Coit, D.W.; Dey, K.A.: Analysis of Grouped Data Field-Failure Reporting Systems. Reliability Engineering and Systems Safety, 65 (1999) 95-101. Elsevier.

Deshpande, V.S.; Modak, J.P.: Application of RCM to medium scale industry. Reliability Engineering and System Safety, 77 (2002) 31-43. Elsevier.

Dhillon, B.S.: Design Reliability - Fundamentals and Applications. CRR press, New York, 1999.

Dodson, B.; Nolan, D.: Reliability Engineering Bible. Quality Publishing, Tucson Arizona, (1995). 489p. Elsevier.

Eisinger, S.; Rakowsky, U. K.: Modeling of uncertainties in reliability centered maintenance - a probabilistic approach. Reliability Engineering and System Safety, 71 (2001) 158-164, Elsevier.

Edwards, K. L.: Towards more strategic product design for manufacturing and assembly: priorities for concurrent engineering. Materials and Design 23 (2002) 651-656.

Fynes, B.; Búrca, S.: The effects of design quality on quality performance. International Journal of Production Economics. 96 (2005) 1-14.

Frosdik, S.: The techniques of risk analysis are insufficient in themselves. Disater Prevention and Management. Volume 6 - Number 3 - 1997 - pp 165-177. MCB University Press.

Gerhardt, D.J.; Hutchinson W.R.: Dseging for Manufacturing and Assembly: Case studies in its implementation. International Journal of Advanced Manufacturing Technology, 6 (1991) 131-140.

Hart-Smith, L.J.: Design for Assembly (DFA) - The Key to Making Parts-Count Reduction Profitable. SAE Technical Papers Series 1999-01-2281. 
Hassan, A.; et al.:Conceptual process planning - an improvement approach using QFD, FMEA, and ABC methods. International Journal of Robotics and Computer-Integrated Manufacturing. 26 (2010) 392-401.

Henley, E. J.; Kumamoto, H.: Probabilistic Risk Assessment - Reliability Engineering, Design, and Analysis - IEEE PRESS, 1992.

Hill, V. L.: A simulation model of warranty analysis. International Journal of Production Economics, 22 (1991) 131-140.

Hillmer, S.; Kocabasoglu, C.: Using Quality Data to Learn Abaut Customer Needs: Understanding Employer Desires When Designing a MBA Program. The Quality Management Journal; 2008; 15,2; ABI/INFORM Complete pag. 51.

Hyman, B.: Fundamentals of Engineering Design. Prentice-Hall (1998).

James, I.; Marshall, J.; Walls, L.: Improving design for reliability with in service data analysis. Proccidings Annual Reliability and Maintainability Symposium. 0-78037348-0/02, 2002. IEEE.

Jiang, R.; Murthy, D.N.P.: Impact of quality variations on product reliability. Reliability Engineering and System Safety, 91 (2009) 490-496. Elsevier.

Jung, M.; Bai, D. S.: Analisis of field data under two dimensional warranty. Reliability Engineering and System Safety, 92 (2007) 135-143, Elsevier.

Jones, J.A.; Hayes, J.A.: Use of a field failure database for improvement of product reliability. Reliability Engineering and System Safety, 55 (1997) 131-134. Elsevier.

Kardec, A.; Nascif, J.: Manutenção Função Estratégica. Qualitymark, Rio de Janeiro, 2001. 
Kapur, K.C.; Lamberson, L.R.: Reliability in Engineering Design. Department of Industrial Engineering and Operations Reseach. Wayne State University. Detroit, Michigan. John Wiley \& Sons, 1977

Kim, S.; Nakhai, B.: The dynamics of quality costs in continuous improvement. International Journal of Quality \& Reliability Management. Vol. 25, 8 (2008) 842-859. Emerald.

Krasich, $M_{.:}$Use of tree analysis for evaluation of system reliability improvement in design phases. Annual Reliability and Maintainability Symposium, 0-7803-5848-1. 2000.

Krishnamoorthi, K.S.: Reliability Methods for Engineers. (1992) ASQ Quality Press.

Kuijt-Evers, L. F. M.; Morel, K. P. N.: Application of the QFD as a design approach to ensure comfort in using hand tools: Can design team complete the House of Quality appropriately? Journal of Applied Ergonomics. 40 (2009) 519-526.

Kumar, S.; Chattopadhyay, G.; Kumar, U.: Reliability improvement through alternative designs - A case study. Reliability Engineering and System Safety, 92 (2007) 983-991. Elsevier.

LAFRAIA, J.R.B.: Manual de Confiabilidade, Mantenabilidade e Disponibilidade. Qualitymark, Rio de Janeiro, 2001.

Leitch, R.: Reliability Analysis for Engineers. Oxford Press, New York. (1995).

Lewis, W. P.; Samuel, A. E.: An analysis of designing for quality in the automotive industry. 1991. Butterworth-Heinemann Ltd.

Liker, J.: The Toyota Product Development System. Productivity Press - New York 2006. 
Linebaugh, K.: Fábricas Flexíveis Garantem Expansão da Honda nos EUA. The Wall Street Journal, East Liberty, EUA, 01/Outubro/2008.

Luko, S. N.: A Review of the Weibull Distribution and Selected Engineering Applications. SAE Technical Paper Series. 1999-01-2859.

Majdara, A.; Wakabayashi, T.: Component-based modeling of systems for automated fault tree generation. Reliability Engineering and System Safety, Elsevier Science Limited, 94 (2009) 1076-1086.

Majeske, K.D.: A mixture model for automotive warranty data. Reliability Engineering and System Safety, Elsevier Science Limited, 2003.

Molenaar, P. A.; et al.: Why do quality and reliability feedback loops not always work in practice: a case study. Reliability Engineering and System Safety, 75 (2002) 295-302. Elsevier

Morgan, J.: High Performance Product Development: A System Approach to a Lean Product Development Process. Dissertation submitted to The University of Michigan, 2002.

Morettin, P.A.; Bussab, W.O.: Estatística Básica. Editora Saraiva 5ª Edição, 2004

MOUBRAY, J.: RCM - Reliability Centered Maintenance. Industrial Press Inc. 1992.

Murad, C.A.; Martha de Souza, G.F.: Análise de Confiabilidade de Componentes e Sistemas. SAE 2006-01-2914.

Murthy, D.N.P.; Virtanen, S.: Investiment in new product reliability. Reliability Engineering and System Safety, 94 (2009) 1593-1600. Elsevier.

Neubeck, K.: Practical Reliability Analysis. Pearson Prentice Hall (2004), LTD 338p. 
O'Connor, P. D. T.: Practical Reliability Engineering. John Wiley \& Sons $\left(2002-4^{\text {th }}\right.$ Edition). LTD. 513p.

O'Connor, P. D. T.: Standards in reliability and safety engineering. Reliability Engineering and System Safety, 60 (1998) 173-177. Elsevier.

Park, T.; Kim, K.: Determination of optimal set of design requirements using house of quality. Journal of Operations Management 16 (1998) 569-581.

PRIEST, J.W., SÁNCHEZ, J.M.: Product Development and Design for Manufacturing. Marcel Dekker Inc., New York, 2001

Pujadas, W.; Chen, F. F.: A reliability centered maintenance strategy for a discrete part manufacturing facility. Computers Industrial Engineering vol. 31 No.1/2, pp 244-241, 1996.

Reliability \& Maintenance Analyst: Engineered Software, Inc. P.O. Box 80935 Rochester, MI - www.engineeredsoftware.com

Righini, R.: A New Method for Reliability Centerded Maintenance Improvement. SAE Technical Papers Series 1999-01-3364.

Rouvroye, J. L.; van den Bliek, E. G.: Comparing safety analusis techniques. Reliability Engineering and System Safety, 75 (2002) 289-294. Elsevier.

Segismundo, A.; Miguel, P. A. C.: Failure mode and effects analysis (FMEA) in the contexto f risk management in new product development. International Journal of Quality \& Reliability Management Vol. 25 No.9, 2008, pp 899-912.

Selvaraj, P.; Adithan, M.: An integrated approach to design for manufacturing and assembly based on reduction of product development time and cost. International Journal of Advanced Manufacturing Technology, 42 (2009) 13-29. 
Selvik, J. T.; Aven, T.: A framework for reliability and risk centered maintenance. Reliability Engineering System Safaty (2010) doi:10.1016/j.ress.2010.08.001

Setijono D.; Dahlgaard, J. J.: The value of quality improvement. International Journal of Quality \& Reliability Management. Volume 25, Number 8, 2008, 292-312. Emerald.

SINGH, B.K.R.N.: Reliability Analysis and Prediction with Warranty Data. CRC Press, Taylor and Francis Group, 2009.

SLACK, N., CHAMBERS, S., JOHNSTON, R.: Administração da Produção. Atlas, 2002.

Tang, J.: Mechanical system reliability analysis using a combination of graph theory and Boolean function. Reliability Engineering and System Safety, 72 (2001) 21-30. Elsevier.

Vatn, J.: An overall model for maintenance optimization. Reliability Engineering and System Safety, 51 (1996) 241-257. Elsevier Science Limited.

Volkanovski, A.; Cepin, M.; Mavko, B.: Application of the tree analysis for assessment of power system reliability. Reliability Engineering and System Safety, 94 (2009) 1116-1127. Elsevier.

Walls, L.; Quigley, J.: Learning to improve reliability during system development. European Journal of Operational Research. 119 (1999) 495-509.

Wasserman G. S.: Reliability Verification, Testing, and Analysis in Engineering Design. Wayne State University, Detroit, Michigan USA, Marcel Dekker Inc., 2002.

Yadav, O.P.; Goel, P.S.: Customer satisfaction driven quality improvement target planning for product development in automotive industry. International Journal of Production Economics 113 (2008) 997-1011. 
ZHOU, J.: Reliability and Robustness Mindset in Automotive Product Development for Global Markets. SAE 2005-01-1212.

Zhu, Y.; Alard, R.: Design Quality: The Crucial Factor for Product Quality Improvement in International Production Networks. 978-1-4244-2108-4/08-2008 IEEE. 
ANEXO 1: Distribuição F, com 95\% de confiança. (fonte: Morettin e Bussab - 2004)

\begin{tabular}{|c|c|c|c|}
\hline \multicolumn{2}{|c|}{ 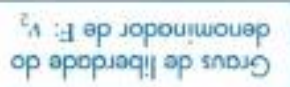 } & 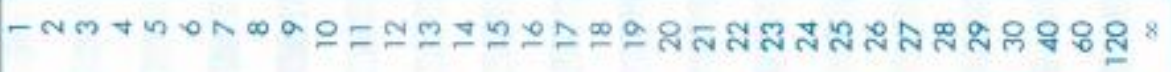 & \\
\hline 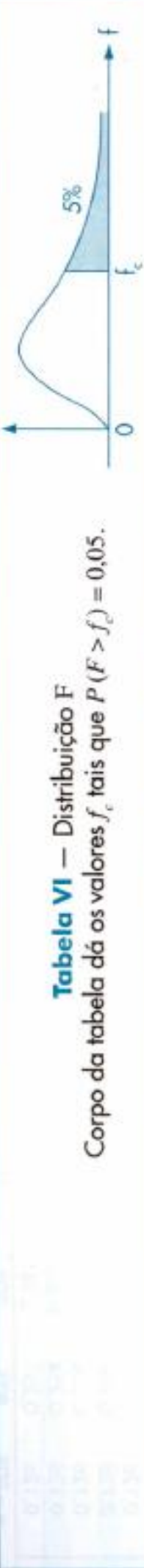 & 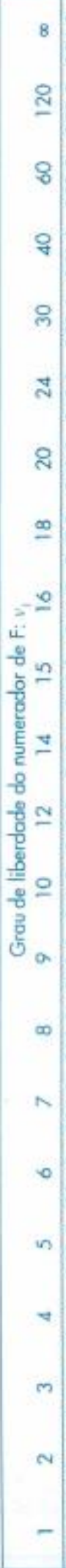 & 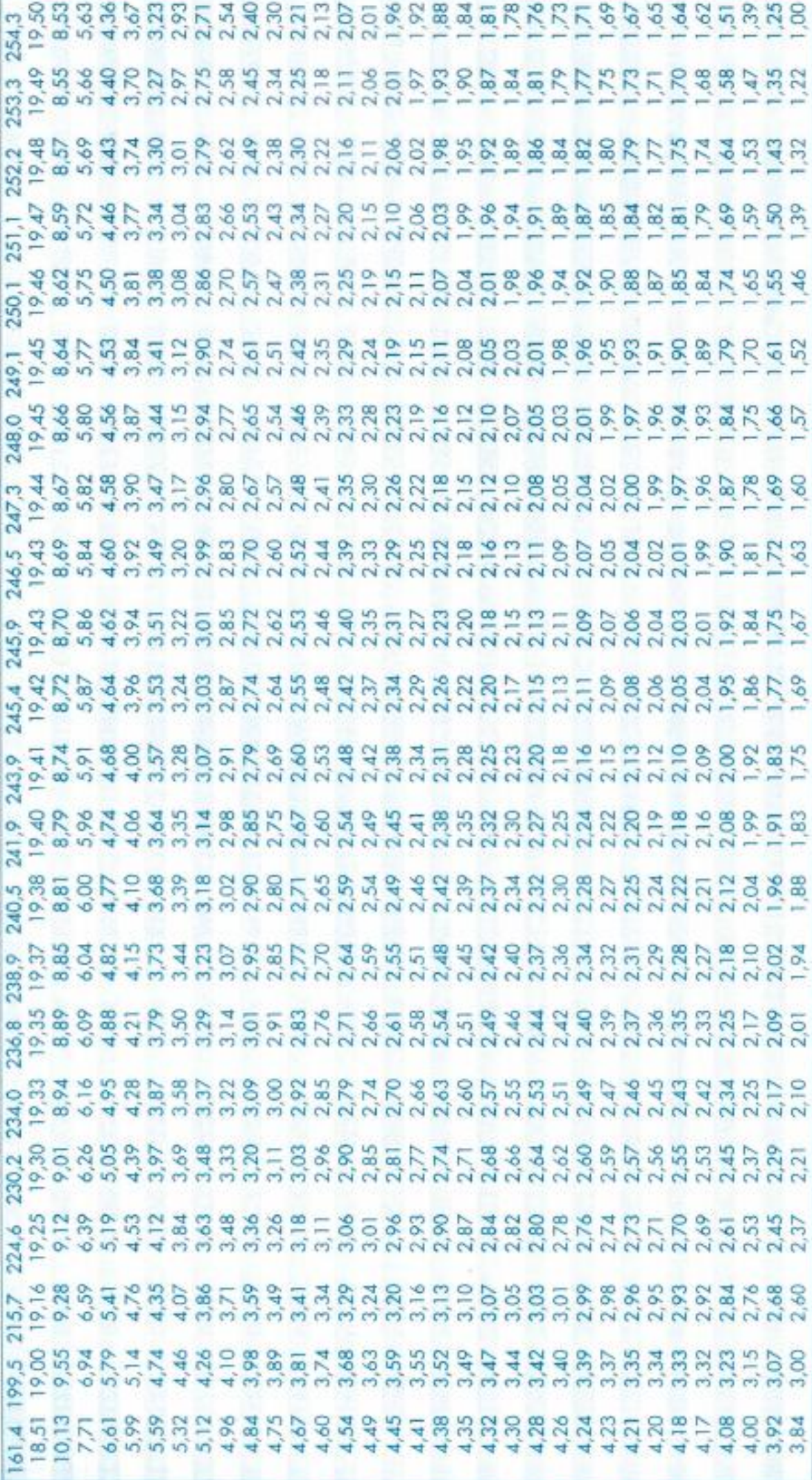 & \\
\hline & & 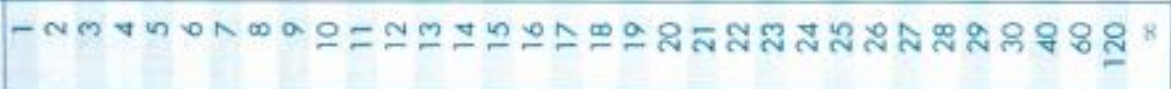 & \\
\hline
\end{tabular}


Anexo 2: Teste de Hipótese - Projeto ALFA vs. GAMA

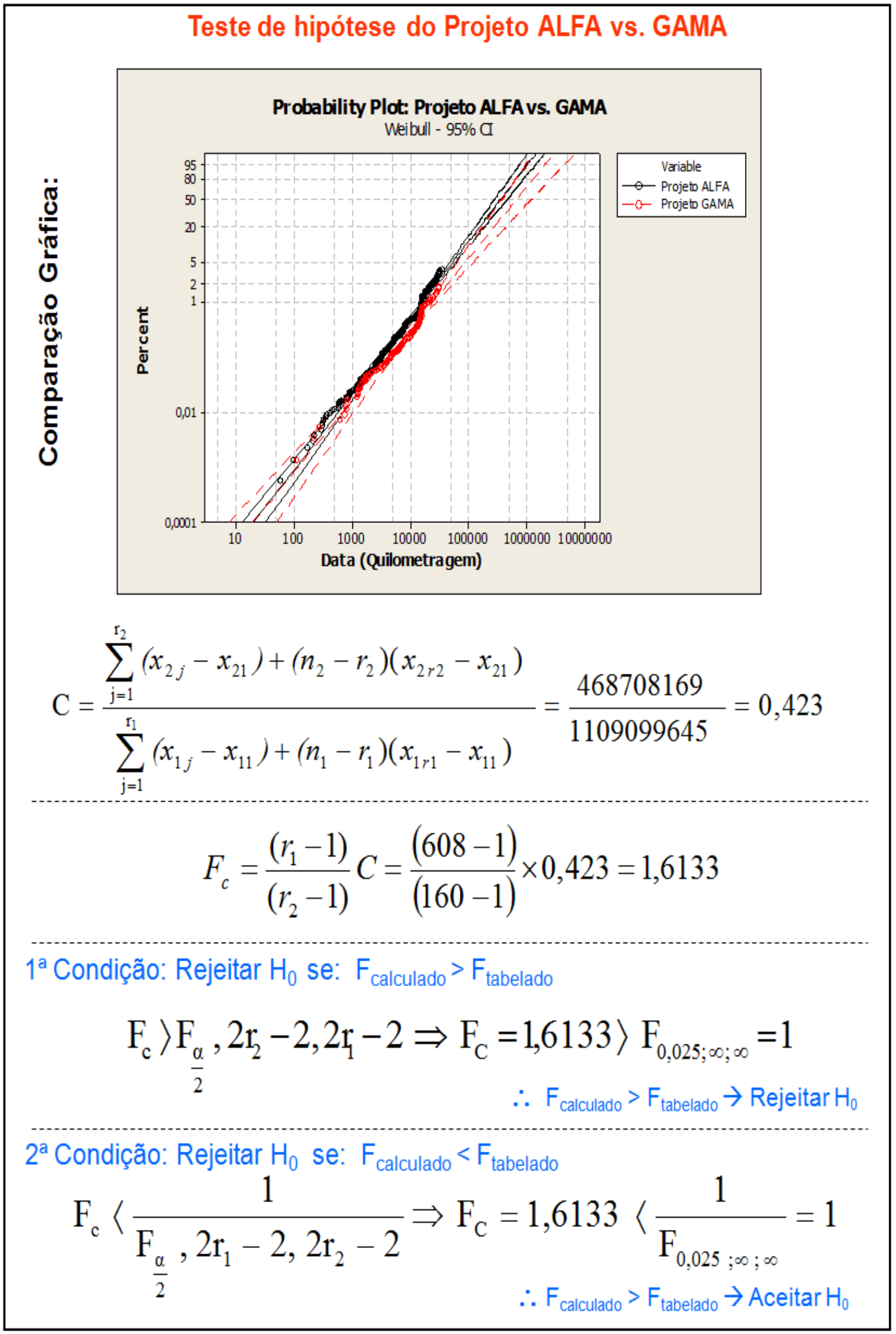


Anexo 3: Teste de Hipótese - Projeto ALFA vs. DELTA

Teste de hipótese do Projeto ALFA vs. DELTA

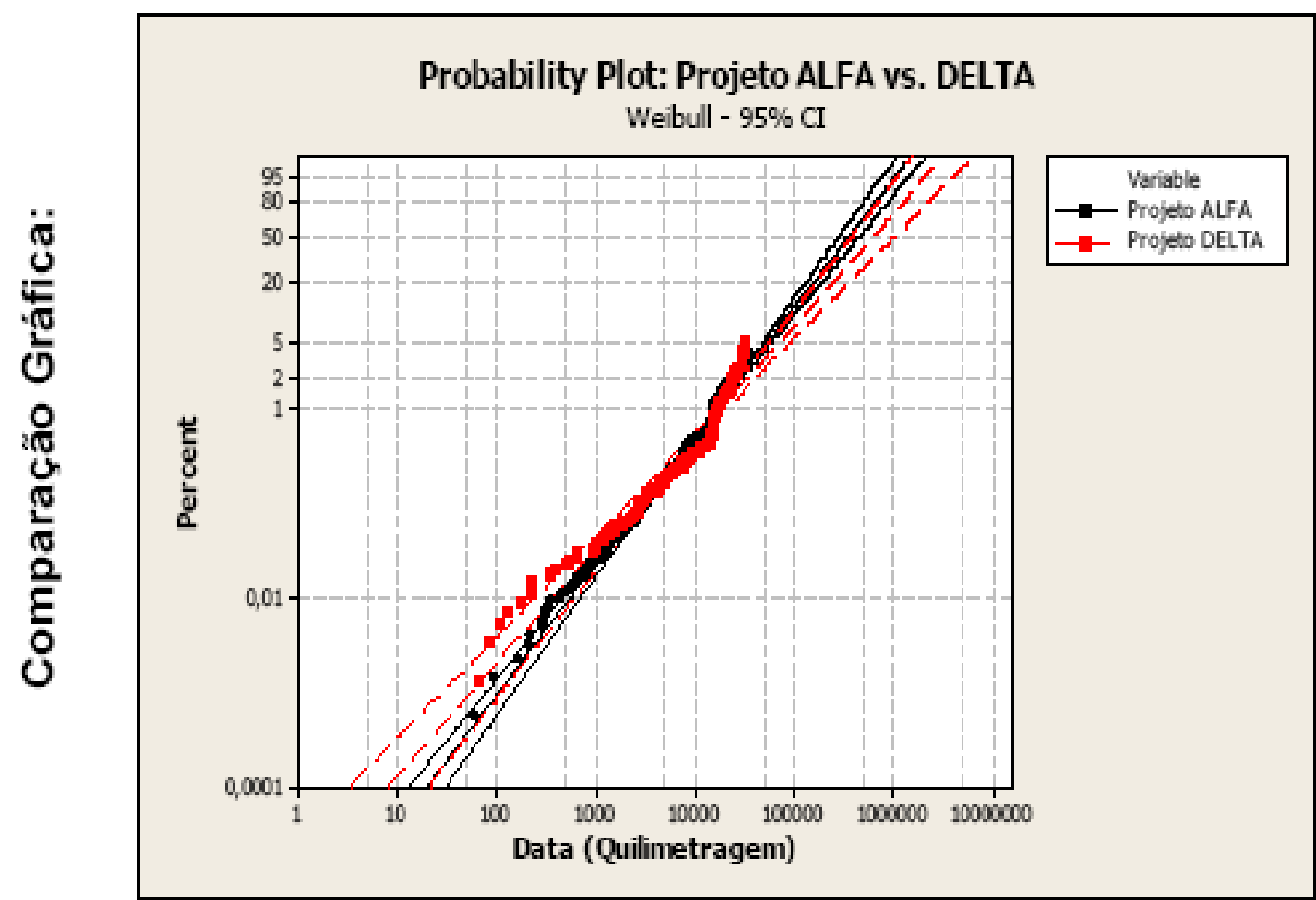

$\mathrm{C}=\frac{\sum_{\mathrm{j}=1}^{\mathrm{r}_{2}}\left(x_{2 j}-x_{21}\right)+\left(n_{2}-r_{2}\right)\left(x_{2 r 2}-x_{21}\right)}{\sum_{\mathrm{j}=1}^{\mathrm{r}_{1}}\left(x_{1 j}-x_{11}\right)+\left(n_{1}-r_{1}\right)\left(x_{1 r 1}-x_{11}\right)}=\frac{480910141}{1109099645}=0,434$

$$
F_{c}=\frac{\left(r_{1}-1\right)}{\left(r_{2}-1\right)} C=\frac{(608-1)}{(232-1)} \times 0,434=1,1394
$$

$1^{\text {a }}$ Condição: Rejeitar $\mathrm{H}_{0}$ se: $\mathrm{F}_{\text {calculado }}>\mathrm{F}_{\text {tabelado }}$

$$
\begin{array}{r}
\mathrm{F}_{\mathrm{c}}>\mathrm{F}_{\frac{\alpha}{2}}, 2 \mathrm{r}_{2}-2,2 \mathrm{r}_{1}-2 \Rightarrow \mathrm{F}_{\mathrm{C}}=1,1394>\mathrm{F}_{0,025 ; \infty ; \infty}=1 \\
\therefore \mathrm{F}_{\text {calculado }}>\mathrm{F}_{\text {tabelado }} \rightarrow \text { Rejeitar } \mathrm{H}_{0}
\end{array}
$$

$2^{\mathrm{a}}$ Condição: Rejeitar $\mathrm{H}_{0}$ se: $\mathrm{F}_{\text {calculado }}<\mathrm{F}_{\text {tabelado }}$

$$
\begin{aligned}
& \mathrm{F}_{\mathrm{c}}\left\langle\frac{1}{\mathrm{~F}_{\frac{\alpha}{2}}, 2 \mathrm{r}_{\mathrm{l}}-2,2 \mathrm{r}_{2}-2} \Rightarrow \mathrm{F}_{\mathrm{C}}=\right. 1,1394<\frac{1}{\mathrm{~F}_{0,025 ; \infty ; \infty}}=1 \\
& \therefore \mathrm{F}_{\text {calculado }}>\mathrm{F}_{\text {tabelado }} \rightarrow \text { Aceitar } \mathrm{H}_{0}
\end{aligned}
$$


Anexo 4: Teste de Hipótese - Projeto BETA vs. GAMA

Teste de hipótese do Projeto BETA vs. GAMA

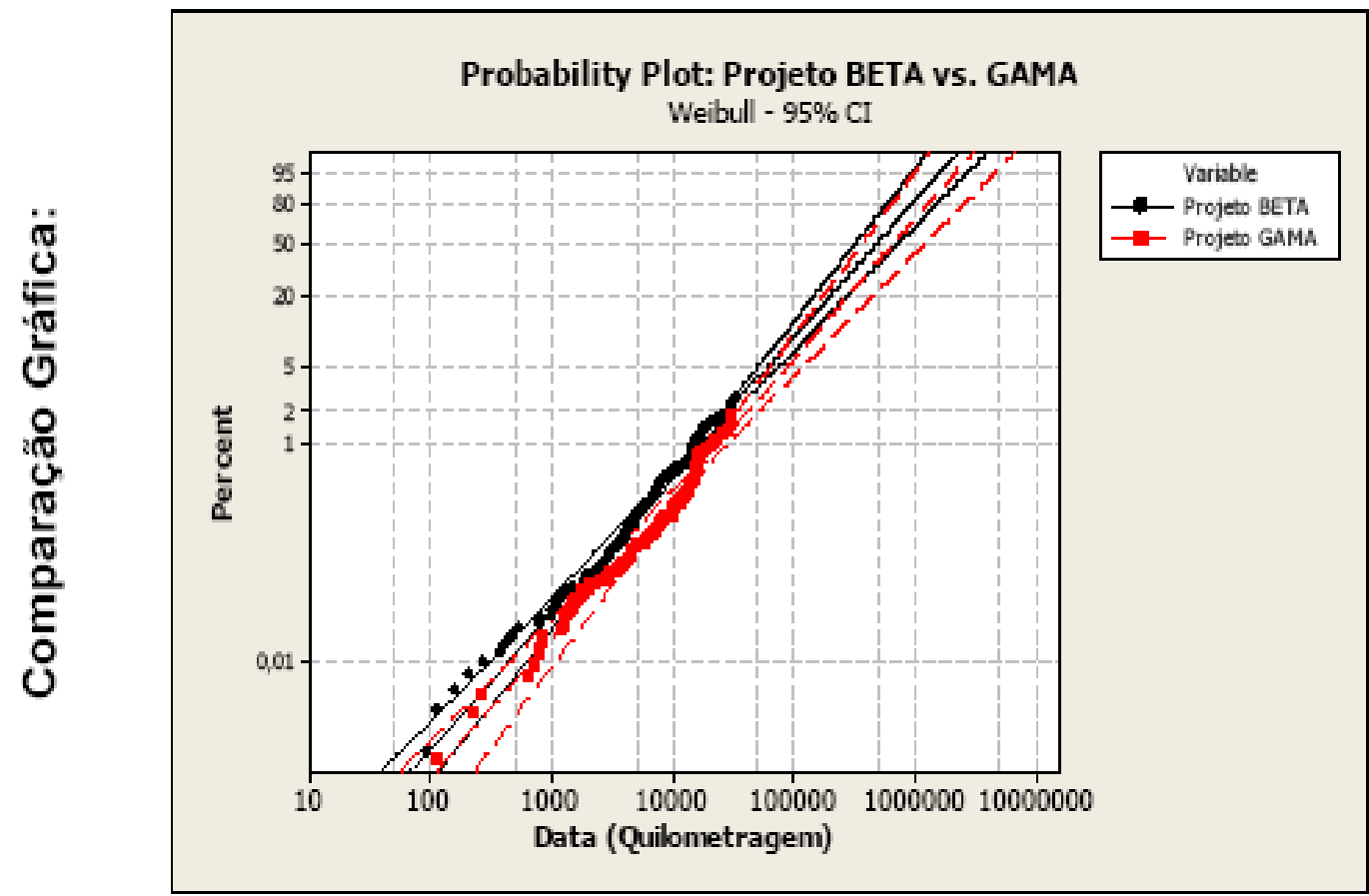

$$
\mathrm{C}=\frac{\sum_{\mathrm{j}=1}^{\mathrm{r}_{2}}\left(x_{2 j}-x_{21}\right)+\left(n_{2}-r_{2}\right)\left(x_{2 r 2}-x_{21}\right)}{\sum_{\mathrm{j}=1}^{\mathrm{r}_{1}}\left(x_{1 j}-x_{11}\right)+\left(n_{1}-r_{1}\right)\left(x_{1 r 1}-x_{11}\right)}=\frac{468708169}{442583946}=1,059
$$

$$
F_{c}=\frac{\left(r_{1}-1\right)}{\left(r_{2}-1\right)} C=\frac{(248-1)}{(160-1)} \times 1,059=1,6452
$$

1 ${ }^{\text {a }}$ Condição: Rejeitar $\mathrm{H}_{0}$ se: $\mathrm{F}_{\text {calculado }}>\mathrm{F}_{\text {tabelado }}$

$$
\begin{array}{r}
\mathrm{F}_{\mathrm{c}}>\mathrm{F}_{\frac{\alpha}{2}}, 2 \mathrm{r}_{2}-2,2 \mathrm{r}_{1}-2 \Rightarrow \mathrm{F}_{\mathrm{C}}=1,059>\mathrm{F}_{0,025 ; \infty ; \infty}=1 \\
\therefore \mathrm{F}_{\text {calculado }}>\mathrm{F}_{\text {tabelado }} \rightarrow \text { Rejeitar } \mathrm{H}_{0}
\end{array}
$$

$2^{\mathrm{a}}$ Condição: Rejeitar $\mathrm{H}_{0}$ se: $\mathrm{F}_{\text {calculado }}<\mathrm{F}_{\text {tabelado }}$

$$
\begin{aligned}
& \mathrm{F}_{\mathrm{c}}<\frac{1}{\mathrm{~F}_{\frac{\alpha}{2}}, 2 \mathrm{r}_{1}-2,2 \mathrm{r}_{2}-2} \Rightarrow \mathrm{F}_{\mathrm{C}}= 1,061<\frac{1}{\mathrm{~F}_{0,025 ; \infty ; \infty}}=1 \\
& \therefore \mathrm{F}_{\text {calculado }}>\mathrm{F}_{\text {tabelado }} \rightarrow \text { Aceitar } \mathrm{H}_{0}
\end{aligned}
$$


Anexo 5: Teste de Hipótese - Projeto BETA vs. DELTA

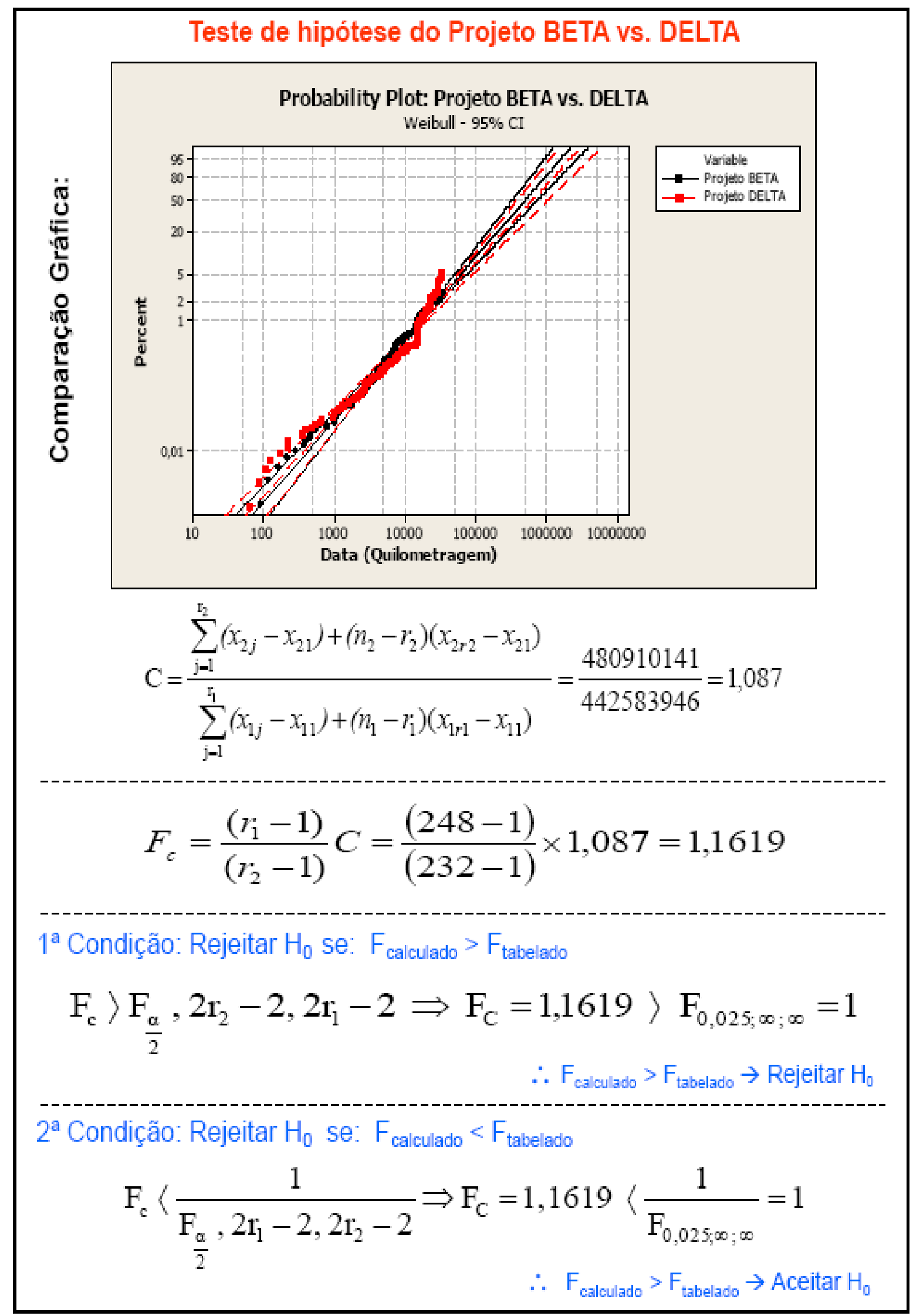


Anexo 6: Teste de Hipótese - Projeto DELTA vs. GAMA

\section{Teste de hipótese do Projeto DELTA vs. GAMA}

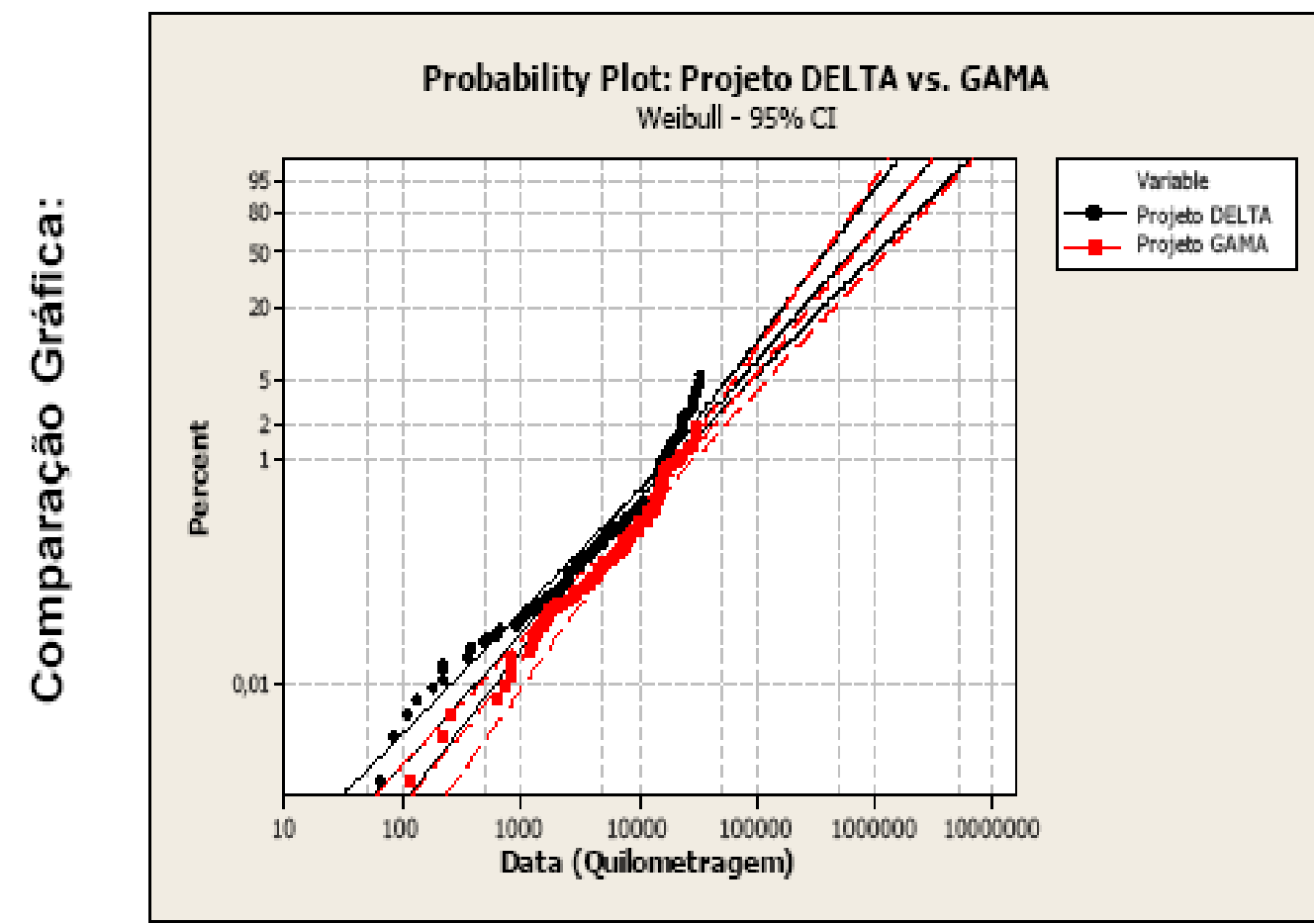

$$
\mathrm{C}=\frac{\sum_{\mathrm{j}=1}^{\mathrm{r}_{2}}\left(x_{2 j}-x_{21}\right)+\left(n_{2}-r_{2}\right)\left(x_{2 r 2}-x_{21}\right)}{\sum_{\mathrm{j}=1}^{\mathrm{I}_{1}}\left(x_{1 j}-x_{11}\right)+\left(n_{1}-r_{1}\right)\left(x_{1 r 1}-x_{11}\right)}=\frac{468710558}{480910141}=0,975
$$

$$
F_{c}=\frac{\left(r_{1}-1\right)}{\left(r_{2}-1\right)} C=\frac{(248-1)}{(232-1)} \times 0,975=1,4160
$$

$1^{\text {a }}$ Condição: Rejeitar $\mathrm{H}_{0}$ se: $\mathrm{F}_{\text {calculado }}>\mathrm{F}_{\text {tabelado }}$

$$
\begin{array}{r}
\mathrm{F}_{\mathrm{c}}>\mathrm{F}_{\frac{\alpha}{2}}, 2 \mathrm{r}_{2}-2,2 \mathrm{r}_{1}-2 \Rightarrow \mathrm{F}_{\mathrm{C}}=1,4160>\mathrm{F}_{0,025 ; \infty ; \infty}=1 \\
\therefore \mathrm{F}_{\text {calculado }}>\mathrm{F}_{\text {tabelado }} \rightarrow \text { Rejeitar } \mathrm{H}_{0}
\end{array}
$$

$2^{\mathrm{a}}$ Condição: Rejeitar $\mathrm{H}_{0}$ se: $\mathrm{F}_{\text {calculado }}<\mathrm{F}_{\text {tabelado }}$

$$
\mathrm{F}_{c}<\frac{1}{\mathrm{~F}_{\frac{\alpha}{2}}, 2 \mathrm{r}_{1}-2,2 \mathrm{r}_{2}-2} \Rightarrow \mathrm{F}_{\mathrm{C}}=1,4160<\frac{1}{\mathrm{~F}_{0,025 ; \infty ; \infty}}=1
$$

$$
\therefore \mathrm{F}_{\text {calculado }}>\mathrm{F}_{\text {tabelado }} \rightarrow \text { Aceitar } \mathrm{H}_{0}
$$


Anexo 7: Probabilidade de Ocorrência (Adaptado de Lafraia, 2001)

\begin{tabular}{|c|l|l|}
\hline Ordem & \multicolumn{1}{|c|}{ Taxa de Falhas } & \multicolumn{1}{c|}{ Probabilidade de Falha } \\
\hline 1 & Menor que 1 em 1.000.000 & Remota: falha improvável \\
\hline 2 & 1 em 20.000 & Baixa: relativamente poucas falhas \\
\hline 3 & 1 em 4.000 & Baixa: relativamente poucas falhas \\
\hline 4 & 1 em 1.000 & Moderada: falhas ocasionais \\
\hline 5 & 1 em 400 & Moderada: falhas ocasionais \\
\hline 6 & 1 em 80 & Moderada: falhas ocasionais \\
\hline 7 & 1 em 40 & Alta: falhas repetitivas \\
\hline 8 & $1 \mathrm{em} 20$ & Alta: falhas repetitivas \\
\hline 9 & $1 \mathrm{em} 8$ & Muito alta: falhas quase que inevitáveis \\
\hline 10 & $1 \mathrm{em} 2$ & Muito alta: falhas quase que inevitáveis \\
\hline
\end{tabular}

Anexo 8: Probabilidade de Detecção (Adaptado de Lafraia, 2001)

\begin{tabular}{|c|l|}
\hline Ordem & \multicolumn{1}{c|}{ Probabilidade de Detecção } \\
\hline 1 & Muito alta: falha certamente será notada durante operação \\
\hline 2 & Muito alta: falha certamente será notada durante operação \\
\hline 3 & Alta: boa chance de determinar a falha \\
\hline 4 & Alta: boa chance de determinar a falha \\
\hline 5 & Moderada: $50 \%$ de chance de determinar a falha \\
\hline 6 & Moderada: $50 \%$ de chance de determinar a falha \\
\hline 7 & Baixa: não é provável que a falha seja detectável \\
\hline 8 & Baixa: não é provável que a falha seja detectável \\
\hline 9 & Muito baixa: muito improvável detectar a falha \\
\hline 10 & Absolutamente indetectável: falha não será detectada com certeza \\
\hline
\end{tabular}


Anexo 9: Severidade das Consequências (Adaptado de Lafraia, 2001)

\begin{tabular}{|c|l|}
\hline Ordem & \multicolumn{1}{|c|}{ Severidade das Consequências } \\
\hline 1 & Marginal: a falha não tem efeito real no sistema, o usuário não notaria a falha \\
\hline 2 & Baixa: provoca apenas pequenos transtornos aos usuários, que notará leves variações no sistema \\
\hline 3 & Baixa: provoca apenas pequenos transtonos aos usuários, que notará leves variações no sistema \\
\hline 4 & Moderada: usuário notará razoável deterioração no desempenho do sistema \\
\hline 5 & Moderada: usuário notará razoável deterioração no desempenho do sistema \\
\hline 6 & Moderada: usuário notará razoável deterioração no desempenho do sistema \\
\hline 7 & Alta: sistema torna-se inoperável \\
\hline 8 & Mlta: sistema torna-se inoperável \\
\hline 10 & Muito alta: a falha envolve riscos à operação segura do sistema \\
\hline
\end{tabular}

